\title{
Testing to Evaluate Processes Expected to Occur during MSR Salt Spill Accidents
}

Chemical and Fuel Cycle Technologies Division, Argonne National Laboratory 


\begin{abstract}
About Argonne National Laboratory
Argonne is a U.S. Department of Energy laboratory managed by UChicago Argonne, LLC under contract DE-AC02-06CH11357. The Laboratory's main facility is outside Chicago, at 9700 South Cass Avenue, Argonne, Illinois 60439. For information about Argonne and its pioneering science and technology programs, see www.anl.gov.
\end{abstract}

\title{
DOCUMENT AVAILABILITY \\ Online Access: U.S. Department of Energy (DOE) reports produced after 1991 and a growing number of pre-1991 documents are available free at OSTI.GOV (http://www.osti.gov/), a service of the US Dept. of Energy's Office of Scientific and Technical Information.
}

\author{
Reports not in digital format may be purchased by the public from the \\ National Technical Information Service (NTIS): \\ U.S. Department of Commerce \\ National Technical Information Service \\ 5301 Shawnee Rd \\ Alexandria, VA 22312 \\ www.ntis.gov \\ Phone: (800) 553-NTIS (6847) or (703) 605-6000 \\ Fax: (703) 605-6900 \\ Email: orders@ntis.gov
}

Reports not in digital format are available to DOE and DOE contractors from the Office of Scientific and Technical Information (OSTI):

U.S. Department of Energy

Office of Scientific and Technical Information

P.O. Box 62

Oak Ridge, TN 37831-0062

www.osti.gov

Phone: (865) 576-8401

Fax: (865) 576-5728

Email: reports@osti.gov

\section{Disclaimer}

This report was prepared as an account of work sponsored by an agency of the United States Government. Neither the United States Government nor any agency thereof, nor UChicago Argonne, LLC, nor any of their employees or officers, makes any warranty, express or implied, or assumes any legal liability or responsibility for the accuracy, completeness, or usefulness of any information, apparatus, product, or process disclosed, or represents that its use would not infringe privately owned rights. Reference herein to any specific commercial product, process, or service by trade name, trademark, manufacturer, or otherwise, does not necessarily constitute or imply its endorsement, recommendation, or favoring by the United States Government or any agency thereof. The views and opinions of document authors expressed herein do not necessarily state or reflect those of the United States Government or any agency thereof, Argonne National Laboratory, or UChicago Argonne, LLC. 


\section{Testing to Evaluate Processes Expected to Occur during MSR Salt Spill Accidents}

Prepared by

Sara Thomas and Josh Jackson

Chemical and Fuel Cycle Technologies Division, Argonne National Laboratory

September 22, 2021 


\section{Acknowledgements}

This report was produced under the auspices of the US DOE Fuel Cycle R\&D program Advanced Reactors Regulatory Development Campaign. Issuance of this report meets milestone M2RD-21AN0601059. The authors gratefully acknowledge Dr. Melissa Rose, Dr. Timothy Lichtenstein, Dr. Levi Gardner, and Ms. Julia Kreuger for assistance in synthesizing the molten salt, developing the methods, and preparing the workspace used in the tests described herein. The authors also thank Dr. Vineeth Gattu and Dr. Evan Wu for running the electrochemical corrosion tests, and Dr. Sarah Stariha for assistance with SEM imaging. Ms. Yifen Tsai and Ms. Kristin DeAngeles are acknowledged for performing the compositional analyses and developing the method to quantify total iodine using ICP-MS discussed herein. The suggestions and discussions with participants of the MSR Campaign as well as Argonne staff including Mr. Mike Kalensky, Dr. Nicholas Condon, Dr. Mitchell Farmer, Dr. Shayan Shahbazi, Dr. David Grabaskas, and Dr. Matthew Bucknor benefitted this project and are greatly appreciated.

This work was conducted at Argonne National Laboratory and supported by the U.S. Department of Energy, Office of Nuclear Energy, under Contract DE-AC02-06CH11357. 


\section{Table of Contents}

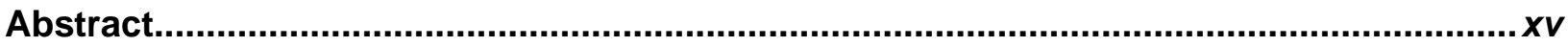

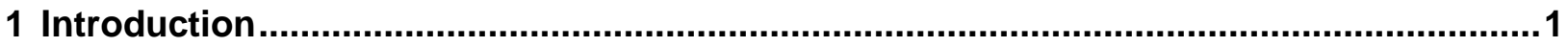

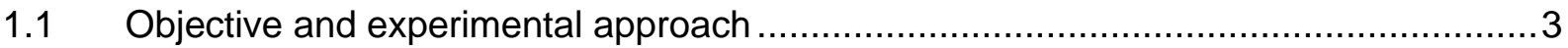

1.2 Summary of experimental methods .................................................................

1.2.1 Experimental method 1: Molten salt spreading and heat transfer ................................................. 4

1.2.2 Experimental method 2: Molten salt flowing and freezing behavior through tubing ............................ 5

1.2.3 Experimental method 3: Stainless steel corrosion kinetics in molten salt ............................................ 6

1.2.4 Experimental method 4: Molten salt splashing and aerosol formation ............................................

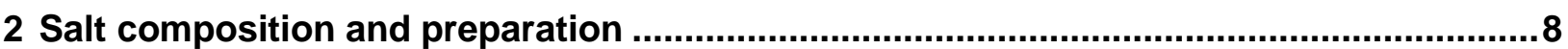

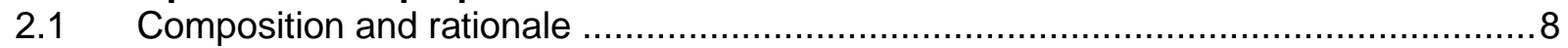

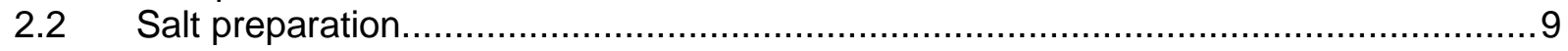

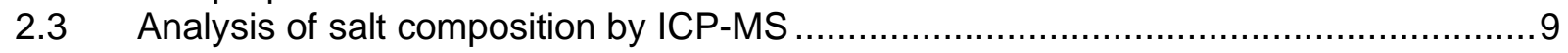

3 Molten salt spreading and heat transfer....................................................................10

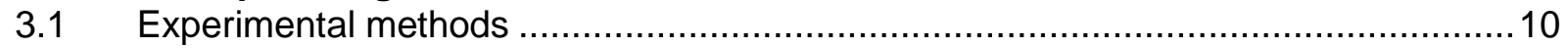

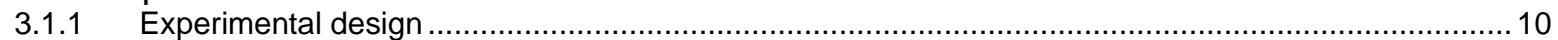

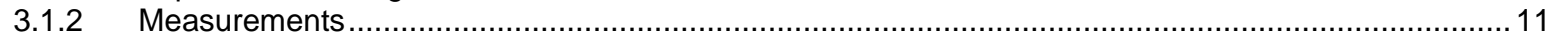

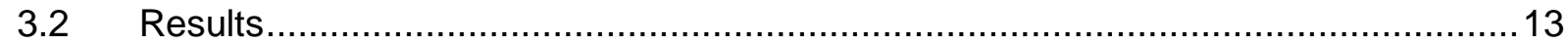

3.2.1 Images from tests of molten salt spreading and freezing on a stainless steel sheet ......................... 14

3.2.2 Temperature of salt surface and estimate of FLiNaK emissivity .................................................16

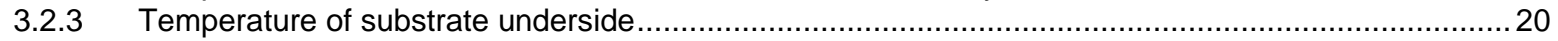

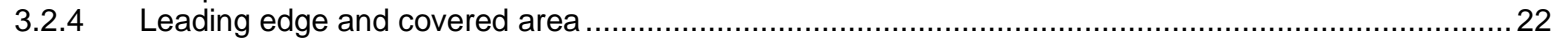

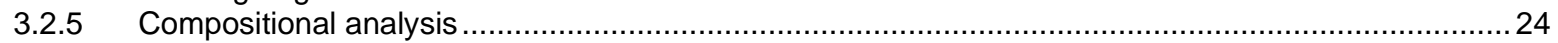

4 Molten salt flowing and freezing behavior through tubing .........................................26

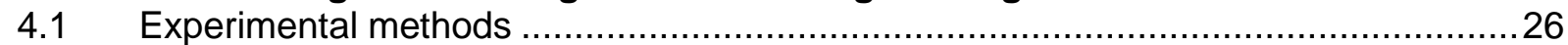

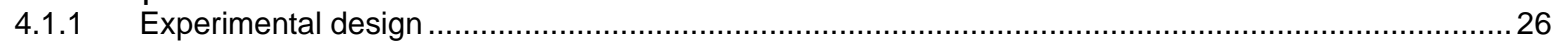

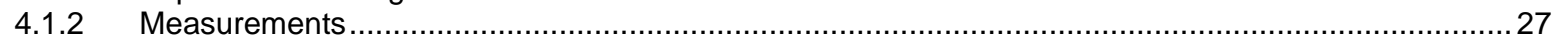

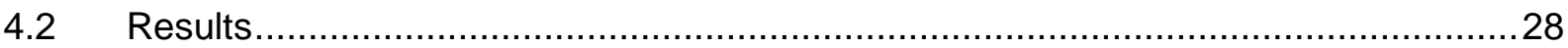

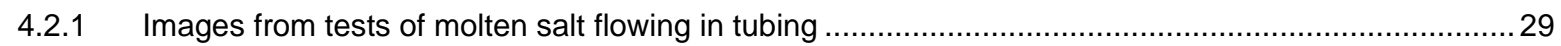

4.2.2 Temperature measurement of the stainless steel tubing …......................................................... 33

4.2.3 Temperature of the underside of the stainless steel beaker ……................................................36

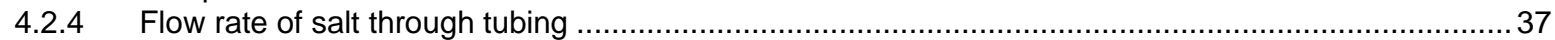

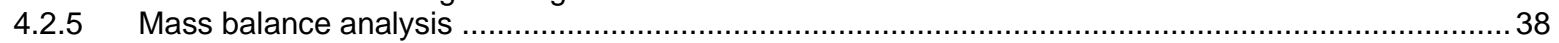

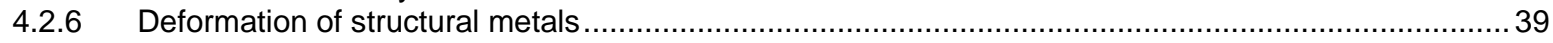

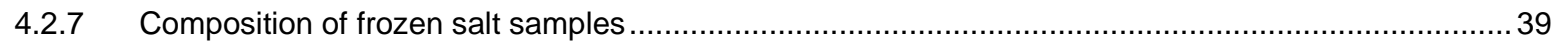

5 Stainless steel corrosion kinetics in molten salt ...........................................................39

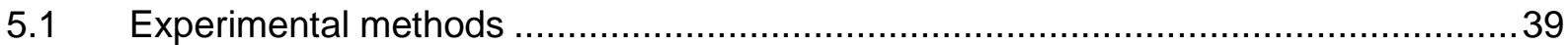

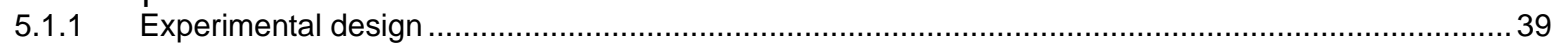

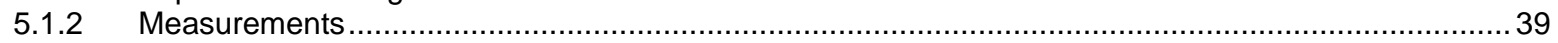

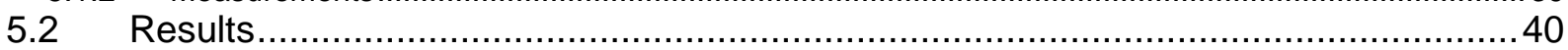

5.2.1 Corrosion kinetics of stainless steel in molten FLiNaK

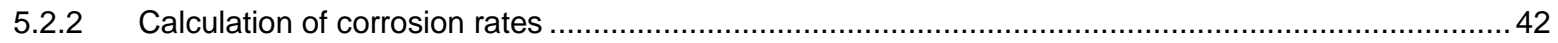

6 Molten salt splashing and aerosol formation ...............................................................43

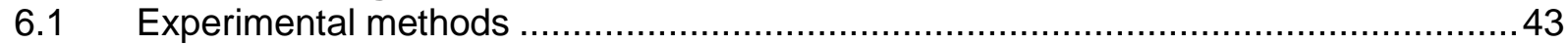

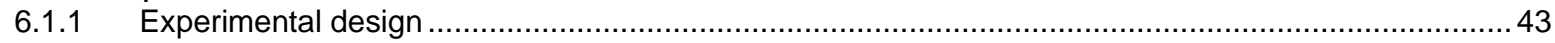

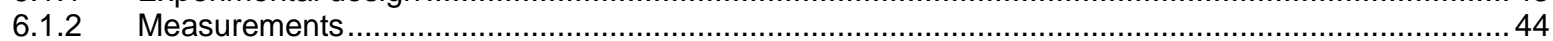

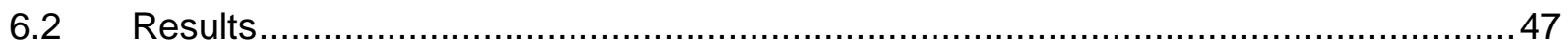

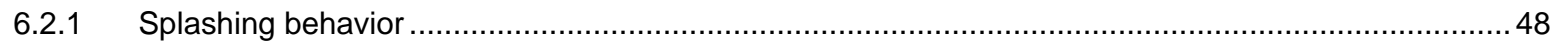

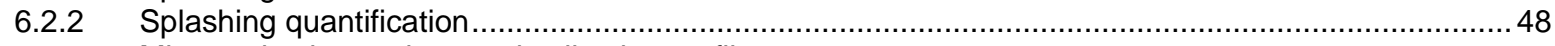

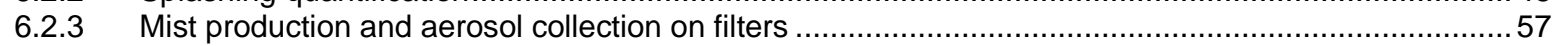

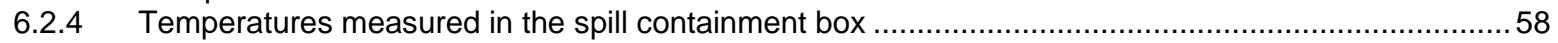

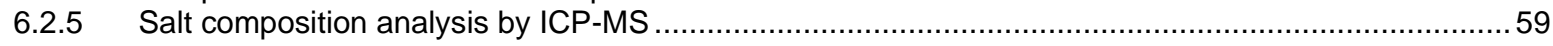

6.2.6 Composition of condensation on ceiling of spill containment box ................................................59

6.2.7 Splatter and aerosol particle composition by SEM-EDS .............................................................. 61 
7 Conclusions and recommendations...........................................................................64

7.1 Effectiveness of methods for measuring individual processes...........................65

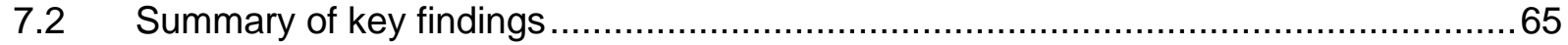

7.2.1 Experimental method 1: Molten salt spreading and heat transfer ..................................................65

7.2.2 Experimental method 2: Molten salt flowing and freezing behavior through tubing ............................66

7.2.3 Experimental method 3: Stainless steel corrosion kinetics in molten salt .........................................67

7.2.4 Experimental method 4: Molten salt splashing and aerosol formation ...............................................67

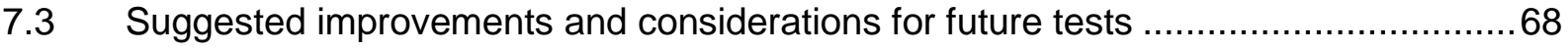

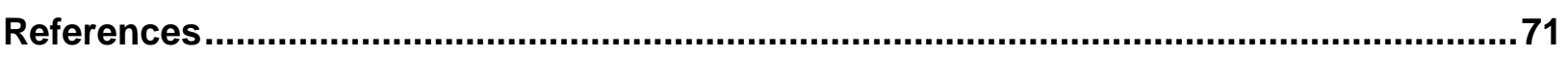

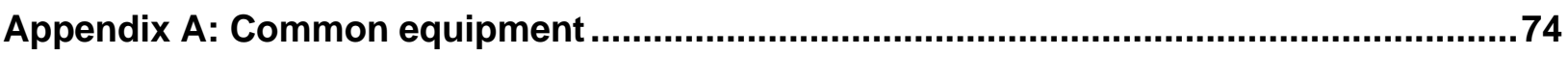

Appendix B: Experimental methods for measuring surface temperature .........................75

Appendix C: Molten salt aerosol measurement techniques and historical data................83 


\section{Figures}

1. Schematic that depicts molten salt spilling from a leak in the primary loop of a generic MSR onto a catch pan lining the primary containment floor.....

2. Conceptual information flow for the parallel development of models and experiments to close mechanistic source term gaps. The modeling and simulation pathway was adapted from Leute et al., 2021.

3. (A) Schematic of the molten salt spreading and heat transfer test. (B) Image taken of the experimental setup in the glovebox.

4. The thermocouple layout at the underside of the stainless steel sheet. The top end of the sheet is on the left side of the photograph and salt flows from left to right. Thermocouple 8 was positioned approximately $0.5 \mathrm{in}$. from the bottom of the sheet. Thermocouples 1, 4, 7, and 8 were positioned in the center of the substrate (lengthwise) and Thermocouples 2, 3, 5, and 6 were positioned 2 in. from the edges of the substrate.

5. (A) Raw image measured by IR camera, (B) processed image showing the temperature of just the salt, and $(\mathrm{C})$ binary image showing the salt (white) on the stainless steel background (black). The top-most part of the image was cropped to remove the crucible from the field of view so that the crucible did not interfere with image processing.

6. Still frames from video taken by the visible camera that show $49 \mathrm{~g}$ of FLiNaK at an initial temperature of approximately $530{ }^{\circ} \mathrm{C}$ flowing and spreading onto a stainless steel sheet tilted at an angle of $2.5^{\circ}$ (Test 3). The frames were taken (A) 2 and (B) 4 seconds after the molten salt first touched the stainless steel sheet.

7. Still frames from video taken by the visible camera that show $25 \mathrm{~g}$ of FLiNaK at an initial temperature of approximately $640{ }^{\circ} \mathrm{C}$ flowing and spreading onto a stainless steel sheet tilted at an angle of $5^{\circ}$ (Test 5). The frames were taken (A) 1 and (B) 2 seconds after the molten salt first touched the stainless steel sheet.

8. Still frames from video taken by the visible camera that show approximately $30 \mathrm{~g}$ of FLiNaK at an initial temperature of approximately $800^{\circ} \mathrm{C}$ flowing and spreading onto a stainless steel sheet tilted at an angle of $2.5^{\circ}$ (Test 9). The frames were taken (A) 1 and (B) 2 seconds after the molten salt first touched the stainless steel sheet. (C) $A$ photo taken after the spreading test shows thick pieces of frozen salt on the sheet and sections of frozen salt that rose above the sheet.

9. Still frames from video taken by the IR camera that show $49 \mathrm{~g}$ of FLiNaK at an initial temperature of approximately $530{ }^{\circ} \mathrm{C}$ flowing and spreading onto a stainless steel sheet tilted at an angle of $2.5^{\circ}$ (Test 3). The frames were taken between 1 and 6 seconds after the molten salt first touched the stainless steel sheet $(A-F)$. The reported temperature is the raw temperature reading from the IR camera. 
10. Still frames from video taken by the IR camera that show approximately $30 \mathrm{~g}$ of FLiNaK at an initial temperature of approximately $650{ }^{\circ} \mathrm{C}$ flowing and spreading onto a stainless steel sheet tilted at an angle of $2.5^{\circ}$ (Test 6$)$. The frames were taken (A) 1, (B) 1.5, (C) 2, (D) 3, (E) 4, and (F) 6 seconds after the molten salt first touched the stainless steel sheet. The reported temperature is the raw temperature reading from the IR camera.

11. Still frames from video taken by the IR camera that show approximately $30 \mathrm{~g}$ of FLiNaK at an initial temperature of approximately $800^{\circ} \mathrm{C}$ flowing and spreading onto a stainless steel sheet tilted at an angle of $2.5^{\circ}$ (Test 9). The frames were taken $(A)$ 0.5, (B) 1, (C) 1.5, (D) 2, (E) 4, and (F) 10 seconds after the molten salt first touched the stainless steel sheet. The reported temperature is the raw temperature reading from the IR camera.

12. The apparent temperature measured by the IR camera of a pixel in a pool of static molten FLiNaK from this study (black; uncorrected for emissivity) and the temperature of molten FLiNaK in a stainless steel crucible recorded by using a thermocouple from Carotti et al., 2015 (red) plotted as a function of time. The cooling curve from Carotti et al., 2015 was normalized so that the rate was comparable to the cooling rate from this study.

13. Results for salt spreading Test 3: (A) Location of thermocouples attached to the underside of the substrate overlaid on an image of the salt spreading path, $(B)$ the temperature profiles measured by Thermocouples 1, 7, and 8 along the flow path, and $(\mathrm{C})$ the temperature profiles measured by Thermocouples 3, 5, and 6 off the flow path.

14. Results for salt spreading Test 6: (A) Location of thermocouples attached to the underside of the substrate overlaid on an image of the salt spreading path, $(B)$ the temperature profiles measured by Thermocouples 1, 4, 7, and 8 along the flow path, and $(C)$ the temperature profiles measured by Thermocouples 2, 3, 5, and 6 off the flow path.

15. Results for salt spreading Test 9: (A) Location of thermocouples attached to the underside of the substrate overlaid on an image of the salt spreading path, (B) the temperature profiles measured by Thermocouples 1, 4, 7, and 8 along the flow path, and $(C)$ the temperature profiles measured by Thermocouples 2, 3, 5, and 6 off the flow path.

16. (A) The area of the substrate covered by salt and (B) the leading edge of the flowing salt as a function of time for three tests (Tests 1,6, and 9) with different initial salt temperatures, a total mass poured of $30 \mathrm{~g}$, and a substrate tilt angle of $2.5^{\circ}$. The initial salt temperatures and average pour rates are provided in the legend.

17. (A) The total area of salt covering the substrate when the leading edge first reached the end of the substrate plotted as a function of the mass of salt that was poured. The total covered area is presented for three ranges of initial salt temperature. (B) The time it took for the leading edge to reach the end of the substrate (spreading duration) plotted as a function of the pour rate for substrate tilt angles of $2.5^{\circ}$ and $5^{\circ}$ at different initial salt temperatures. 
18. (A) Schematic of the experimental setup to study molten salt flowing through stainless steel tubing. (B) Image of the experimental setup in the argon atmosphere glovebox.

19. Images from Test 1 of $25 \mathrm{~g}$ of FLiNaK at an initial temperature of approximately $660^{\circ} \mathrm{C}$ flowing and freezing in stainless steel tubing with an inner diameter of $0.25 \mathrm{in}$. and wall thickness of $0.0625 \mathrm{in}$. Still frames were taken from visible camera video $(A)$ one second and (B) five seconds after the pouring started. (C) Image of the inside of the stainless steel tubing to show frozen salt coating the walls. (D) Image of salt pieces that froze inside the stainless steel tubing and were removed after the test....

20. Images from Test 2 of $25 \mathrm{~g}$ of FLiNaK at an initial temperature of approximately $660^{\circ} \mathrm{C}$ flowing and freezing in stainless steel tubing with an inner diameter of $0.1875 \mathrm{in}$. and wall thickness of $0.0625 \mathrm{in}$. Still frames were taken from visible camera video $(A)$ one second and $(B)$ five seconds after the pouring started. Image of the inside of the stainless steel tubing (C) at the end of the tube and (D) at the beginning of the tube to show frozen salt coating the walls. (E) Image of salt pieces that froze inside the stainless steel tubing and were removed after the test.

21. Images from Test 3 of $25 \mathrm{~g}$ of FLiNaK at an initial temperature of approximately $490^{\circ} \mathrm{C}$ flowing and freezing in stainless steel tubing with an inner diameter of $0.1875 \mathrm{in}$. and wall thickness of $0.0625 \mathrm{in}$. Still frames were taken from visible camera video $(A)$ one second and $(B)$ five seconds after the pouring started. Images were taken of the frozen salt that was removed (C) from the top of the funnel, (D) from the stainless steel beaker, and $(E)$ from the inside of the stainless steel tubing.

22. Images from Test 4 of $25 \mathrm{~g}$ of FLiNaK at an initial temperature of approximately $775^{\circ} \mathrm{C}$ flowing and freezing in stainless steel tubing with an inner diameter of $0.1875 \mathrm{in}$. and wall thickness of $0.0625 \mathrm{in}$. Still frames were taken from visible camera video (A) one second and (B) five seconds after the pouring started. Images were taken of salt that froze inside the stainless steel tubing $(C)$ at the end of the tube and (D) at the beginning of the tube to show frozen salt coating the walls. (E) Image of salt piece that froze at the bottom of the stainless steel tubing that was removed after the test.

23. Still frames from video taken by the IR camera that show the temperature of the outer wall of the stainless steel tubing with an inner diameter of 0.25 in. and wall thickness of $0.0625 \mathrm{in}$. The lower $10 \mathrm{in}$. of the $11 \mathrm{in}$. tube is shown in the frame. The frames were taken (A) $0 \mathrm{~s}$, (B) $0.5 \mathrm{~s},(\mathrm{C}) 1 \mathrm{~s},(\mathrm{D}) 2 \mathrm{~s},(\mathrm{E}) 5 \mathrm{~s},(\mathrm{~F}) 10 \mathrm{~s},(\mathrm{G}) 20 \mathrm{~s}$, and (H) $50 \mathrm{~s}$ after $25 \mathrm{~g}$ of FLiNaK at an initial temperature of approximately $660{ }^{\circ} \mathrm{C}$ was poured into the tubing (Test 1). The reported temperature has been corrected for the emissivity of the tubing coating.

24. Still frames from video taken by the IR camera that show the temperature of the outer wall of the stainless steel tubing with an inner diameter of 0.1875 in. and wall thickness of $0.0625 \mathrm{in}$. The lower $10 \mathrm{in.} \mathrm{of} \mathrm{the} 11 \mathrm{in}$. tube is shown in the frame. The frames were taken (A) $0 \mathrm{~s}$, (B) $1.5 \mathrm{~s},(\mathrm{C}) 2 \mathrm{~s}$, (D) $5 \mathrm{~s},(\mathrm{E}) 10 \mathrm{~s},(\mathrm{~F}) 20 \mathrm{~s},(\mathrm{G}) 50 \mathrm{~s}$, and (H) $80 \mathrm{~s}$ after $25 \mathrm{~g}$ of FLiNaK at an initial temperature of approximately $660^{\circ} \mathrm{C}$ was poured into the tubing (Test 2). The reported temperature has been corrected for the emissivity of the tubing coating.... 
25. Still frames from video taken by the IR camera that show the temperature of the outer wall of the stainless steel tubing with an inner diameter of 0.1875 in. and wall thickness of $0.0625 \mathrm{in}$. The lower $10 \mathrm{in.}$ of the $11 \mathrm{in.}$ tube is shown in the frame. The frames were taken (A) $0 \mathrm{~s},(B) 1 \mathrm{~s},(\mathrm{C}) 2 \mathrm{~s}$, (D) $5 \mathrm{~s}$, (E) $10 \mathrm{~s},(\mathrm{~F}) 20 \mathrm{~s}$, (G) $50 \mathrm{~s}$, and (H) $100 \mathrm{~s}$ after $25 \mathrm{~g}$ of FLiNaK at an initial temperature of approximately $490{ }^{\circ} \mathrm{C}$ was poured into the tubing (Test 3 ). The reported temperature has been corrected for the emissivity of the tubing coating.

26. Still frames from video taken by the IR camera that show the temperature of the outer wall of the stainless steel tubing with an inner diameter of 0.1875 in. and wall thickness of $0.0625 \mathrm{in}$. The lower $10 \mathrm{in.}$ of the $11 \mathrm{in}$. tube is shown in the frame. The frames were taken (A) $0 \mathrm{~s},(\mathrm{~B}) 1 \mathrm{~s},(\mathrm{C}) 2 \mathrm{~s}$, (D) $3 \mathrm{~s},(\mathrm{E}) 5 \mathrm{~s},(\mathrm{~F}) 10 \mathrm{~s},(\mathrm{G}) 50 \mathrm{~s}$, and (H) $100 \mathrm{~s}$ after $25 \mathrm{~g}$ of FLiNaK at a temperature of approximately $775^{\circ} \mathrm{C}$ was poured into the tubing (Test 4). The reported temperature has been corrected for the emissivity of the tubing coating.

27. The temperature of the underside of the stainless steel beaker that collected the molten salt that flowed through the tubing for $25 \mathrm{~g}$ of FLiNaK that was poured at different initial salt temperatures and inner tube diameters. The beaker thickness was 0.03125 in and was insulated at the bottom.

28. The mass of salt in the stainless steel beaker below the tubing that was recorded by the data logging scale for the four tests on molten salt flowing in tubing. The scale starts recording when it first detects a weight and records at an interval of one second.

29. The mass fractions of frozen salt that were recovered from the top of the funnel, recovered from inside the tubing, recovered from the stainless steel beaker below the tubing, and not recovered for the four tests on molten salt flowing in tubing.....

30. (A) Schematic of the experimental setup to study 316 stainless steel corrosion in molten salt. (B) Image of the 316 stainless steel working electrode attached to a 316 stainless steel lead wire (0.02 in. diameter).

31. PD scans of 316 stainless steel coupons in molten FLiNaK at temperatures of $500{ }^{\circ} \mathrm{C}$, $650{ }^{\circ} \mathrm{C}$, and $800{ }^{\circ} \mathrm{C}$. The spots mark the steady corrosion currents that were measured in PS tests conducted at $0.2 \mathrm{~V}$ and $0.1 \mathrm{~V}$ above the $\mathrm{E}_{\mathrm{CORR}}$ values for salt temperatures of $500{ }^{\circ} \mathrm{C}$ and $800^{\circ} \mathrm{C}$, respectively.

32. Results of PS tests with 316 stainless steel coupons in molten FLiNaK at fixed potentials of $0.2 \mathrm{~V}$ and $0.1 \mathrm{~V}$ above $\mathrm{E}_{\mathrm{CORR}}$ and temperatures of $500{ }^{\circ} \mathrm{C}$ and $800{ }^{\circ} \mathrm{C}$, respectively.

33. (A) Schematic of the spill containment box for the molten salt splashing and aerosol collection test. (B) Image of the spill containment box that identifies the various measurement components including thermocouples, coupons to collect molten salt splatter, a filter to collect aerosols, and the visible camera.

34. An example of a raw image, cropped image, and processed binary image of salt particles collected on a coupon from a molten salt splashing test. 
35. Still frames from the video taken of molten FLiNaK at an initial temperature of approximately (A) $800^{\circ} \mathrm{C},(B) 650^{\circ} \mathrm{C}$, and (C) $500^{\circ} \mathrm{C}$ pouring into the catch pan. Each still frame was taken approximately 0.02 seconds after the salt first touched the catch pan.

36. Still frames from the video taken of molten FLiNaK at an initial temperature of approximately $800{ }^{\circ} \mathrm{C}$ pouring into the catch pan. The still frames were taken approximately (A) 0.03 seconds, (B) 0.13 seconds, (C) 0.32 seconds, and (D) 0.54 seconds after the salt first touched the catch pan floor.

37. The coupon labels and locations in the catch pan relative to the salt spill zone. The filter for aerosol collection is positioned directly above Coupon 7 on the far wall from the spill zone and is connected to a pump set to a constant flow rate of $4 \mathrm{~L} \mathrm{~min}^{-1}$.

38. The far wall from the spill zone and Coupon $7(\mathrm{~A})$ before and $(\mathrm{B})$ after spilling $15 \mathrm{~g}$ of FLiNaK at an initial temperature of approximately $650^{\circ} \mathrm{C}$ into the spill containment box. The coupon dimension is 1 in $\times 1 \mathrm{in}$.

39. The wall near the spill zone containing Coupons 1 and $2(\mathrm{~A})$ before and $(\mathrm{B})$ after spilling $15 \mathrm{~g}$ of FLiNaK at an initial temperature of approximately $650^{\circ} \mathrm{C}$ into the spill containment box. The coupon dimensions are 1 in $\times 1$ in.

40. Examples of the raw and processed visible images of $(A)$ Coupon 5, (B) Coupon 3, and $(\mathrm{C})$ Coupon 7 after $15 \mathrm{~g}$ of FLiNaK at an initial temperature of approximately 500 ${ }^{\circ} \mathrm{C}$ was poured into the spill containment box (Test 2). The images were cropped prior to analysis. The dimensions of the cropped images were (A) $23.2 \mathrm{~mm} \times 18.8 \mathrm{~mm}$, (B) $22.7 \mathrm{~mm} \times 18.1 \mathrm{~mm}$, and (C) $20.6 \mathrm{~mm} \times 20.0 \mathrm{~mm}$.

41. Examples of the raw and processed visible images of $(A)$ Coupon 5, (B) Coupon 6, and $(\mathrm{C})$ Coupon 7 after $15 \mathrm{~g}$ of FLiNaK at an initial temperature of approximately 650 ${ }^{\circ} \mathrm{C}$ was poured into the spill containment box (Test 4). The images were cropped prior to analysis. The dimensions of the cropped images were $(A) 23.0 \mathrm{~mm} \times 21.2 \mathrm{~mm}$, (B) $22.4 \mathrm{~mm} \times 20.3 \mathrm{~mm}$, and (C) $13.0 \mathrm{~mm} \times 19.7 \mathrm{~mm}$.

42. Examples of the raw and processed visible images of $(A)$ Coupon 5, (B) Coupon 3, and $(\mathrm{C})$ Coupon 7 after $15 \mathrm{~g}$ of FLiNaK at an initial temperature of approximately 800 ${ }^{\circ} \mathrm{C}$ was poured into the spill containment box (Test 5 ). The images were cropped prior to analysis. The dimensions of the cropped images were (A) $21.6 \mathrm{~mm} \times 16.6 \mathrm{~mm}$, (B) $23.7 \mathrm{~mm} \times 20.7 \mathrm{~mm}$, and (C) $19.0 \mathrm{~mm} \times 23.4 \mathrm{~mm}$.

43. The number of particles within defined size ranges per $1000 \mathrm{~mm}^{2}$ that were collected on $(A)$ the lower coupons near the spill zone (average of Coupons 2, 3, and 5), (B) the upper coupons near the spill zone (average of Coupons 1, 4, and 6), and (C) Coupon 7 on the far wall from the spill zone. The results are averages from replicate experiments at each initial salt temperature and the error bars represent one standard deviation.

44. Large splatter droplets splashed outside of the stainless steel catch pan and adhered to the inner walls of the spill containment box for FLiNaK at an initial temperature of $500^{\circ} \mathrm{C}$ but not at $650^{\circ} \mathrm{C}$ or $800^{\circ} \mathrm{C}$. Significant splash height was observed $(\mathrm{A})$ near the salt spill zone and $(\mathrm{B})$ on the wall furthest from the salt spill zone. 
45. The fraction of the total mass poured that was $(A)$ collected as the pooled salt at the bottom of the catch pan, (B) collected as splatter particles, and (C) not recovered. The results are averages from replicate experiments at each initial salt temperature and the error bars are one standard deviation.

46. Still frames from video recorded of the catch pan after spilling $15 \mathrm{~g}$ of FLiNaK containing cesium and iodine at an initial temperature of approximately $800{ }^{\circ} \mathrm{C}$ into the spill containment box. The still frames were taken (A) 5 seconds, (B) 14 seconds, and (C) 20 seconds after the salt was spilled. Subplot $A$ shows the absence of mist and subplots $B$ and $C$ show wisps of mist floating towards the filter, which is positioned below the photographs outside of the field of view.

47. The temperature recorded at $(A)$ the underside of the catch pan and $(B)$ various locations in the spill containment box atmosphere after spilling $15 \mathrm{~g}$ of FLiNaK containing cesium and iodine at an initial temperature of approximately $650{ }^{\circ} \mathrm{C}$. (C) Photograph showing the thermocouple locations within the spill containment box. TC4 recorded the temperature of the atmosphere near the filter inlet.

48. (A) Secondary electron image and (B - F) elemental maps of a splatter particle collected near the spill zone during Test 2 .

49. (A) Secondary electron image, (B) EDS line scan for salt component elements, (C) EDS line scan for common contaminant elements, and (D) EDS spectrum of the spot marked by the red cross for the control which consisted of FLiNaK powder that was sprinkled onto carbon tape coating a nickel coupon.

50. (A) Secondary electron image and (B) EDS line scan that passes through several salt particles that were identified on coupon 7 for Test 3 with an initial salt temperature of approximately $650^{\circ} \mathrm{C}$. The red line in subplot $A$ identifies the path of the line scan.

51. (A) Secondary electron image of particles on Coupon 7 for Test 5 with an initial salt temperature of approximately $800^{\circ} \mathrm{C}$. EDS spectra of (B) spot 1 and (C) spot 2. 


\section{Tables}

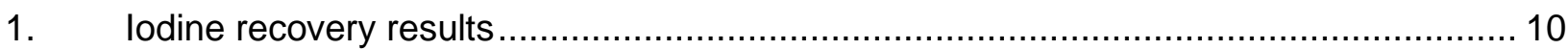

2. Summary of spreading and heat transfer test conditions for tests using molten FLiNaK.

3. Concentrations of major components in FLiNaK before the tests (mol \%) …................ 24

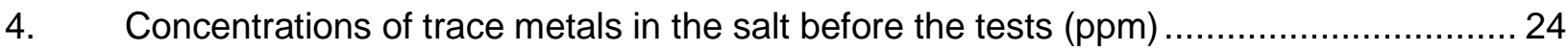

5. Concentrations of major components after spreading (mol \%) ……………............... 25

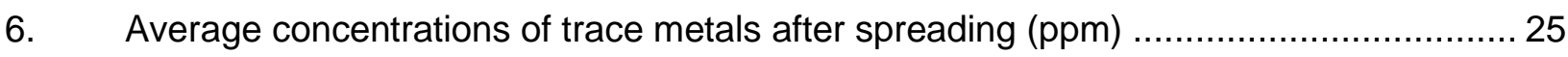

7. Average concentrations of major components after spreading (mol \%) ........................ 25

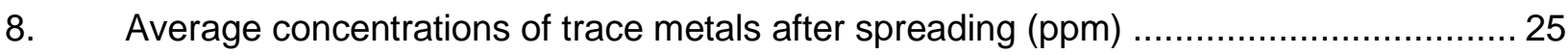

9. Summary of test conditions to study molten FLiNaK flowing through tubing ...................28

10. The maximum temperature recorded at the beaker underside, the thickness of the frozen salt pool, and salt mass in beaker .....

11. Summary of test conditions to study the corrosion of 316 stainless steel in molten

FLiNaK.

12. Summary of splashing and aerosol generation test conditions for tests using molten

FLiNaK with surrogate fission products.

13. Elemental composition of particulates collected on $0.45 \mu \mathrm{m}$ filters ..............................58

14. Composition of frozen salt samples collected from splash tests ...................................6 60

15. Trace metal composition of frozen salt samples collected from splash tests ..................60

16. Elemental composition of wipe sample from ceiling of spill containment box .................6 60 


\section{Acronyms}

$\begin{array}{ll}\text { ARE } & \text { Aircraft Reactor Experiment } \\ \text { DSC } & \text { Differential scanning calorimetry } \\ \text { ECORR } & \text { Corrosion potential } \\ \text { EDS } & \text { Energy dispersive X-ray spectroscopy } \\ \text { EIS } & \text { Electrochemical impedance spectroscopy } \\ \text { FFTF } & \text { Fast Flux Test Facility } \\ \text { FLiNaK } & \text { LiF-NaF-KF eutectic (46.5-11.5-42 mol \%) } \\ \text { ICP-MS } & \text { Inductively coupled plasma-mass spectrometry } \\ \text { ICP-OES } & \text { inductively coupled plasma-optical emission spectroscopy } \\ \text { IR } & \text { Infrared } \\ \text { LWR } & \text { Light water reactor } \\ \text { MSR } & \text { Molten salt reactor } \\ \text { MSRE } & \text { Molten Salt Reactor Experiment } \\ \text { NRC } & \text { Nuclear Regulatory Commission } \\ \text { PD } & \text { Potentiodynamic } \\ \text { PS } & \text { Potentiostatic } \\ \text { PTFE } & \text { Poly(tetrafluoroethylene) } \\ \text { SEM } & \text { Scanning electron microscopy } \\ \text { SFR } & \text { Sodium Fast Reactor } \\ \text { SSCs } & \text { structures, systems, and components } \\ \text { TOF } & \text { Time of flight } \\ \text { XRD } & \text { X-ray diffraction }\end{array}$




\begin{abstract}
Obtaining a license for a new nuclear reactor requires the identification and assessment of the potential consequences of specified accident scenarios, which are achieved using accident progression models. Those models need to be parameterized and validated using experimental data, but existing experimental data addressing processes relevant to molten salt reactor accidents are sparse. Specifically, experimental data that quantify the sensitivities of important processes to the initial conditions of the spill, the ambient environment, and the containment features are needed to parameterize individual process models. Integrated experiments that simulate accident scenarios are also needed to provide data for model validation, but these experiments will require the use of proven methods to quantify the processes under evaluation.

The overarching objectives of this work are to develop the methods for simulating the targeted processes, to determine the effectiveness of the methods in producing the data required for model development, to generate data that can be used to parameterize individual process models, and to provide key insights into the behavior of spilled molten salt that should be considered in models. Experimental methods were designed to quantify aspects of individual processes expected to occur during or after a molten salt spill accident that will affect the fate of spilled molten salt and the radionuclides within. These processes include 1) molten salt spreading and heat transfer, 2) molten salt flowing and freezing in tubing, 3) stainless steel corrosion kinetics in molten salt, and 4) molten salt splashing and aerosol generation. The initial tests described in this report were conducted using eutectic FLiNaK to demonstrate the test methods, the data that are generated, and the analyses of the data to derive values needed for modeling. The primary variables that were tested include initial salt temperature and the presence of volatile surrogate fission products (e.g., cesium and iodine). The developed methods are shown to be effective in quantifying the desired processes and can be applied to study more complex salt compositions of interest to molten salt reactor developers, a wide range of environmental conditions of interest to modelers, and additional variables relevant to salt spill accidents. The developed methods and insights gained from laboratory tests can also be incorporated in future large-scale integrated tests used to simulate molten salt spill accidents.
\end{abstract}




\section{Introduction}

This report summarizes the results from a suite of laboratory experiments that were conducted at Argonne to provide technical bases for accident progression and mechanistic source term models for molten salt reactors (MSRs). Different experimental methods were used to study the key processes that will occur during molten salt spills from breached MSRs (i.e., salt spill accidents) and the subsequent radionuclide release modes. Demonstrating reactor safety is an essential part of the licensing process and involves the identification and assessment of accident scenarios to determine the potential radiological consequences. Several methods and requirements to demonstrate the safety of advanced, non-LWR reactors (including MSRs) have been proposed (NRC, 2020; NRC, 2016; Nuclear Energy Institute, 2018; Holcomb et al., 2020). In all safety demonstration approaches, the license application process for MSR developers will involve several common features: identifying hazards; assessing initiating events and scenarios that challenge the fundamental safety functions (reactivity control, decay heat removal, and radionuclide retention); analyzing the safety of structures, systems, and components (SSCs); evaluating defense-in-depth; and calculating the source term for licensing basis events. Addressing these licensing topics requires experimental data to develop and validate appropriate models. One such model is MELCOR, which is a fully integrated systems analysis code that models the progression of severe accidents (L. L. Humphries et al., 2017). MELCOR was initially developed for modeling LWRs but is being applied to model the consequences of specified MSR accidents, including the potential radionuclide release (i.e., source term) (L. Humphries et al., 2018; Kalilainen et al., 2020). A thorough understanding of the consequences of potential MSR accidents will not only benefit model development but will also provide valuable feedback into the design and decision-making process to ensure the safe and successful operation of an MSR.

A common postulated accident scenario for many MSR concepts involves a rupture within the primary loop that leads to molten fuel salt spilling onto the reactor containment floor. This accident scenario is depicted for a generic MSR in Figure 1, which identifies processes that will likely determine the fate of the spilled salt and radionuclides. These include flow and spreading, heat transfer, corrosion and warping, vaporization, splashing and bubble bursting, aerosol generation, condensation and deposition, and evaporation and resuspension.

Significant uncertainties remain regarding the thermal and chemical consequences of a salt spill event, which will depend on many factors related to the MSR design and the conditions of the spill. A recent report identified the experimental data that needs to be generated to support source term models that will satisfy NRC requirements for reactor licensing (Shahbazi and Grabaskas, 2021). Experiments that provide insight into the behavior of spilled molten salt and the radionuclides within were listed as high priority and high effort needs in that report. The existing data on molten salt behavior due to processes associated with spilling (e.g., agitation) comes from records that were collected during the operation of the Molten Salt Reactor Experiment (MSRE) nearly 50 years ago. Even with data collected over several years during MSRE operation, important information gaps have been identified on the following topics:

- The bulk flow behavior of spilled salt within a defined containment geometry.

- The efficiency of heat transfer from the spilled salt to its surroundings.

- The vapor pressures of radionuclides above a spilled salt pool.

- The abundance, size distribution, and composition of aerosols that form to due molten salt splashing and vapor condensation. 


\section{Primary containment}

evaporation/

resuspension

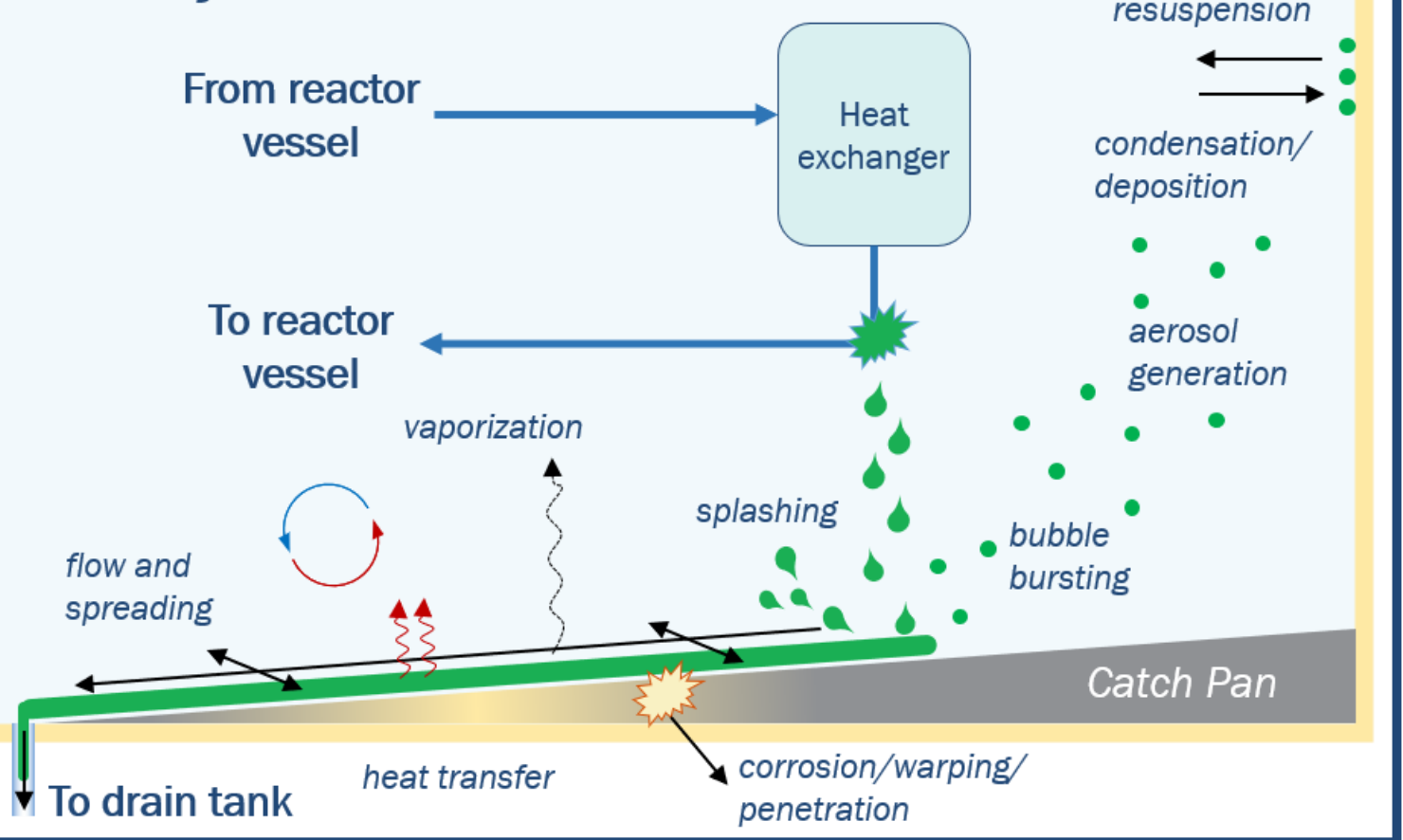

Figure 1: Schematic that depicts molten salt spilling from a leak in the primary loop of a generic MSR onto a catch pan lining the primary containment floor.

- The extent of corrosion and warping of the catch pan or containment floor due to contact with spilled molten salt.

- The freezing behavior of molten salt that is flowing through vertical tubing (e.g., leading to a drain tank).

Experimentalists and modelers must work in parallel to develop experimental and modeling capabilities to efficiently close the gaps in our understanding of the consequences of salt spill accidents (Figure 2). The advancement of mechanistic source term and accident progression modeling capability first requires the identification of data gaps in existing models. In parallel, experimentalists develop the techniques that can be used provide quality data needed to close the identified gaps. Scoping calculations can then be performed using models and scoping tests can be performed at the laboratory benchtop scale to identify processes that have the greatest impact and the highest priority. Experimentalists can then design and run integrated tests using larger scale systems to provide the experimental data needed to close the highest priority gaps and support accident scenario assessments needed for licensing. The experimental results may reveal important processes that had previously not been accounted for in models, and the modeling results will identify the processes with the greatest influence on the model outcome. An integrated and collaborative experimental and modeling approach will provide confidence that accident conditions have been fully considered and consequences have been reliably assessed. 


\section{Modeling and simulation aspect}

Identify data gaps in existing models
Information

exchange

\section{Experimental aspect}

Develop techniques to measure data gap phenomena at lab scale

\begin{abstract}
Perform scoping calculations on identified gaps to identify highest priority phenomena

ping calculations
gaps to identify
rity phenomena
\end{abstract}

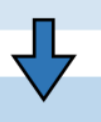

Update and validate models using latest experimental results

\section{Develop and run integrated} tests at appropriate scale to address highest priority gaps

Figure 2: Conceptual information flow for the parallel development of models and experiments to close mechanistic source term gaps. The modeling and simulation pathway was adapted from Leute et al., 2021.

\subsection{Objective and experimental approach}

The objective of this project is to provide the experimental data that are needed to close identified gaps in mechanistic source term and accident progression models for molten salt spill accidents. The objective was addressed by designing and conducting modular laboratory-scale experiments that focused on specific high-priority processes likely to occur during or after a molten salt spill accident.

The objectives of the work described herein include:

- Develop methods to generate data that quantify aspects of individual processes that can be employed in future integrated tests,

- Generate data needed to optimize and validate individual process models for applications to specific salt compositions, and

- Identify key factors and priorities that should be considered in models and included in future integrated tests.

\subsection{Summary of experimental methods}

Four experimental methods were developed, using a well-characterized fluoride salt, which focused on individual processes that are expected to occur during or after a molten salt spill 
accident (i.e., those depicted in Figure 1). The processes that were the focus of the experimental methods are summarized as follows:

- Molten salt spreading and heat transfer

- Molten salt flowing and freezing in tubing

- Stainless steel corrosion kinetics in molten salt under controlled salt temperature and redox

- Molten salt splashing and aerosol generation

Tests were conducted using salt heated to several different temperatures and salt doped with surrogate fission products. The initial objectives were to establish the effectiveness of the method in simulating the targeted processes and detecting the responses that are needed to generate data for use in models. This included measuring sensitivities to salt temperature and composition. The following sections describe the background, motivation, and types of data that are generated from each of the four test methods for use in models. This report provides examples of the obtained experimental data to show the capabilities of each test method and to summarize key findings. The complete suite of results from the work described herein will be included in an upcoming report (Thomas and Jackson, 2021).

\subsubsection{Experimental method 1: Molten salt spreading and heat transfer}

\subsubsection{Background and motivation}

The extent to which spilled molten salt will spread laterally will either be limited by the freezing behavior of the salt or the balance between the surface tension of the molten salt and gravity. Spreading behavior is important to understand because it will determine the extent of radionuclidebearing salt dispersal within the reactor building. In addition, the rate of vapor release from a molten salt pool is directly proportional to the surface area of the pool that is exposed to the atmosphere. The extent of spreading also determines the surface area of the salt that is in contact with the underlying structure, which affects the cooling rate of the salt: the greater the extent of spreading, the faster the cooling.

Knowing the efficiency of heat transfer from spilled molten salt to its surroundings is essential to predicting whether the protective underlying structural material will maintain its integrity and prevent molten salt from contacting concrete or other sensitive material below. Heat transfer efficiency is also needed to develop the strategy for removing decay heat. Finally, the cooling behavior of a spilled molten salt pool will govern the duration that the pool stays molten, which determines when the salt surface freezes and halts the volatilization of radionuclides.

Catch pans are included in designs of sodium fast reactors (SFRs) to protect concrete floors from being contacted by molten sodium during a spill and some experimental data exist on the heat transfer of spilled molten sodium to its surroundings. For example, a large-scale molten sodium spill onto a stainless steel catch pan covering a concrete floor and walls was conducted during the development of the Fast Flux Test Facility (FFTF) (Boehmer and Hilliard, 1975). Fewer experiments have been conducted to study the heat transfer from molten salt pools to catch pan structures to obtain data that can be used in model validation. One large scale test was conducted during the Aircraft Reactor Experiment (ARE) to gain insight on decay heat removal requirements for molten salt pools (ORNL, 1955). In that experiment, $188 \mathrm{~kg}$ of molten FLiNaK (LiF-NaF-KF, 46.5-11.5-42 mol \%) was heated to $816^{\circ} \mathrm{C}$ in a melt tank then cooled in a cylindrical steel tank 
with dished bottom that was partially submerged in water $\left(85^{\circ} \mathrm{C}\right)$. The only measurement that was taken was the outer temperature of the bottom of the steel tank. The main conclusion from the test was that the heat transfer from the molten salt to the water was not sufficient to remove any afterheat. While this test provided qualitative information on the heat transfer behavior of molten salt to underlying structures in contact with water, additional measurements on the state of the system are needed for model validation. In addition, the above-described ARE molten salt heat transfer experiment is specific to one containment geometry (a basin) that is positioned in a pool of water. Spreading and heat transfer information for molten salt in different containment geometries, such as sloped catch pans leading to a drain tank, are more relevant to modern MSR designs.

\subsubsection{Generated data}

The spreading and heat transfer behavior of molten salt on sloped stainless steel sheets was studied as a function of initial salt temperature, initial salt pour mass, sheet tilt angle, and salt pour rate. The experimental details and results are provided in Section 3. Measurements were made for each condition that was evaluated to obtain the salt flow velocity, the salt spreading morphology and area, the salt compositional heterogeneity, and the temperatures of the sheet underside, salt surface, and atmosphere during and after molten salt spreading. In addition, the salt spreading behavior in each test was filmed using visible and infrared (IR) cameras for detailed and thorough analyses performed after the experiments. The methods that were developed to measure molten

salt spreading and heat transfer behavior can be applied to any salt composition and incorporated into future integrated tests.

\subsubsection{Experimental method 2: Molten salt flowing and freezing behavior through tubing}

\subsubsection{Background and motivation}

Modern MSR designs include a safety feature that enables the liquid fuel salt to be quickly drained from the reactor core into a passively cooled drain tank during a transient. A similar concept is being considered to handle large molten salt spills within the reactor containment building, wherein the spilled salt will flow along a sloped catch pan and into a passively cooled drain tank. The ability to model molten salt as it flows down a sloped surface, into a vertical drain, and then through tubing into the tank and predict the extent of freezing at different locations is essential to design systems that ensure the success of this safety feature.

The salt thermophysical properties, initial salt temperature, total spill volume that requires draining, and tube dimensions will affect the freezing behavior of salt that is flowing through tubing. The composition of the molten salt will also affect its freezing behavior. The slow freezing of MSRE fuel salt ( $\mathrm{LiF}_{-} \mathrm{BeF}_{2}-\mathrm{ZrF}_{4}-\mathrm{ThF}_{4}-\mathrm{UF}_{4}, 70-23.7-5-1-0.3 \mathrm{~mol} \%$ ) was postulated to occur in stages, with $6 \mathrm{LiF} \cdot \mathrm{BeF}_{2} \cdot \mathrm{ZrF}_{4}$ solidifying first and $2 \mathrm{LiF} \cdot \mathrm{BeF}_{2}$ appearing as a secondary phase after $20 \mathrm{wt} \%$ of the fuel had frozen as $6 \mathrm{LiF} \cdot \mathrm{BeF}_{2} \cdot \mathrm{ZrF}_{4}$ (Briggs, 1962). The preferential freezing of salt components can lead to actinides becoming concentrated in certain locations within the drain system, which could have undesirable consequences.

\subsubsection{Generated data}

The flowing and freezing behavior of molten salt in stainless steel tubing was studied as a function of initial salt temperature and inner tube diameter to represent salt draining from a catch pan and into a drain tank. The experimental details and results are provided in Section 4. For each condition that was evaluated, measurements were made to determine the temperature of the outer tube 
surface, the temperature of the salt remaining on the simulated catch pan, the flow rate of salt through the tubing, the mass fraction of salt that froze in the tubing, compositional changes in the salt, and the temperature of the underside of the stainless steel beaker used to collect the salt. Each test was filmed using visible and IR cameras for detailed and thorough analyses that were performed after the experiments. The methods that were developed to measure molten salt flowing and freezing behaviors in tubing can be applied to measure the effect of additional variables on salt freezing (including different salt compositions) and included in future integrated tests.

\subsubsection{Experimental method 3: Stainless steel corrosion kinetics in molten salt}

\subsubsection{Background and motivation}

It is important to address the corrosion of stainless steel and other relevant structural materials that may be contacted by spilled molten salt in accident progression models. The salt composition, salt temperature, and the environmental conditions may be significantly different under accident conditions than during normal operations. The corrosion of structural materials relevant to molten salt reactors has been predominantly studied by using coupon immersion tests (e.g., Zheng and Sridharan, 2018; Keiser et al., 1977). Zheng and Sridharan, 2018 studied the corrosion of Hastelloy $\mathrm{N}^{\circledR}$ and 316 stainless steel in molten FLiBe at $700{ }^{\circ} \mathrm{C}$ in both graphite and metallic capsules for between 1000 and 3000 hours. They found that corrosion resulted in the loss of chromium from the alloy surface and was more pronounced along the grain boundaries than in the bulk grains. Keiser et al., 1977 studied the corrosion of 316 stainless steel in molten FLiBe in a thermal convection loop with a maximum temperature of $650^{\circ} \mathrm{C}$ and a temperature difference of $160^{\circ} \mathrm{C}$. The corrosion rate was found to correlate with the fluoride ion oxidation potential (i.e., the salt redox potential) and decreased as the initial impurities in the salt were consumed and with the addition of beryllium metal.

The results from coupon immersion tests do not provide the quantitative corrosion rates under controlled solution chemistry and solution redox that are needed to parametrize accident progression models for the following reasons:

- Immersion tests only provide corrosion rates at the corrosion potential ( $\left.E_{\mathrm{CORR}}\right)$ attained in the test, whereas models must provide corrosion rates at a range of redox potentials that the structural material may experience during its lifetime. Studying corrosion under a range of fixed redox environments is especially important to understand the consequences of accidents, which may impose highly oxidizing conditions due to the introduction of air, water, or other contaminants to the salt.

- The potential at which corrosion occurs in an immersion test ( $\left.E_{C O R R}\right)$ will change in response to changes in solution composition and coupon surface properties that occur throughout the test duration. The measured corrosion rate represents the cumulative response to changing conditions. It does not represent the corrosion rate at a particular redox potential, which is needed to parameterize models.

- Immersion tests provide average corrosion rates based on the cumulative corrosion that occurred throughout the test. In many cases, the majority of corrosion occurs as an initial transient and this corrosion rate is poorly represented by the measured cumulative rate.

Models require instantaneous corrosion rates, which can be measured by using electrochemical methods. In addition, electrochemical methods provide the quantitative dependencies on redox potentials and salt chemistries (i.e., salt compositions and impurity levels) needed in models. Few 
studies have applied electrochemical methods to study the corrosion of structural materials in molten salt. One recent study has assessed the corrosion of $316 \mathrm{~L}$ stainless steel in FLiNaK by using electrochemical methods (Qiu et al., 2020). However, this study only assessed qualitative corrosion behavior and did not quantify the corrosion rates needed for model development.

\subsubsection{Generated data}

The corrosion kinetics of 316 stainless steel in molten salt as a function of initial salt temperature were measured using electrochemical methods and a protocol developed at Argonne. The experimental details and results are provided in Section 5. For each condition that was evaluated, the measurements provided corrosion rates at fixed redox potentials and controlled salt chemistry that can be used directly in models.

\subsubsection{Experimental method 4: Molten salt splashing and aerosol formation}

\subsubsection{Background and motivation}

Radionuclides can be released during a salt spill accident as vapors and as aerosols. The formation of aerosols containing radionuclides is of concern in nuclear accident analysis because aerosol transport is a pathway for radionuclide dispersal and respirable aerosols that contain radionuclides are particularly harmful to human health. Respirable aerosols can deposit in the respiratory tract and expose internal organs to radiation for extended periods. The aerodynamic diameter of an aerosol determines its transport properties and the tendency to be respired.

An aerosol is defined as a liquid or a solid that is suspended in a gas (Kulkarni et al., 2011). The extent of aerosol formation from molten salt is not well understood and experimental data are needed to provide insight into aerosol size distribution, abundance, and composition as a function of the conditions of the salt spill (Leute et al., 2021). Aerosols that contain radionuclides can be formed directly from spilled salt through the breakup of molten salt into particles or from the condensation of radionuclide vapors from the spilled molten salt pool.

Mechanical processes identified to produce aerosols in nuclear accidents include (Allelein et al., 2009):

- The entrainment of solids or liquid droplets in high velocity gas flows,

- The expulsion of droplets by gases bubbling through liquids,

- Shock waves such as those produced in energetic interactions of molten materials with coolants, and

- High pressure melt ejection from the reactor coolant system.

Mechanical processes tend to not produce the fine particles that are of particular concern for aerosol transport and radionuclide release (i.e., those less than $2 \mu \mathrm{m}$ ) and are largely omitted from nuclear accident analyses (Allelein et al., 2009). The rupture of bubbles at the molten salt surface may be an exception. Bubble rupture is known to produce respirable aerosols from aqueous solutions (Ke et al., 2017) and may be relevant to salt spill accident scenarios. This is because molten fuel salt will entrain non-condensable fission product gases (e.g., xenon and krypton) and may also entrain gas during a spill or when molten salt impacts a substrate (Leute et al., 2021). Aerosols may form when these gas bubbles rupture. 
The data needs regarding molten salt aerosol formation that are relevant to salt spill accidents include the bubble formation rate and subsequent aerosol release as a result of different levels of molten salt agitation (Leute et al., 2021). In addition, experimental data on the molten salt aerosols that form from the condensation of vapors as the vapors cool in the atmosphere above the molten salt pool is required (Leute et al., 2021). The nucleation of particles from supersaturated vapors is the more significant aerosol formation mechanism for reactor accidents in the existing accident analysis models (Allelein et al., 2009). The physical and chemical reactions of molten salt with water may also produce radionuclide-bearing aerosols and be of concern for some MSR designs. The importance of this process was demonstrated in early MSRE tests in which mixing a small amount of fuel salt with water resulted in droplet formation and dispersal all over the container (Briggs, 1962).

\subsubsection{Generated data}

The abundance and composition of molten salt splatter and aerosols that form as a result of molten salt spilling into a catch pan were measured as a function of initial salt temperature and composition. The experimental details and results are provided in Section 6 . For each condition that was evaluated, measurements were made to determine the mass fraction of spilled salt that became splatter; the abundance, size distribution, and composition of the splatter; the temperature of the atmosphere above the spilled salt pool and below the catch pan; and the compositions of aerosol particles that deposited onto a $0.45 \mu \mathrm{m}$ pore size filter and onto coupons coated in adhesive. Each test was filmed using a relatively high-speed visible camera to view the splashing behavior of the molten salt in video slowed down by a factor of 20 . The methods that were developed to measure splatter and aerosol formation can be applied to any salt composition and incorporated into future tests. The insight gained from this experiment can also be used to improve aerosol quantification methods in future tests that quantify molten salt aerosol formation.

\section{Salt composition and preparation}

\subsection{Composition and rationale}

Eutectic FLiNaK was used in the initial experiments discussed in this report to assess the suitability of the test methods and analytical measurements to generate the data needed for process modeling. The key physical and chemical properties of FLiNaK have been well-characterized and are appropriate for evaluating a wide range of spill conditions. Some tests employed FLiNaK that was doped with surrogate fission products cesium and iodine to understand the fate of key radionuclides that may represent a significant fraction of the source term after a spill. Radioisotopes of cesium and iodine will accumulate in the fuel salt as products of fission, decay, or neutron absorption (Compere et al., 1975). Cesium and iodine are of particular concern due to their radiotoxicity (Eckerman et al., 1988) and the fact that the cesium and iodine species that form in fluoride salts (e.g., Csl, I, HI, Lil) are relatively volatile (Kalilainen et al., 2020; Beneš et al., 2021). The abundance of cesium and iodine in the fuel salt at a given time will depend on many factors including the reactor design, the choice of fuel, the operation schedule, and burnup. The concentrations of both cesium and iodine are expected to be less than $1 \mathrm{~mol} \%$ in the fuel salt, with cesium approximately 10 times more abundant than iodine (McMurray et al., 2021; Capelli et al., 2018). The doped FLiNaK used in the experiments contained $0.9 \mathrm{~mol} \% \mathrm{CsF}$ and $0.099 \mathrm{~mol} \%$ Csl so that the total cesium concentration was approximately $1 \mathrm{~mol} \%$ and the cesium to iodine molar ratio was approximately 10 . The CsF concentration in this study approached $1 \mathrm{~mol} \%$ to maximize the amount of cesium and iodine present so that they would be easier to detect with the analytical methods being employed. Future tests may use salts having lower concentrations of surrogate fission products. 


\subsection{Salt preparation}

Previous reports describe the preparation of the FLiNaK used in these tests and its characterization using X-ray diffraction (XRD), inductively coupled plasma-optical emission spectroscopy (ICP-OES), and inductively coupled plasma-mass spectrometry (ICP-MS) (Rose et al., 2020; Lichtenstein et al., 2020). Briefly, reagent salts were dried then mixed by mass to achieve the eutectic composition of $46.5 \mathrm{~mol} \% \mathrm{LiF}, 11.5 \mathrm{~mol} \% \mathrm{NaF}$, and $42.0 \mathrm{~mol} \% \mathrm{KF}$. The mixture was fused at approximately $550{ }^{\circ} \mathrm{C}$ in a graphite crucible, then crushed and remelted to homogenize.

The FLiNaK containing surrogate fission products was made by mixing FLiNaK with prescribed amounts of dried CsF and Csl. Prior to mixing, the CsF and Csl powders were baked to dryness separately in nickel crucibles at $300^{\circ} \mathrm{C}$ for 6 hours, and the FliNaK was ground into a fine powder using an agate mortar and pestle. Before an experiment, the desired amounts of FLiNaK, CsF, and Csl were weighed out directly into a nickel crucible and then mixed. The sample in the nickel crucible was heated to the desired temperature in a furnace and allowed to equilibrate for approximately 1 hour to homogenize the mixture. Heating FLiNaK with surrogate fission products for longer than 1 hour after reaching the desired temperature was avoided to minimize the loss of cesium and iodine due to vaporization while still in the furnace.

\subsection{Analysis of salt composition by ICP-MS}

The concentrations of major cations lithium, sodium, and potassium and trace elements calcium, chromium, manganese, iron, nickel, rubidium, and cesium were analyzed by using ICP-MS. Measurements were made with a PerkinElmer NexION 2000 ICP Mass Spectrometer calibrated with standards prepared from NIST-traceable solutions. Individual salt samples were weighed, transferred to a Teflon ${ }^{\mathrm{TM}}$ beaker, and refluxed on a hot plate with a small amount of deionized water, $5 \mathrm{~mL}$ of nitric acid (Optima Grade), and $1 \mathrm{~mL}$ of hydrochloric acid (Optima Grade) until the samples had visibly dissolved. The solutions were then transferred to polypropylene centrifuge tubes and diluted to $50 \mathrm{~mL}$ with deionized water for analysis by ICP-MS. The ICP-MS technique is typically accurate to within $10 \%$ of the measured value.

When appropriate, the concentration of iodine in a salt sample was also determined by using ICP-MS. The sample preparation method for a salt sample containing added iodine differed from that used for iodine-free samples. Specifically, the FLiNaK samples with added CsI and CsF were split into two aliquots: one for metals analysis (described above) and the other for iodine analysis. The samples for iodine analysis were prepared by first adding $1 \mathrm{~mL}$ of $2 \%$ boric acid to the sample. This solution was then diluted to $25 \mathrm{~mL}$ with deionized water and allowed to fully dissolve over the course of several days. Larger samples received an additional $1 \mathrm{~mL}$ of $2 \%$ boric acid and were diluted to $40 \mathrm{~mL}$ with deionized water. The iodine concentration in the resulting dissolved mixture was then determined by using ICP-MS. To verify the effectiveness of the method, a sample of FLiNaK powder was spiked with Csl powder and $99.9 \%$ of the iodine was recovered.

The abundance of iodine, cesium, sodium, potassium, and lithium in particulates collected on PTFE filters for the molten salt splashing tests reported in Section 6 were analyzed by using ICP-MS. Specifically, each filter was transferred to a PYREX® beaker and then rinsed with methanol to reduce the hydrophobicity. The methanol was then evaporated, and the filter was covered with deionized water and $1 \mathrm{~mL}$ of $2 \%$ boric acid. The immersed filter was agitated and allowed to leach for 1 hour. The filters were then removed from the solution, rinsed with deionized water, and set aside for future acid leaching if necessary. The solutions were transferred to $50 \mathrm{~mL}$ centrifuge tubes and diluted to $30 \mathrm{~mL}$ with deionized water. 
The efficiency of iodine recovery using the reported methods with and without treatment with methanol was tested by using pure Csl powder and the results are shown in Table 1 . The recovery of iodine was $95 \%$ regardless of whether the Csl powder was treated with methanol.

Table 1: lodine recovery results

\begin{tabular}{lccc}
\hline Sample & Expected I $(\mathrm{mg})$ & Measured I $(\mathrm{mg})$ & Recovery (\%) \\
\hline Csl powder & 21.6 & 20.6 & 95.0 \\
Csl powder treated with methanol & 34.7 & 33.0 & 95.0 \\
\hline
\end{tabular}

\section{Molten salt spreading and heat transfer}

\subsection{Experimental methods}

\subsubsection{Experimental design}

The objective of this experimental method is to measure the flow and spreading behavior of spilled molten salt on a sloped catch pan. To achieve this, molten FLiNaK was poured onto a 316 stainless steel sheet (McMaster-Carr, item no. 88885K24) that was 22 in. long, 10 in. wide, and 0.06 in. thick with a 1-in. lip on three sides to prevent spillover (Figure 3A). The top end of the substrate was elevated to create a tilt angle of between $2.5^{\circ}$ and $5^{\circ}$ for this study. The salt was heated to the target temperature in a furnace using a custom nickel crucible and then manually poured onto the top end of the substrate without the lip using long crucible tongs. The spreading and heat transfer tests were conducted within an argon atmosphere glovebox $\left(\mathrm{O}_{2}<10 \mathrm{ppm}, \mathrm{H}_{2} \mathrm{O}<5 \mathrm{ppm}\right)$. An IR camera and a visible camera mounted on a tripod and positioned approximately three feet above the substrate were used to record video of molten salt spreading as it was poured (Figure 3B). The IR camera was used to measure the surface temperatures of the salt and substrate as a function of time. Several thermocouples were attached to the top surface and underside of the substrate and placed in the atmosphere above the substrate to record temperatures throughout the tests.

(A)

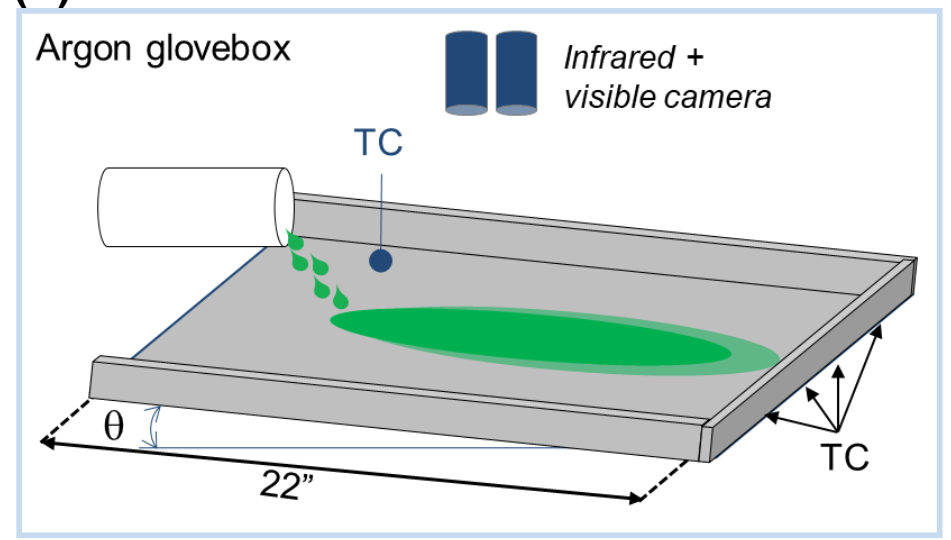

(B)

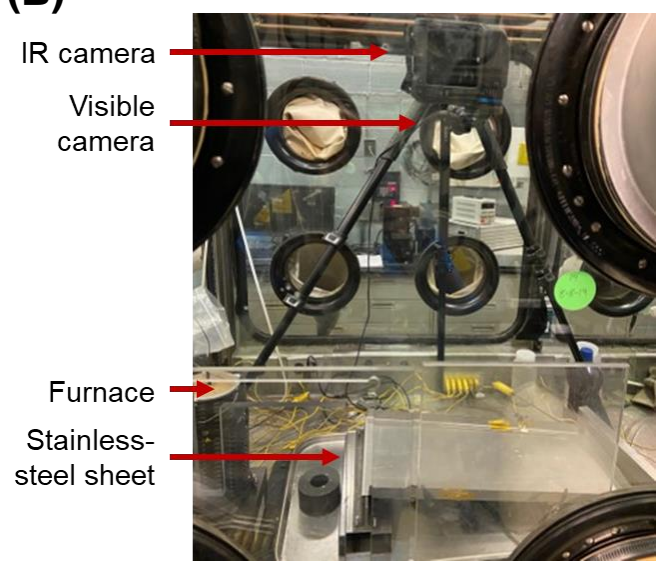

Figure 3: (A) Schematic of the molten salt spreading and heat transfer test. (B) Image taken of the experimental setup in the glovebox. 
Figure 4 shows the thermocouple layout at the underside of the stainless steel substrate. The salt was poured down the center of the substrate so that it would flow over Thermocouples 1, 4, 7, and 8 (in that order). A description of the IR camera, data logger for thermocouple measurements, visible camera, and furnace is provided in Appendix A. Technical aspects of temperature measurements and calibrations are discussed in Appendix B.

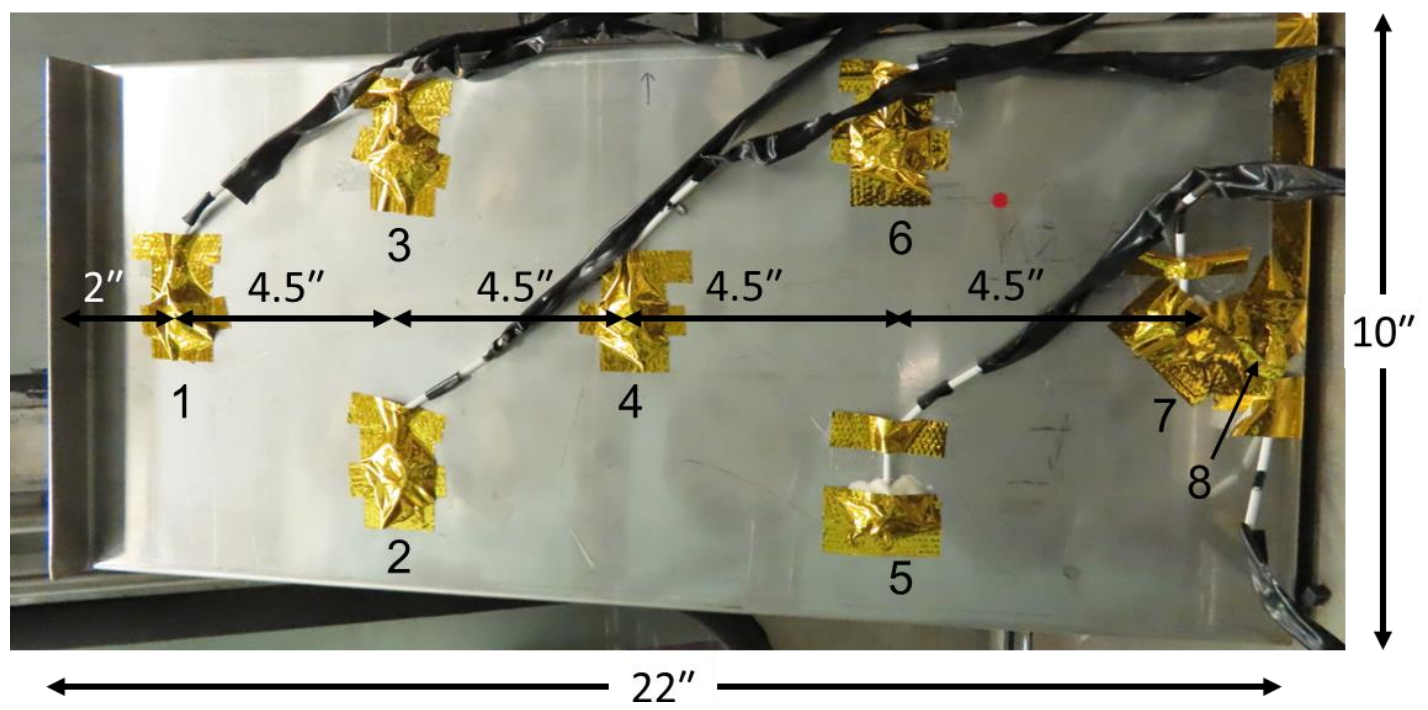

Figure 4: The thermocouple layout at the underside of the stainless steel sheet. The top end of the sheet is on the left side of the photograph and salt flows from left to right. Thermocouple 8 was positioned approximately $0.5 \mathrm{in}$. from the bottom of the sheet. Thermocouples 1, 4, 7, and 8 were positioned in the center of the substrate (length-wise) and Thermocouples 2, 3, 5, and 6 were positioned 2 in. from the edges of the substrate.

\subsubsection{Measurements}

\subsubsection{Temperature}

The temperatures at the underside of the substrate and at the edges of the substrate surface were recorded with butt-welded thermocouple lead wires with the junction attached to the surfaces with thermally conductive cement (Appendix B Section B.2). The performance of the surface temperature measurement obtained using the thermocouples is presented in Appendix B Section B.2.

The temperatures of the molten salt surface and substrate surface were recorded with an IR camera with $42^{\circ}$ lens. The lens was chosen so that the entire stainless steel sheet could be in the field of view of the camera. The emissivity of FLiNaK as a function of temperature is unknown and was assumed to be unity for the salt surface temperatures reported herein. Section 3.2.2 provides an estimation of FLiNaK emissivity near the freezing temperature.

The furnace temperature provided an estimate of the initial molten salt temperature immediately before it was poured. The reading from the furnace may not reflect the actual salt temperature because the thermocouple in the furnace was placed in the furnace liner (not directly in the molten salt) and the salt cools when it is removed from the furnace prior to being poured. Therefore, the initial salt temperature in the crucible was estimated using the IR camera. 
Sheath-type thermocouples (ungrounded, $\mathrm{K}$ type) positioned in the atmosphere approximately 2 feet above the substrate and directly above the molten salt pool that formed at the end of the substrate during the spreading test (exact distance varied by test) provided the temperature of the atmosphere as a function of time.

\subsubsection{Average pour rate}

The average pour rate was determined by dividing the mass of salt that was poured by the duration of the pour. The mass of salt poured is equal to the mass added to the crucible subtracted by the mass that remained in the crucible after pouring. The duration of the pour was determined from footage from the IR camera, which showed the time when the salt first hit the substrate and the time when hot salt ceased flowing from the crucible.

\subsubsection{Leading edge and covered area as a function of time}

The IR camera records video at a rate of 30 frames per second, which provided detailed information on the leading edge and covered area as a function of time. The leading edge and covered area of the molten salt flowing on the stainless steel sheet was determined for each still frame of the IR video. The raw IR video that was collected for each molten salt spreading experiment was uploaded to the software FLIR ResearchIR (Version 4.40.11.35) and the dataset (matrix of temperature values per pixel at each frame of the video) was exported into a MATLAB®readable format. The difference in the emissivity of molten FLiNaK (assumed to be 1) and the emissivity of the stainless steel substrate (between 0.1 and 0.3 ; see Figure B4-A) provides sufficient contrast in the IR images to distinguish the two materials. The Image Processing Toolbox ${ }^{\mathrm{TM}}$ in MATLAB® was used to distinguish between the two materials in the temperature matrix of each still frame so that each pixel could be identified as salt or stainless steel to create a binary image. Specifically, the entire temperature matrix was corrected for emissivity by using the emissivity of stainless steel at known temperatures (the procedure is summarized in Appendix B Section B.1.3). This action provided accurate temperature values of the stainless steel surface but over-corrected the temperature of the molten salt surface to temperature values above the initial temperature of the salt due to the much higher emissivity of molten salt. The pixels with corrected temperatures above the initial temperature of the poured molten salt were simply assigned as salt pixels and the remaining pixels were assigned as stainless steel pixels.

Figure 5A provides a raw IR image of salt spreading on a stainless steel sheet (approximately two seconds after the test started). The top-most part of the image was cropped to remove the crucible from the field of view so that the crucible surface did not interfere with image processing. Figure 5B provides the processed image showing the temperature of just the salt and Figure $5 \mathrm{C}$ provides a binary image of the salt (white) on a black background (the steel substrate).

The leading edge and covered area for each still frame recorded by the IR camera were determined from the corresponding binary image in units of pixels. The dimensions of each pixel were determined by using the known length and width of the stainless steel sheet and used to convert the leading edge and covered area from numbers of pixels to units of millimeters and square millimeters, respectively.

\subsubsection{Video and images obtained by visible camera}

A visible camera mounted on a tripod filmed visible video of the molten salt spreading and freezing on the stainless steel sheet. Photographs of the frozen salt were also taken to show the morphology and freezing behavior. 
(A)

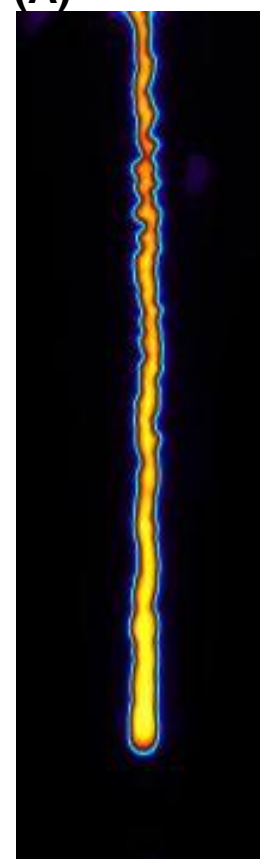

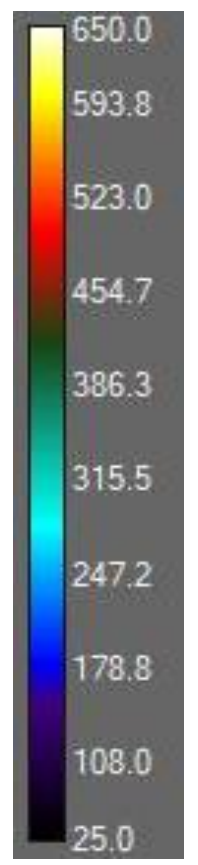

(B)

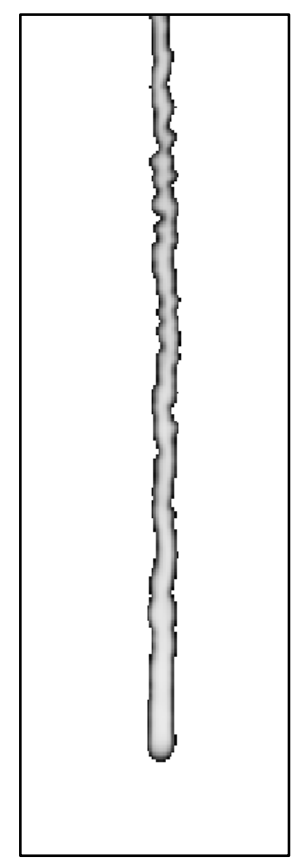

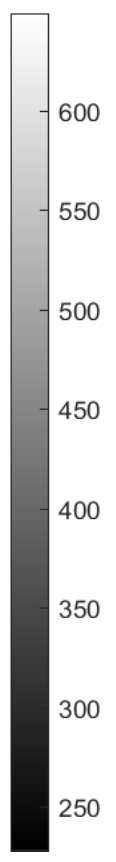

(C)

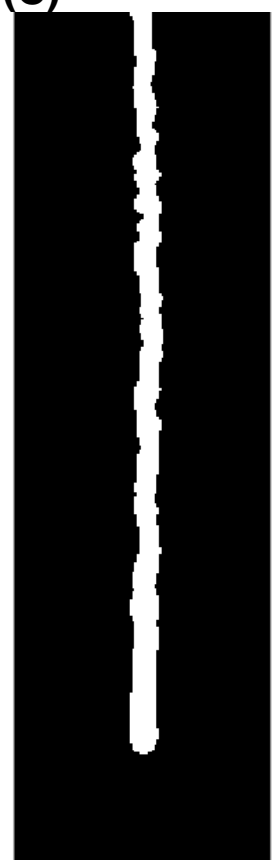

Figure 5: (A) Raw image measured by IR camera, (B) processed image showing the temperature of just the salt, and (C) binary image showing the salt (white) on the stainless steel background (black). The top-most part of the image was cropped to remove the crucible from the field of view so that the crucible did not interfere with image processing.

\subsubsection{Composition of frozen salt}

The salt that froze on the stainless steel sheet was analyzed for major cation (lithium, sodium, and potassium) and trace metal (calcium, manganese, iron, nickel, chromium, cesium, and rubidium) concentrations by using ICP-MS following the methods reported in Section 2.3. Samples were taken from different locations on the stainless steel substrate to compare compositions within the flow path.

\subsubsection{Glovebox conditions}

The temperature, total pressure, $\mathrm{O}_{2}$ content, and $\mathrm{H}_{2} \mathrm{O}$ content of the atmosphere of the argon glovebox was recorded before and after pouring molten salt for each test.

\subsection{Results}

Table 2 provides a summary of the conditions used in each FLiNaK spreading and heat transfer test that was conducted. This section includes examples of the results that were derived from the measurements that were taken and summarizes key findings. The full suite of results will be included in a data package in an upcoming report (Thomas and Jackson, 2021). The results from modeling FLiNaK spreading and heat transfer on a stainless steel sheet and an uncertainty analysis of thermophysical properties will be published in an upcoming report (Thomas, Jackson, and Farmer, 2021). 
Table 2: Summary of spreading and heat transfer test conditions for tests using molten FLiNaK

\begin{tabular}{ccccccc}
\hline Test & $\begin{array}{c}\text { Target initial salt } \\
\text { temp. }\left({ }^{\circ} \mathrm{C}\right)^{\mathrm{a}}\end{array}$ & $\begin{array}{c}\text { Max temp. } \\
\left({ }^{\circ} \mathrm{C}\right)^{\mathrm{b}}\end{array}$ & $\begin{array}{c}\text { Mass of salt } \\
\text { poured }(\mathrm{g})\end{array}$ & $\begin{array}{c}\text { Average pour } \\
\text { rate }\left(\mathrm{g} \mathrm{s}^{-1}\right)\end{array}$ & $\begin{array}{c}\text { Sheet tilt } \\
\text { angle }\left({ }^{\circ}\right)\end{array}$ & $\begin{array}{c}\text { CsF + Csl } \\
\text { addition }\end{array}$ \\
\hline 1 & 500 & 476.7 & 28.4 & 20.8 & 2.5 & $\mathrm{~N}$ \\
2 & 500 & 494.5 & 38.4 & 21.8 & 5.0 & $\mathrm{~N}$ \\
3 & 550 & 530.0 & 49.0 & 18.6 & 2.5 & $\mathrm{~N}$ \\
4 & 650 & 625.3 & 30.0 & 19.6 & 2.5 & $\mathrm{Y}$ \\
5 & 650 & 640.0 & 24.3 & 13.3 & 5.0 & $\mathrm{~N}$ \\
6 & 650 & 649.0 & 29.6 & 22.2 & 2.5 & $\mathrm{~N}$ \\
7 & 800 & 731.5 & 19.1 & 9.7 & 5.0 & $\mathrm{~N}$ \\
8 & 800 & 734.1 & 30.3 & 13.6 & 2.5 & $\mathrm{~N}$ \\
9 & 800 & 794.5 & 30.6 & 29.6 & 2.5 & $\mathrm{~N}$ \\
\hline
\end{tabular}

a The actual salt temperature may have differed from the target temperature.

$\mathrm{b}$ The maximum temperature of the salt measured by the IR camera (uncorrected for emissivity) provides an estimate of the actual salt temperature as it was poured.

\subsubsection{Images from tests of molten salt spreading and freezing on a stainless steel sheet}

Figure 6, Figure 7, and Figure 8 show still frames taken from video recorded by the visible camera of FLiNaK spreading on the stainless steel substrate at initial salt temperatures of approximately $530{ }^{\circ} \mathrm{C}, 650^{\circ} \mathrm{C}$, and $800^{\circ} \mathrm{C}$, respectively. The molten FLiNaK is transparent and has a water-like appearance at initial temperatures of approximately $530^{\circ} \mathrm{C}$ and $650{ }^{\circ} \mathrm{C}$ (Figure 6 and Figure 7). The salt glows pink at an initial temperature of approximately $800{ }^{\circ} \mathrm{C}$ (Figure 8). The still frames from the video of molten salt spreading show that the salt does not wet the surface of the stainless steel substrate and does not spread much wider than the inner diameter of the crucible from which it was poured. It is important to note that these tests were conducted within an argon atmosphere glovebox using pure FLiNaK, and the surface wetting behavior may be different for more complex salt compositions or in an air atmosphere. The surface roughness of the substrate will also influence the wetting behavior of molten salts (Grosu et al., 2019); only smooth stainless steel surfaces were used in this study. In general, the salt flow path was straight at the lower temperatures and meandering at the higher temperatures.

The molten salt flowed quickly down the length of the stainless steel substrate regardless of the pour conditions and reached the end of the sheet within three seconds in all tests. A pool of salt formed at the end of the stainless steel sheet in all tests, and the spreading behavior did not appear to be limited by salt freezing. We consistently observed a crust at the salt-substrate interface that produced a trail of frozen salt the entire length of the flow path on the substrate regardless of the spill condition (e.g., Figure 6). Figure $8 \mathrm{C}$ shows an image of the crust that froze along the length of the stainless steel sheet for FLiNaK that was poured at an initial temperature of approximately $800{ }^{\circ} \mathrm{C}$ (i.e., Test 9). The crust raised off the substrate as it cooled, which was a phenomenon that was consistently observed in all tests. The crust thickness was measured after the salt cooled in each test. The frozen salt that formed the trail along the substrate shown in Figure $8 \mathrm{C}$ had a thickness of approximately $2.5 \pm 0.2 \mathrm{~mm}$ near the top of the substrate (upstream) and approximately $1.5 \pm 0.1 \mathrm{~mm}$ near the bottom of the substrate (downstream). 


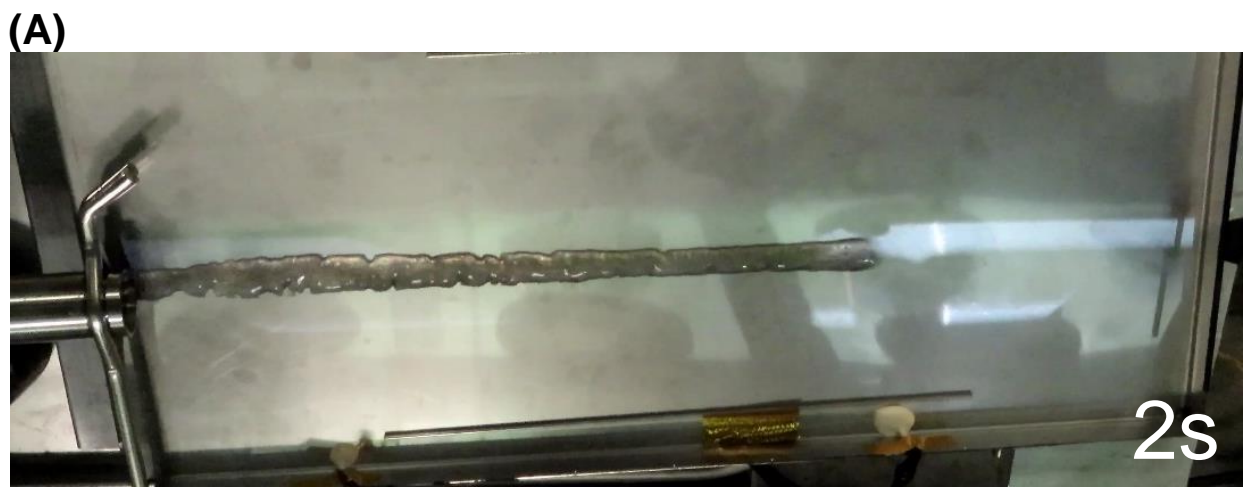

(B)

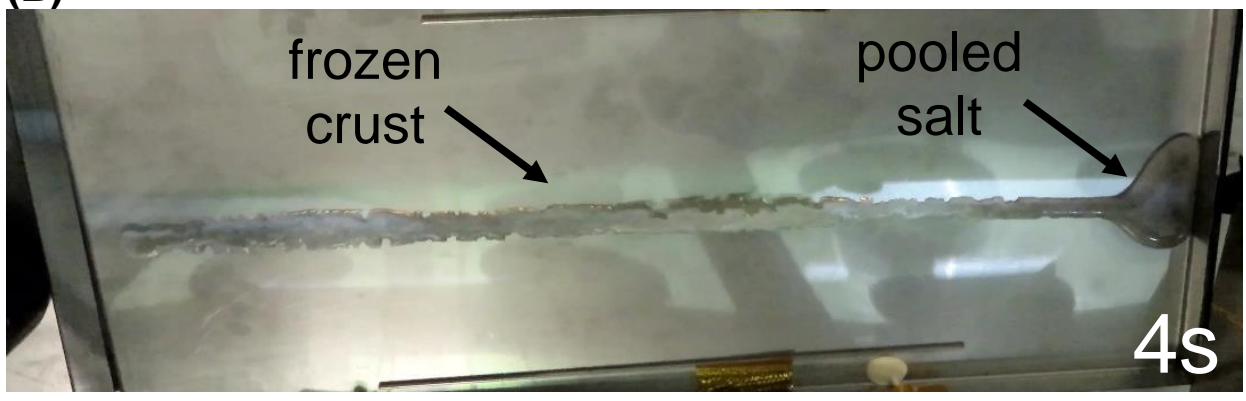

Figure 6: Still frames from video taken by the visible camera that show $49 \mathrm{~g}$ of FLiNaK at an initial temperature of approximately $530^{\circ} \mathrm{C}$ flowing and spreading onto a stainless steel sheet tilted at an angle of $2.5^{\circ}$ (Test 3). The frames were taken (A) 2 and (B) 4 seconds after the molten salt first touched the stainless steel sheet.

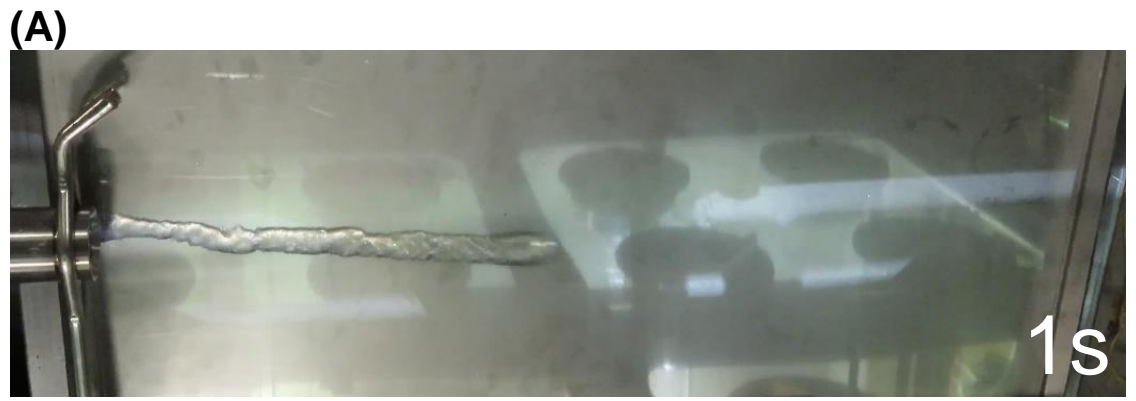

(B)

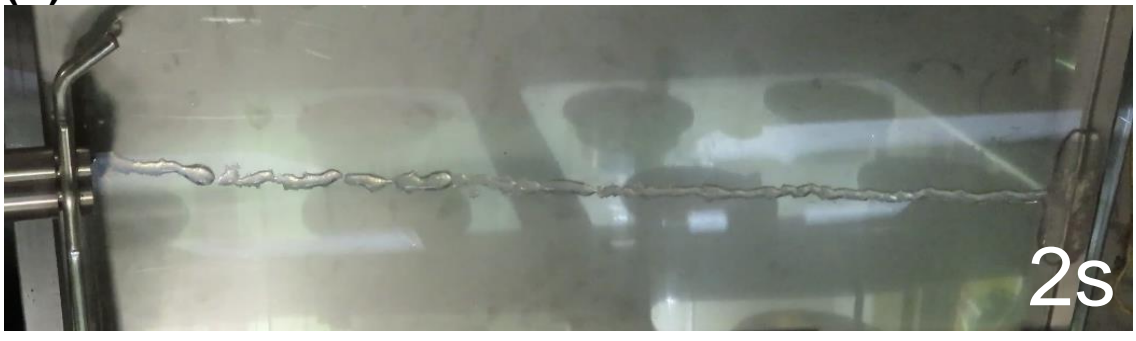

Figure 7: Still frames from video taken by the visible camera that show $25 \mathrm{~g}$ of FLiNaK at an initial temperature of approximately $640{ }^{\circ} \mathrm{C}$ flowing and spreading onto a stainless steel sheet tilted at an angle of $5^{\circ}$ (Test 5). The frames were taken (A) 1 and (B) 2 seconds after the molten salt first touched the stainless steel sheet. 


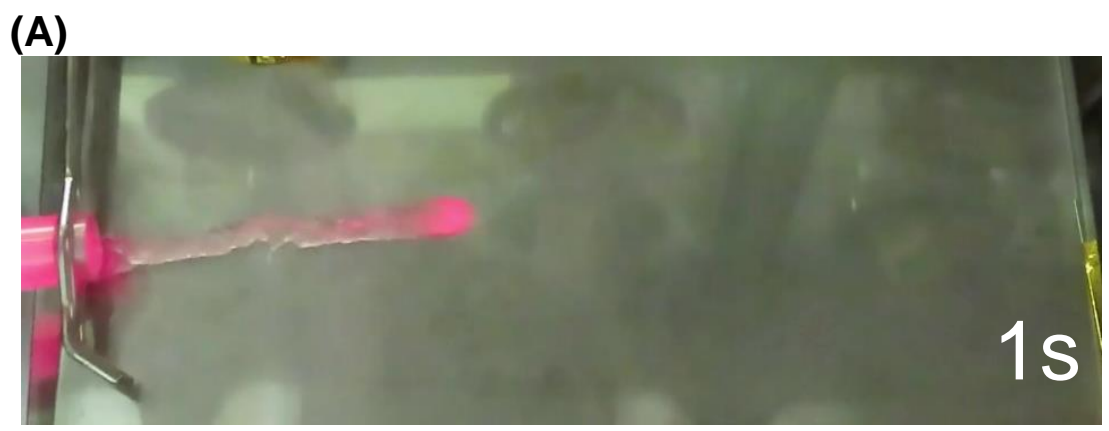

(B)

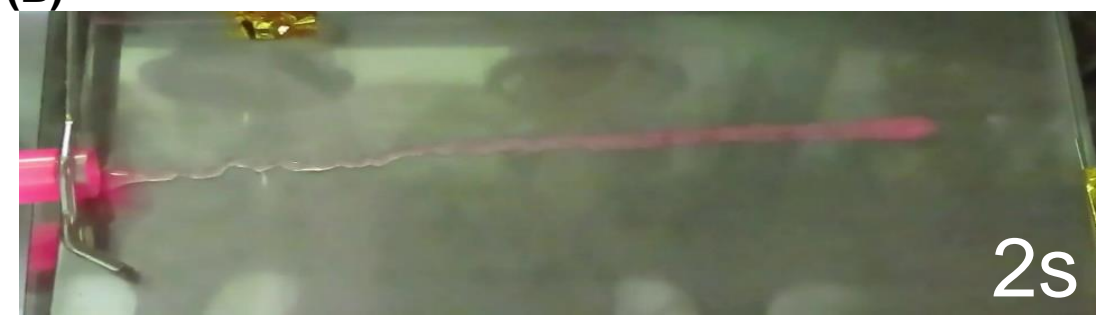

(C)

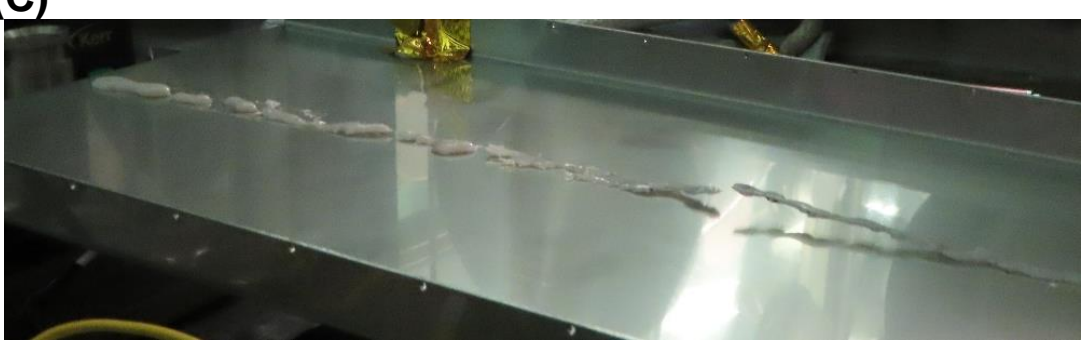

Figure 8: Still frames from video taken by the visible camera that show approximately $30 \mathrm{~g}$ of FLiNaK at an initial temperature of approximately $800^{\circ} \mathrm{C}$ flowing and spreading onto a stainless steel sheet tilted at an angle of $2.5^{\circ}$ (Test 9). The frames were taken (A) 1 and (B) 2 seconds after the molten salt first touched the stainless steel sheet. (C) A photo taken after the spreading test shows thick pieces of frozen salt on the sheet and sections of frozen salt that rose above the sheet.

Some batches of salt contained visible black contamination that was introduced into the salt from the graphite crucible in which the salt was made. This contamination floated to the surface of the molten salt and traveled with the bulk salt to the end of the stainless steel substrate. The trail of molten salt crust was consistently free of visible contamination. The formation of a frozen crust at the molten salt-substrate interface is an important processes to understand because the thermal properties of the crust may differ from the liquid salt.

\subsubsection{Temperature of salt surface and estimate of FLiNaK emissivity}

Figure 9, Figure 10, and Figure 11 show still frames taken from video recorded by the IR camera of FLiNaK spreading on the stainless steel substrate in tests performed with initial salt temperatures of approximately $530{ }^{\circ} \mathrm{C}, 650{ }^{\circ} \mathrm{C}$, and $800{ }^{\circ} \mathrm{C}$, respectively. The minimum temperatures of the legends for the temperature scales in Figure 9, Figure 10, and Figure 11 were set to $450^{\circ} \mathrm{C}$ (which is the approximate freezing temperature of FLiNaK) so that the frozen salt has the same color as the background of the image. 
(A)

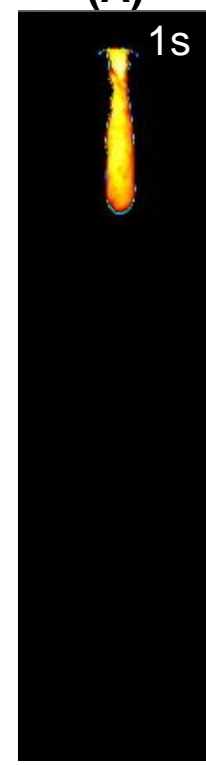

(B)

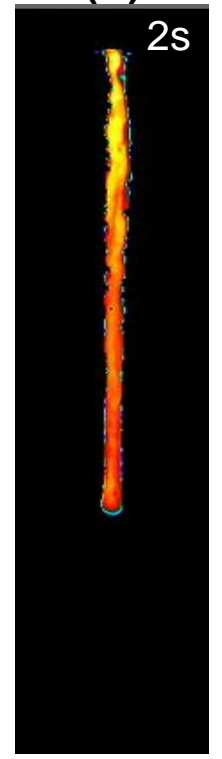

(C)

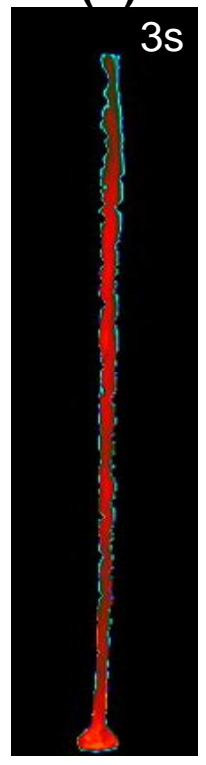

(D)

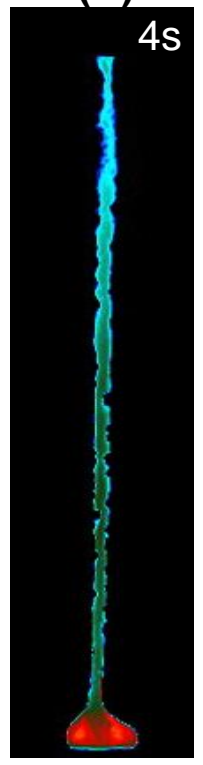

(E)

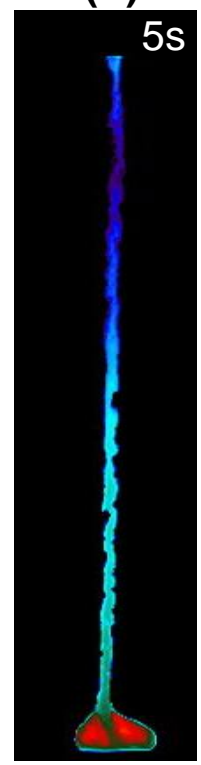

(F)

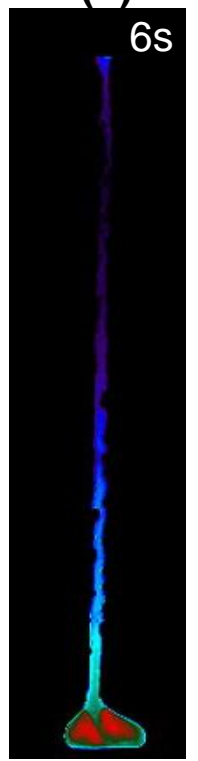

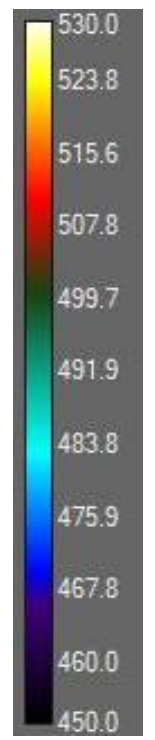

Figure 9: Still frames from video taken by the IR camera that show $49 \mathrm{~g}$ of FLiNaK at an initial temperature of approximately $530{ }^{\circ} \mathrm{C}$ flowing and spreading onto a stainless steel sheet tilted at an angle of $2.5^{\circ}$ (Test 3). The frames were taken between 1 and 6 seconds after the molten salt first touched the stainless steel sheet $(A-F)$. The reported temperature is the raw temperature reading from the IR camera.

(A)

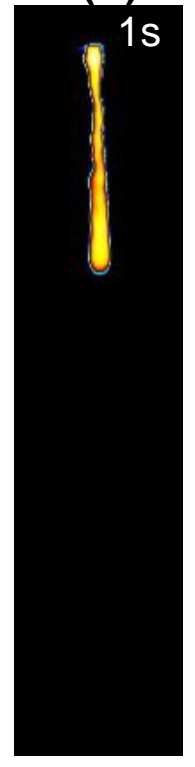

(B)

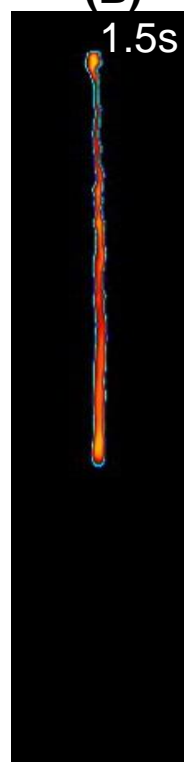

(C)

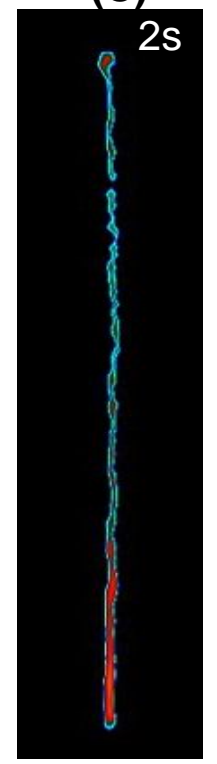

(D)

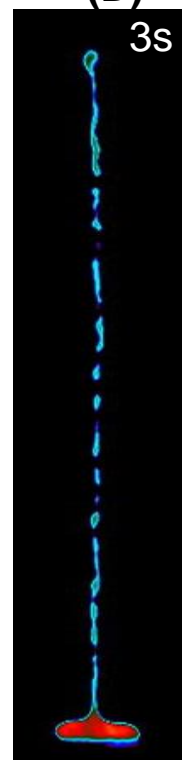

(E)

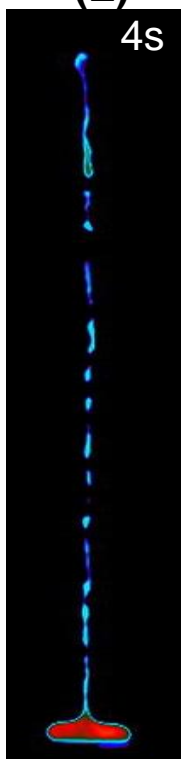

(F)

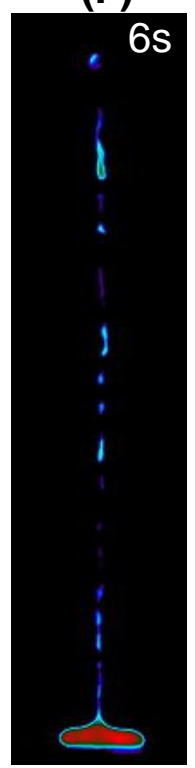

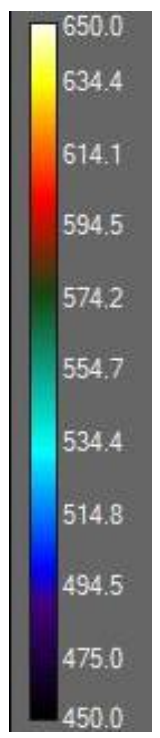

Figure 10: Still frames from video taken by the IR camera that show approximately $30 \mathrm{~g}$ of FLiNaK at an initial temperature of approximately $650^{\circ} \mathrm{C}$ flowing and spreading onto a stainless steel sheet tilted at an angle of $2.5^{\circ}$ (Test 6). The frames were taken (A) 1, (B) 1.5, (C) 2, (D) 3, (E) 4, and (F) 6 seconds after the molten salt first touched the stainless steel sheet. The reported temperature is the raw temperature reading from the IR camera. 
(A)

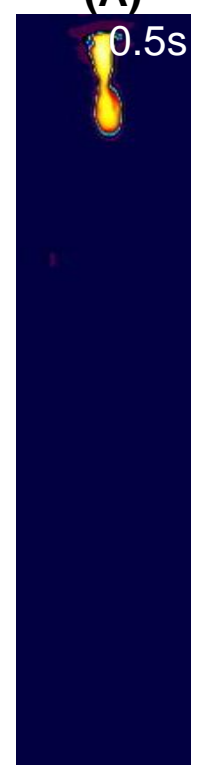

(B)

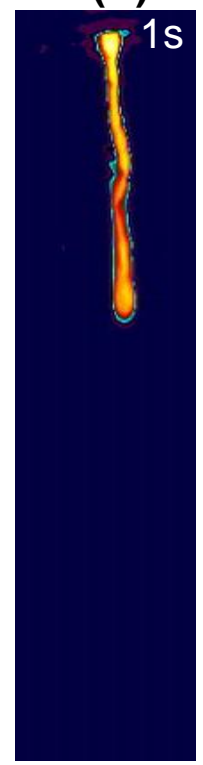

(C)

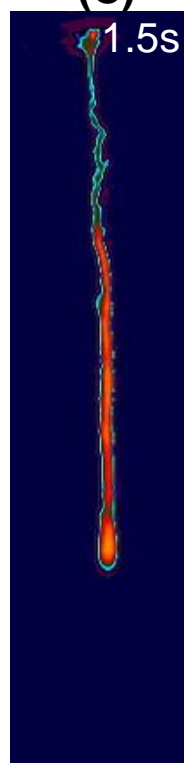

(D)

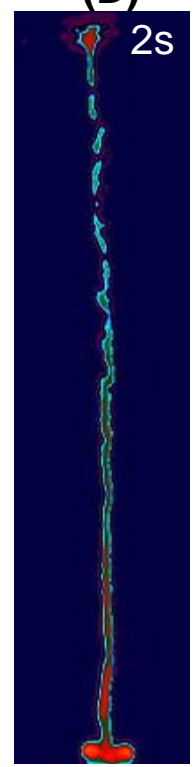

(E)

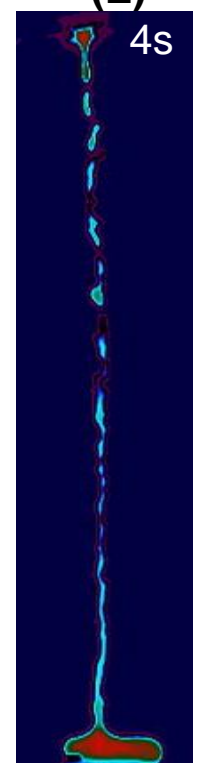

(F)

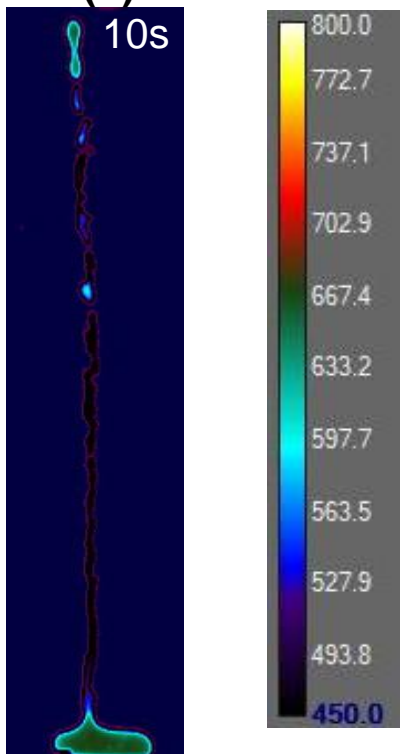

Figure 11: Still frames from video taken by the IR camera that show approximately $30 \mathrm{~g}$ of FLiNaK at an initial temperature of approximately $800^{\circ} \mathrm{C}$ flowing and spreading onto a stainless steel sheet tilted at an angle of $2.5^{\circ}$ (Test 9). The frames were taken (A) 0.5, (B) 1, (C) 1.5, (D) 2, (E) 4, and (F) 10 seconds after the molten salt first touched the stainless steel sheet. The reported temperature is the raw temperature reading from the IR camera.

A temperature correction was not performed on the raw temperature data that was recorded by the IR camera because the emissivity of FLiNaK is not known. The fact that molten salts are transparent makes emissivity determination difficult. The emissivity of molten nitrate and chloride salts has been studied to a limited extent (Tetreault-Friend, 2018) and was found to depend on temperature. Tetreault-Friend, 2018 measured the effective emissivity, which neglects transmitted radiation and instead designates thickness-dependent values of emissivity.

We estimated the emissivity of molten FLiNaK at its freezing point by using the cooling curves that were collected at single pixels of static molten salt in the field of view of the IR camera. The black curve in Figure 12 presents the salt surface temperature as a function of time that was recorded at one pixel in the molten salt pool that formed at the bottom of the sheet for the spill test that was shown in Figure 9 (Test 3). The flat part of the cooling curve from the uncorrected temperature data measured by the IR camera shown in Figure 12 indicates that the freezing temperature is approximately $457^{\circ} \mathrm{C}$. This uncorrected salt freezing temperature can be compared to the actual freezing temperature of the FLiNaK batch $\left(456.2^{\circ} \mathrm{C}\right)$ that was measured by using differential scanning calorimetry (DSC) (Lichtenstein et al., 2020). The fact that the uncorrected freezing temperature measured by the IR camera is nearly identical to the actual freezing temperature measured using DSC suggests that the emissivity of FLiNaK is approximately unity near its freezing point. This indicates that the raw salt surface temperatures measured by the IR camera are close approximations of the actual temperatures. After the emissivity of FLiNaK is determined as a function of temperature, the temperature data reported herein can be updated, if necessary. 


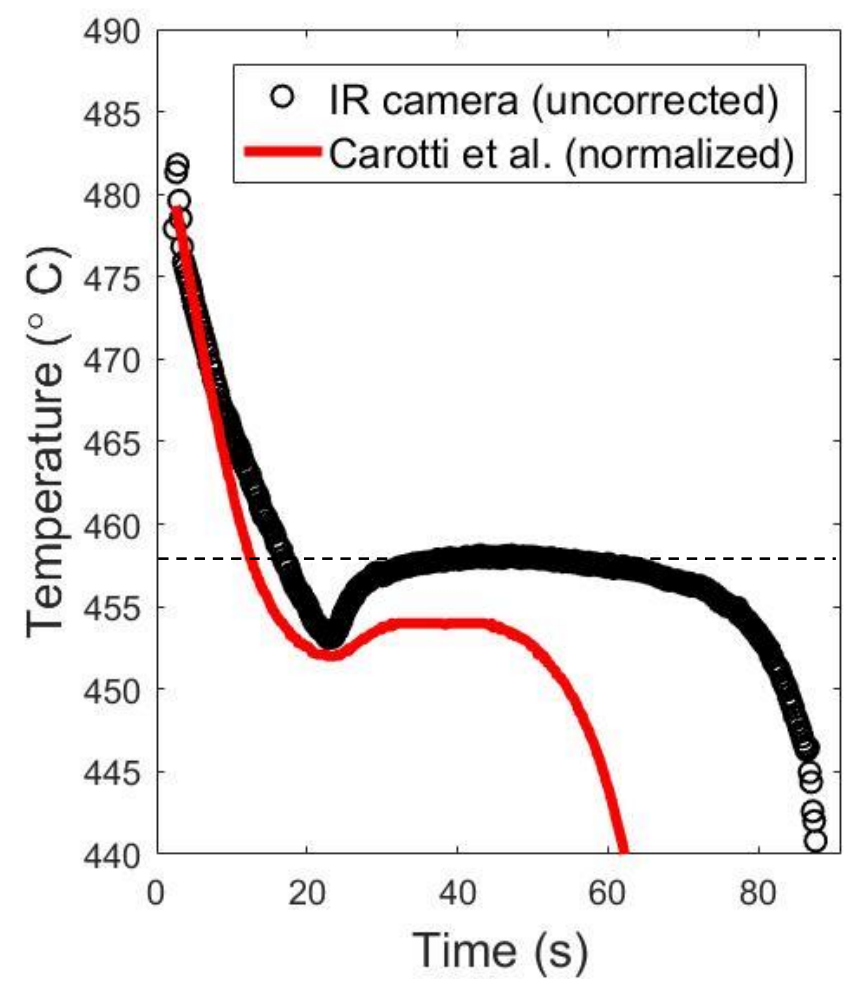

Figure 12: The apparent temperature measured by the IR camera of a pixel in a pool of static molten FLiNaK from this study (black; uncorrected for emissivity) and the temperature of molten FLiNaK in a stainless steel crucible recorded by using a thermocouple from Carotti et al., 2015 (red) plotted as a function of time. The cooling curve from Carotti et al., 2015 was normalized so that the rate was comparable to the cooling rate from this study.

A notable super-cooling feature was observed in the cooling curves of FLiNaK that pools at the bottom of the substrate when spreading stops (black curve in Figure 12). This is apparent from the dip in the molten salt temperature below its freezing point between approximately 17 and 29 seconds after the measurement began. The super-cooling feature was present in the cooling curves of static salt pools for all tests conducted on spreading and heat transfer discussed in this section. Carotti et al., 2015 also observed super-cooling of molten FLiNaK in a stainless steel crucible placed at ambient temperature. They measured the temperature of FLiNaK in the crucible directly by inserting a stainless steel-sheathed Type $\mathrm{K}$ thermocouple into the bulk liquid salt. The cooling curve from Carotti et al., 2015 was normalized so that the rate was similar to the cooling rate from this study to facilitate comparison and is plotted as the red curve in Figure 12.

The observation that molten FLiNaK cools to temperatures below its freezing temperature during spreading tests suggests that non-equilibrium freezing may influence the behavior of spilled molten salt pools. The presence of nucleation sites to initiate freezing (e.g., impurities in the salt), rapid quenching, and local temperature gradients can shift freezing behavior from the equilibrium transition temperatures reported in phase diagrams (Carotti et al., 2015). 


\subsubsection{Temperature of substrate underside}

Figure 13A, Figure 14A, and Figure 15A indicate the layout of the thermocouples attached to the underside of the stainless steel substrate overlaid on a still frame of video collected by using the IR camera for Tests 3,6 , and 9 at initial salt temperatures of approximately $530^{\circ} \mathrm{C}, 650{ }^{\circ} \mathrm{C}$, and $800{ }^{\circ} \mathrm{C}$, respectively. The position of Thermocouple 8 was approximately $0.5 \mathrm{in}$. from the bottom of the sheet for all tests. These images show the positions of the salt after spreading ceased relative to the locations of the thermocouples. The temperatures recorded by each thermocouple are provided in subplots B and C of Figure 13, Figure 14, and Figure 15. The thermocouples at positions 2 and 4 failed in Test 3 and temperatures for those positions are not reported (Figure 13)

(A)

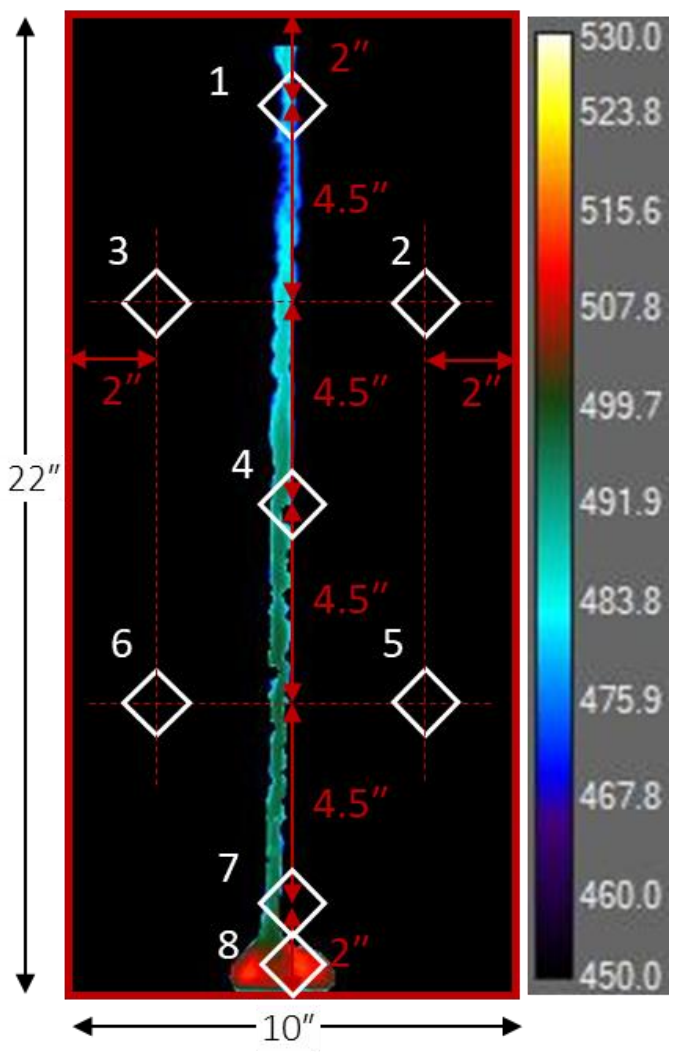

(B)

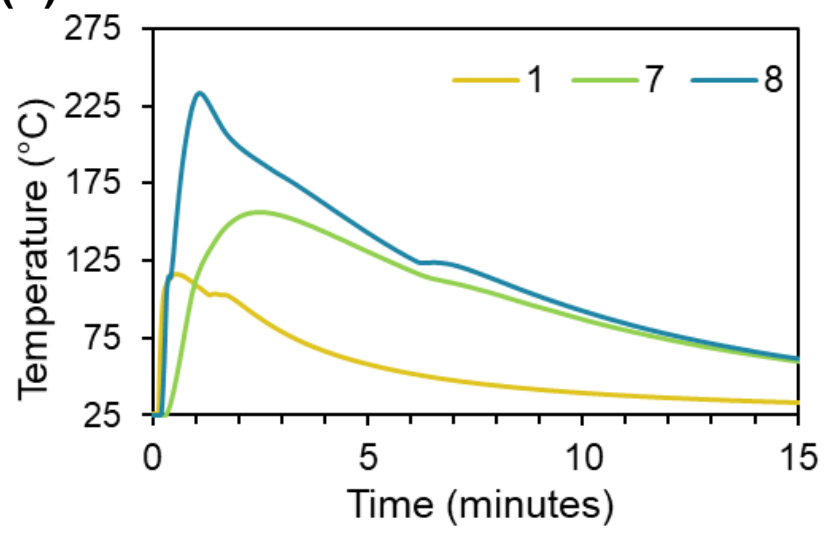

(C)

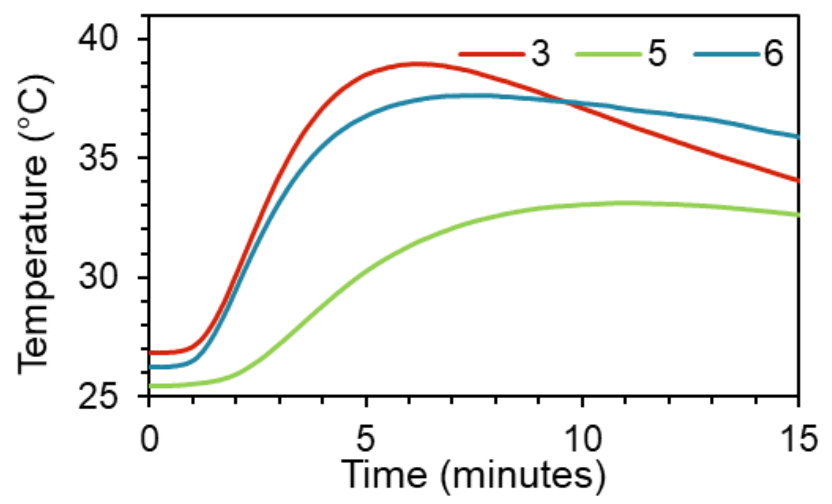

Figure 13: Results for salt spreading Test 3: (A) Location of thermocouples attached to the underside of the substrate overlaid on an image of the salt spreading path, $(B)$ the temperature profiles measured by Thermocouples 1, 7, and 8 along the flow path, and (C) the temperature profiles measured by Thermocouples 3, 5, and 6 off the flow path.

The temperature underneath the static salt pool that formed at the bottom of the substrate (recorded by Thermocouple 8) was consistently the highest recorded temperature but did not exceed $300^{\circ} \mathrm{C}$ in any test. The maximum temperature recorded by Thermocouple 8 for Tests 3 , 6 , and 9 were approximately $230^{\circ} \mathrm{C}, 295^{\circ} \mathrm{C}$, and $190^{\circ} \mathrm{C}$, respectively. The maximum recorded temperature at Thermocouple 8 did not correlate with the initial salt temperature likely because 
(A)

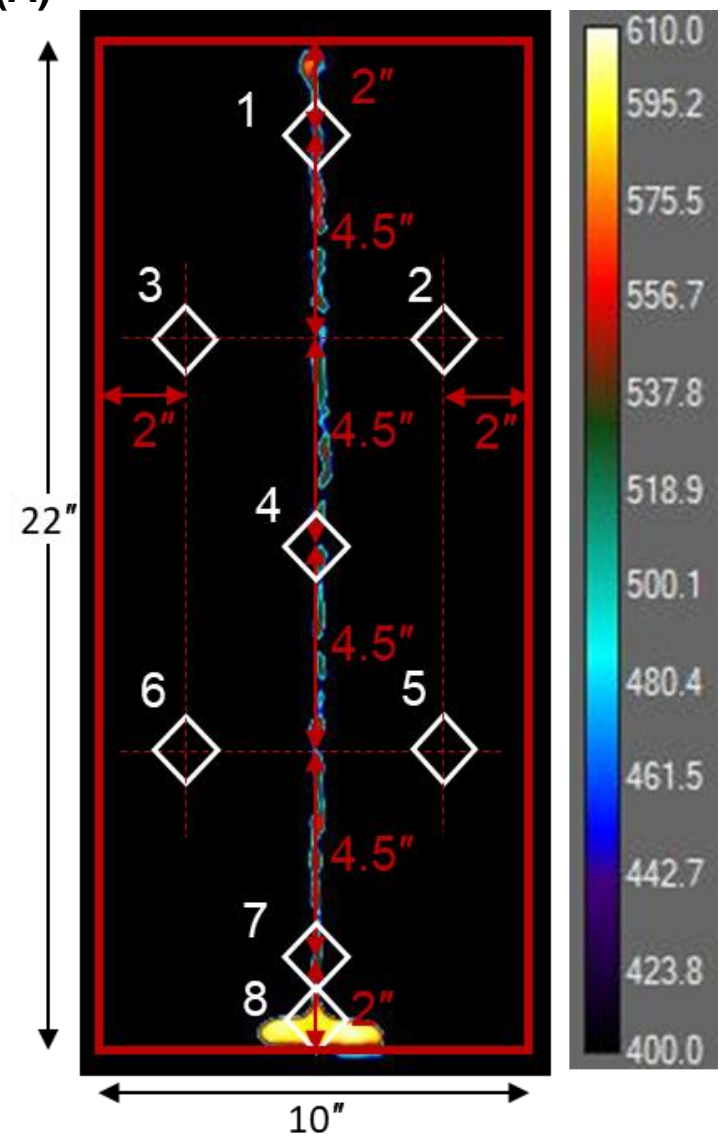

(B)

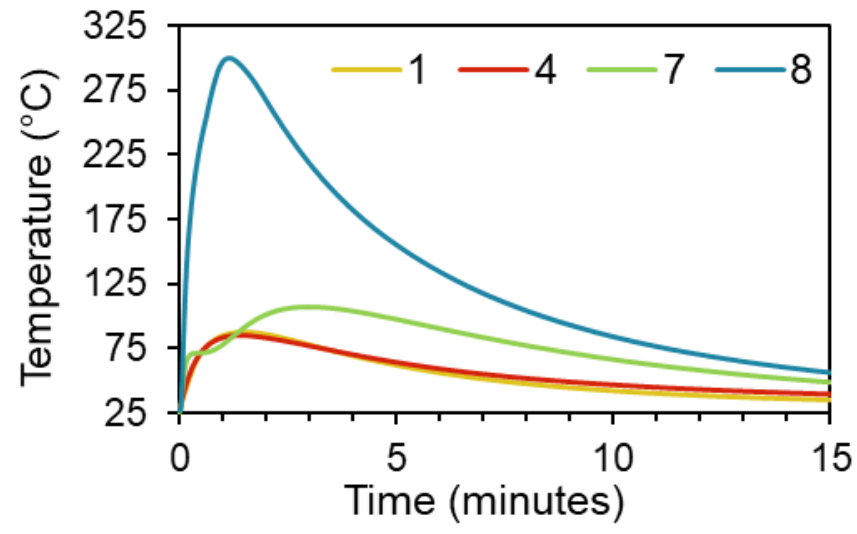

(C)

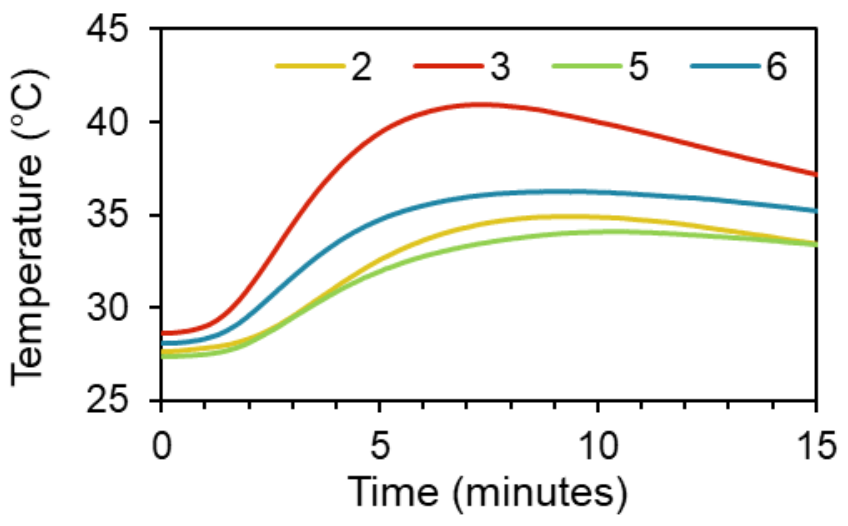

Figure 14: Results for salt spreading Test 6: (A) Location of thermocouples attached to the underside of the substrate overlaid on an image of the salt spreading path, $(B)$ the temperature profiles measured by Thermocouples 1, 4, 7, and 8 along the flow path, and (C) the temperature profiles measured by Thermocouples 2, 3, 5, and 6 off the flow path.

the salt pool was not always positioned above Thermocouple. For example, the salt pool for Test 9 was not centered above Thermocouple 8 (Figure 15A). The temperatures recorded by Thermocouples 1,4 , and 7 in the salt flow path were consistently lower than those measured by Thermocouple 8 (Figure 13B, Figure 14B, and Figure 15B). The temperatures recorded by Thermocouples $2,3,5$, and 6 out of the salt flow path reached values that were slightly above the initial substrate temperature. The maximum recorded temperature by a thermocouple out of the flow path was $45^{\circ} \mathrm{C}$ (measured by Thermocouple 3 in Test 9; Figure 15C).

We measured the thickness of the frozen salt pools that formed at the bottom of the substrate for Tests 6 and 8 by taking three thickness measurements near the center of the pool after it had cooled to room temperature by using calipers. The thickness of the pooled molten salt that formed at the end of the substrate was $4.4 \pm 0.3 \mathrm{~mm}$ in Test 6 and $4.3 \pm 0.3 \mathrm{~mm}$ in Test 8 . The thickness of the salt pool that formed in Test 3 was not measured. The frozen salt pools for all tests did not have a uniform thickness, and the spatially dependent thickness was not measured. 
(A)

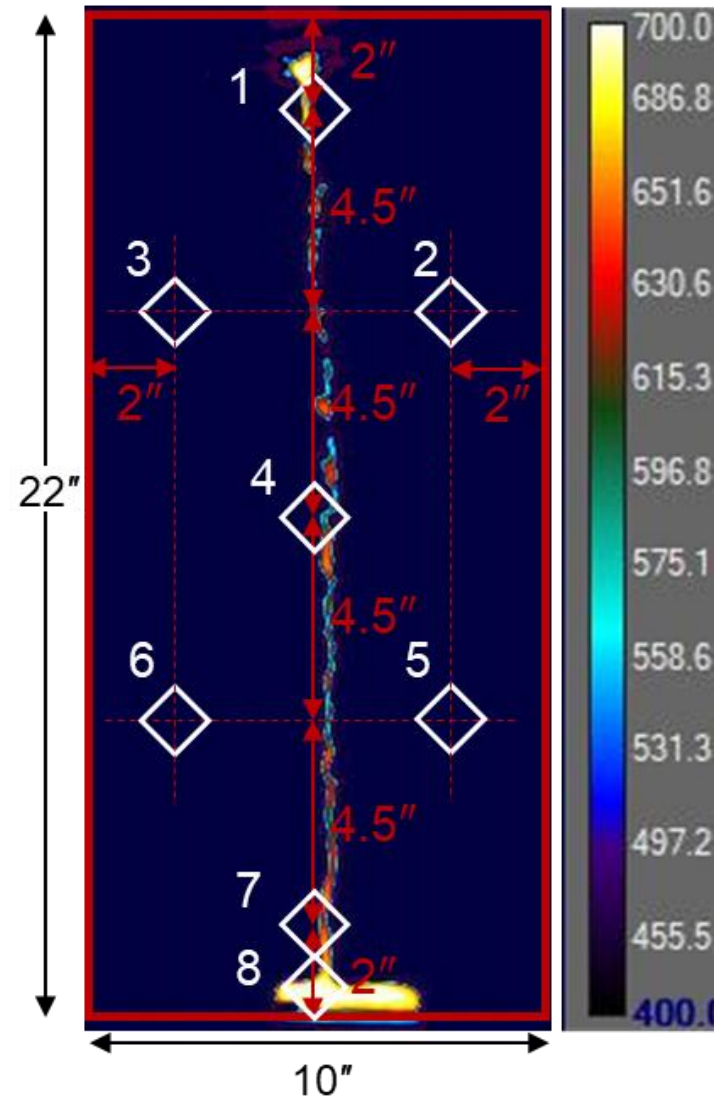

(B)

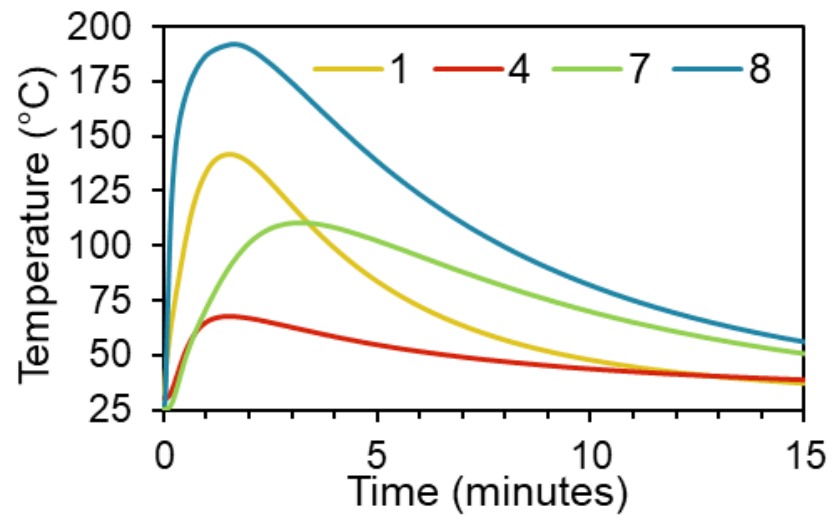

(C)

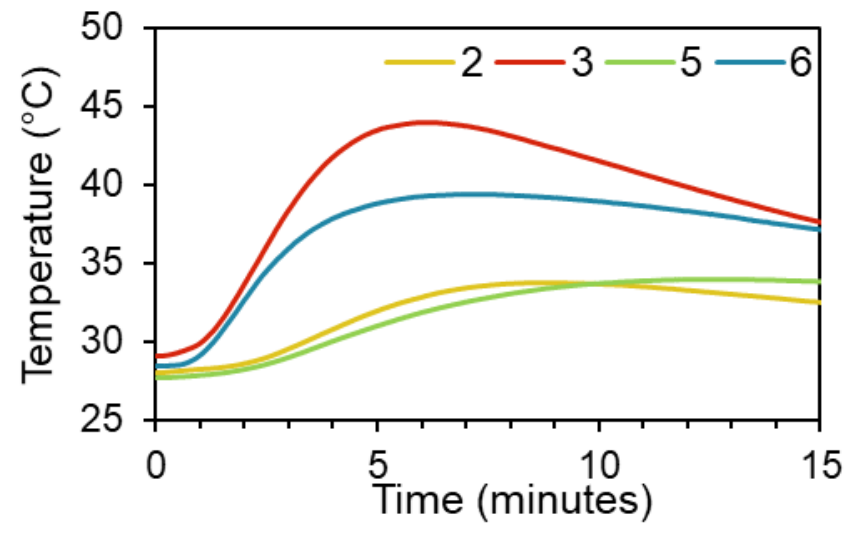

Figure 15: Results for salt spreading Test 9: (A) Location of thermocouples attached to the underside of the substrate overlaid on an image of the salt spreading path, (B) the temperature profiles measured by Thermocouples 1, 4, 7, and 8 along the flow path, and (C) the temperature profiles measured by Thermocouples 2, 3, 5, and 6 off the flow path.

\subsubsection{Leading edge and covered area}

The leading edge of the molten salt stream that flowed down the substrate and the area of the substrate covered by salt was determined for each test as a function of time. Figure 16A provides an example of the covered area of salt on the substrate as a function of time and Figure 16B provides an example of the leading edge position of salt as a function of time that were measured in tests with three different initial salt temperatures (i.e., Tests 1,6, and 9). The area of the substrate covered by the salt was determined during spreading until the leading edge first touched the bottom lip of the substrate so that the area covered by the salt pool formed at the end of the substrate was not included in the area analysis. For the same salt mass $(30 \mathrm{~g})$ and substrate tilt angle $\left(2.5^{\circ}\right)$, the total area covered by the salt when the leading edge first reached the end of the substrate was negatively correlated with salt temperature (Figure 16A). In addition, the salt with the highest temperature reached the end of the substrate in the shortest time (Figure 16B). The average pour rates are provided in the legends of Figure 16, which also likely impact the flow velocity recorded in Figure 16B. 
(A)

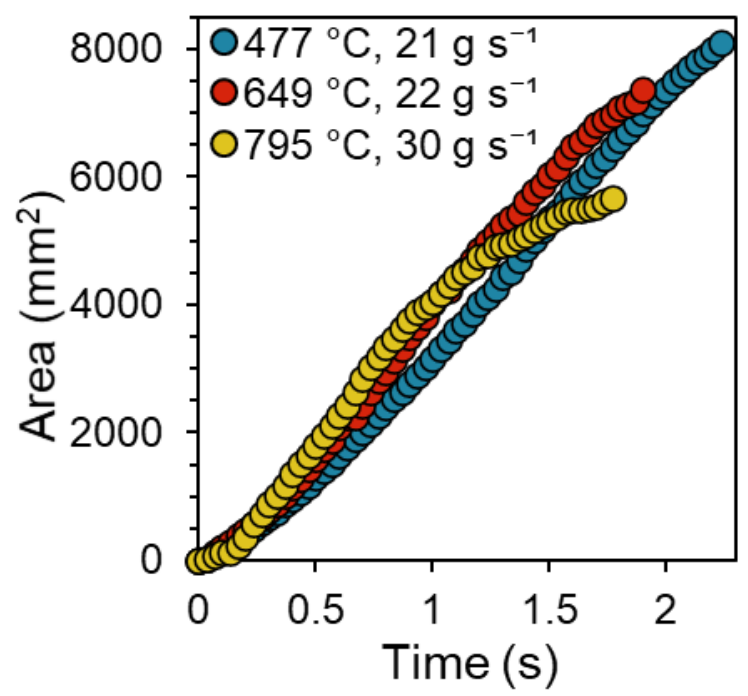

(B)

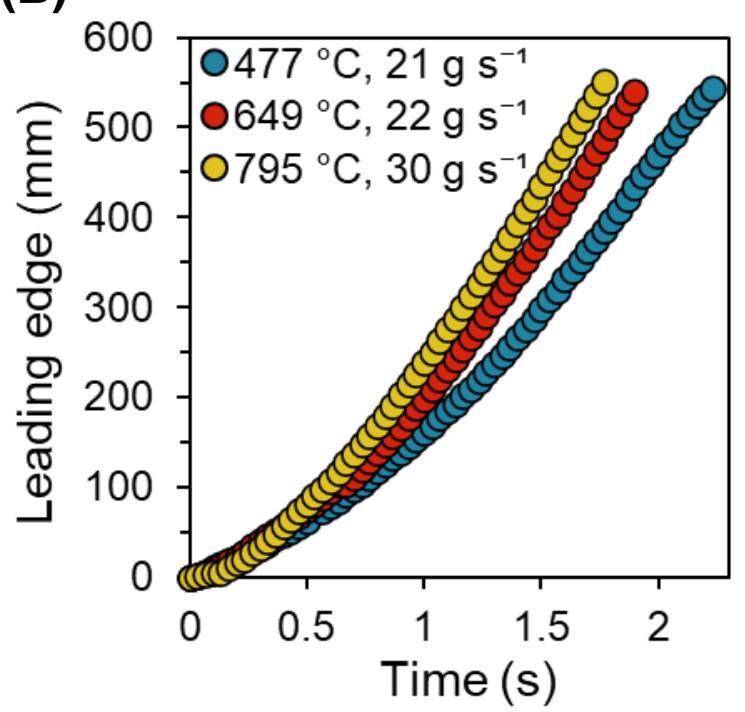

Figure 16: $(A)$ The area of the substrate covered by salt and (B) the leading edge of the flowing salt as a function of time for three tests (Tests 1,6, and 9) with different initial salt temperatures, a total mass poured of $30 \mathrm{~g}$, and a substrate tilt angle of $2.5^{\circ}$. The initial salt temperatures and average pour rates are provided in the legend.

(A)

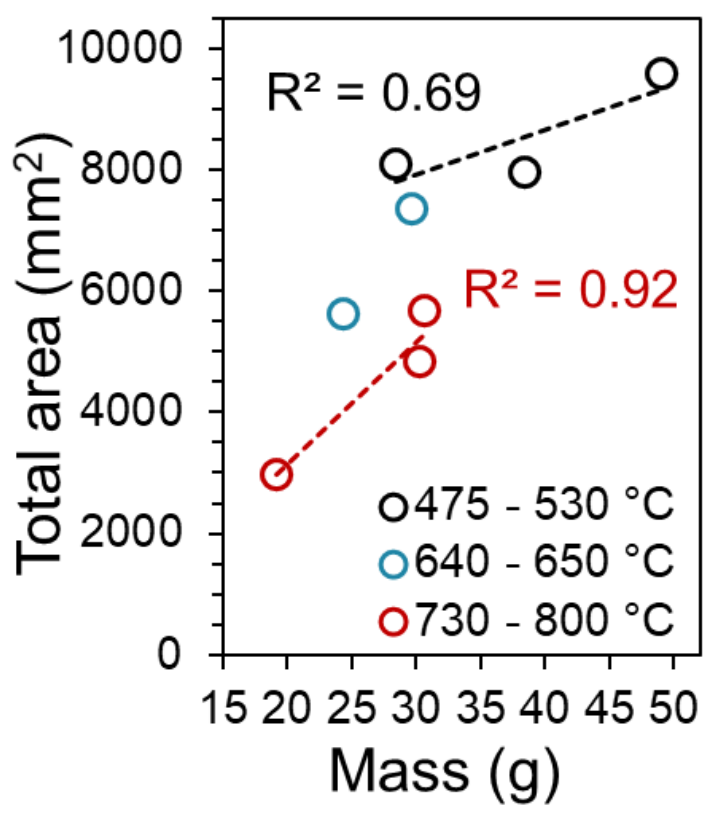

(B)

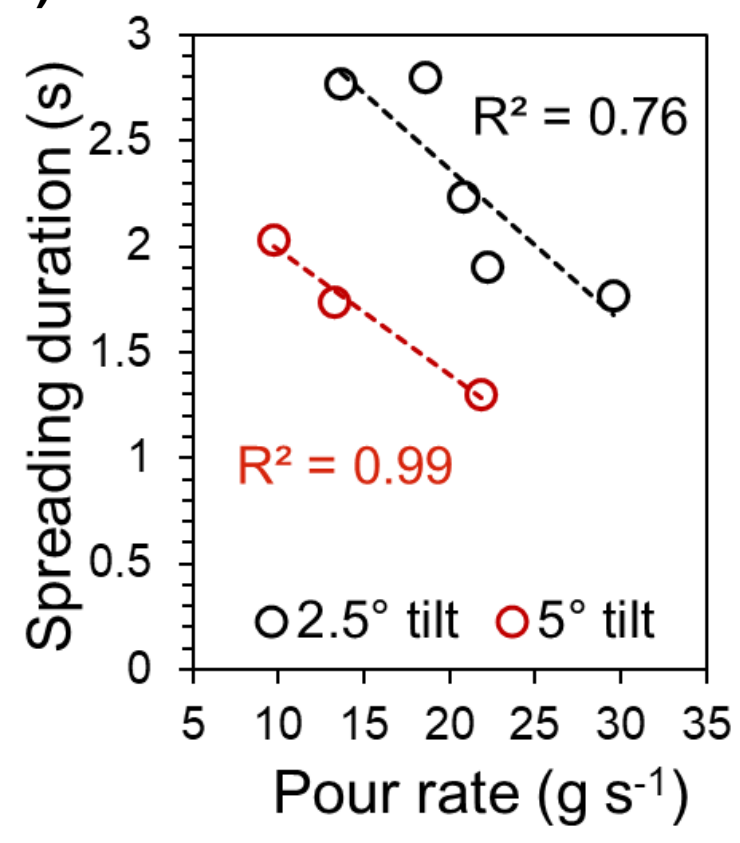

Figure 17: (A) The total area of salt covering the substrate when the leading edge first reached the end of the substrate plotted as a function of the mass of salt that was poured. The total covered area is presented for three ranges of initial salt temperature. (B) The time it took for the leading edge to reach the end of the substrate (spreading duration) plotted as a function of the pour rate for substrate tilt angles of $2.5^{\circ}$ and $5^{\circ}$ at different initial salt temperatures. 
A correlation between the total mass poured and the total area of the substrate covered by salt when the leading edge first reached the end of the substrate was observed for the entire dataset shown in Figure 17A. The correlation was stronger for tests performed with salt at the same initial salt temperature, as shown with the best-fit lines and coefficient of determination (i.e., $R^{2}$ ) presented in Figure 17A. Additional datapoints are required to increase the statistical evidence for this apparent correlation. A correlation between the total mass poured and the spreading area is expected when the spreading behavior of a melt is limited by the balance between the surface tension of the molten salt and gravity.

A correlation between the duration of spreading, defined as the time it took for the salt to reach the end of the substrate, and the pour rate was also observed (Figure 17B). Increasing the substrate tilt angle from $2.5^{\circ}$ to $5^{\circ}$ significantly decreased the spreading duration in tests at all pour rates (Figure 17B). The correlation between salt pour rate and spreading duration existed regardless of the initial salt temperature.

\subsubsection{Compositional analysis}

The concentrations of the major cations and the trace metals in the source batch of FLiNaK used for these tests was reported by Lichtenstein et al., 2020 and are reproduced in Table 3 and Table 4, respectively. The major cation concentrations were determined by ICP-OES, and the trace metal concentrations were determined by ICP-MS (Lichtenstein et al., 2020). Contamination from the ceramic mortar and pestle used to grind the FLiNaK into a powder is likely responsible for the high calcium concentration reported in Table 4.

Table 5 and Table 6 list the concentrations of major cations and trace metals, respectively, that were measured in the salt that was recovered after spreading in tests that used three different initial salt temperatures. The reported values are the mean and one standard deviation calculated from replicate experiments with the same target initial salt temperature.

Table 7 and Table 8 provide the concentrations of major cations and trace metals, respectively, that were measured in the salt after spreading as a function of sampling location. Specifically, samples were taken from the salt pool that formed at the bottom of the substrate and from the frozen crust upstream from the pool. These concentrations were averaged for replicate experiments based on the location from which the salt was collected, regardless of the initial salt temperature.

Table 3: Concentrations of major components in FLiNaK before the tests (mol \%) ${ }^{\text {a }}$

\begin{tabular}{ccc}
\hline $\mathrm{LiF}$ & $\mathrm{NaF}$ & $\mathrm{KF}$ \\
\hline $46.5 \pm 0.5$ & $11.5 \pm 0.2$ & $42.0 \pm 0.6$ \\
\hline a The values are the mean \pm one standard deviation.
\end{tabular}

Table 4: Concentrations of trace metals in the salt before the tests (ppm) $)^{a, b}$

\begin{tabular}{lcccccc}
\hline $\mathrm{Ca}$ & $\mathrm{Cr}$ & $\mathrm{Mn}$ & $\mathrm{Fe}$ & $\mathrm{Ni}$ & $\mathrm{Rb}$ & $\mathrm{Cs}$ \\
\hline $980 \pm 490$ & $<10$ & $<3$ & $<150$ & $120 \pm 12$ & $28 \pm 3$ & $1.8 \pm 0.4$ \\
\hline a The values are the mean \pm one standard deviation. & & & \\
b The number after $<$ is the detection limit.
\end{tabular}


Table 5: Concentrations of major components after spreading (mol \%) ${ }^{\mathrm{a}}$

\begin{tabular}{cccc}
\hline $\begin{array}{c}\text { Target initial } \\
\text { temperature }\left({ }^{\circ} \mathrm{C}\right)\end{array}$ & $\mathrm{LiF}$ & $\mathrm{NaF}$ & $\mathrm{KF}$ \\
\hline $500^{\mathrm{b}}$ & $47.4 \pm 0.3$ & $11.2 \pm 0.2$ & $41.4 \pm 0.4$ \\
650 & $47.4 \pm 0.2$ & $11.2 \pm 0.2$ & $41.4 \pm 0.2$ \\
800 & $47.5 \pm 0.1$ & $11.5 \pm 0.2$ & $41.1 \pm 0.1$ \\
\hline
\end{tabular}

${ }^{a}$ The values are the mean \pm one standard deviation.

${ }^{\mathrm{b}}$ Test 3 with a target initial salt temperature of $550^{\circ} \mathrm{C}$ was included.

Table 6: Concentrations of trace metals after spreading (ppm)a,b

\begin{tabular}{cccccccc}
\hline $\begin{array}{c}\text { Target initial } \\
\text { temp. }\left({ }^{\circ} \mathrm{C}\right)\end{array}$ & $\mathrm{Ca}$ & $\mathrm{Cr}$ & $\mathrm{Mn}$ & $\mathrm{Fe}$ & $\mathrm{Ni}$ & $\mathrm{Rb}$ & $\mathrm{Cs}$ \\
\hline 500 & $649 \pm 450$ & $<2$ & $3 \pm 1$ & $<30$ & $15 \pm 9$ & $23.0 \pm 0.8$ & $3 \pm 4$ \\
650 & $760 \pm 320$ & $<2$ & $5 \pm 1$ & $<30$ & $10 \pm 8$ & $22 \pm 1$ & $9 \pm 12$ \\
800 & $610 \pm 240$ & $<2$ & $6 \pm 2$ & $<30$ & $7 \pm 3$ & $22 \pm 1$ & $3 \pm 2$ \\
\hline
\end{tabular}

${ }^{\mathrm{a}}$ The values are the mean \pm one standard deviation.

${ }^{\mathrm{b}}$ The number after $<$ is the detection limit.

Table 7: Concentrations of major components after spreading (mol \%) ${ }^{a}$

\begin{tabular}{cccc}
\hline Location & $\mathrm{Li}$ & $\mathrm{Na}$ & $\mathrm{K}$ \\
\hline Crust & $47.4 \pm 0.2$ & $11.3 \pm 0.1$ & $41.3 \pm 0.2$ \\
Pool & $47.4 \pm 0.3$ & $11.3 \pm 0.3$ & $41.3 \pm 0.5$ \\
\hline${ }^{\mathrm{a}}$ The values are the mean \pm one standard deviation.
\end{tabular}

Table 8: Concentrations of trace metals after spreading $(\mathrm{ppm})^{\mathrm{a}, \mathrm{b}}$

\begin{tabular}{cccccccc}
\hline Location & $\mathrm{Ca}$ & $\mathrm{Cr}$ & $\mathrm{Mn}$ & $\mathrm{Fe}$ & $\mathrm{Ni}$ & $\mathrm{Rb}$ & $\mathrm{Cs}$ \\
\hline Crust & $690 \pm 320$ & $<2$ & $4 \pm 2$ & $<30$ & $9 \pm 8$ & $23 \pm 1$ & $6 \pm 8$ \\
Pool & $630 \pm 400$ & $<2$ & $5 \pm 2$ & $<30$ & $12 \pm 8$ & $23 \pm 1$ & $2 \pm 1$ \\
\hline
\end{tabular}

${ }^{\mathrm{a}}$ The values are the mean \pm one standard deviation.

${ }^{b}$ The number after $<$ is the detection limit.

The compositional analyses indicate that neither the initial salt temperature nor the location at which the salt freezes significantly influenced the composition of the salt after spreading. One exception is the increase in manganese concentration in the frozen salt with increasing initial salt temperature (Table 6).

While these observations are relevant for pure FLiNaK, salts that contain actinides and fission products may behave differently. In addition, conducting tests under oxidizing conditions (e.g., in air) may accelerate the corrosion of the substrate that is in contact with the salt and introduce corrosion products (e.g., chromium, manganese, and iron species) into the salt. More complex salt compositions and atmospheric conditions should be a focus of future spreading tests. 


\section{Molten salt flowing and freezing behavior through tubing}

\subsection{Experimental methods}

\subsubsection{Experimental design}

The objective of this experimental method is to measure molten salt flowing and freezing behavior across a simulated catch pan and into a vertical drain leading to a drain tank. To measure the flowing and freezing behaviors, custom 316 stainless steel funnels were made with a cone diameter of 10 in., a tube length of 11 in., and various tube inner diameters (Figure 18A). The two funnels used in the tests described in this section had inner diameters of $0.1875 \mathrm{in}$. and $0.2500 \mathrm{in}$. The thickness of the tubing and cone walls for both funnels was 0.0625 in.

(A)

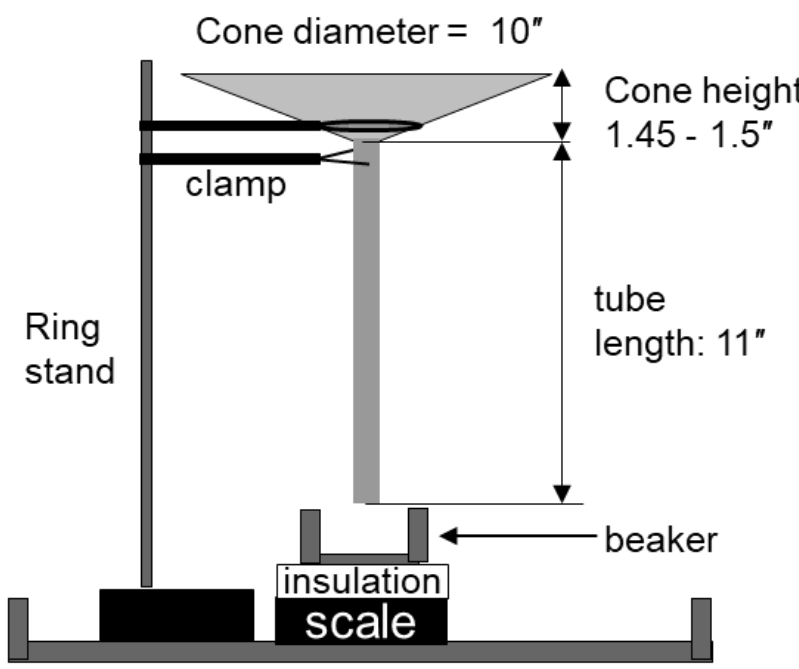

Catch pan with $1 "$ walls
(B)

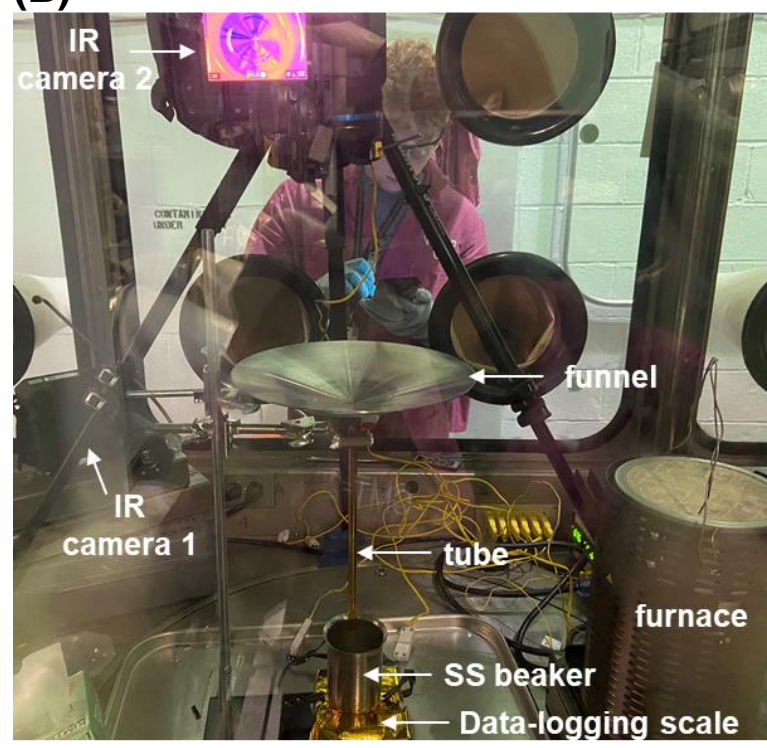

Figure 18: (A) Schematic of the experimental setup to study molten salt flowing through stainless steel tubing. (B) Image of the experimental setup in the argon atmosphere glovebox.

A ring and insulated clamp attached to a ring stand held the funnel above a stainless steel beaker that was used to collect the salt that flowed through the funnel (Figure 18A). The beaker was placed on a data logging scale that recorded the mass at one-second intervals. Foam insulation was placed between the beaker and the scale to avoid heating the scale. Two thermocouples were attached to the bottom of the beaker to record the temperature as a function of time. The salt was manually poured from a custom nickel crucible onto the funnel cone using long crucible tongs after the salt in the crucible was heated to the target temperature in a furnace.

The tests on molten salt flowing and freezing in tubing were conducted within an argon atmosphere glovebox $\left(\mathrm{O}_{2}<10 \mathrm{ppm}, \mathrm{H}_{2} \mathrm{O}<5 \mathrm{ppm}\right)$. One IR camera and one visible camera were positioned above the funnel on a tripod to record video of the molten salt as it drained into the tubing (Figure 18B). A second IR camera recorded video of the outer surface temperature of the tubing during the test (Figure 18B). The length of the tube was covered with high-temperature, high- 
emissivity tape (McMaster-Carr, item no. 1618N1) to facilitate the temperature correction for emissivity.

A description of the IR camera, data logger for thermocouple measurements, visible camera, and furnace is provided in Appendix $A$.

\subsubsection{Measurements}

\subsubsection{Average pour rate}

The average pour rate was determined by dividing the mass of salt poured by the duration of the pour. The mass of salt poured is equal to the difference between the mass added to the crucible and the mass that remained in the crucible after pouring. The duration of the pour was determined from footage from the IR camera, which showed the time when the salt first hit the funnel top and the time when salt ceased flowing from the crucible.

\subsubsection{Flow rate of salt through the funnel tubing}

The data logging scale recorded the mass of salt that passed through the funnel tubing and accumulated in the stainless steel beaker at one second intervals.

\subsubsection{Temperature}

The temperature of the underside of the stainless steel beaker that collected the molten salt that passed through the funnel was recorded with thermocouples attached to the surface with thermally conductive cement. The performance of the surface temperature measurement obtained using the thermocouples is presented in Appendix B Section B.2.

The temperature of the molten salt surface that was poured into the funnel top was recorded with an IR camera. The emissivity of FLiNaK as a function of temperature is unknown and was assumed to be unity for the salt surface temperatures reported herein. Section 3.2.2 provides an estimation of FLiNaK emissivity near the freezing temperature.

The furnace temperature provided an estimate of the initial molten salt temperature immediately before it was poured. The reading from the furnace may not reflect the actual salt temperature because the thermocouple in the furnace was placed in the furnace liner (not directly in the molten salt) and the salt cools when it is removed from the furnace prior to being poured. The initial salt temperature in the crucible was also estimated by using the IR camera.

The temperature of the outer surface of the funnel tubing was recorded with an IR camera. The IR camera provided the spatial temperature distribution of the tubing with a resolution of approximately $0.5 \mathrm{~mm}^{2}$ per pixel at a collection rate of 30 frames per second. The funnel tubing was coated with a high emissivity, high temperature tape and the temperature recorded by the IR camera was corrected for emissivity and the known reflected temperature of the tape by using the methods described in Section B.1.3.

A thermocouple positioned approximately 2 feet away from the funnel top was used to measure the temperature of the glovebox atmosphere as a function of time during the tests. 


\subsubsection{Mass fraction of frozen salt in the tubing and at the top of the funnel}

The salt that did not pass through the tubing and froze at the top of the funnel was collected and weighed. The salt that froze inside the tubing was removed by plunging a stainless steel rod into the tubing to extract intact salt pieces that were weighed and analyzed visually.

\subsubsection{Time and location at which the tubing plugs with frozen salt}

The temperature of the outer surface of the stainless steel tubing provides an indication of the thickness of the salt layer that forms while molten salt flows through and freezes within the tubing. A higher temperature in one location relative to other locations along the tube within the same frame of the IR image indicates a thicker salt layer had formed at the hotter location. When a visual inspection indicated that the tubing had completely plugged with salt, a stainless steel rod was inserted into the tubing to measure the depth at which the plug was located.

\subsubsection{Composition of frozen salt}

The composition of salt that flowed through the stainless steel tubing was analyzed for major cations (lithium, sodium, and potassium) and trace metals (calcium, manganese, iron, nickel, chromium, cesium, and rubidium) by using ICP-MS according to the methods reported in Section 2.3. Specifically, one sample was taken from the salt that was collected in the stainless steel beaker and one sample was taken from the salt that froze inside the stainless steel tubing for comparison.

\subsection{Results}

Table 9 provides a summary of the conditions of each test on FLiNaK flowing and freezing in tubing that was conducted. This section includes representative results obtained using the measurements that were made and summarizes key findings. The full suite of results will be included in a data package in an upcoming report (Thomas and Jackson, 2021).

Table 9: Summary of test conditions to study molten FLiNaK flowing through tubing ${ }^{\text {a }}$

\begin{tabular}{ccccc}
\hline Test No. & $\begin{array}{c}\text { Target initial salt } \\
\text { temp. }\left({ }^{\circ} \mathrm{C}\right)^{\mathrm{b}}\end{array}$ & $\begin{array}{c}\text { Max salt temp. } \\
\left({ }^{\circ} \mathrm{C}\right)^{\mathrm{c}}\end{array}$ & $\begin{array}{c}\text { Avg. pour rate } \\
\left(\mathrm{g} \mathrm{s}^{-1}\right)\end{array}$ & $\begin{array}{c}\text { Tube diameter } \\
\text { (in) }\end{array}$ \\
\hline 1 & 675 & 660 & 14.8 & 0.25 \\
2 & 675 & 660 & 16.4 & 0.1875 \\
3 & 525 & 490 & 18.3 & 0.1875 \\
4 & 800 & 775 & 10.7 & 0.1875 \\
\hline
\end{tabular}

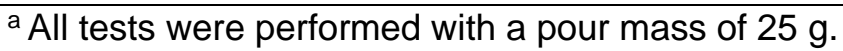

b The actual salt temperatures may have slightly differed from the target temperature.

c The maximum temperature of the salt measured by the IR camera (uncorrected for emissivity) provided an estimate of the actual salt temperature as it was poured. 


\subsubsection{Images from tests of molten salt flowing in tubing}

Figure 19A and Figure 19B present still frames taken from video recorded by the visible camera one second and five seconds, respectively, after pouring $25 \mathrm{~g}$ of FLiNaK at an initial temperature of approximately $660^{\circ} \mathrm{C}$ into a funnel having stainless steel tubing with an inner diameter of $0.25 \mathrm{in}$. A fraction of the salt froze on the cone of the stainless steel funnel before it reached the tubing inlet, but the inlet of the tubing was not obstructed by frozen salt after most of the salt flowed through the tubing (Figure 19B). An inspection of the inside of the tubing after the test revealed that frozen salt coated the walls of the tubing and formed a hollow tube of frozen salt in some sections along the tube length (Figure 19C). The salt that froze inside the tubing was removed after the test for a visual inspection (Figure 19D) and was weighed for a mass balance (Section 4.2.5).

(A)

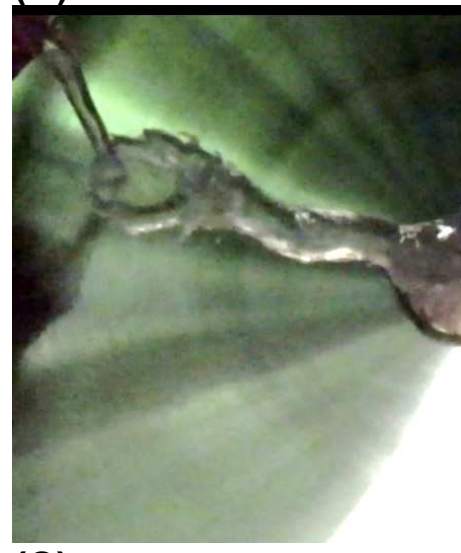

(C)

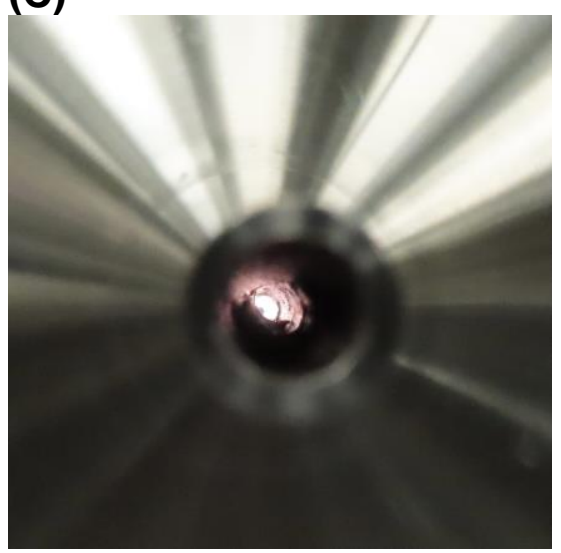

(B)

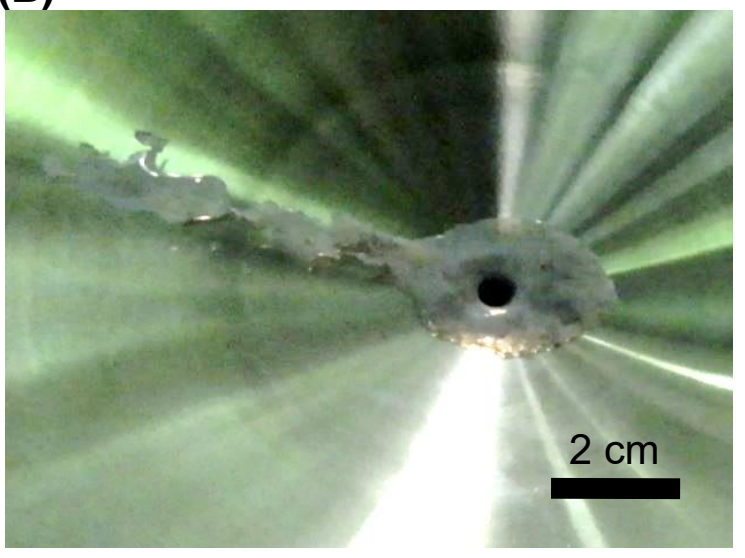

(D)

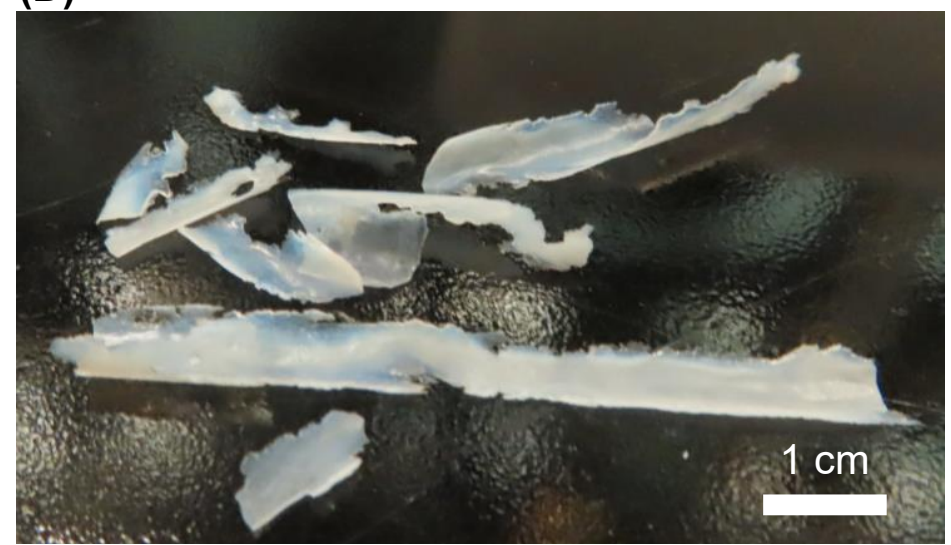

Figure 19: Images from Test 1 of $25 \mathrm{~g}$ of FLiNaK at an initial temperature of approximately $660^{\circ} \mathrm{C}$ flowing and freezing in stainless steel tubing with an inner diameter of $0.25 \mathrm{in}$. and wall thickness of $0.0625 \mathrm{in}$. Still frames were taken from visible camera video $(A)$ one second and (B) five seconds after the pouring started. (C) Image of the inside of the stainless steel tubing to show frozen salt coating the walls. (D) Image of salt pieces that froze inside the stainless steel tubing and were removed after the test. 
Additional tests to study molten FLiNaK flowing and freezing in tubing were performed using a funnel with an inner tube diameter of $0.1875 \mathrm{in}$. More salt froze inside the tubing in tests performed with an inner tube diameter of $0.1875 \mathrm{in}$. compared to tests performed with an inner tube diameter of $0.25 \mathrm{in}$. Changing the dimensions of the tubing while using a fixed pour mass of $25 \mathrm{~g}$ allows for studying the effect of the ratio of pour mass to inner tube diameter without requiring the use of large volumes of salt. Future tests can be performed with larger salt volumes and larger tube diameters and employ the same methods developed using smaller salt volumes and tube diameters.

Figure 20A and Figure 20B present still frames taken from video recorded by the visible camera one second and five seconds, respectively, after pouring $25 \mathrm{~g}$ of FLiNaK at an initial temperature of approximately $660{ }^{\circ} \mathrm{C}$ into a funnel having stainless steel tubing with an inner diameter of $0.1875 \mathrm{in}$. A fraction of the salt froze on the cone of the stainless steel funnel before it reached the tubing inlet, but the inlet of the tubing was not obstructed by frozen salt after most of the salt flowed through the tubing (Figure 20B). Notably, a plug of frozen salt formed at the outlet of the tubing that had a small hole in the center through which molten salt presumably continued to flow (Figure 20C). Frozen salt that coated the tubing walls was also detected at the tubing inlet (Figure 20D). The salt that froze inside the tubing was removed and hollow tubes of frozen salt and nearly solid frozen salt plugs were recovered (Figure 20D).

(A)

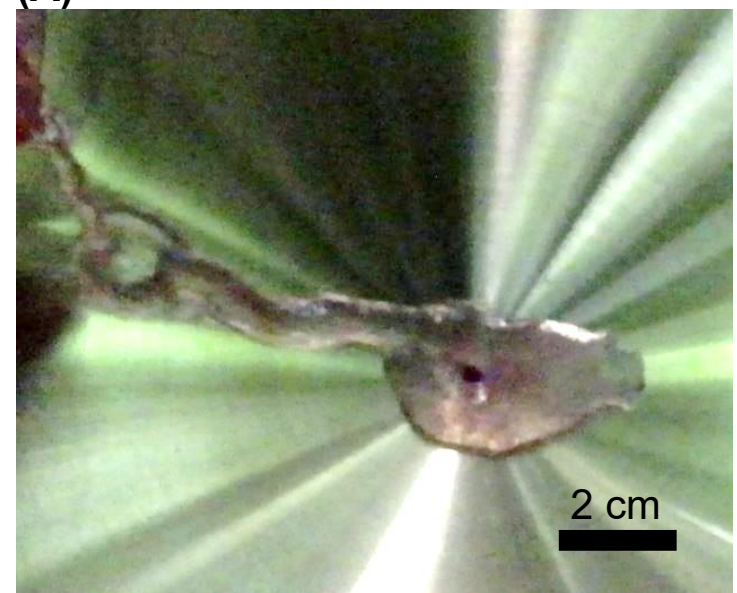

(C)

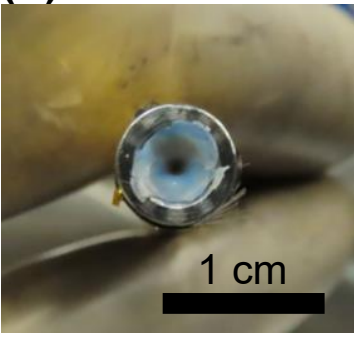

(D)

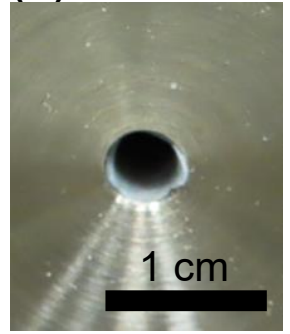

(B)

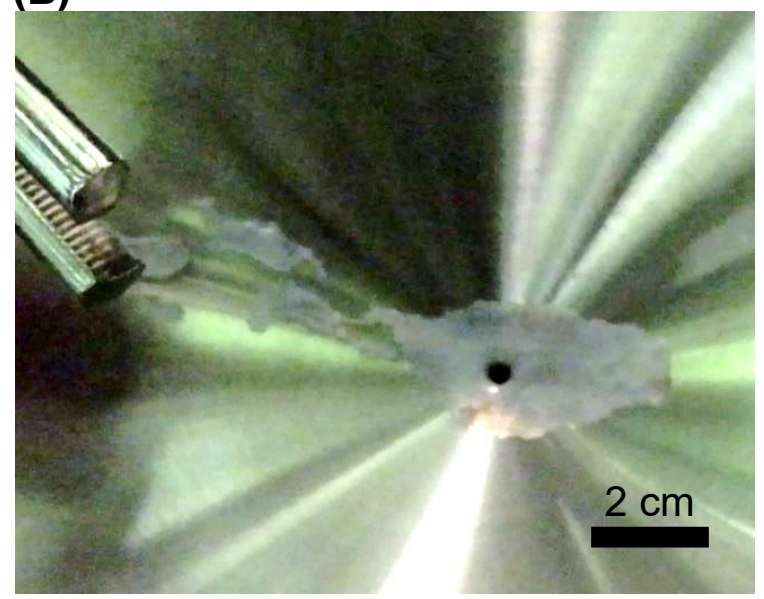

(E)

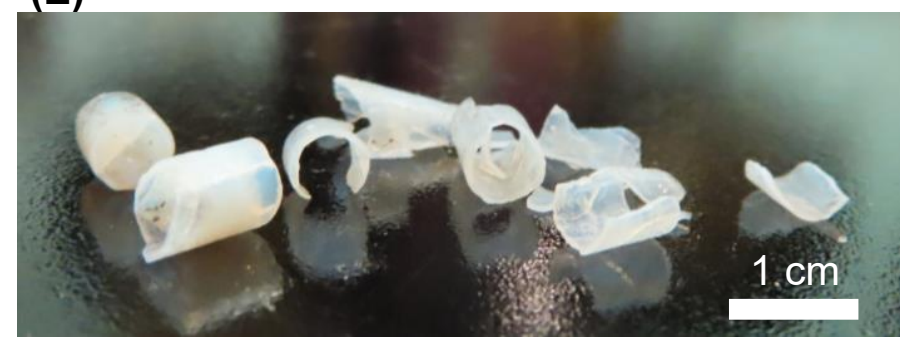

Figure 20: Images from Test 2 of $25 \mathrm{~g}$ of FLiNaK at an initial temperature of approximately $660^{\circ} \mathrm{C}$ flowing and freezing in stainless steel tubing with an inner diameter of $0.1875 \mathrm{in}$. and wall thickness of $0.0625 \mathrm{in}$. Still frames were taken from visible camera video $(A)$ one second and (B) five seconds after the pouring started. Image of the inside of the stainless steel tubing $(C)$ at the end of the tube and (D) at the beginning of the tube to show frozen salt coating the walls. (E) Image of salt pieces that froze inside the stainless steel tubing and were removed after the test. 
Figure 21A and Figure 21B present still frames taken from video recorded by the visible camera one second and five seconds, respectively, after pouring $25 \mathrm{~g}$ of FLiNaK at an initial temperature of approximately $490{ }^{\circ} \mathrm{C}$ into a funnel having stainless steel tubing with an inner diameter of $0.1875 \mathrm{in}$. The behavior of the salt at this temperature was notably different than the behavior of the salt that was poured at higher initial temperatures. First, salt that froze at the top of the funnel plugged the tubing inlet (Figure 21B). Black contamination was also present in the salt batch for this test (Test 3 ), which floated at the molten salt surface and was encapsulated when the salt froze in the funnel cone (Figure $21 \mathrm{~A}$ and Figure 21B). The frozen salt that plugged the inlet of the tubing (Figure 21C), frozen salt that was collected in the stainless steel beaker (Figure 21D), and pieces of frozen salt from inside the tubing (Figure 21E) were recovered. The frozen salt in the stainless steel beaker formed a pool with a narrow cylindrical spike sticking out of it that appeared

(A)

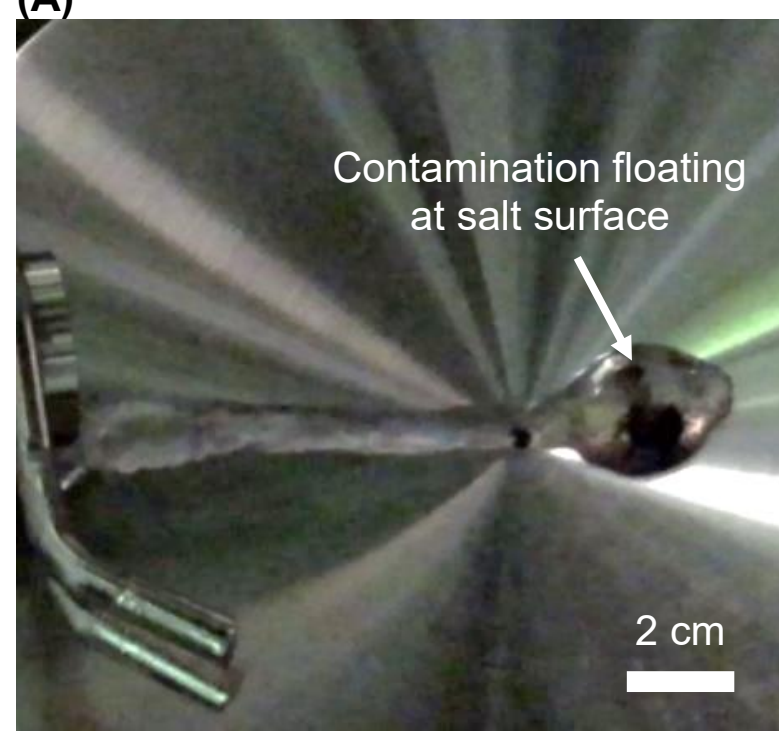

(C)

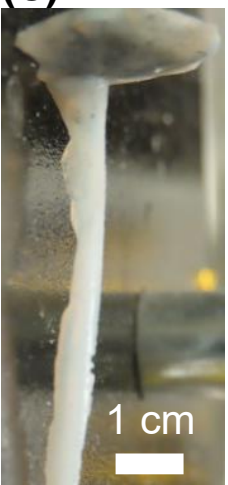

(D)

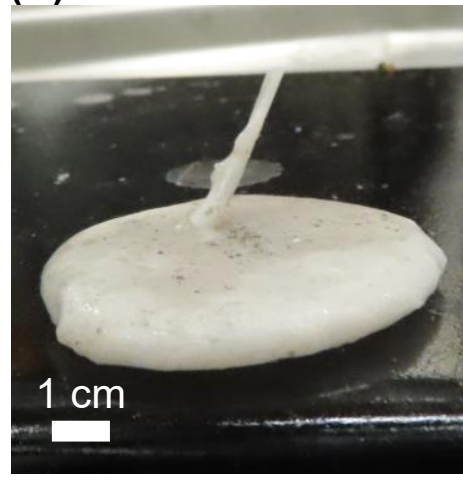

(B)

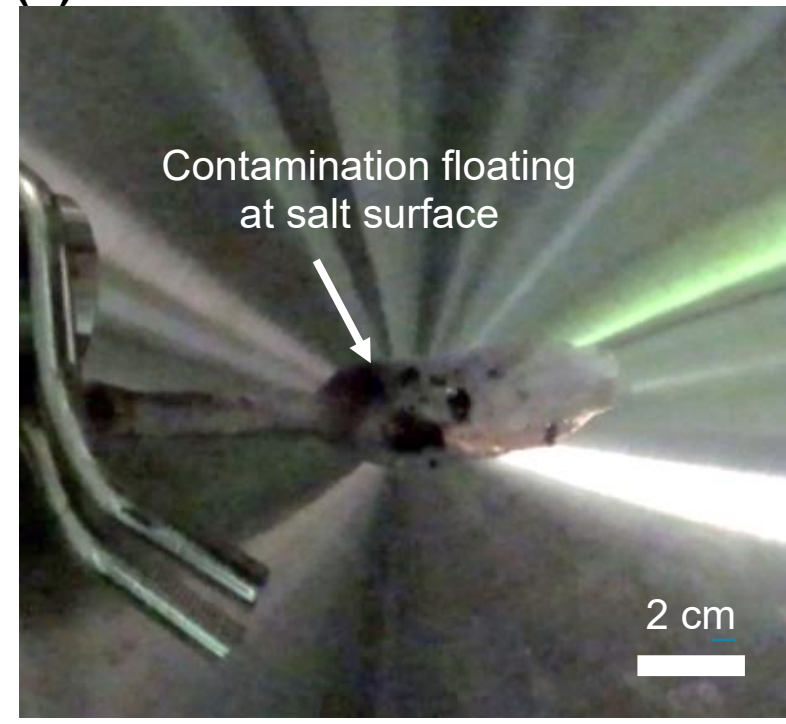

(E)

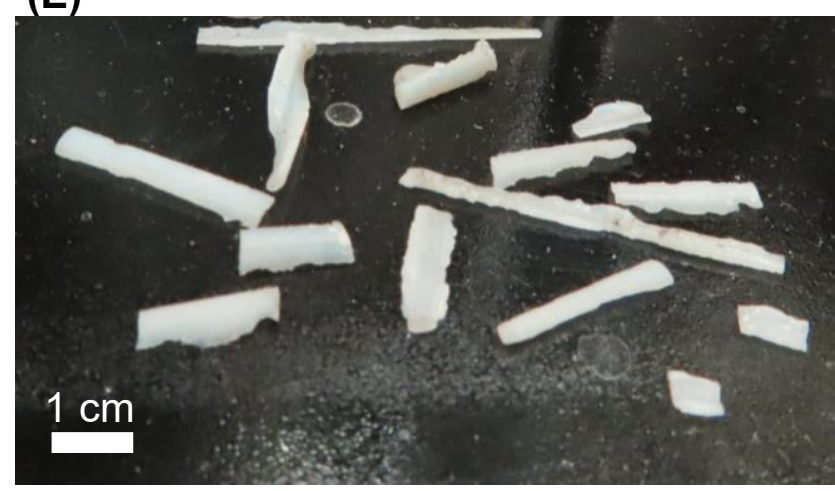

Figure 21: Images from Test 3 of $25 \mathrm{~g}$ of FLiNaK at an initial temperature of approximately $490{ }^{\circ} \mathrm{C}$ flowing and freezing in stainless steel tubing with an inner diameter of $0.1875 \mathrm{in}$. and wall thickness of 0.0625 in. Still frames were taken from visible camera video (A) one second and (B) five seconds after the pouring started. Images were taken of the frozen salt that was removed (C) from the top of the funnel, (D) from the stainless steel beaker, and (E) from the inside of the stainless steel tubing. 
to have the same diameter as the tubing (Figure 21D). This suggests that salt that had frozen inside the tubing subsequently fell out and was supported in an upright position by the salt pool in the beaker that was still molten.

Figure 22A and Figure 22B present still frames taken from video recorded by the visible camera one second and five seconds, respectively, after pouring $25 \mathrm{~g}$ of FLiNaK at an initial temperature of approximately $775^{\circ} \mathrm{C}$ into a funnel having stainless steel tubing with an inner diameter of 0.1875 in. The salt during this test (Test 4 ) behaved similarly to the salt from Test 2 , which used the same tube inner diameter and an initial salt temperature of approximately $660{ }^{\circ} \mathrm{C}$. A plug of frozen salt at the outlet of the tubing that contained a small hole in the center (Figure 22C) and frozen salt that coated the tubing walls (Figure 22D) were observed. A mostly solid piece of salt was recovered from the outlet of the tubing (Figure 22E).

(A)

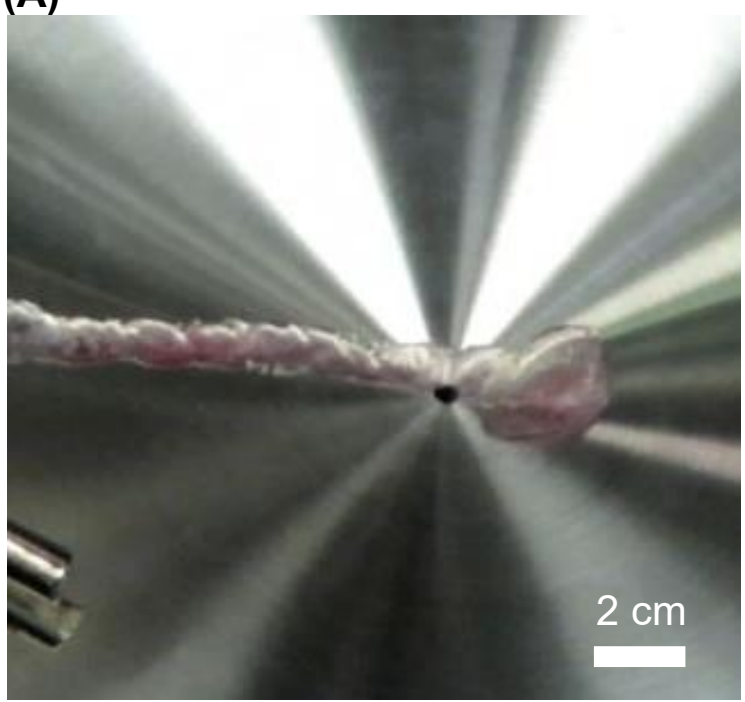

(C)

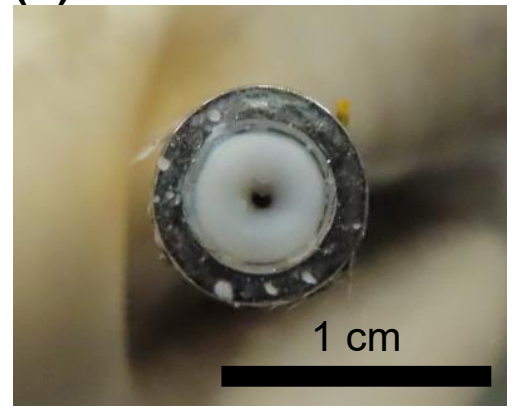

(B)

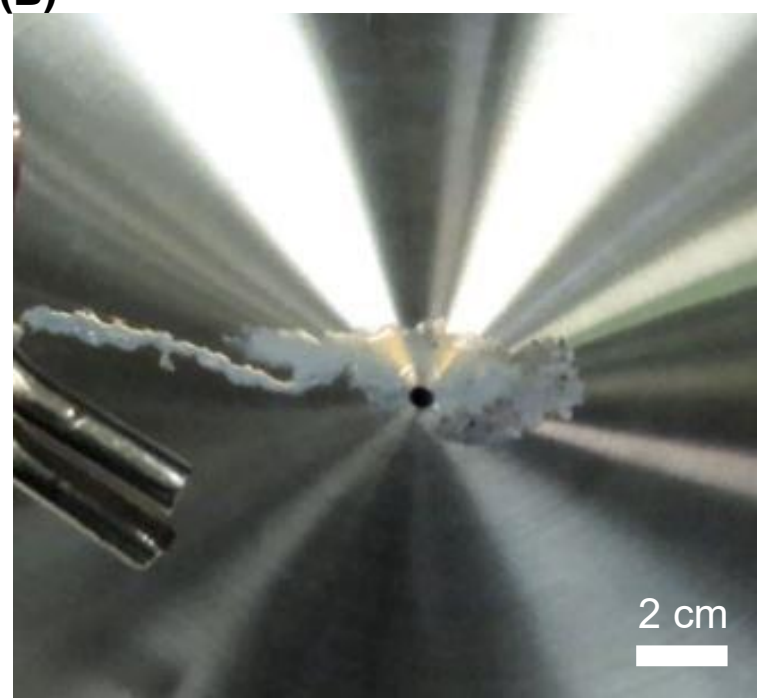

(E)
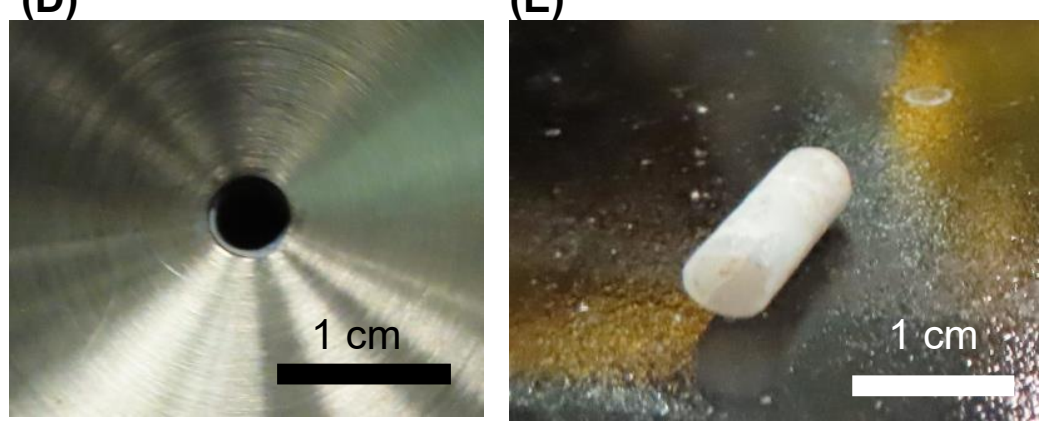

Figure 22: Images from Test 4 of $25 \mathrm{~g}$ of FLiNaK at an initial temperature of approximately $775^{\circ} \mathrm{C}$ flowing and freezing in stainless steel tubing with an inner diameter of $0.1875 \mathrm{in}$. and wall thickness of 0.0625 in. Still frames were taken from visible camera video (A) one second and (B) five seconds after the pouring started. Images were taken of salt that froze inside the stainless steel tubing $(C)$ at the end of the tube and (D) at the beginning of the tube to show frozen salt coating the walls. (E) Image of salt piece that froze at the bottom of the stainless steel tubing that was removed after the test. 


\subsubsection{Temperature measurement of the stainless steel tubing}

Figure 23 presents still frames taken from IR video that provide the temperature of the outer tubing surface after approximately $25 \mathrm{~g}$ of FLiNaK at an initial temperature of approximately $660^{\circ} \mathrm{C}$ was poured into a stainless steel tube with a 0.25 in. inner diameter (Test 1 ). The hot spots in the still frames indicate that a thicker layer of salt had frozen to that section of the tubing, leading to more efficient heat transfer. The maximum recorded outer tube surface temperature was approximately $130{ }^{\circ} \mathrm{C}$ and the hot spots are localized near the tubing outlet 20 seconds after the salt was poured for this condition.

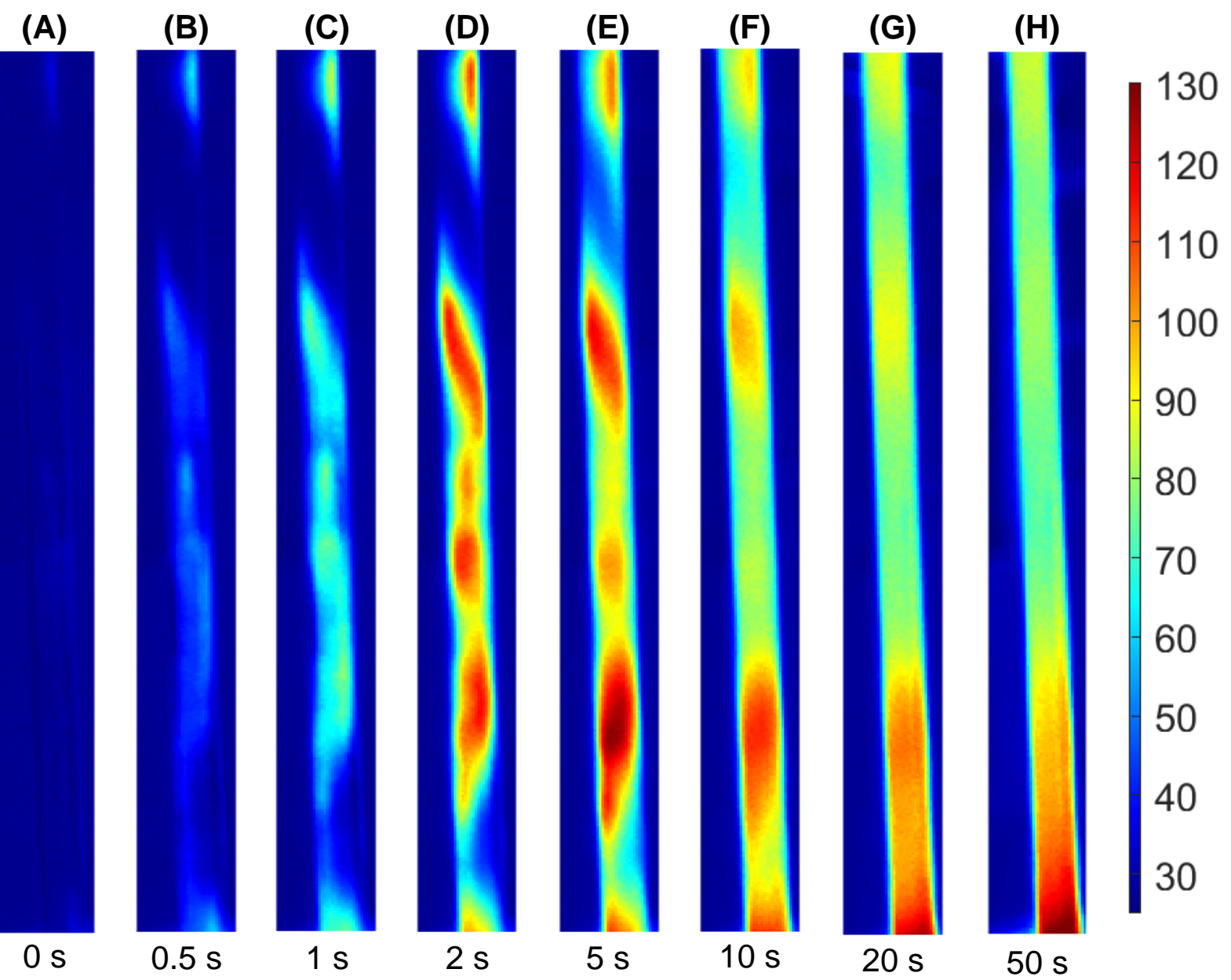

Figure 23: Still frames from video taken by the IR camera that show the temperature of the outer wall of the stainless steel tubing with an inner diameter of $0.25 \mathrm{in}$. and wall thickness of $0.0625 \mathrm{in}$. The lower $10 \mathrm{in}$. of the $11 \mathrm{in}$. tube is shown in the frame. The frames were taken (A) $0 \mathrm{~s},(\mathrm{~B}) 0.5 \mathrm{~s}$, (C) $1 \mathrm{~s}$, (D) $2 \mathrm{~s}$, (E) $5 \mathrm{~s},(\mathrm{~F}) 10 \mathrm{~s},(\mathrm{G}) 20 \mathrm{~s}$, and (H) $50 \mathrm{~s}$ after $25 \mathrm{~g}$ of FLiNaK at an initial temperature of approximately $660^{\circ} \mathrm{C}$ was poured into the tubing (Test 1). The reported temperature has been corrected for the emissivity of the tubing coating. 
Figure 24, Figure 25, and Figure 26 show still frames taken from IR video that provide the temperature of the outer tubing surface after approximately $25 \mathrm{~g}$ of FLiNaK at an initial temperature of approximately $660^{\circ} \mathrm{C}, 490^{\circ} \mathrm{C}$, and $775^{\circ} \mathrm{C}$, respectively, was poured into stainless steel funnels that had 0.1875 in. inner diameter tubes (Tests 2, 3, and 4). The maximum recorded temperatures of the outer tube surfaces correlated with the initial salt temperatures and were approximately $120^{\circ} \mathrm{C}, 225^{\circ} \mathrm{C}$, and $330^{\circ} \mathrm{C}$ when the initial salt temperature was approximately $490^{\circ} \mathrm{C}, 660^{\circ} \mathrm{C}$, and $775^{\circ} \mathrm{C}$, respectively. Within ten seconds after pouring molten salt at approximately $660{ }^{\circ} \mathrm{C}$ into the tube, the temperature of the outer tube surface was nearly uniform along its length (Figure 24). In contrast, a temperature hot spot was generated near the outlet of the tubing when the initial salt temperature was approximately $490^{\circ} \mathrm{C}$ (Figure 25). When the initial salt temperature was approximately $775^{\circ} \mathrm{C}$, temperature hot spots were observed initially at the tube inlet and later at the tube outlet (Figure 26).

(A)

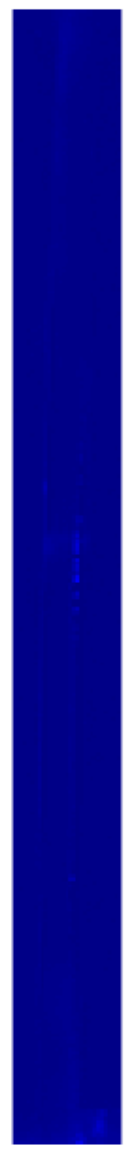

$0 \mathrm{~s}$
(B)

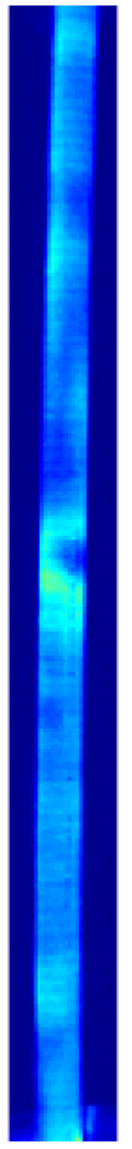

$1.5 \mathrm{~s}$
(C)

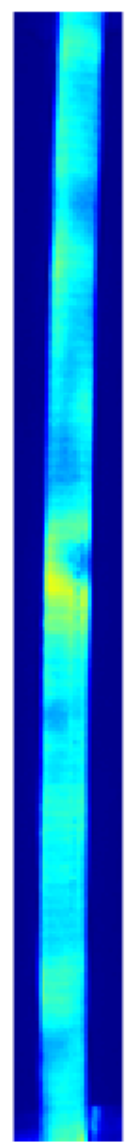

$2 \mathrm{~s}$
(D)

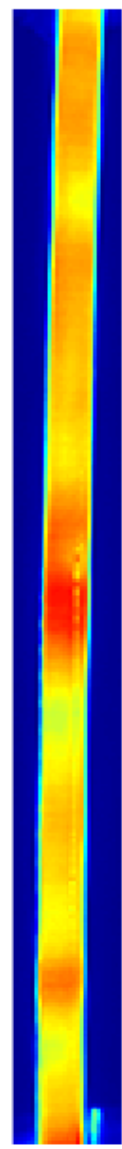

$5 \mathrm{~s}$
(E)

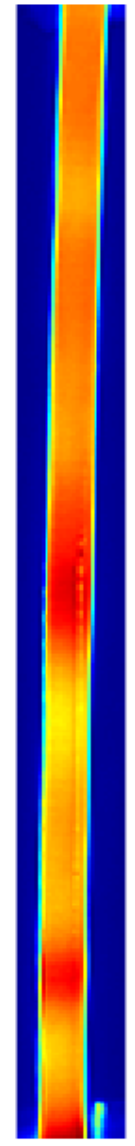

$10 \mathrm{~s}$
(F)

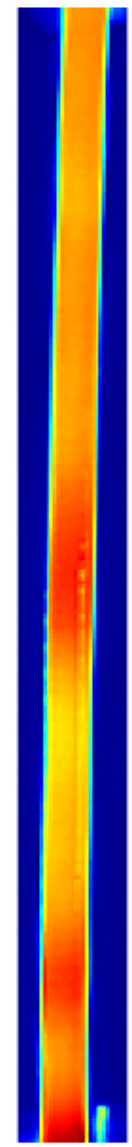

$20 \mathrm{~s}$
(G)

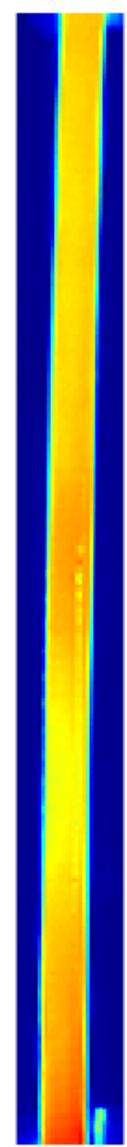

$50 \mathrm{~s}$
(H)

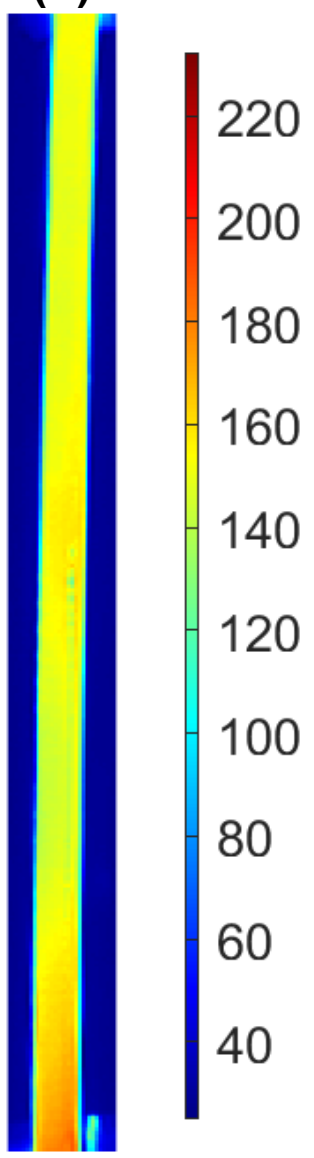

$80 \mathrm{~s}$

Figure 24: Still frames from video taken by the IR camera that show the temperature of the outer wall of the stainless steel tubing with an inner diameter of 0.1875 in. and wall thickness of $0.0625 \mathrm{in}$. The lower $10 \mathrm{in}$. of the $11 \mathrm{in}$. tube is shown in the frame. The frames were taken (A) $0 \mathrm{~s}$, (B) $1.5 \mathrm{~s},(\mathrm{C}) 2 \mathrm{~s},(\mathrm{D}) 5 \mathrm{~s}$, (E) $10 \mathrm{~s},(\mathrm{~F}) 20 \mathrm{~s},(\mathrm{G}) 50 \mathrm{~s}$, and (H) $80 \mathrm{~s}$ after $25 \mathrm{~g}$ of FLiNaK at an initial temperature of approximately $660{ }^{\circ} \mathrm{C}$ was poured into the tubing (Test 2). The reported temperature has been corrected for the emissivity of the tubing coating. 


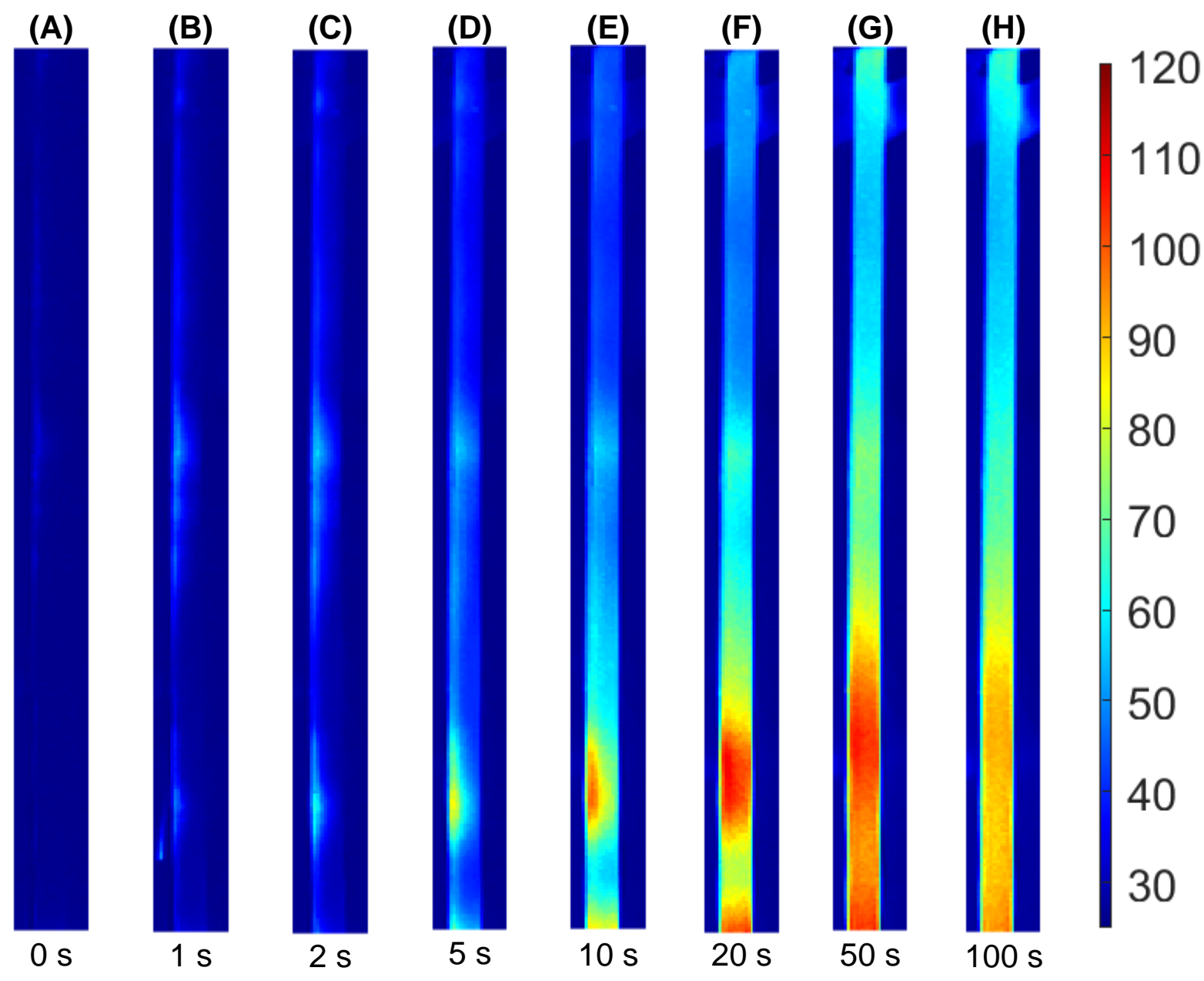

Figure 25: Still frames from video taken by the IR camera that show the temperature of the outer wall of the stainless steel tubing with an inner diameter of $0.1875 \mathrm{in}$. and wall thickness of $0.0625 \mathrm{in}$. The lower $10 \mathrm{in}$. of the $11 \mathrm{in}$. tube is shown in the frame. The frames were taken (A) $0 \mathrm{~s}$, (B) $1 \mathrm{~s},(\mathrm{C}) 2 \mathrm{~s},(\mathrm{D}) 5 \mathrm{~s},(\mathrm{E}) 10 \mathrm{~s},(\mathrm{~F}) 20 \mathrm{~s},(\mathrm{G}) 50 \mathrm{~s}$, and (H) $100 \mathrm{~s}$ after $25 \mathrm{~g}$ of FLiNaK at an initial temperature of approximately $490{ }^{\circ} \mathrm{C}$ was poured into the tubing (Test 3). The reported temperature has been corrected for the emissivity of the tubing coating. 
(G)

(H)
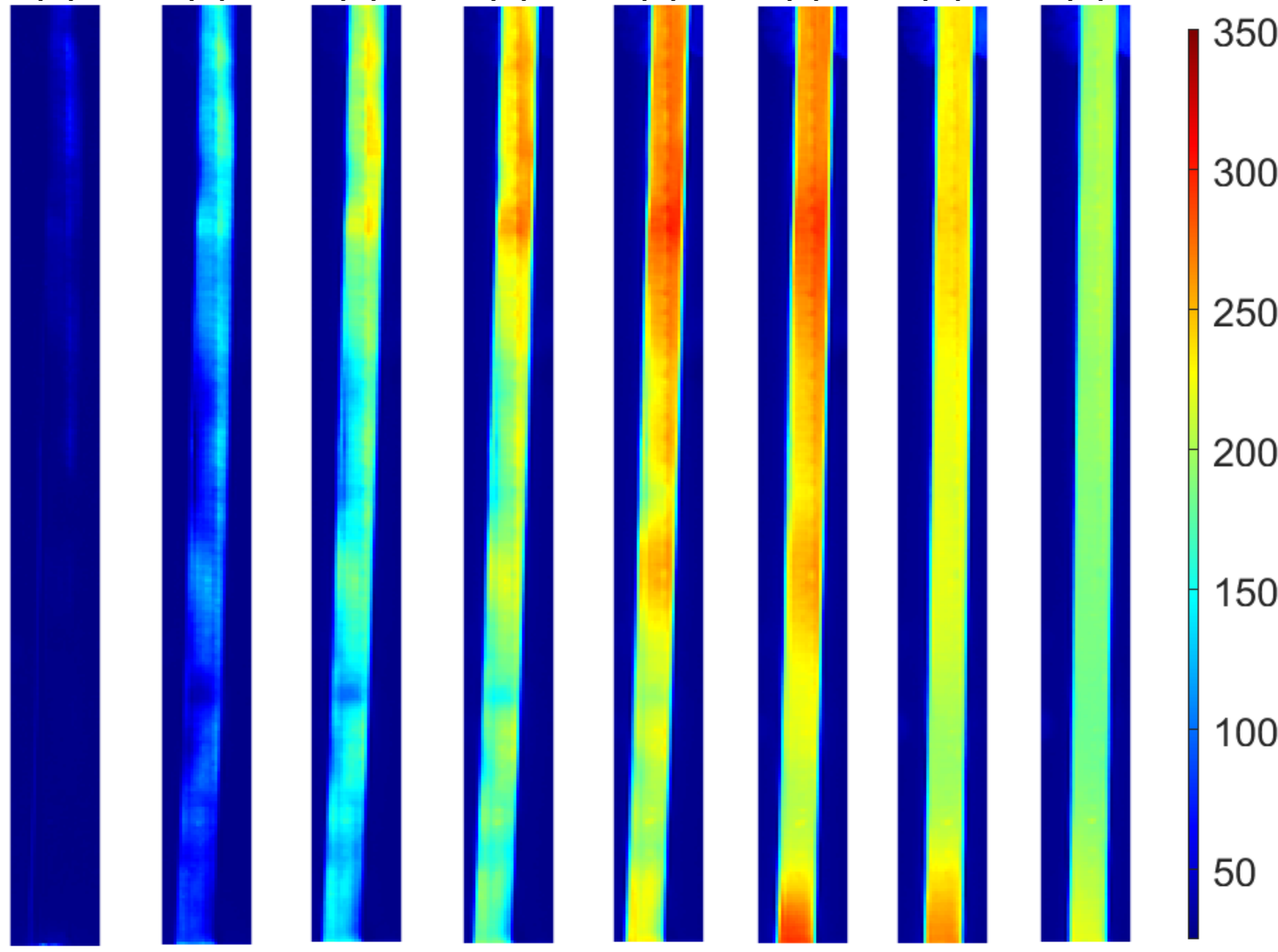

$0 \mathrm{~s}$

$1 \mathrm{~s}$

$2 \mathrm{~s}$

$5 \mathrm{~s}$

$50 \mathrm{~s}$

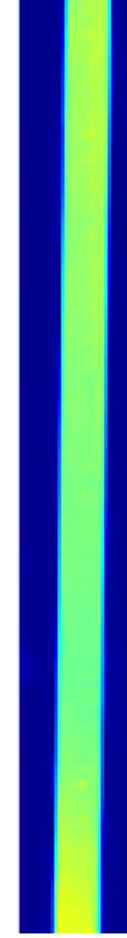

250

200

150

100

50

Figure 26: Still frames from video taken by the IR camera that show the temperature of the outer wall of the stainless steel tubing with an inner diameter of 0.1875 in. and wall thickness of $0.0625 \mathrm{in}$. The lower $10 \mathrm{in}$. of the $11 \mathrm{in}$. tube is shown in the frame. The frames were taken (A) $0 \mathrm{~s}$, (B) $1 \mathrm{~s},(\mathrm{C}) 2 \mathrm{~s}$, (D) $3 \mathrm{~s}$, (E) $5 \mathrm{~s},(\mathrm{~F}) 10 \mathrm{~s}$, (G) $50 \mathrm{~s}$, and (H) $100 \mathrm{~s}$ after $25 \mathrm{~g}$ of FLiNaK at a temperature of approximately $775{ }^{\circ} \mathrm{C}$ was poured into the tubing (Test 4). The reported temperature has been corrected for the emissivity of the tubing coating.

\subsubsection{Temperature of the underside of the stainless steel beaker}

The temperature of the underside of the stainless steel beaker that collected the molten salt that flowed through the tubing was measured for all test conditions and is reported in Figure 27. The maximum temperature recorded at the beaker underside was $422{ }^{\circ} \mathrm{C}$ for the test condition with $25 \mathrm{~g}$ of $\mathrm{FLiNaK}$ at an initial salt temperature of approximately $660^{\circ} \mathrm{C}$ flowing through tubing with an inner diameter of $0.25 \mathrm{in}$. (Test 1 ). The three other tests recorded lower maximum temperatures at the beaker underside. Notably, the cooling curves for Tests 1, 2, and 4 were nearly identical approximately 5 minutes after the salt first entered the beaker (Figure 27). Table 10 provides the maximum temperature recorded at the beaker underside, the average thickness of the frozen salt pool in the beaker after it had cooled to room temperature, and the mass of salt in the beaker for the four tests discussed in this section. 


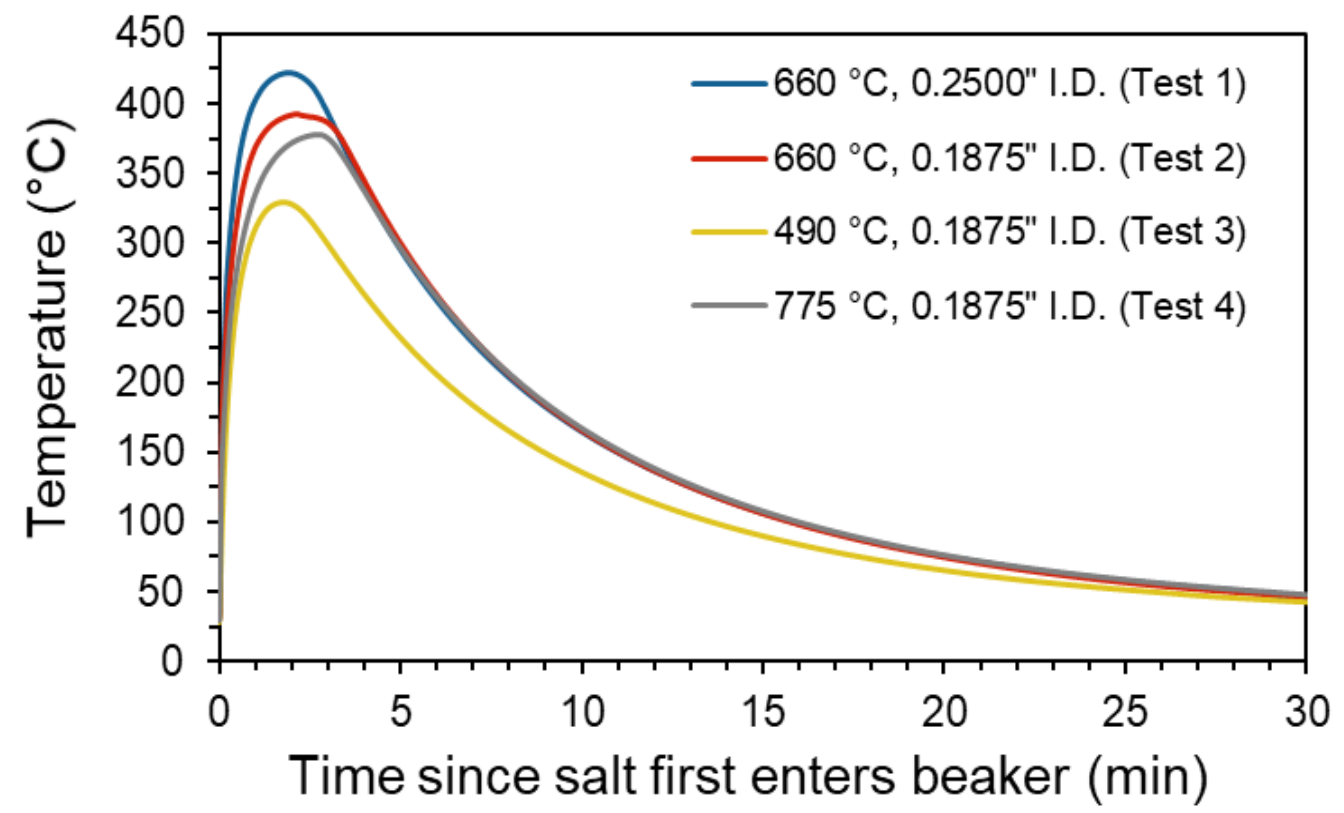

Figure 27: The temperature of the underside of the stainless steel beaker that collected the molten salt that flowed through the tubing for $25 \mathrm{~g}$ of FLiNaK that was poured at different initial salt temperatures and inner tube diameters. The beaker thickness was 0.03125 in and was insulated at the bottom.

Table 10: The maximum temperature recorded at the beaker underside, the thickness of the frozen salt pool, and salt mass in beaker ${ }^{\mathrm{a}}$

\begin{tabular}{cccc}
\hline Test No. & $\begin{array}{c}\text { Max. beaker } \\
\text { underside temp. }\left({ }^{\circ} \mathrm{C}\right)\end{array}$ & $\begin{array}{c}\text { Salt thickness } \\
(\mathrm{mm})^{\mathrm{b}}\end{array}$ & $\begin{array}{c}\text { Salt mass in } \\
\text { beaker }(\mathrm{g})\end{array}$ \\
\hline 1 & 422 & $4.5 \pm 0.6$ & 21.6 \\
2 & 393 & $5.6 \pm 0.3$ & 17.9 \\
3 & 330 & $5.3 \pm 0.2$ & 17.1 \\
4 & 378 & $5.0 \pm 0.1$ & 16.8 \\
\hline
\end{tabular}

a The conditions of each test are provided in Table 9.

${ }^{b}$ Mean \pm one standard deviation.

\subsubsection{Flow rate of salt through tubing}

The flow rate of the salt through the tubing was recorded with a data logging scale that recorded the mass of the beaker at one second intervals. The scale starts to record once it detects a change from the tare weight. Figure 28 reports the mass of salt in the stainless steel beaker as a function of time after the scale first detects a weight for the four tests in this section. It is clear in Figure 28 that most of the salt has passed through the tubing within two seconds after the scale first started recording. The lowest flow rate occurred for the test with an initial salt temperature of $490{ }^{\circ} \mathrm{C}$ (Figure 28). 


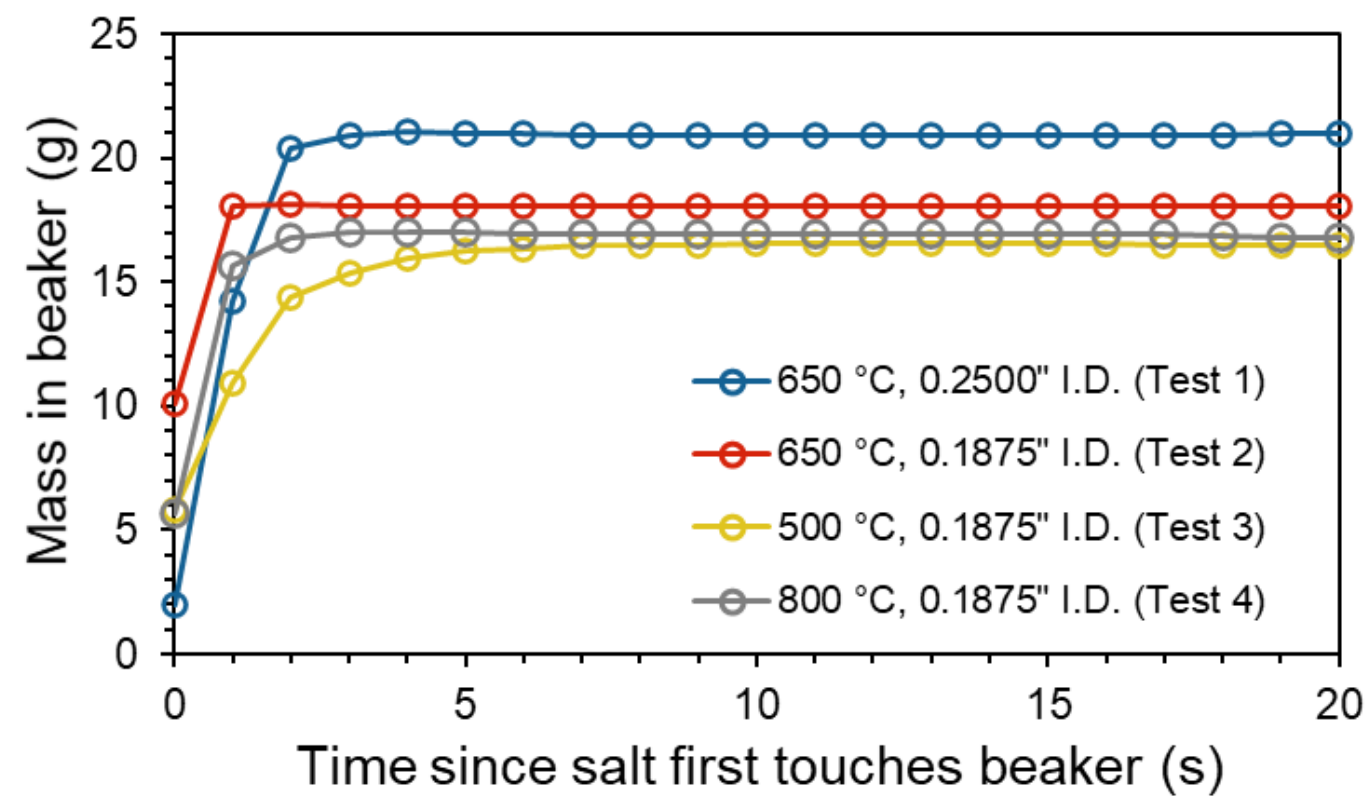

Figure 28: The mass of salt in the stainless steel beaker below the tubing that was recorded by the data logging scale for the four tests on molten salt flowing in tubing. The scale starts recording when it first detects a weight and records at an interval of one second.

\subsubsection{Mass balance analysis}

Figure 29 presents the amounts of frozen salt that were recovered from the top of the funnel, from inside the tubing, from the stainless steel beaker below the tubing, and not recovered as a fraction of the total mass poured for the four tests conditions in this section. For all conditions, the majority

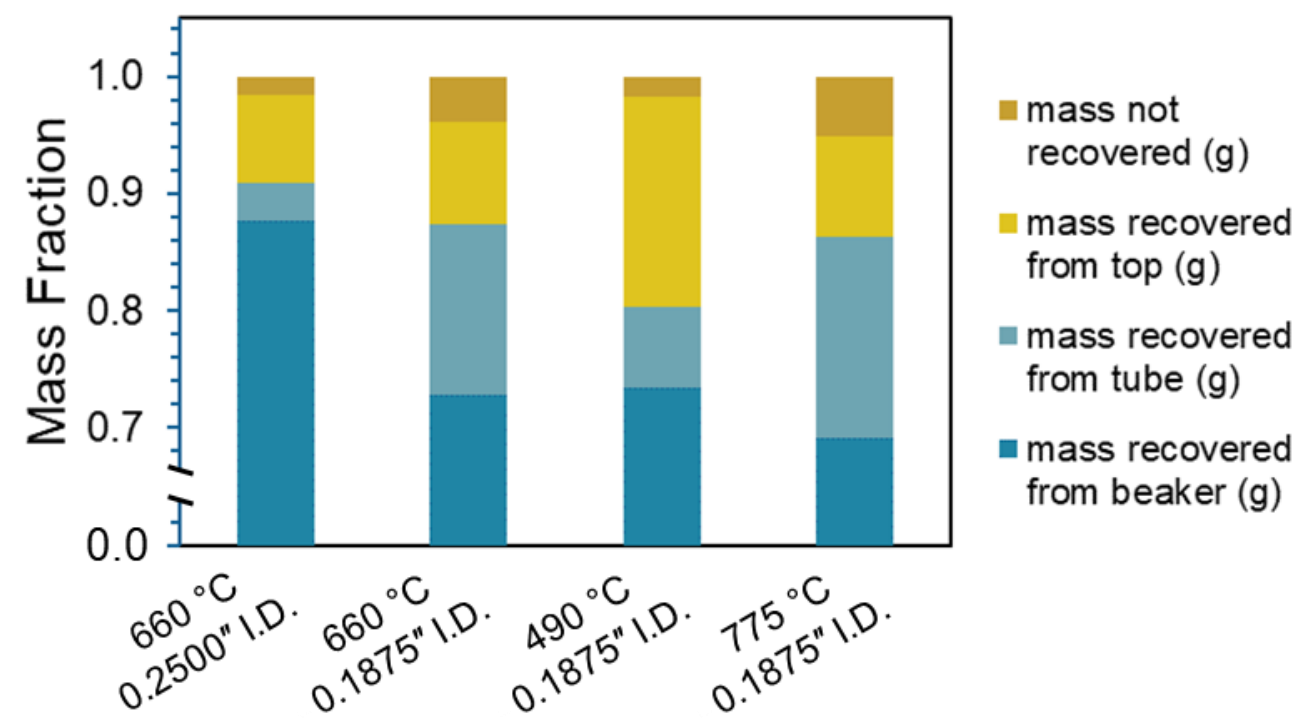

Figure 29: The mass fractions of frozen salt that were recovered from the top of the funnel, recovered from inside the tubing, recovered from the stainless steel beaker below the tubing, and not recovered for the four tests on molten salt flowing in tubing. 
of the salt flowed through the tubing and was recovered from the beaker (Figure 29). A smaller fraction of the total salt that was poured froze in the tubing when the inner tube diameter was $0.25 \mathrm{in}$. than when it was $0.1875 \mathrm{in}$. for the same initial salt temperature $\left(660^{\circ} \mathrm{C}\right)$ and pour mass. The largest fraction of the total mass poured that froze at the top of the funnel before it could flow into the tubing was from the test that had the lowest initial salt temperature. Notably, a greater fraction of the total mass that was poured froze inside the tubing in tests with initial salt temperatures of $660^{\circ} \mathrm{C}$ and $775^{\circ} \mathrm{C}$ than in the test with salt at $490{ }^{\circ} \mathrm{C}$ for the same inner tube diameter of 0.1875 in.

\subsubsection{Deformation of structural metals}

There was no indication that the funnel, tubing, or stainless steel beaker deformed during the tests, even for the test in which the 0.03125 in.-thick beaker underside reached $420{ }^{\circ} \mathrm{C}$ (Test 1$)$. Tests at a larger scale in which the salt remains molten for longer durations will likely be needed to assess structural material deformation due to contact with molten salt.

\subsubsection{Composition of frozen salt samples}

The composition of the salt that froze within and passed through the tubing is under analysis and will be included in a data package of salt spill test results in an upcoming report (Thomas and Jackson, 2021).

\section{Stainless steel corrosion kinetics in molten salt}

\subsection{Experimental methods}

\subsubsection{Experimental design}

The Argonne ElectroCorrosion Toolkit ${ }^{\mathrm{TM}}$ developed for aqueous corrosion of metallic waste forms (Gattu and Ebert, 2020) was applied to study the corrosion kinetics of 316 stainless steel in molten FLiNaK. This method uses a 316 stainless steel coupon as the working electrode and the molten FLiNaK as the electrolyte. Figure 30A provides a schematic of the experimental setup, which was located within an argon atmosphere glovebox $\left(\mathrm{O}_{2}<10 \mathrm{ppm}, \mathrm{H}_{2} \mathrm{O}<5 \mathrm{ppm}\right)$. The FLiNaK was heated in a nickel crucible and held at the target temperature throughout the duration of the corrosion test in a furnace. The working electrode consisted of a polished 0.75 in. $\times 0.25$ in. $\times$ 0.03 in. $(L \times W \times D) 316$ stainless steel coupon that was attached to a 316 stainless steel lead wire (0.02 in. diameter). The counter electrode consisted of a nickel rod, and the reference electrode consisted of a silver wire (1 mm diameter). A VersaSTAT® potentiostat was used to fix a potential at the interface between the stainless steel and molten salt. The potentiostat can apply a wide range of potentials that are independent of the chemical and atmospheric conditions to determine the effect of the stainless steel surface potential on corrosion rate.

\subsubsection{Measurements}

\subsubsection{Potentiodynamic scans and potentiostatic tests}

A potentiodynamic (PD) scan was performed first to assess the qualitative electrochemical response of the 316 stainless steel coupon when first contacted with molten FLiNaK for each test condition. The PD scans are used to determine the corrosion potential of the polished surface when at equilibrium with the salt ( $\left.E_{\mathrm{CORR}}\right)$, at which the cathodic and anodic half reactions occurring 
at the surface are kinetically balanced with no net electron transfer. The PD scans also provide information on the propensity of the surface to oxidize at higher voltages and the voltages at which corrosion behaviors change. Potentiostatic (PS) tests were performed on a freshly polished stainless steel surface by imposing a constant surface potential above $E_{c o r R}$ to directly measure the anodic current. The PS tests were run for several hours until a steady current was achieved. The steady current represents the long-term corrosion behavior of 316 stainless steel at the specified surface potential and chemistry of the molten salt after time-dependent processes have stabilized. The voltage corresponding to reduction of $\mathrm{Li}^{+}\left(\mathrm{Li} / \mathrm{Li}^{+}\right)$was used as an internal reference for all measurements.

(A)

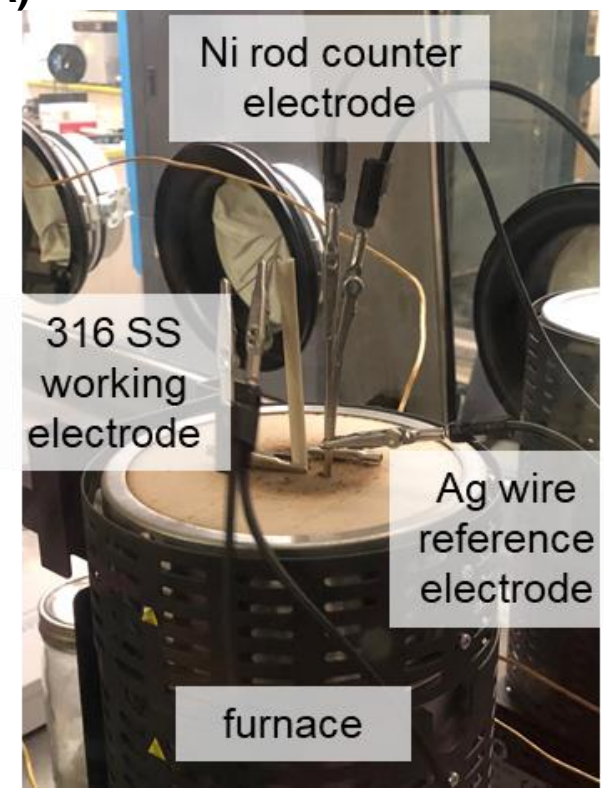

(B)

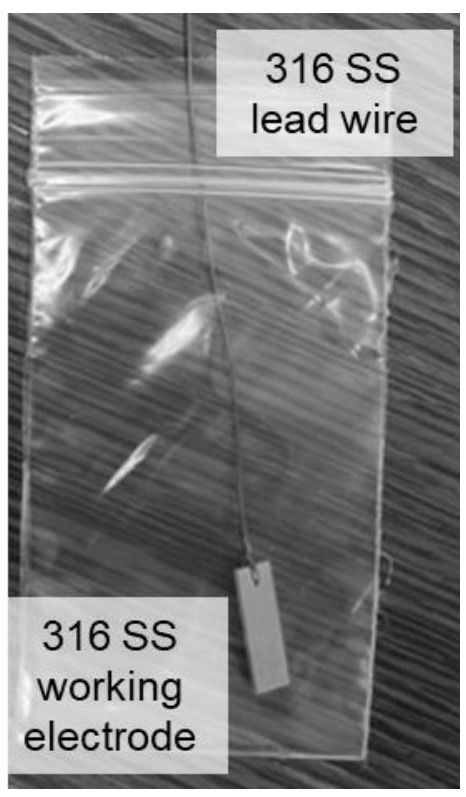

Figure 30: (A) Schematic of the experimental setup to study 316 stainless steel corrosion in molten salt. (B) Image of the 316 stainless steel working electrode attached to a 316 stainless steel lead wire (0.02 in. diameter).

\subsubsection{Evolution of corroding 316 stainless steel surface}

Electrochemical impedance spectroscopy (EIS) was performed during the PS tests to identify changes in the electrochemical properties of the surface of the stainless steel coupon, such as the formation of surface layers. Test coupons were archived for layer analyses to determine changes in the surface microstructure and composition and to identify corrosion mechanism(s).

\subsection{Results}

Table 11 provides a summary of the electrochemical corrosion test conditions conducted with 316 stainless steel in molten FLiNaK. This section includes representative examples of the data obtained from the measurements and summarizes key findings. The full suite of results will be included in a data package in an upcoming report (Thomas and Jackson, 2021). 
Table 11: Summary of test conditions to study the corrosion of 316 stainless steel in molten FLiNaK

\begin{tabular}{ccccc}
\hline Test No. & Salt temp. $\left({ }^{\circ} \mathrm{C}\right)$ & PD scan & PS test & $\begin{array}{c}\text { PS hold potential } \\
\text { (V above EcorR) }\end{array}$ \\
\hline 1 & 500 & $\mathrm{Y}$ & $\mathrm{Y}$ & 0.2 \\
2 & 650 & $\mathrm{Y}$ & $\mathrm{N}$ & $\mathrm{n} / \mathrm{a}$ \\
3 & 800 & $\mathrm{Y}$ & $\mathrm{Y}$ & 0.1 \\
\hline
\end{tabular}

\subsubsection{Corrosion kinetics of stainless steel in molten FLiNaK}

Figure 31 presents PD scans of 316 stainless steel coupons in molten FLiNaK at temperatures of $500{ }^{\circ} \mathrm{C}, 650^{\circ} \mathrm{C}$, and $800^{\circ} \mathrm{C}$. The $\mathrm{E}_{\text {corr }}$ of the stainless steel coupon in molten FLiNaK (the potential at which current density is at a minimum) was temperature-dependent and was $1.44 \mathrm{~V}$ (vs. Li/Li+), $1.32 \mathrm{~V}$ (vs. Li/Li+), and $1.30 \mathrm{~V}\left(\right.$ vs. $\left.\mathrm{Li}^{\prime} / \mathrm{Li}^{+}\right)$at temperatures of $500^{\circ} \mathrm{C}, 650^{\circ} \mathrm{C}$, and $800{ }^{\circ} \mathrm{C}$, respectively.

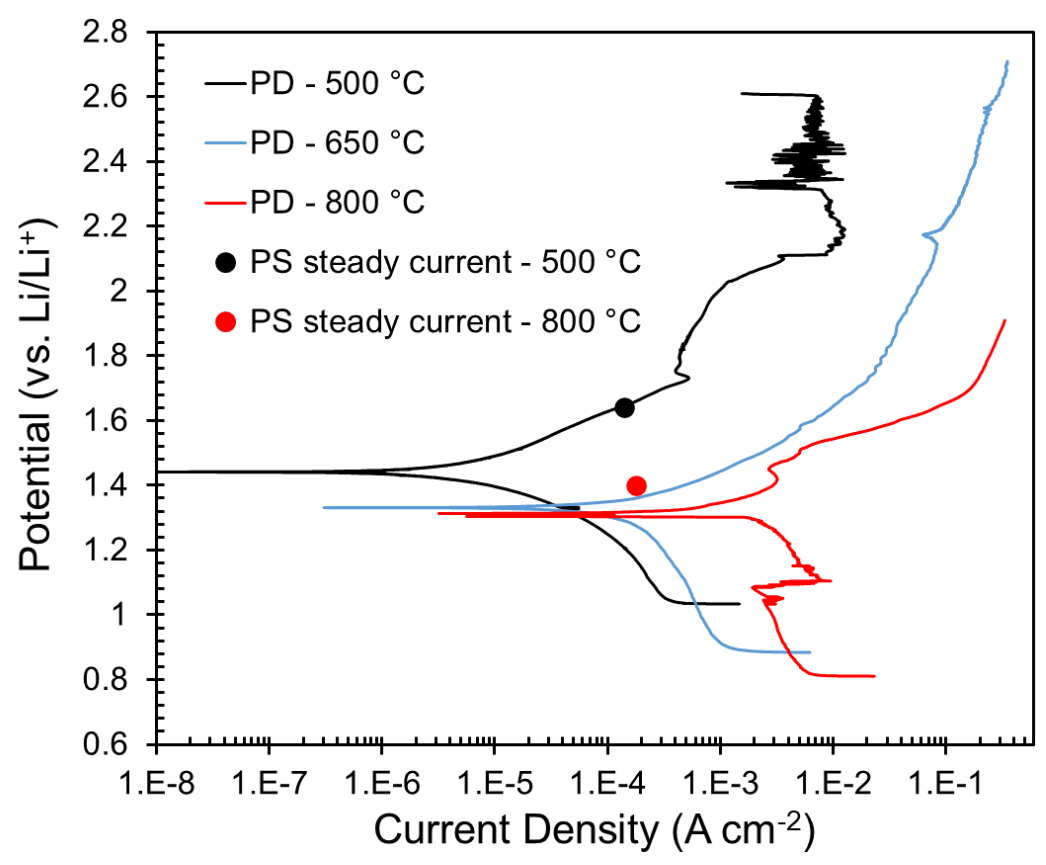

Figure 31: PD scans of 316 stainless steel coupons in molten FLiNaK at temperatures of $500{ }^{\circ} \mathrm{C}$, $650^{\circ} \mathrm{C}$, and $800^{\circ} \mathrm{C}$. The spots mark the steady corrosion currents measured in PS tests conducted at $0.2 \mathrm{~V}$ and $0.1 \mathrm{~V}$ above the $\mathrm{E}_{\mathrm{CORR}}$ values for salt temperatures of $500^{\circ} \mathrm{C}$ and $800^{\circ} \mathrm{C}$, respectively.

Figure 32 presents the combined results from PS tests at $500^{\circ} \mathrm{C}$ and $800{ }^{\circ} \mathrm{C}$ that were conducted at fixed potentials of $0.2 \mathrm{~V}$ and $0.1 \mathrm{~V}$ above the $E_{\text {CorR }}$ value determined from the PD scan at each temperature, respectively. The current densities measured during the beginning of the PS test at $500{ }^{\circ} \mathrm{C}$ fluctuated before stabilizing, and the current densities measured during the beginning of the PS test at $800^{\circ} \mathrm{C}$ decreased steadily. The initial instabilities occurred because the stainless steel surface had not yet equilibrated with the salt at the imposed conditions. Future assessments of the EIS spectra collected during the PS tests and an inspection of the microstructure and 
composition of the coupon after the PS test using scanning electron microscopy (SEM) with associated energy dispersive X-ray spectroscopy (EDS) will provide insight into the observed corrosion behavior. For example, the changes in corrosion current observed during the beginning of the PS tests could be attributed to the leaching of chromium and molybdenum or the buildup of surface layers.

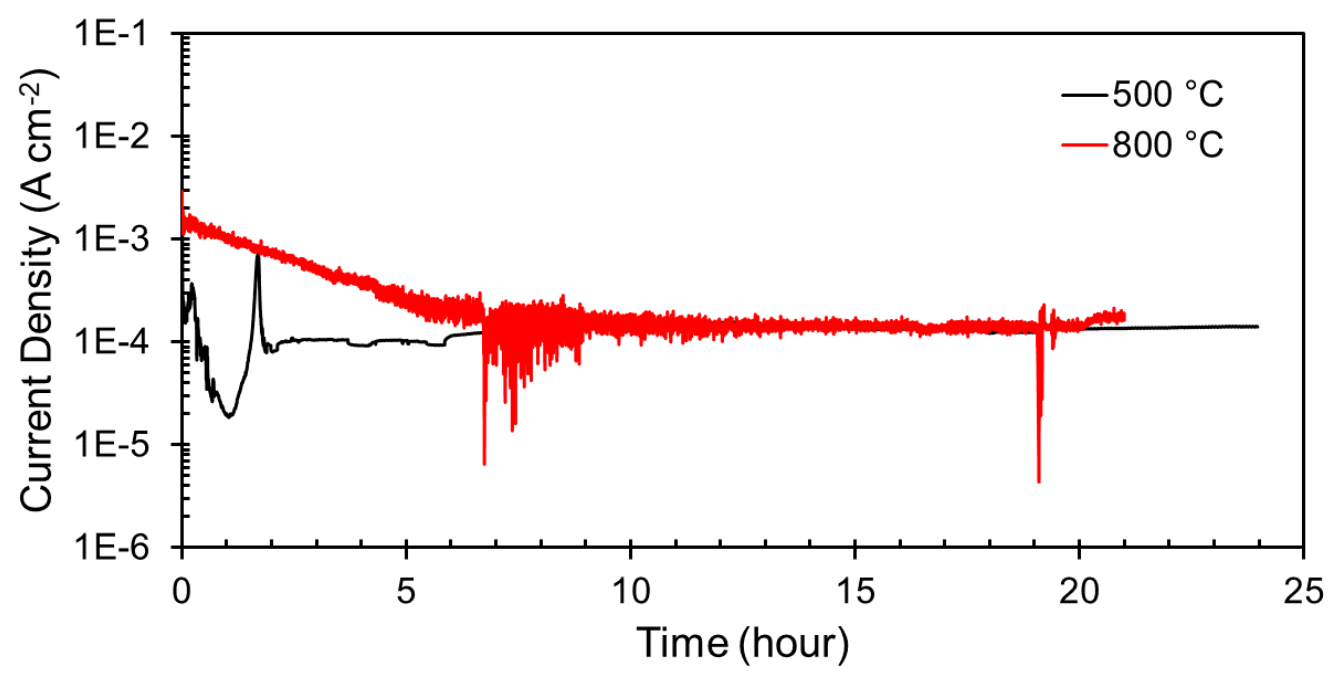

Figure 32: Results of PS tests with 316 stainless steel coupons in molten FLiNaK at fixed potentials of $0.2 \mathrm{~V}$ and $0.1 \mathrm{~V}$ above $\mathrm{E}_{\mathrm{CORR}}$ and temperatures of $500^{\circ} \mathrm{C}$ and $800{ }^{\circ} \mathrm{C}$, respectively.

The steady corrosion current densities of 316 stainless steel measured in the PS tests at both temperatures were both approximately $1.8 \times 10^{-4} \mathrm{~A} \mathrm{~cm}^{-2}$ (Figure 32). This value can be used to calculate a mass corrosion rate for the known conditions of the test (Section 5.2.2).

\subsubsection{Calculation of corrosion rates}

The total mass of material oxidized per day per unit area can be calculated from the anodic current by using Faraday's law as follows:

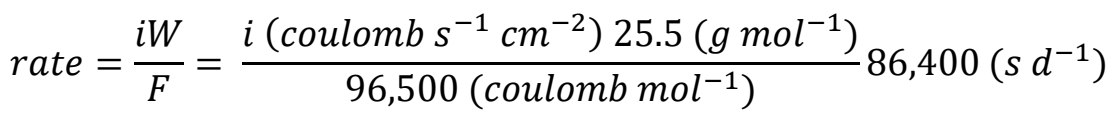

where rate is the mass corrosion rate $\left(\mathrm{g} \mathrm{cm}^{-2} \mathrm{~d}^{-1}\right), i$ is the measured current density $\left(\mathrm{A} \mathrm{cm}^{-2}\right), W$ is the alloy equivalent weight $\left(\mathrm{g} \mathrm{mol}^{-1}\right)$, and $F$ is Faraday's constant $\left(9.65 \times 10^{4}\right.$ coulombs mol $\left.^{-1}\right)$. The factor $86,400 \mathrm{~s} \mathrm{~d}^{-1}$ is included to convert the rate from $\mathrm{g} \mathrm{cm}^{-2} \mathrm{~s}^{-1}$ to $\mathrm{g} \mathrm{cm}^{-2} \mathrm{~d}^{-1}$. The equivalent weight is the mass of material in grams that is oxidized by the passage of one Faraday $(96,500$ coulombs) of electric charge. For an alloy, the alloy composition and the valence of the oxidation products determine the equivalent weight. An equivalent weight of $25.5 \mathrm{~g} \mathrm{~mol}^{-1}$ was used for 316 stainless steel to calculate the mass corrosion rate (ASTM 2015).

The steady current density of $1.8 \times 10^{-4} \mathrm{~A} \mathrm{~cm}^{-2}$ translates to a mass corrosion rate of $4.1 \times 10^{-3} \mathrm{~g} \mathrm{~cm}^{-2} \mathrm{~d}^{-1}$. The density of 316 stainless steel $\left(8.02 \mathrm{~g} \mathrm{~cm}^{-3}\right.$; ASTM 2015) was used to convert the mass corrosion rate into a penetration rate of $1.9 \mathrm{~mm} \mathrm{yr}^{-1}$. It is important to note that 
this corrosion rate was calculated for one salt composition at one fixed surface potential. Electrochemical corrosion tests such as these must be conducted over a range of possible salt compositions and surface potentials to understand the corrosion behavior of stainless steel contacted by molten salt during and after a molten salt spill accident.

These initial tests demonstrate the use of the method to determine corrosion rates at fixed surface potentials, salt compositions, environmental conditions, and salt temperature. Future tests will explore the effect of salt composition, impurities absorbed from the atmosphere (e.g., $\mathrm{O}_{2}$ and $\mathrm{H}_{2} \mathrm{O}$ ), and fission products that affect the redox potential and will likely affect the corrosion rate. The results generated in these tests can be directly input into models that predict the structural integrity of the catch pan for transients involving changes in salt redox, composition, and temperature.

\section{Molten salt splashing and aerosol formation}

\subsection{Experimental methods}

\subsubsection{Experimental design}

The objective of this experimental method is to measure the splatter and aerosols that are generated due to splashing of molten salt doped with surrogate fission products onto a catch pan surface. A 12 in. $\times 12$ in. $\times 12$ in. $(\mathrm{L} \times \mathrm{W} \times \mathrm{H})$ stainless steel "spill containment box" was constructed to study molten salt splashing and aerosol formation (Figure 33A). The purpose of the box is to contain the splatter and aerosols that form within so that they can be collected and analyzed. The top of the box includes a 2.5 in. $\times 2.5$ in. $\times 3$ in. $(\mathrm{L} \times \mathrm{W} \times \mathrm{H})$ opening through which molten salt is poured manually. The pour inlet is wide enough so that the stream of molten salt

(A)

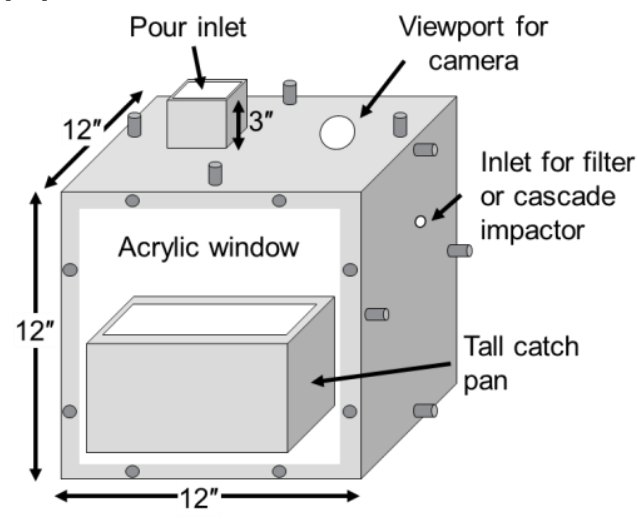

(B)

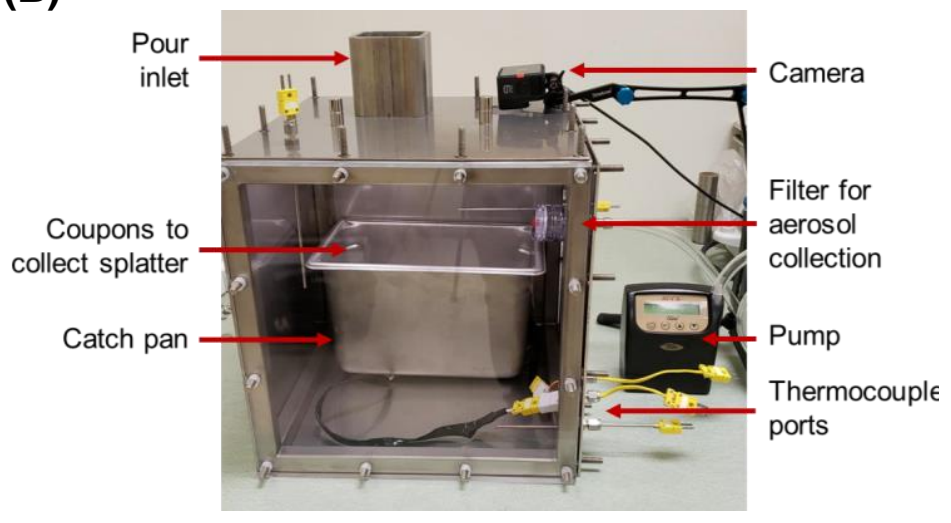

Figure 33: (A) Schematic of the spill containment box for the molten salt splashing and aerosol collection test. (B) Image of the spill containment box that identifies the various measurement components including thermocouples, coupons to collect molten salt splatter, a filter to collect aerosols, and the visible camera. 
does not contact the inlet walls while it is being poured into the box. A catch pan with dimensions of 10.375 in. $\times 6.375$ in. $\times 6$ in. $(\mathrm{L} \times \mathrm{W} \times \mathrm{H})$ and a wall thickness of 0.03125 in. was placed inside the spill containment box to collect the molten salt that is poured through the inlet. A removable acrylic window was placed on one side of the box to provide access to the inside of the box. The edges of the window were lined with a foam rubber seal to ensure a snug fit when the window is in place. A 2-in. diameter hole cut into the top of the box was used as a viewport for a visible camera (Figure 33A). All molten salt splashing and aerosol generation tests were conducted within an argon atmosphere glovebox $\left(\mathrm{O}_{2}<10 \mathrm{ppm}, \mathrm{H}_{2} \mathrm{O}<5 \mathrm{ppm}\right)$.

Tubing was passed through a small hole in the wall of the spill containment box farthest from the pour inlet and attached to a filter in an aerosol cassette or a cascade impactor to collect aerosols (Figure 33A). The other end of the tubing was connected to a personal sampling pump (Buck Elite $^{T M}$ ) to pull gas through the filter or cascade impactor. Figure 33B shows an image of the spill containment box and identifies the various measurement components. Nickel coupons (1 in. $\times 1$ in.) covered with double sided carbon tape (Electron Microscopy Sciences) on one side were hung on the catch pan walls to retain splatter contacting the adhesive during the test for later analysis. Thermocouples cemented to the underside of the catch pan (directly under the spill zone) and threaded through tube fittings on the spill containment box walls were used to measure the temperature of the catch pan underside and the temperature of the atmosphere, respectively (Figure 33B).

A description of the data logger for thermocouple measurements, visible camera, and furnace is provided in Appendix A.

\subsubsection{Measurements}

\subsubsection{Average pour rate}

The average flow rate of the salt was determined by dividing the mass of salt that was poured by the duration of the pour. The mass of salt poured is equal to the difference between the mass added to the crucible and the mass that remained in the crucible after pouring. The duration of the pour was determined using footage from the visible camera that was filming the salt splashing into the catch pan in the spill containment box.

\subsubsection{Temperature}

The temperature of the underside of the stainless steel catch pan that collected the molten salt that was poured into the spill containment box was recorded with butt-welded thermocouple lead wires with the junction attached to the surface with thermally conductive cement (Appendix B Section B.2). The performance of the surface temperature measurement obtained using the thermocouples is presented in Appendix B Section B.2. The thermocouple probes were attached to the catch pan directly under the anticipated spill zone location.

Sheath-type thermocouples (ungrounded, $\mathrm{K}$ type) were inserted into the spill containment box at three locations through tube fittings to gauge temperature gradients and the evolution of the temperature of the atmosphere after the spill. The furnace temperature provided an estimate of the initial molten salt temperature immediately before it was poured. 


\subsubsection{Video and images obtained by visible camera}

A visible camera mounted on a tripod and positioned above the camera viewport of the spill containment box (Figure 33A) was used to generate a video of the molten salt splashing into the stainless steel catch pan. The video was collected at a rate of 240 frames per second and was slowed down by a factor of 20 to achieve slow motion footage of molten salt splashing. Photographs after the splashed salt had cooled were also taken to show the distribution of salt particles that had stuck to the walls of the catch pan and the coupons.

\subsubsection{Glovebox conditions}

The temperature, total pressure, $\mathrm{O}_{2}$ content, and $\mathrm{H}_{2} \mathrm{O}$ content of the argon atmosphere in the glovebox was recorded before and after pouring molten salt for each test.

\subsubsection{Composition of splatter by ICP-MS}

Samples of splattered salt that froze on the walls of the stainless steel catch pan and salt that froze in a pool on the catch pan floor were collected and analyzed for major cations (lithium, sodium, and potassium), trace metals (calcium, manganese, iron, nickel, chromium, cesium, and rubidium), and iodine by using ICP-MS according to the methods reported in Section 2.3.

\subsubsection{Aerosol composition}

Aerosols that formed in the spill containment box during the test were collected on a $37 \mathrm{~mm}$ diameter PTFE filter $(0.45 \mu \mathrm{m}$ pore size) that was connected to a personal sampling pump. The pump was set to a constant flow rate of $4 \mathrm{~L} \mathrm{~min}^{-1}$ and was turned on approximately 30 seconds before pouring molten salt into the spill containment box to achieve a steady flow of glovebox gas through the filter. The pump ran for approximately 10 minutes after the salt was first splashed into the box. The efficiency of particle collection is unknown and the total mass of particles collected on the filter was less than $100 \mu \mathrm{g}$ for all tests described.

After the test, the aerosol sampling cassette with PTFE filter was carefully removed from the spill containment box so that the collected particulates could be washed off the filter and analyzed to determine elemental composition. The concentrations of total iodine, cesium, sodium, potassium, and lithium in the wash solutions were analyzed by using ICP-MS as described in Section 2.3.

\subsubsection{Splatter abundance and size distribution}

Nickel coupons were hung on the walls of the catch pan surrounding the spill zone and on the wall furthest from the spill zone just below the aerosol collection filter to collect splatter for the determination of particle abundance and size distribution. The coupons were covered in black carbon tape to improve the adhesion of particles to the coupons. The coupons were weighed before and after splatter deposition, but the total mass of particles that were collected on the coupons was typically less than the detection limit of the scale $(100 \mu \mathrm{g})$. A photograph was taken of each coupon using a visible camera after the splashing test so that the image could be analyzed for total particle abundance and particle size. The pixel dimensions of the image were determined using the known dimensions of the nickel coupon. The image was then cropped to include only the region of interest for analysis and the total area of the region of interest was determined using the known pixel dimensions. Figure 34 provides an example of a raw image, cropped image, and processed binary image of salt particles collected on a coupon from a molten salt splashing test. 


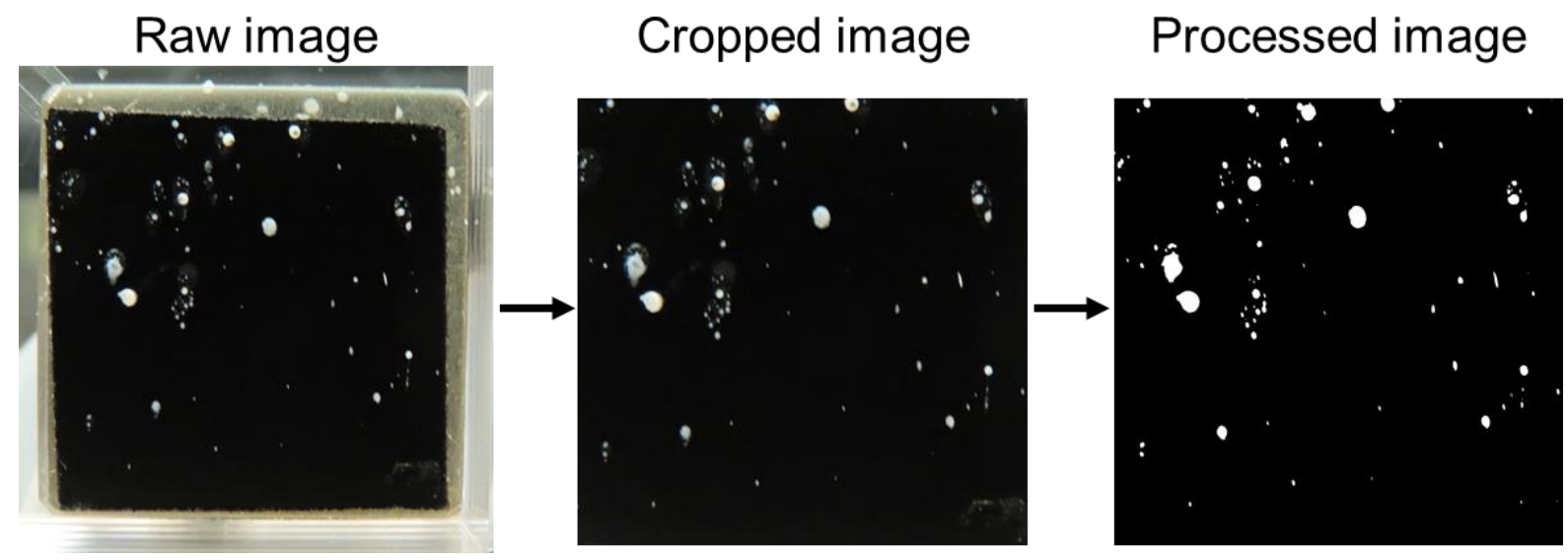

Figure 34: An example of a raw image, cropped image, and processed binary image of salt particles collected on a coupon from a molten salt splashing test.

The Image Processing Toolbox ${ }^{\mathrm{TM}}$ in MATLAB® was used to identify the salt particles on the black carbon tape background. The contrast of the white FLiNaK salt particles on the black carbon tape facilitated image processing. Image processing consisted of the following procedure:

- Convert to grayscale image.

- Perform background correction (for non-uniform illumination).

- Convert to binary image (particles are white, background is black).

- Define a particle as a group of 10 or more contiguous white pixels.

- Count particles and determine the number of pixels occupied by each particle.

- Convert particle area in pixels to $\mathrm{mm}^{2}$ using known pixel dimensions.

The measured particle area was used to determine its equivalent diameter, which is defined as the diameter of the particle assuming it projects a perfect circle on the coupon. The minimum detectable equivalent diameter of a particle using this method is approximately $50 \mu \mathrm{m}$. The number of particles and size distribution of particles per total area analyzed was obtained in this manner, which enabled the quantification of splashing behavior for individual tests.

Splatter formation was also quantified by collecting and weighing the frozen splatter particles and the frozen salt pool in the catch pan after the test had concluded and performing a mass balance.

\subsubsection{Splatter and aerosol composition by SEM-EDS}

Splatter and aerosol particles captured on nickel coupons covered with carbon tape adhesive were analyzed by using SEM with associated EDS to identify particles that were smaller than the $50 \mu \mathrm{m}$ diameter detection limit of the visible camera and to determine particle compositions. Coupons were sealed in air-tight bags containing desiccant packets to absorb humidity prior to their removal from the argon atmosphere glovebox to prevent water absorption by the salt particles during transfer to the SEM. The coupons were quickly removed from the air-tight bags, carbon coated under vacuum, and then placed in the SEM sample chamber that was evacuated to high vacuum. The coupons were exposed to ambient air for less than a total of two minutes during the process of transferring them into the SEM. A collection of EDS maps, line scans, and single spot analyses were used to identify salt particles and determine their elemental composition. 


\subsubsection{Composition of condensation on ceiling of spill containment box}

A 37-mm diameter glass fiber filter was soaked in methanol and used to wipe the ceiling of the spill containment box to collect condensation that may have been deposited. The ceiling was wiped by smearing the methanol-soaked glass fiber filter using tweezers that were cleaned with methanol prior to use. Only one wipe was taken after all splashing tests described in this section were completed. The wipe was submitted for compositional analysis (total lithium, total sodium, total potassium, total cesium, and total iodine) and the contents of the wipe were extracted using the same methods used for the PTFE filters (Section 2.3). A glass fiber filter that was soaked in methanol was analyzed as a control sample and a glass fiber filter that was not soaked in methanol was analyzed as a blank as part of the compositional analysis.

\subsubsection{Aerosol abundance and size distribution using a cascade impactor}

Aerosol quantification using a cascade impactor (Model 135 MiniMOUDI $^{\mathrm{TM}}$ ) was evaluated as part of the test series. Nickel substrates $(0.001$ in. thick) were fabricated to collect the aerosol particles. The detectable size range was $0.18 \mu \mathrm{m}$ to $10 \mu \mathrm{m}$. The cascade impactor was connected to a personal sampling pump operated at a constant flow rate of $2 \mathrm{~L} \mathrm{~min}^{-1}$ following the manufacturer's instructions. The pump was turned on approximately 30 seconds before pouring molten salt into the spill containment box to achieve steady flow through the cascade impactor and ran for approximately 10 minutes after the salt was first splashed into the box. The substrates onto which aerosols collect were weighed before and after the sampling period to determine the total mass of aerosols collected. The mass of particles collected on all substrates was less than the detection limit of our scale $(100 \mu \mathrm{g})$. This technique is likely more suitable for larger scale tests that produce larger quantities of aerosols. The collection substrates were saved for future analysis to characterize the size and composition of collected particles using SEM-EDS.

\subsection{Results}

Table 12 provides a summary of the conditions of each FLiNaK splashing and aerosol generation test that was conducted. This section includes examples of the results that are obtained for the measurements that are taken and summarizes key findings. The full suite of results will be included in a data package in an upcoming report (Thomas and Jackson, 2021).

Table 12: Summary of splashing and aerosol generation test conditions for tests using molten FLiNaK with surrogate fission products ${ }^{a}$

\begin{tabular}{cccc}
\hline Test No. & $\begin{array}{c}\text { Initial salt temp. } \\
\left({ }^{\circ} \mathrm{C}\right) \text { estimate }\end{array}$ & $\begin{array}{c}\text { Avg. pour rate } \\
\left(\mathrm{g} \mathrm{s}^{-1}\right)\end{array}$ & $\begin{array}{c}\text { CsF and Csl } \\
\text { addition }\end{array}$ \\
\hline 1 & 500 & 18.4 & $\mathrm{Y}$ \\
2 & 500 & 14.8 & $\mathrm{Y}$ \\
3 & 650 & 19.6 & $\mathrm{Y}$ \\
4 & 650 & 19.9 & $\mathrm{Y}$ \\
5 & 800 & 21.2 & $\mathrm{Y}$ \\
6 & 800 & 15.5 & $\mathrm{~N}$ \\
7 & 800 & 16.9 & \\
\hline
\end{tabular}

a The pour mass was $15 \mathrm{~g}$ and the pour height was 15 in for all tests.

b The initial salt temperature was estimated by a thermocouple placed in the furnace liner in which the salt was heated. 


\subsubsection{Splashing behavior}

The slow-motion video of molten FLiNaK pouring into the spill containment box revealed that the liquid salt fell into the catch pan as droplets when the initial salt temperature was $650{ }^{\circ} \mathrm{C}$ and $800{ }^{\circ} \mathrm{C}$ (Figure 35A and Figure 35B), but more stream-like than droplet-like at an initial temperature of $500^{\circ} \mathrm{C}$ (Figure $35 \mathrm{C}$ ). The duration of the spill for all tests discussed in this section was less than one second. The salt that pooled at the bottom of the catch pan remained molten throughout the duration of the spill for all test conditions and the splatter that hit the walls of the catch pan appeared to freeze upon impact. Most splatter particles adhered on the walls of the catch pan temporarily, indicating that the splatter did not freeze prior to contacting the catch pan walls. The splatter that adhered to the catch pan walls eventually fell off, a process that was accelerated when the catch pan was moved. Figure 36 provides still frames of visible video that was collected at different time points during the spilling of molten FLiNaK at an initial temperature of approximately $800^{\circ} \mathrm{C}$ into the spill containment box.

(A)

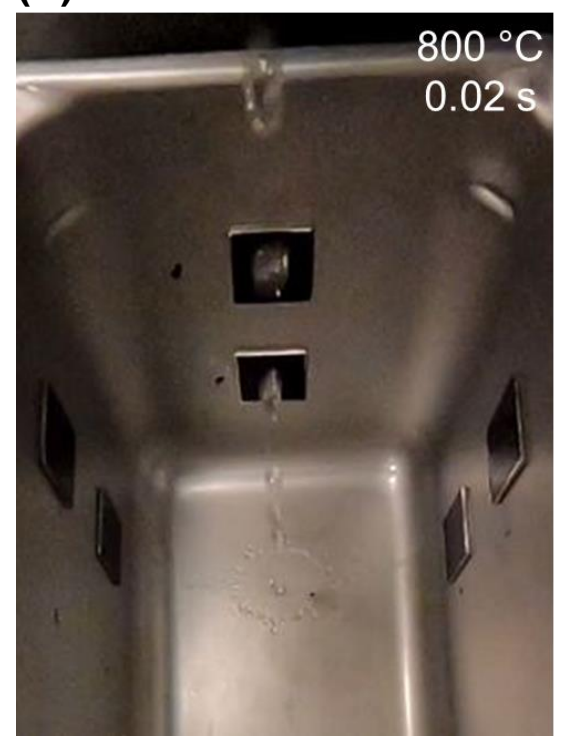

(B)

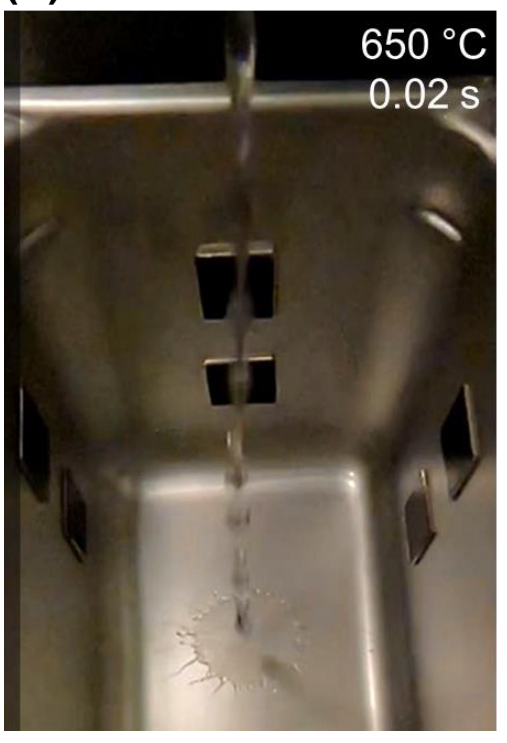

(C)

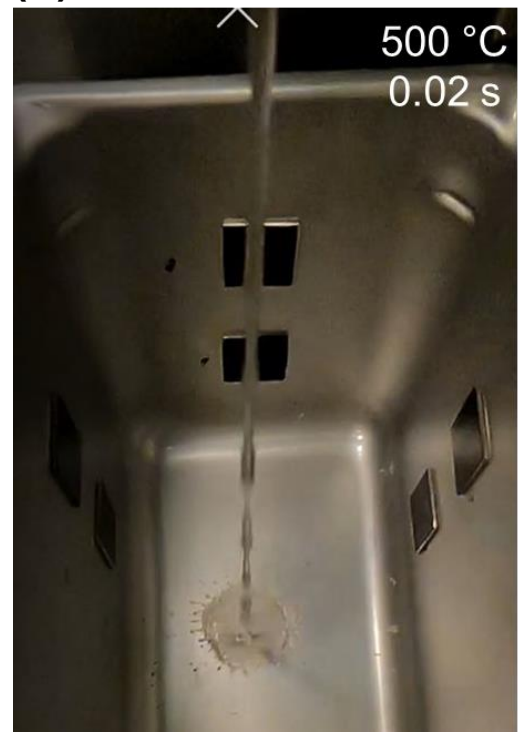

Figure 35: Still frames from the video taken of molten FLiNaK at an initial temperature of approximately (A) $800^{\circ} \mathrm{C}$, (B) $650^{\circ} \mathrm{C}$, and (C) $500^{\circ} \mathrm{C}$ pouring into the catch pan. Each still frame was taken approximately 0.02 seconds after the salt first touched the catch pan.

\subsubsection{Splashing quantification}

Figure 37 provides the layout and labels of nickel coupons that were hung on the walls of the catch pan surrounding the spill zone (Coupons $1-6$ ) to collect splatter for the determination of particle abundance and size distribution. A coupon on the wall furthest from the spill zone just below the aerosol collection filter (Coupon 7) was placed to collect aerosol particles that were suspended in the gas stream flowing towards the filter. 
(A)

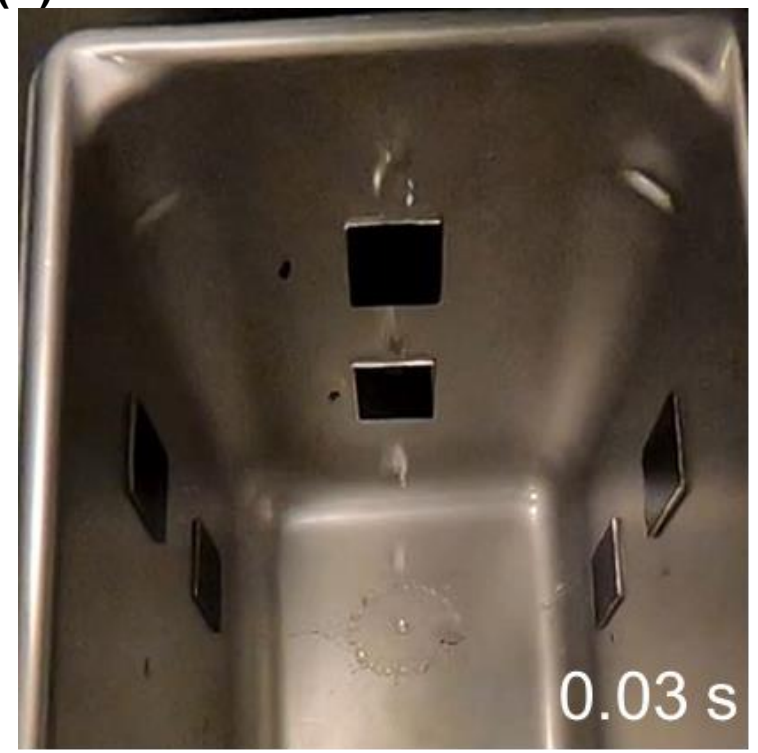

(C)

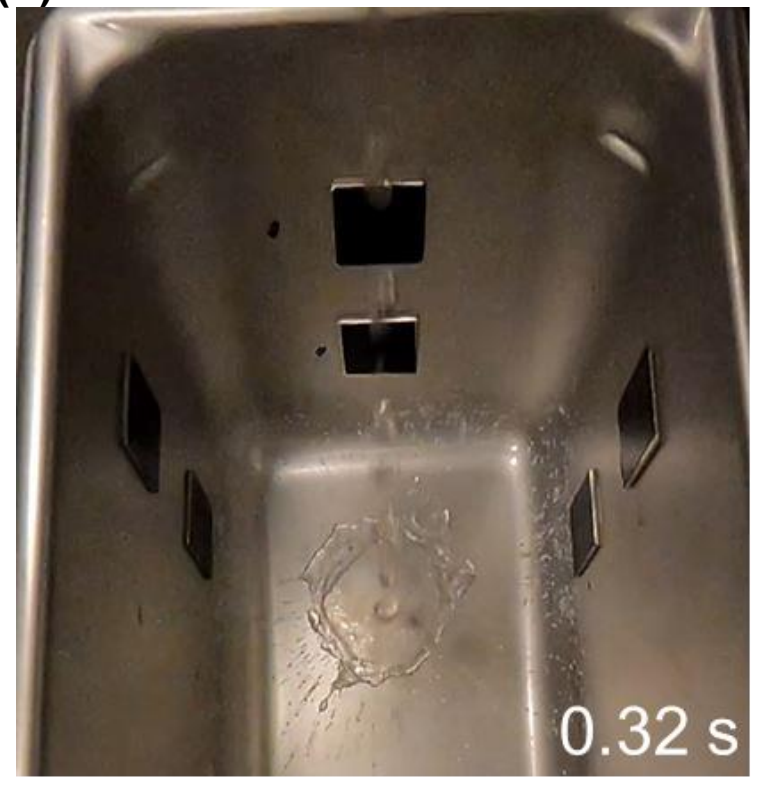

(B)

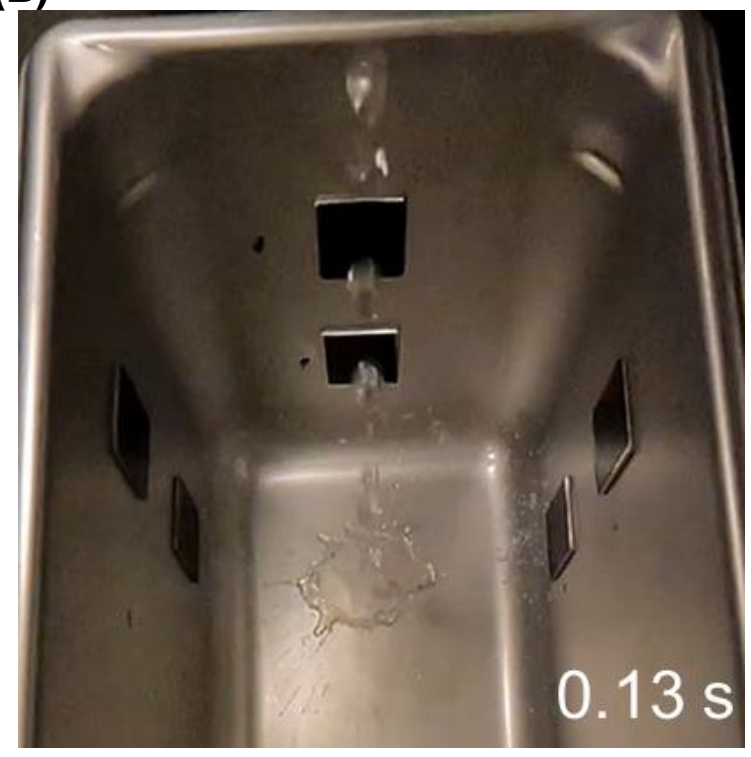

(D)

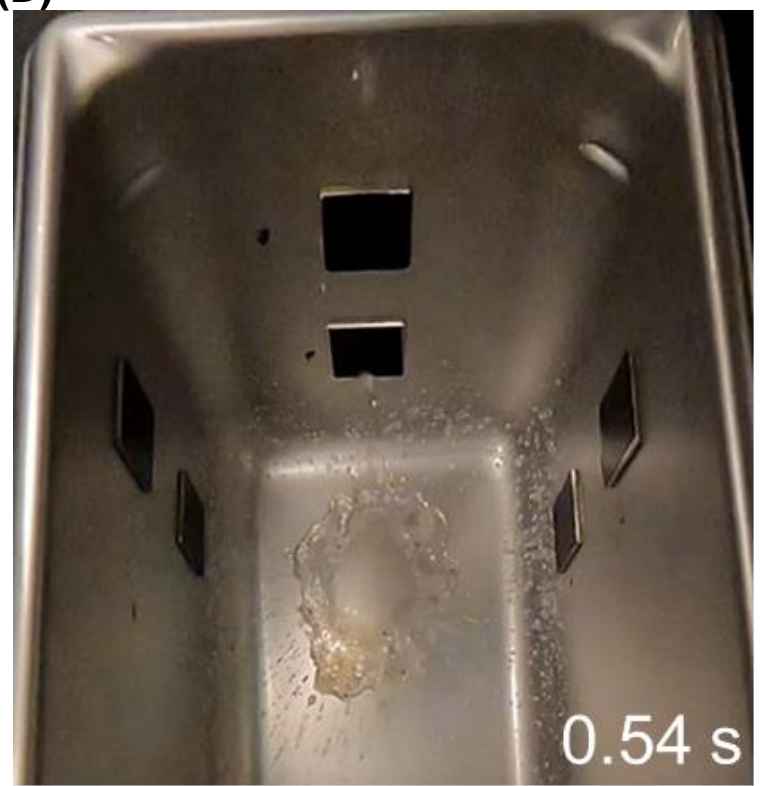

Figure 36: Still frames from the video taken of molten FLiNaK at an initial temperature of approximately $800^{\circ} \mathrm{C}$ pouring into the catch pan. The still frames were taken approximately (A) 0.03 seconds, (B) 0.13 seconds, (C) 0.32 seconds, and (D) 0.54 seconds after the salt first touched the catch pan floor.

Figure 38 shows images of wall furthest from the spill zone and Coupon 7 before and after $15 \mathrm{~g}$ of FLiNaK at an initial temperature of approximately $650^{\circ} \mathrm{C}$ was poured into the spill containment box. White salt particles adhered to the catch pan wall after the spill, with most particles concentrated towards the bottom of the wall (Figure 38B). A few small particles were detected on the upper portion of the wall and a small particle can be seen on Coupon 7 (Figure 38B). 


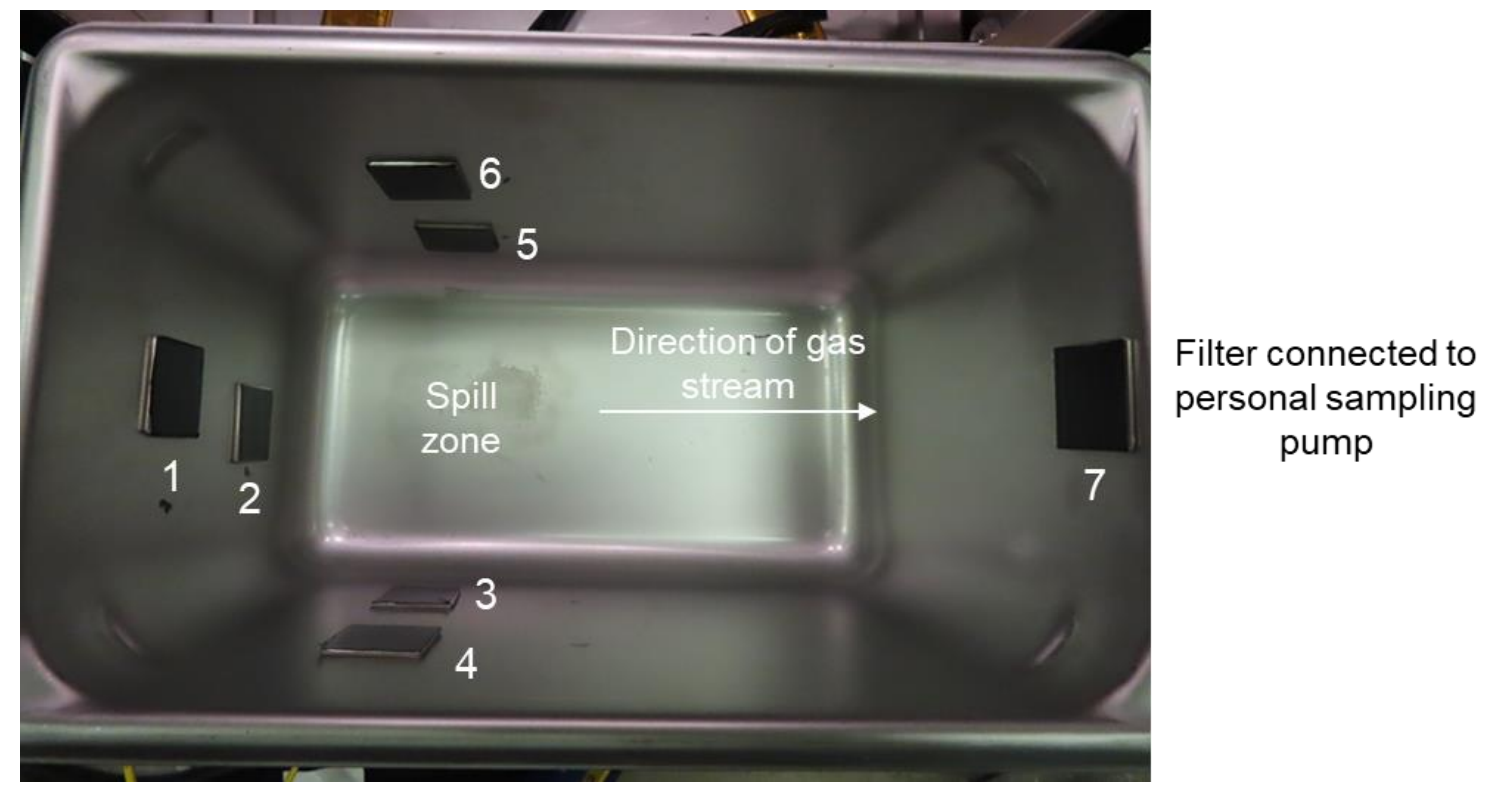

Figure 37: The coupon labels and locations in the catch pan relative to the salt spill zone. The filter for aerosol collection is positioned directly above Coupon 7 on the far wall from the spill zone and is connected to a pump set to a constant flow rate of $4 \mathrm{~L} \mathrm{~min}^{-1}$.

(A)

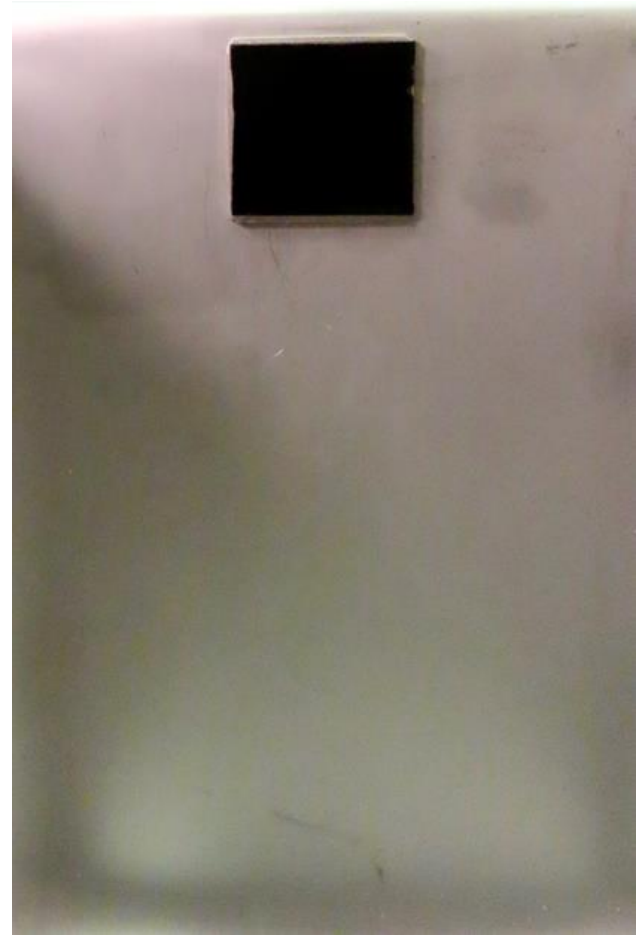

(B)

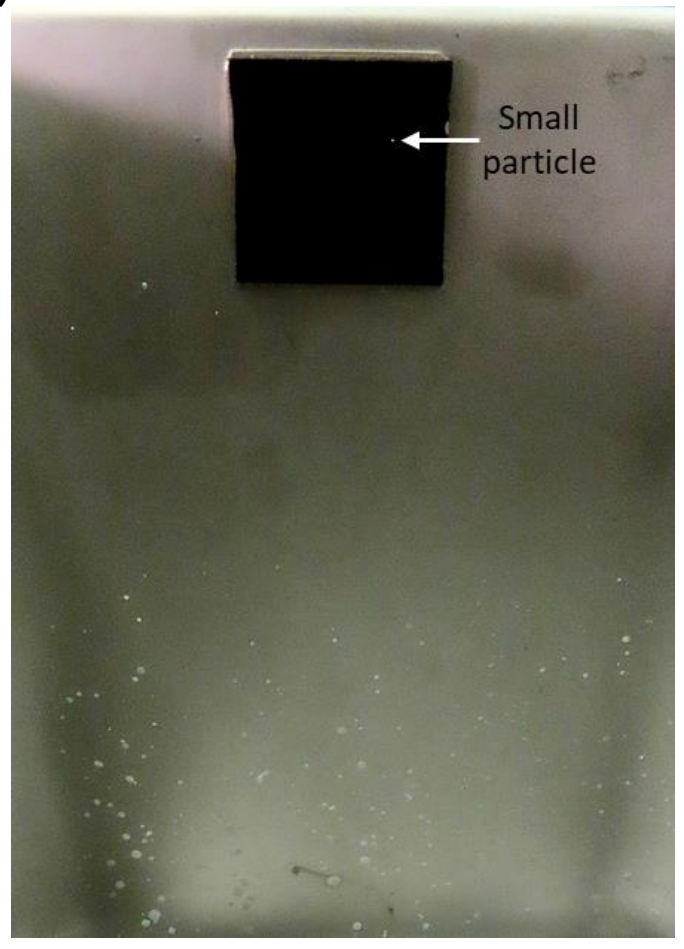

Figure 38: The far wall from the spill zone and Coupon 7 (A) before and (B) after spilling $15 \mathrm{~g}$ of FLiNaK at an initial temperature of approximately $650{ }^{\circ} \mathrm{C}$ into the spill containment box. The coupon dimension is 1 in $\times 1$ in. 
Figure 39 shows images of the wall near the spill zone that held Coupons 1 and 2 before and after $15 \mathrm{~g}$ of FLiNaK at an initial temperature of approximately $650{ }^{\circ} \mathrm{C}$ was poured into the spill containment box. White salt particles that adhered to the catch pan wall are seen concentrated towards the bottom of the wall and attached to Coupon 1 (Figure 39B). Fewer particles were observed towards the top of the wall and attached to Coupon 2 (Figure 39B).

(A)

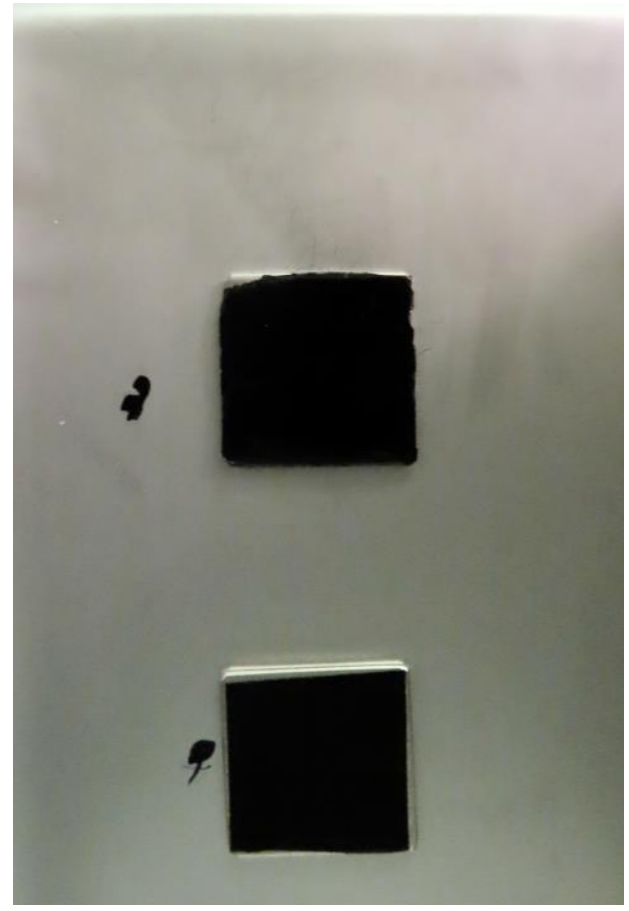

(B)

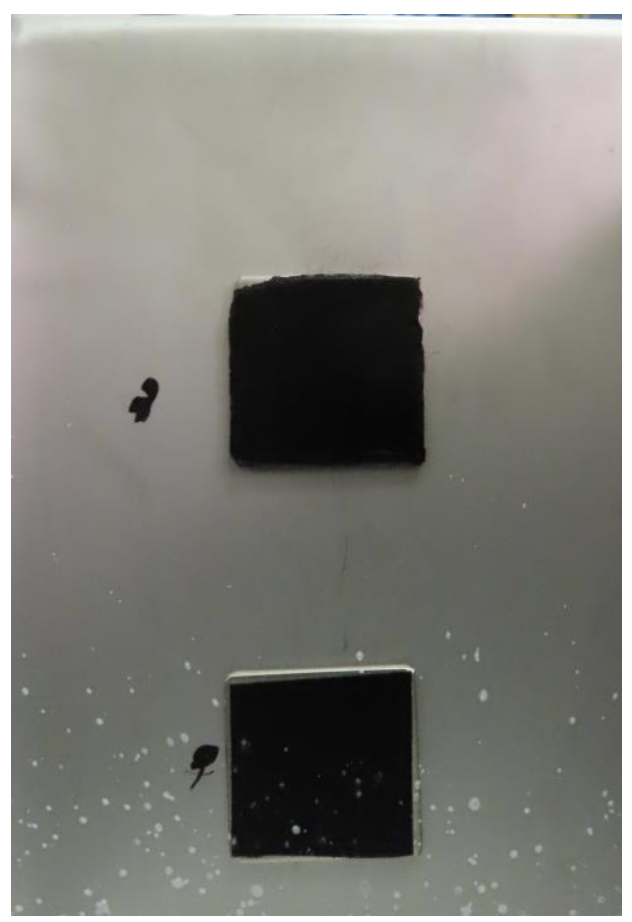

Figure 39: The wall near the spill zone containing Coupons 1 and $2(\mathrm{~A})$ before and $(\mathrm{B})$ after spilling $15 \mathrm{~g}$ of FLiNaK at an initial temperature of approximately $650{ }^{\circ} \mathrm{C}$ into the spill containment box. The coupon dimensions are 1 in $\times 1$ in.

The abundance and size distribution of particles adhered to coupons were determined from visible images taken of each coupon. This was achieved by converting each image into a binary image using the Image Processing Toolbox ${ }^{T M}$ in MATLAB® (as described in Section 6.1.2.7). Figure 40, Figure 41, and Figure 42 provide examples of the raw and processed images of particles adhered to coupons collected after pouring molten FLiNaK at an initial temperature of approximately $500{ }^{\circ} \mathrm{C}, 650^{\circ} \mathrm{C}$, and $800^{\circ} \mathrm{C}$ into the spill containment box, respectively.

The equivalent diameter (i.e., the diameter of the particle assuming it projects a perfect circle on the coupon) was determined from the particle area in $\mathrm{mm}^{2}$ and was the parameter used to compare particle size among different tests. The number of particles collected on coupons on the bottom halves of the walls near the spill zone (Coupons 2, 3, and 5), coupons on the top halves of the walls near the spill zone (Coupons 1, 4, and 6), and Coupon 7 were averaged for each test temperature and normalized to the total area analyzed. The results for the three regions are plotted as a function of size range in Figure 43A, Figure 43B, and Figure 43C, respectively. The smaller particles ( $\leq 250 \mu \mathrm{m}$ equivalent diameter) appear more abundant on the lower coupons near the 
(A)

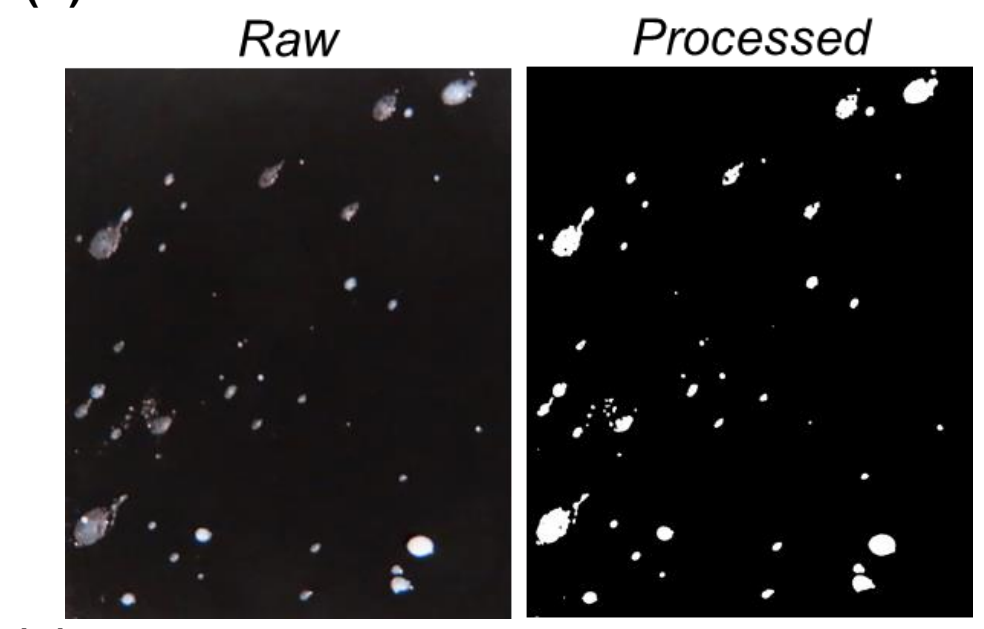

(B)

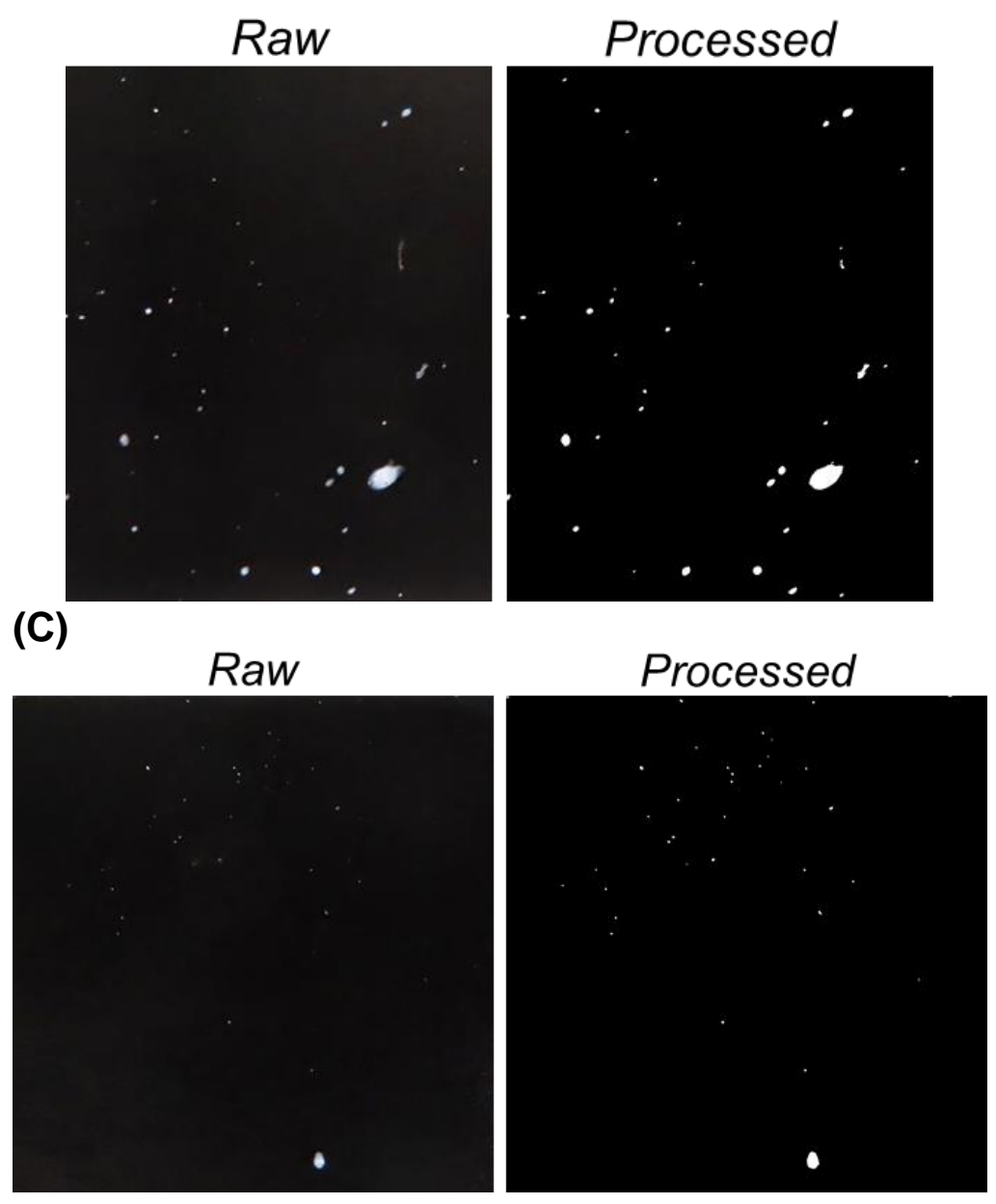

Figure 40: Examples of the raw and processed visible images of (A) Coupon 5, (B) Coupon 3, and (C) Coupon 7 after $15 \mathrm{~g}$ of FLiNaK at an initial temperature of approximately $500{ }^{\circ} \mathrm{C}$ was poured into the spill containment box (Test 2). The images were cropped prior to analysis. The dimensions of the cropped images were (A) $23.2 \mathrm{~mm} \times 18.8 \mathrm{~mm}$, (B) $22.7 \mathrm{~mm} \times 18.1 \mathrm{~mm}$, and (C) $20.6 \mathrm{~mm} \times 20.0 \mathrm{~mm}$. 
(A)

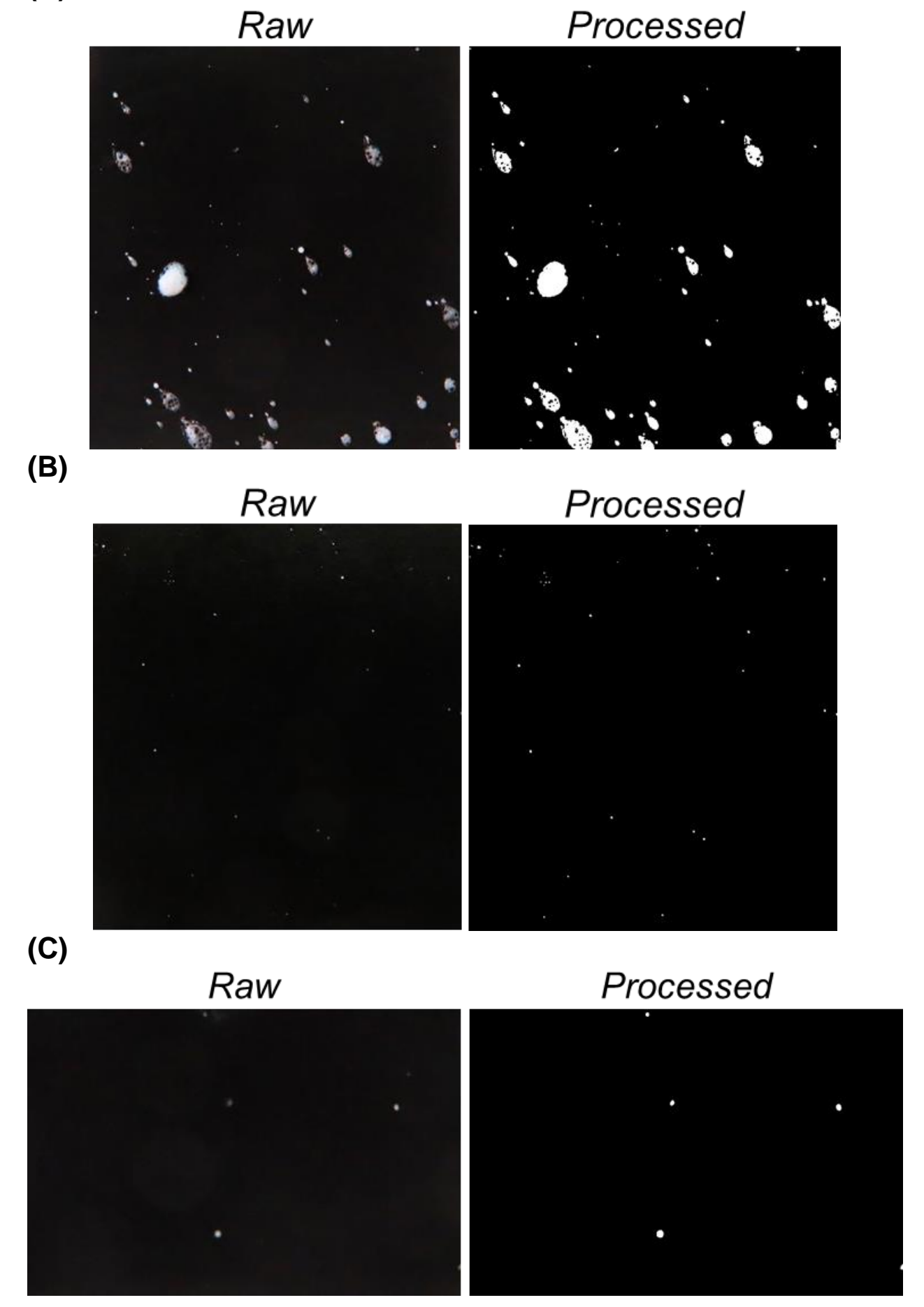

Figure 41: Examples of the raw and processed visible images of (A) Coupon 5, (B) Coupon 6, and (C) Coupon 7 after $15 \mathrm{~g}$ of FLiNaK at an initial temperature of approximately $650{ }^{\circ} \mathrm{C}$ was poured into the spill containment box (Test 4). The images were cropped prior to analysis. The dimensions of the cropped images were (A) $23.0 \mathrm{~mm} \times 21.2 \mathrm{~mm}$, (B) $22.4 \mathrm{~mm} \times 20.3 \mathrm{~mm}$, and (C) $13.0 \mathrm{~mm} \times 19.7 \mathrm{~mm}$. 
(A)
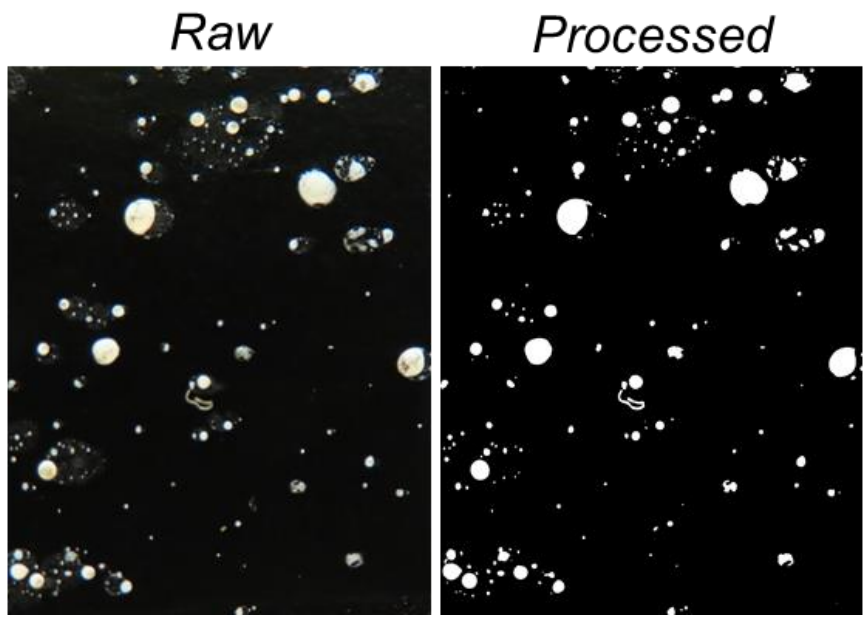

(B)

(C)
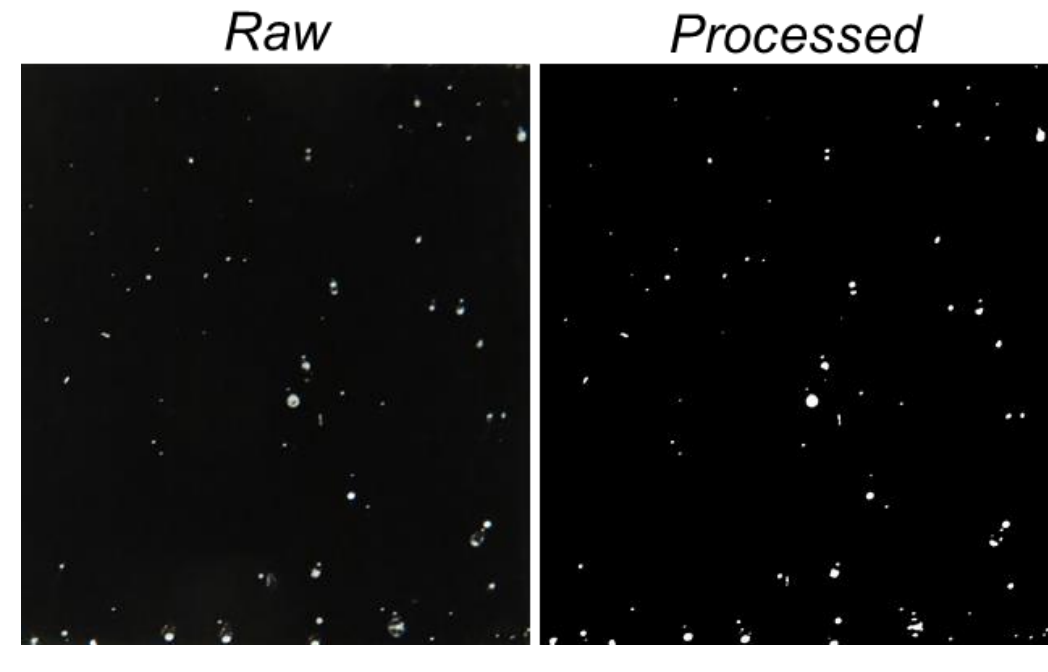

Raw

Processed
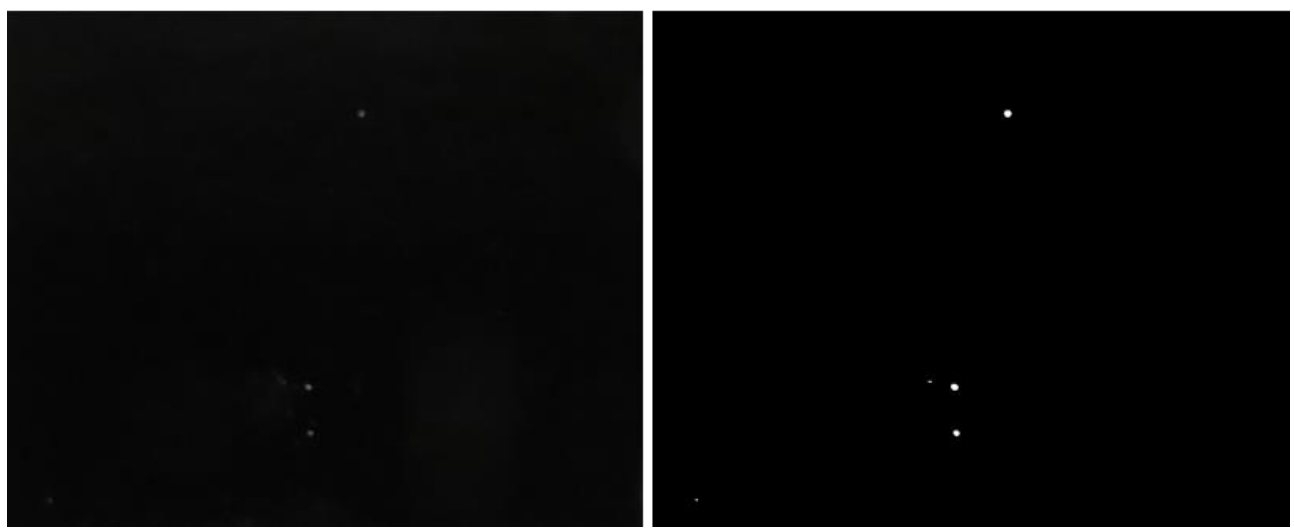

Figure 42: Examples of the raw and processed visible images of (A) Coupon 5, (B) Coupon 3, and (C) Coupon 7 after $15 \mathrm{~g}$ of FLiNaK at an initial temperature of approximately $800{ }^{\circ} \mathrm{C}$ was poured into the spill containment box (Test 5). The images were cropped prior to analysis. The dimensions of the cropped images were (A) $21.6 \mathrm{~mm} \times 16.6 \mathrm{~mm}$, (B) $23.7 \mathrm{~mm} \times 20.7 \mathrm{~mm}$, and (C) $19.0 \mathrm{~mm} \times 23.4 \mathrm{~mm}$. 
spill zone at higher salt temperatures (Figure 43A). In contrast, smaller particles $(\leq 100 \mu \mathrm{m}$ equivalent diameter) appear more abundant on the upper coupons near the spill zone at lower salt temperatures. Figure $43 \mathrm{C}$ indicates that more salt particles within the size range of $50 \mu \mathrm{m}$ to $250 \mu \mathrm{m}$ were collected on Coupon 7 at initial salt temperatures of $500^{\circ} \mathrm{C}$ and $650{ }^{\circ} \mathrm{C}$ than $800{ }^{\circ} \mathrm{C}$. Notably, relatively large salt particles adhered to the walls of the spill containment box above the catch pan during both replicate tests with an initial salt temperature of $500{ }^{\circ} \mathrm{C}$ (Figure 44). This behavior was not observed for any tests conducted using initial salt temperature of $650{ }^{\circ} \mathrm{C}$ or $800^{\circ} \mathrm{C}$.

(A)

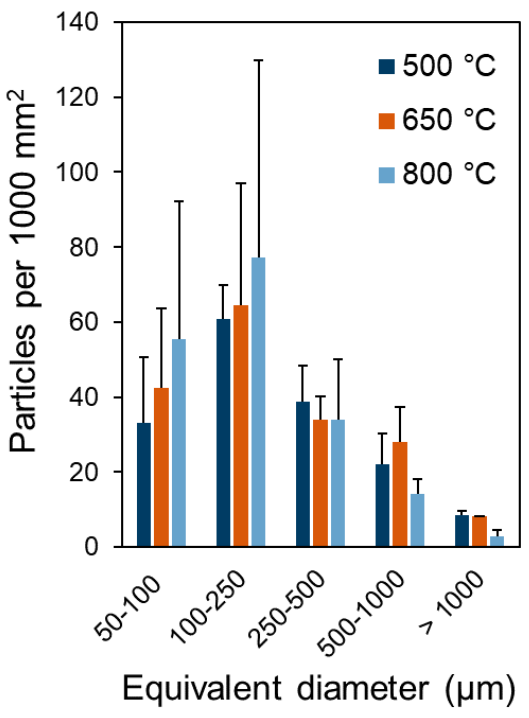

(B)

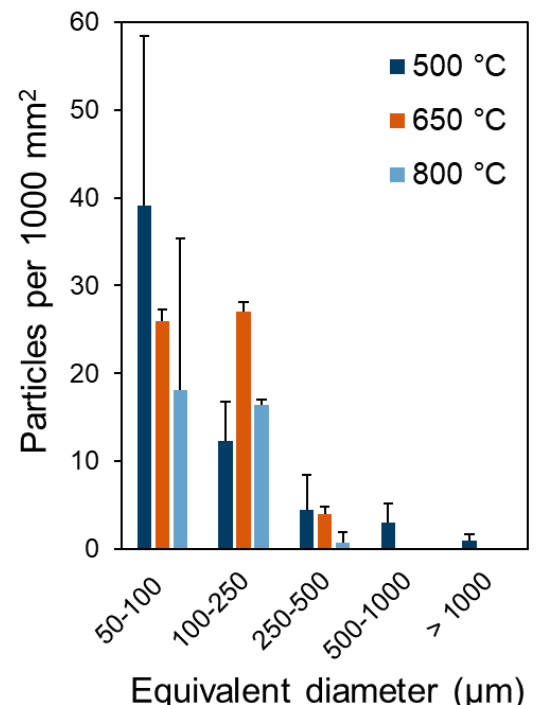

(C)

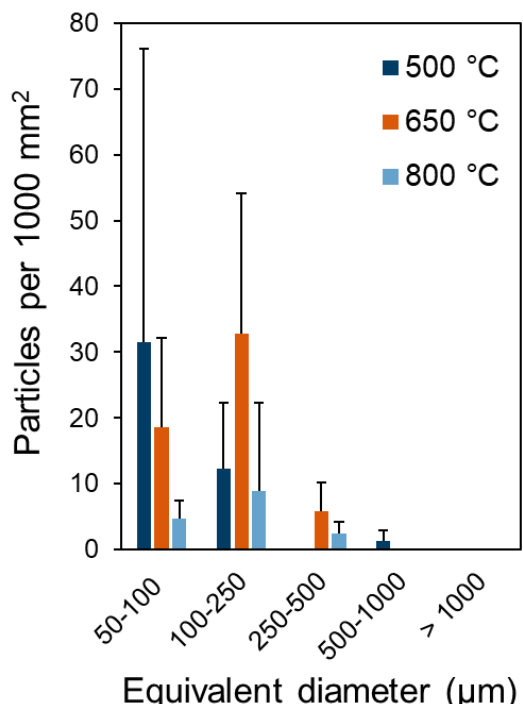

Figure 43: The number of particles within defined size ranges per $1000 \mathrm{~mm}^{2}$ that were collected on (A) the lower coupons near the spill zone (average of Coupons 2, 3, and 5), (B) the upper coupons near the spill zone (average of Coupons 1, 4, and 6), and (C) Coupon 7 on the far wall from the spill zone. The results are averages from replicate experiments at each initial salt temperature and the error bars represent one standard deviation.

The molten salt splashing behavior was also quantified as a function of initial salt temperature by determining the mass fractions of poured salt that pooled at the bottom of the catch pan and that formed splatter particles (Figure 45). The mass fraction of salt that was not recovered was determined by difference (Figure 45C) and includes splatter that adhered to the coupons, splatter that escaped the catch pan, and salt that aerosolized or vaporized. A clear trend is observed between the mass fraction of splatter and initial salt temperature where the most splatter was generated by salt with an initial temperature of $500^{\circ} \mathrm{C}$ (Figure 45B). The mass fraction of splatter decreases with temperature (Figure 45B). The mass fraction of poured salt that was not recovered also appears to be positively correlated with the initial salt temperature (Figure 45C), which could be attributed to more vaporization. 
(A)

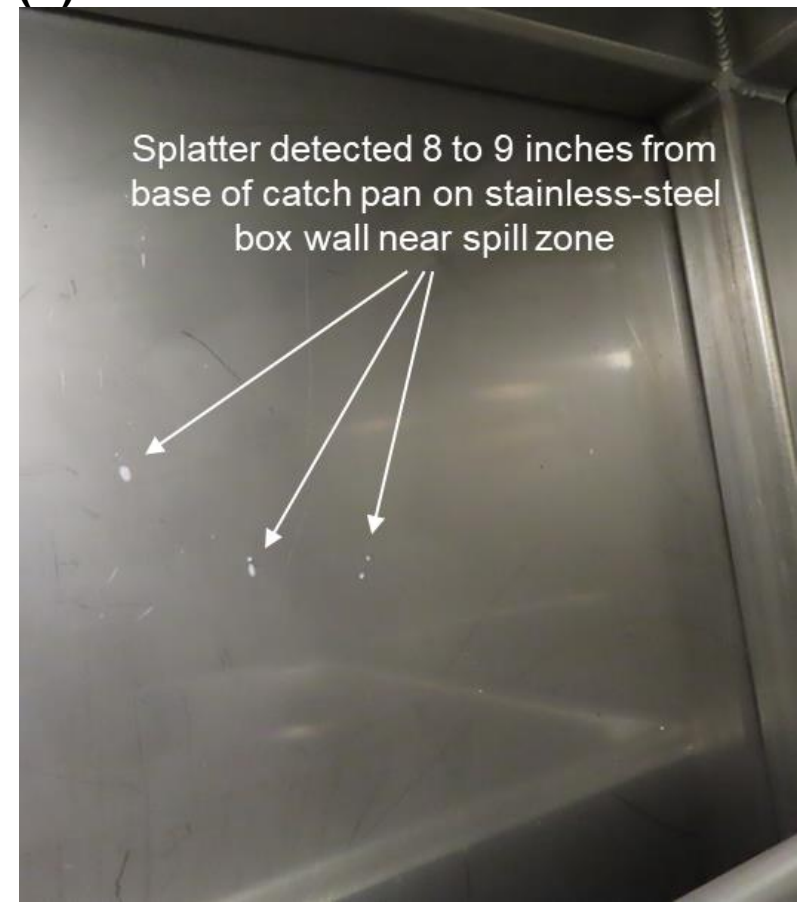

(B)

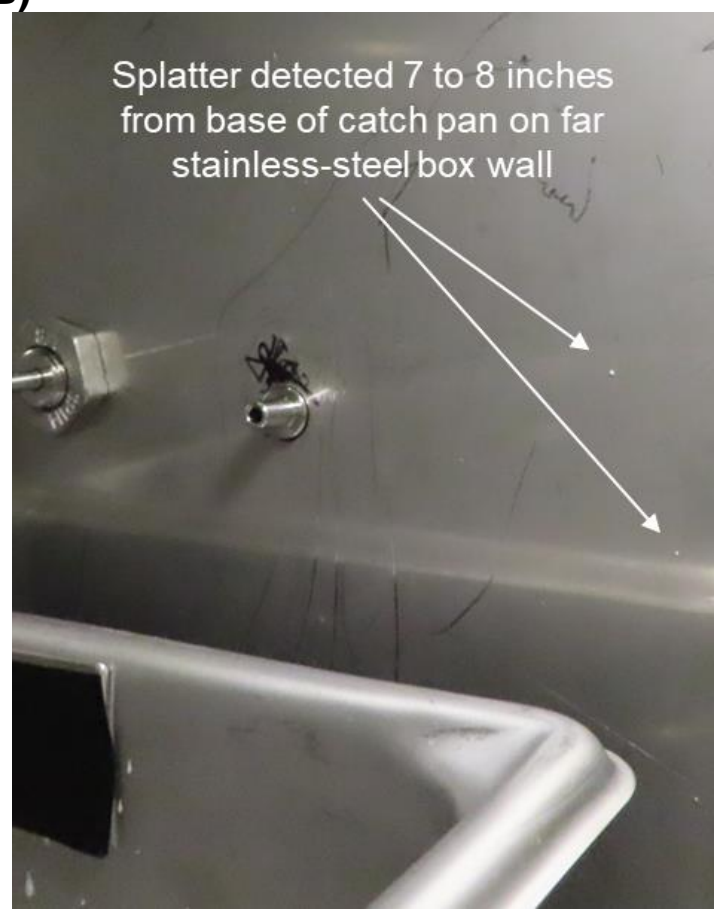

Figure 44: Large splatter droplets splashed outside of the stainless steel catch pan and adhered to the inner walls of the spill containment box for FLiNaK at an initial temperature of $500^{\circ} \mathrm{C}$ but not at $650^{\circ} \mathrm{C}$ or $800^{\circ} \mathrm{C}$. Significant splash height was observed (A) near the salt spill zone and (B) on the wall furthest from the salt spill zone.

(A)

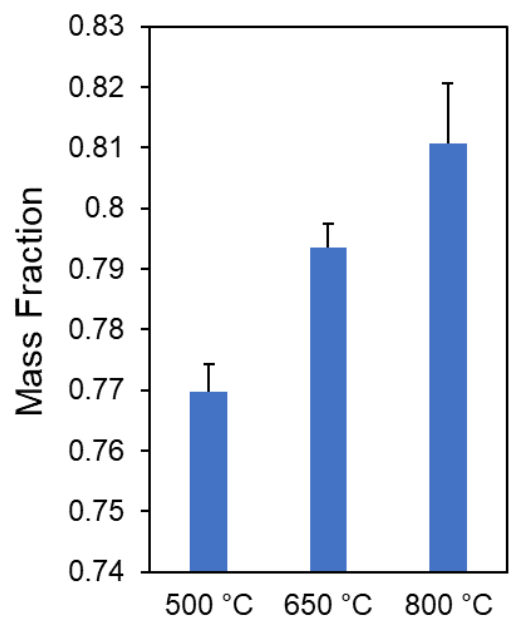

(B)

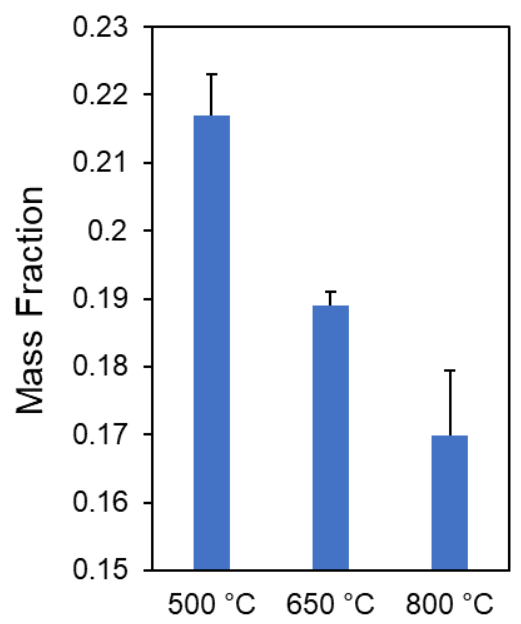

(C)

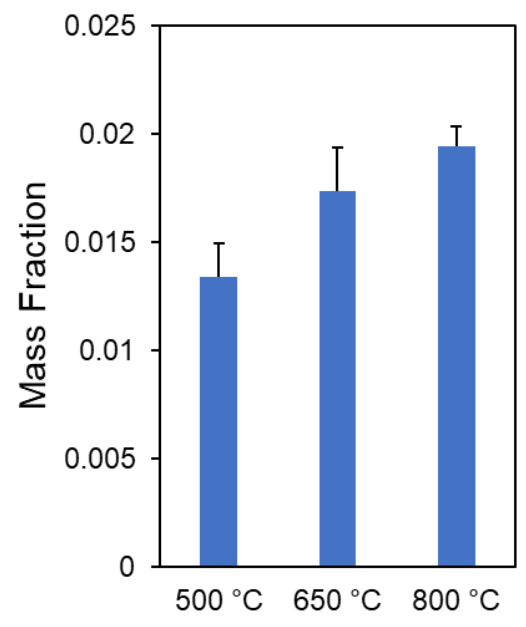

Figure 45: The fraction of the total mass poured that was $(A)$ collected as the pooled salt at the bottom of the catch pan, (B) collected as splatter particles, and (C) not recovered. The results are averages from replicate experiments at each initial salt temperature and the error bars are one standard deviation. 


\subsubsection{Mist production and aerosol collection on filters}

Mist was observed to form above the salt pool during the two replicate tests with FLiNaK containing cesium and iodine at an initial temperature of $800^{\circ} \mathrm{C}$. The mist was captured on video moving towards the $0.45 \mu \mathrm{m}$ PTFE filter through which the spill containment box atmosphere was flowing at a rate of $4 \mathrm{~L} \mathrm{~min}^{-1}$. Still frames from the visible video show wisps of mist in the atmosphere above the spilled salt pool (Figure 46B and Figure 46C). A still frame with no observable mist is provided for comparison (Figure 46A).

Mist was also observed above the salt pool during the two replicate tests with FLiNaK containing cesium and iodine at an initial temperature of $650^{\circ} \mathrm{C}$, albeit to a lesser extent than tests conducted at initial temperature of $800{ }^{\circ} \mathrm{C}$. Mist was not observed on the visible video when FLiNaK without cesium and iodine was poured into the box at an initial temperature of $800{ }^{\circ} \mathrm{C}$ or when FLiNaK containing cesium and iodine was poured into the box at an initial temperature of $500{ }^{\circ} \mathrm{C}$.

(A)

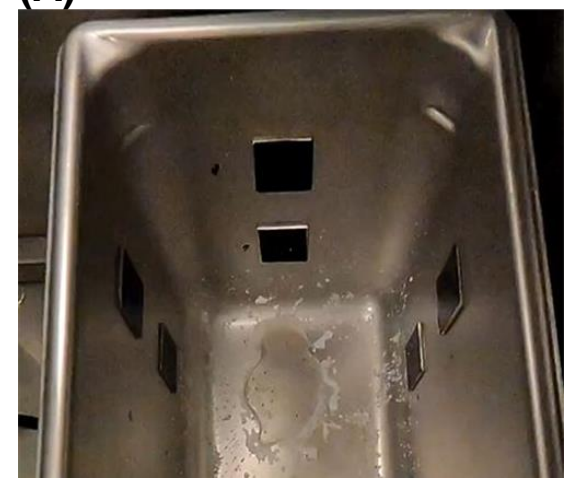

(B)

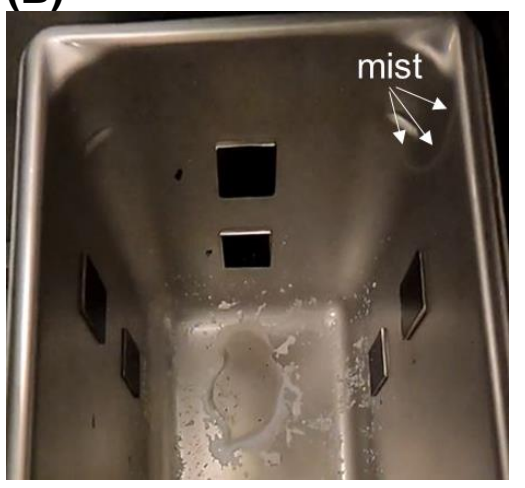

(C)

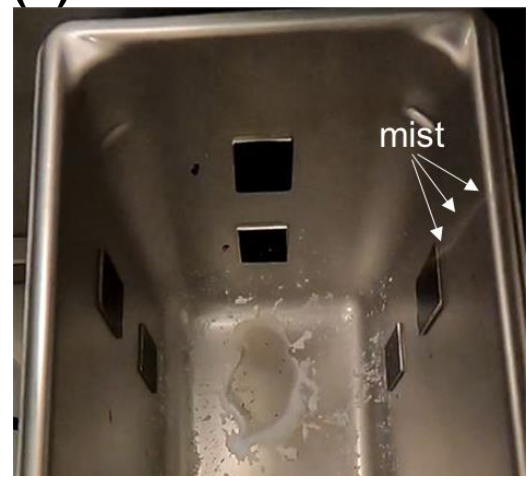

Figure 46: Still frames from video recorded of the catch pan after spilling $15 \mathrm{~g}$ of FLiNaK containing cesium and iodine at an initial temperature of approximately $800^{\circ} \mathrm{C}$ into the spill containment box. The still frames were taken (A) 5 seconds, (B) 14 seconds, and (C) 20 seconds after the salt was spilled. Subplot $A$ shows the absence of mist and subplots $B$ and $C$ show wisps of mist floating towards the filter, which is positioned below the photographs outside of the field of view.

Aerosol cassettes with $0.45 \mu \mathrm{m}$ pore size PTFE filters were used to sample the spill containment box atmosphere for suspended particulates (e.g., the mist that was observed on video). Aerosols were collected on filters for these initial tests so that the conditions of the system could be better understood before more costly methods for aerosol collection were employed. The compositional analysis of collected particulates is provided in Table 13.

The Blank in Table 13 was a filter that was removed from its packaging and directly analyzed, and the Control in Table 13 was a filter that sampled the spill containment box for 10 minutes to obtain a background composition of the glovebox atmosphere. Of the major cations, lithium was below the detection level for all tests and controls and sodium and potassium were detected at similar amounts for all tests, regardless of the initial salt temperature. The amount of sodium detected on the control filter was not significantly different than the amount of sodium on the test filters. A large amount of sodium was detected on the filter for Test 2 relative to the other tests, but the fact that 
Table 13: Elemental composition of particulates collected on $0.45 \mu \mathrm{m}$ filters ${ }^{a, b}$

\begin{tabular}{cccccccc}
\hline Test No. $^{c}$ & $\begin{array}{c}\text { Target initial } \\
\text { temp. }\left({ }^{\circ} \mathrm{C}\right)\end{array}$ & $\begin{array}{c}\mathrm{CsF} \text { and } \\
\mathrm{Csl} \text { added }\end{array}$ & $\begin{array}{c}\mathrm{Li} \\
(\mu \mathrm{g})\end{array}$ & $\begin{array}{c}\mathrm{Na} \\
(\mu \mathrm{g})\end{array}$ & $\begin{array}{c}\mathrm{K} \\
(\mu \mathrm{g})\end{array}$ & $\begin{array}{c}\mathrm{Cs} \\
(\mu \mathrm{g})\end{array}$ & $\begin{array}{c}\mathrm{I} \\
(\mu \mathrm{g})\end{array}$ \\
\hline Blank $^{\mathrm{d}}$ & $\mathrm{n} / \mathrm{a}$ & $\mathrm{n} / \mathrm{a}$ & $<0.12$ & 0.63 & $<0.48$ & $<0.002$ & $<0.02$ \\
Control $^{\mathrm{e}}$ & $\mathrm{n} / \mathrm{a}$ & $\mathrm{n} / \mathrm{a}$ & $<0.01$ & 1.74 & $<0.55$ & 0.01 & $<0.03$ \\
1 & 500 & $\mathrm{Y}$ & $<0.01$ & 1.30 & 0.65 & 0.12 & $<0.03$ \\
2 & 500 & $\mathrm{Y}$ & $<0.12$ & 40.5 & $<0.48$ & 0.14 & $<0.02$ \\
3 & 650 & $\mathrm{Y}$ & $<0.01$ & 2.29 & 1.97 & 0.41 & $<0.03$ \\
4 & 650 & $\mathrm{Y}$ & $<0.12$ & 0.88 & $<0.48$ & 0.33 & $<0.05$ \\
5 & 800 & $\mathrm{Y}$ & $<0.01$ & 1.45 & 1.44 & 1.76 & 0.15 \\
7 & 800 & $\mathrm{~N}$ & $<0.01$ & 1.82 & 1.40 & 0.01 & $<0.03$ \\
\hline
\end{tabular}

${ }^{\mathrm{a}}$ The number following the $<$ is the detection limit.

${ }^{\mathrm{b}}$ The total mass of particulates collected on the filter was too small to measure

${ }^{c}$ A filter measurement was not conducted for Test 6 at an initial salt target temperature of $800{ }^{\circ} \mathrm{C}$ because aerosols were collected using cascade impactors instead.

${ }^{d}$ The composition of the blank filter was measured directly after removal from its packaging.

e The control filter sampled the background glovebox atmosphere for 10 minutes before any FLiNaK splash tests were conducted.

large amounts of lithium and potassium were not detected indicates the sodium likely came from a source other than the spilled FLiNaK. The amount of potassium detected on the control filter was below the detection limit of the method (approximately $0.5 \mu \mathrm{g}$ ). Some potassium was detected for Tests $1,3,5$, and 7 , but the amount of potassium detected was not reproducible for replicate test conditions and does not appear to be correlated with the initial salt temperature.

Notably, the fraction of cesium detected on the test filters increased with increasing initial salt temperature (Table 13). The amounts of iodine on the control and test filters were below the detection limit of $0.03-0.05 \mu \mathrm{g}$ except for the one test conducted with FLiNaK containing cesium and iodine at an initial salt temperature of $800^{\circ} \mathrm{C}$, for which $0.15 \mu \mathrm{g}$ of iodine was detected (Table 13). The ratio of cesium to iodine detected on the filter of Test 5 is approximately 10 , which is consistent with the ratio of cesium to iodine present in the initial salt batch. Replicate tests with FLiNaK containing cesium and iodine at $800^{\circ} \mathrm{C}$ will be conducted in future experiments.

\subsubsection{Temperatures measured in the spill containment box}

Figure 47 provides an example of the temperatures measured in the spill containment box after spilling $15 \mathrm{~g}$ of FLiNaK containing cesium and iodine at an initial temperature of approximately $650^{\circ} \mathrm{C}$ (i.e., Test 3). The maximum temperature that was reached at the underside of the catch pan within the salt spill zone was approximately $250^{\circ} \mathrm{C}$ (Figure 47A). The thickness of the salt pool at the bottom of the catch pan was $2.2 \pm 0.6 \mathrm{~mm}$ for Test 3 . The temperature of the atmosphere of the spill containment box remained relatively constant after pouring molten salt for Test 3 (Figure 47B). The temperature of the atmosphere of the spill containment box was relatively low for all tests described in this section. The maximum temperature recorded at the filter inlet by Thermocouple 4 (TC4) was $34^{\circ} \mathrm{C}$ during a test with an initial salt temperature of $800{ }^{\circ} \mathrm{C}$. 

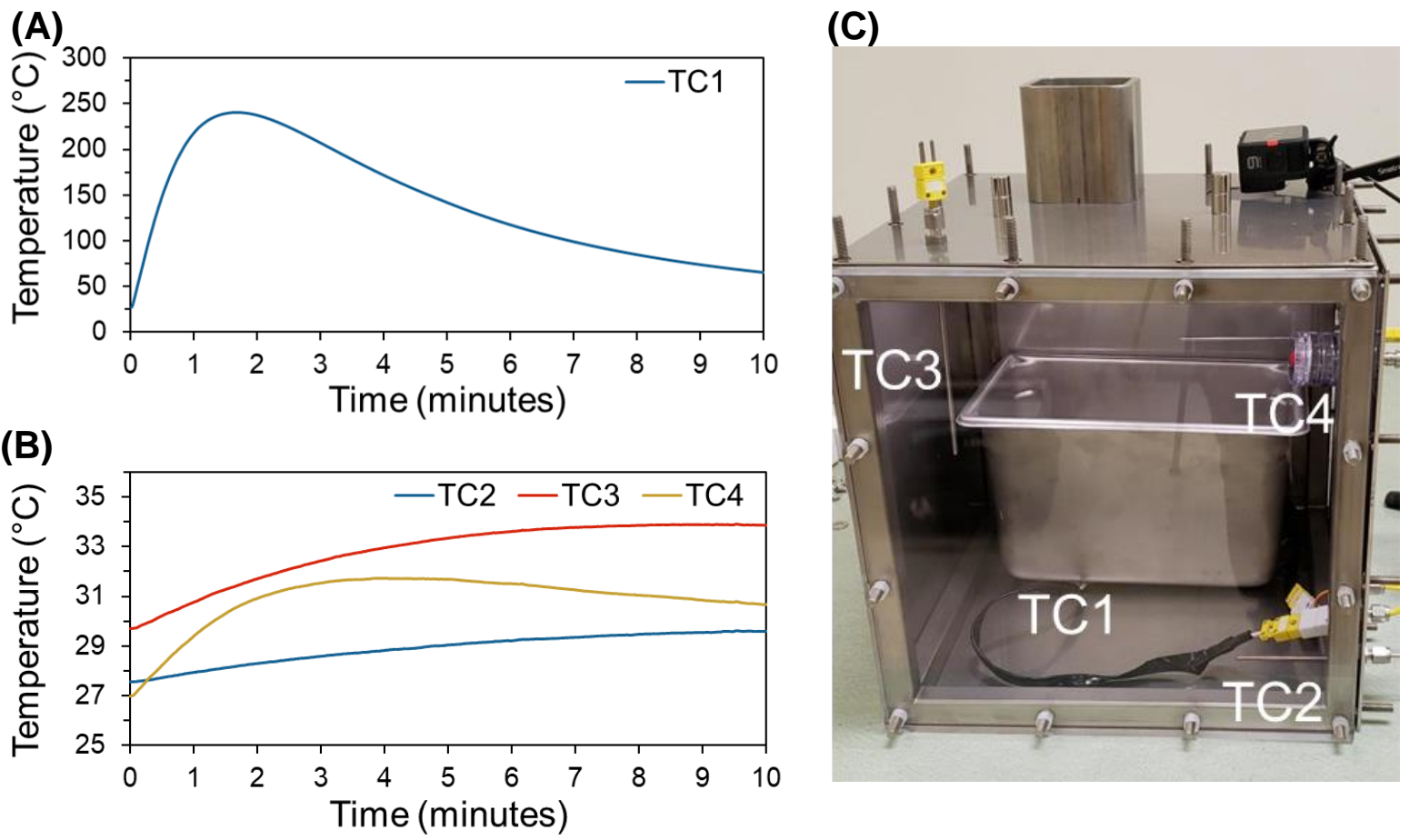

Figure 47: The temperature recorded at $(A)$ the underside of the catch pan and $(B)$ various locations in the spill containment box atmosphere after spilling $15 \mathrm{~g}$ of FLiNaK containing cesium and iodine at an initial temperature of approximately $650^{\circ} \mathrm{C}$. (C) Photograph showing the thermocouple locations within the spill containment box. TC4 recorded the temperature of the atmosphere near the filter inlet.

\subsubsection{Salt composition analysis by ICP-MS}

Table 14 and Table 15 provide the total concentrations of major elements (lithium, sodium, potassium, cesium, and iodine) and trace metals, respectively, that were measured in the salt after splashing as a function of initial salt temperature. The concentrations were averaged for replicate experiments with the same target initial salt temperature and sampling location, which included the salt that pooled at the bottom of the catch pan (pool) and the splatter particles that dispersed within the catch pan (splatter).

\subsubsection{Composition of condensation on ceiling of spill containment box}

The ceiling of the spill containment box was wiped with a methanol-soaked glass fiber filter and analyzed by using ICP-MS to determine the composition of condensed vapor that may have been deposited. Table 16 provides the elemental composition of a blank filter, a control filter, and the sample filter. The blank filter was removed from its packaging and directly analyzed, and the control filter was soaked in methanol and then analyzed. Lithium and cesium were detected in amounts that were significantly greater in the sample than in the blank or control. The amounts of sodium and potassium detected in the sample were approximately the same as on the blank and control. The iodine detected on the sample filter was probably from the methanol and not from wiping the spill containment box ceiling because the control had a similar amount of iodine. 
Table 14: Composition of frozen salt samples collected from splash tests ${ }^{a}$

\begin{tabular}{cccccccc}
\hline $\begin{array}{c}\text { Target initial } \\
\text { temp. }\left({ }^{\circ} \mathrm{C}\right)\end{array}$ & $\begin{array}{c}\text { CsF and } \\
\text { Csl added }\end{array}$ & $\begin{array}{c}\text { Sample } \\
\text { type }\end{array}$ & $\begin{array}{c}\mathrm{LiF} \\
(\mathrm{mol} \%)\end{array}$ & $\begin{array}{c}\mathrm{NaF} \\
(\mathrm{mol} \%)\end{array}$ & $\begin{array}{c}\mathrm{KF} \\
(\mathrm{mol} \%)\end{array}$ & $\begin{array}{c}\mathrm{CsF} \\
(\mathrm{mol} \%)\end{array}$ & $\begin{array}{c}\mathrm{CsI}^{\mathrm{b}} \\
(\mathrm{mol} \%)\end{array}$ \\
\hline \multirow{2}{*}{500} & $\mathrm{Y}$ & Splatter & $47 \pm 2$ & $11.4 \pm 0.2$ & $41 \pm 2$ & $0.9 \pm 0.1$ & $0.09 \pm 0.005$ \\
& & Pool & $48 \pm 2$ & $11.4 \pm 0.2$ & $40 \pm 2$ & $0.9 \pm 0.1$ & $0.08 \pm 0.001$ \\
650 & $\mathrm{Y}$ & Splatter & $47 \pm 1$ & $11.6 \pm 0.1$ & $40 \pm 1$ & $0.9 \pm 0.1$ & $0.10 \pm 0.02$ \\
& & Pool & $47 \pm 2$ & $11.6 \pm 0.4$ & $41 \pm 2$ & $0.9 \pm 0.1$ & $0.10 \pm 0.02$ \\
800 & $\mathrm{Y}$ & Splatter & $46.6 \pm 0.9$ & $11.4 \pm 0.4$ & $41 \pm 1$ & $0.9 \pm 0.02$ & $0.11 \pm 0.005$ \\
& & Pool & $48 \pm 2$ & $11.3 \pm 0.01$ & $40 \pm 2$ & $0.9 \pm 0.01$ & $0.12 \pm 0.002$ \\
$800^{\circ}$ & $\mathrm{N}$ & Splatter & 50.6 & 11.0 & 38.5 & $\mathrm{n} / \mathrm{a}$ & $\mathrm{n} / \mathrm{a}$ \\
& & Pool & 49.3 & 11.3 & 39.4 & $\mathrm{n} / \mathrm{a}$ & $\mathrm{n} / \mathrm{a}$ \\
\hline
\end{tabular}

a The reported values are mean \pm one standard deviation.

${ }^{b} \mathrm{Mol} \%$ of Csl was calculated assuming all detected iodine was present as Csl.

${ }^{\mathrm{c}}$ Replicate tests for this condition were not conducted.

Table 15: Trace metal composition of frozen salt samples collected from splash tests ${ }^{a, b, c}$

\begin{tabular}{ccccccc}
\hline $\begin{array}{c}\text { Target initial } \\
\text { temp. }\left({ }^{\circ} \mathrm{C}\right)\end{array}$ & $\begin{array}{c}\text { CsF and } \\
\text { Csl added }\end{array}$ & $\begin{array}{c}\text { Sample } \\
\text { type }\end{array}$ & $\begin{array}{c}\mathrm{Mn} \\
(\mathrm{ppm})\end{array}$ & $\begin{array}{c}\mathrm{Ni} \\
(\mathrm{ppm})\end{array}$ & $\begin{array}{c}\mathrm{Rb} \\
(\mathrm{ppm})\end{array}$ & $\begin{array}{c}\mathrm{Cs}^{\mathrm{d}} \\
(\mathrm{ppm})\end{array}$ \\
\hline \multirow{2}{*}{500} & $\mathrm{Y}$ & Splatter & $1.3 \pm 0.01$ & $45 \pm 4$ & $25.0 \pm 0.5$ & $\mathrm{n} / \mathrm{a}$ \\
& & Pool & $2 \pm 1$ & $27 \pm 2$ & $24.8 \pm 0.2$ & $\mathrm{n} / \mathrm{a}$ \\
650 & $\mathrm{Y}$ & Splatter & $5 \pm 3$ & $52 \pm 60$ & $24.7 \pm 0.1$ & $\mathrm{n} / \mathrm{a}$ \\
& & Pool & $2.5 \pm 0.4$ & $120 \pm 90$ & $24.1 \pm 0.8$ & $\mathrm{n} / \mathrm{a}$ \\
800 & $\mathrm{Y}$ & Splatter & $18 \pm 20$ & $24.3 \pm 0.01$ & $24 \pm 2$ & $\mathrm{n} / \mathrm{a}$ \\
& & Pool & $4.1 \pm 0.5$ & $24 \pm 3$ & $24.7 \pm 0.6$ & $\mathrm{n} / \mathrm{a}$ \\
$800^{\circ}$ & $\mathrm{N}$ & Splatter & 4.5 & $<0.5$ & 25.4 & 38.9 \\
& & Pool & 6.1 & $<0.7$ & 23.8 & 13.2 \\
\hline
\end{tabular}

a The concentrations of $\mathrm{Ca}, \mathrm{Fe}$, and $\mathrm{Cr}$ in all samples were below the detection limits of $400 \mathrm{ppm}$, 70 ppm, and 3 ppm, respectively.

${ }^{b}$ The results are averages from replicate tests and the error is one standard deviation.

c The number after $<$ is the detection limit.

d The Cs concentration of FLiNaK doped with CsF and Csl is reported in Table 14.

e Replicate tests were not conducted.

Table 16: Elemental composition of wipe sample from ceiling of spill containment box ${ }^{a}$

\begin{tabular}{cccccc}
\hline Test No. & $\mathrm{Li}(\mu \mathrm{g})$ & $\mathrm{Na}(\mu \mathrm{g})$ & $\mathrm{K}(\mu \mathrm{g})$ & $\mathrm{Cs}(\mu \mathrm{g})$ & $\mathrm{I}(\mu \mathrm{g})$ \\
\hline Blank $^{\mathrm{b}}$ & $<0.14$ & 166 & 7.6 & $<0.003$ & $<0.03$ \\
Control $^{\mathrm{c}}$ & $<0.16$ & 174 & 9.7 & 0.05 & 0.17 \\
Sample & 2.00 & 102 & 10.6 & 0.23 & 0.13 \\
\hline
\end{tabular}

${ }^{a}$ The number following the $<$ is the detection limit.

${ }^{\mathrm{b}}$ The Blank was a wipe that was removed from its packaging and directly analyzed.

${ }^{c}$ The Control was a wipe that was soaked in methanol and then analyzed. 


\subsubsection{Splatter and aerosol particle composition by SEM-EDS}

Several SEM-EDS X-ray emission maps of the large splatter particles (> $100 \mu \mathrm{m}$ diameter) deposited on coupons after the splash test were acquired to assess the distribution of elements within the particles. In general, the major elements present in the salt that could be detected by EDS (i.e., sodium, potassium, fluorine, cesium, and iodine) were homogeneously distributed throughout the larger splatter particles. Figure 48 provides an example of the elemental distributions obtained from an EDS X-ray emission map of a splatter particle collected on the

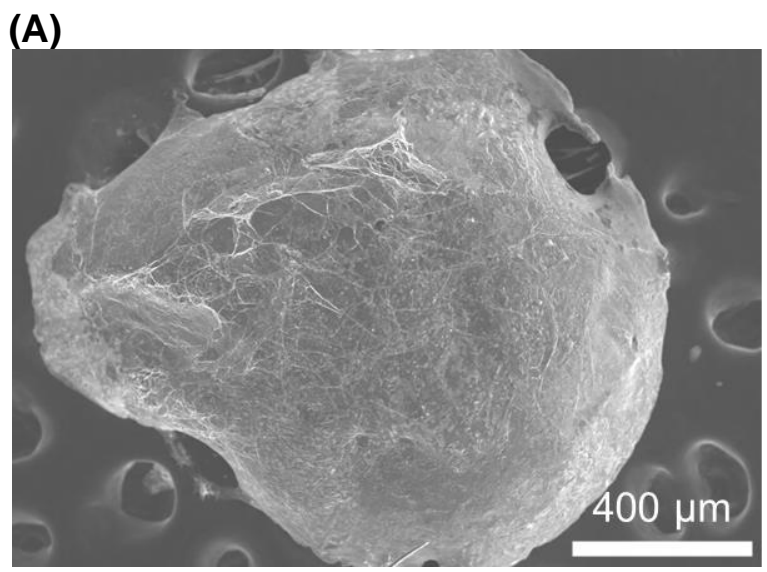

(C)

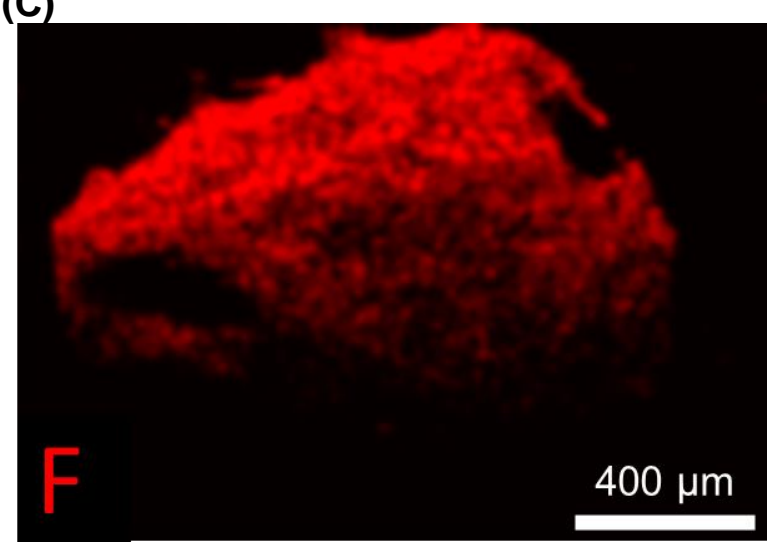

(E)

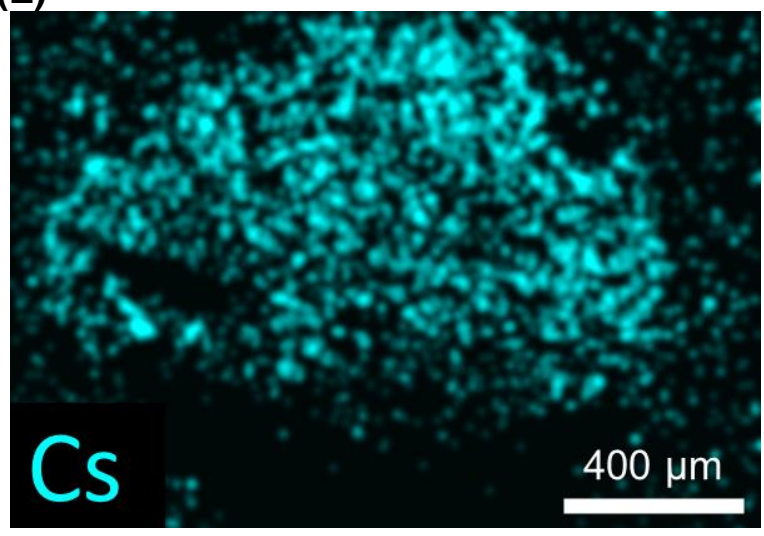

(B)

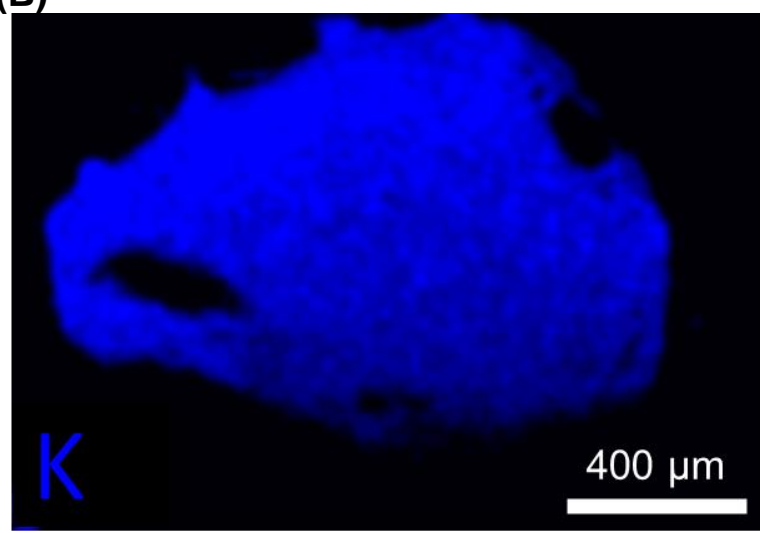

(D)

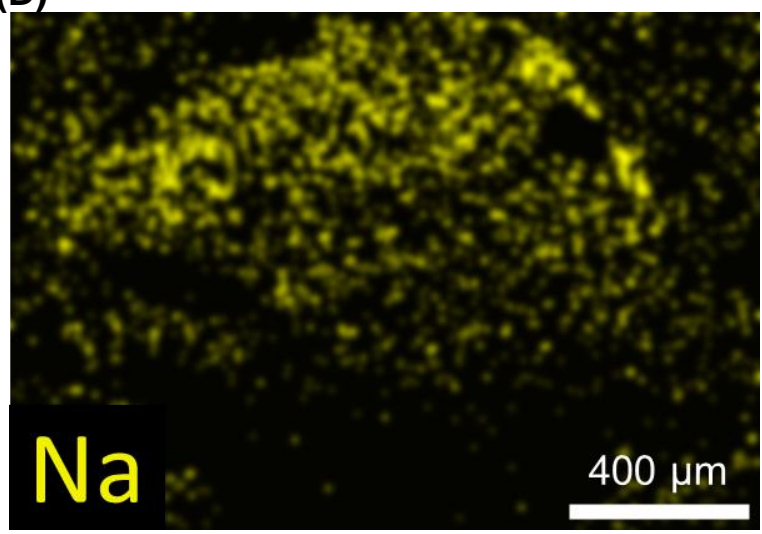

$(\bar{F})$

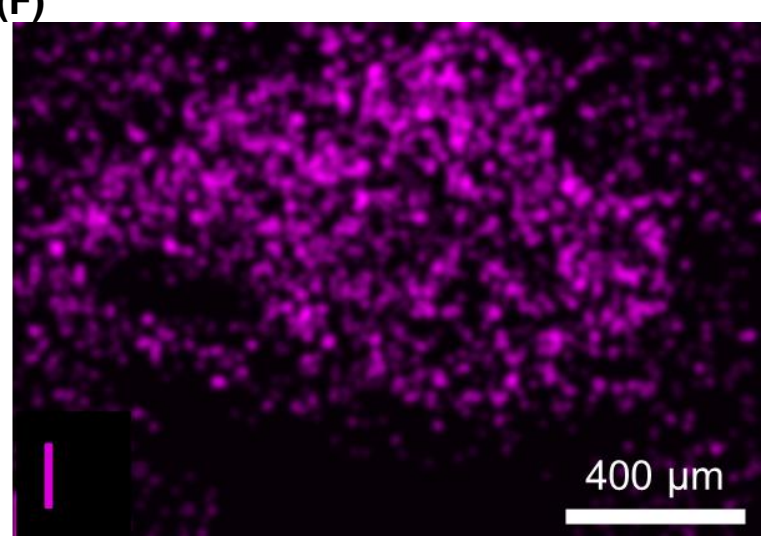

Figure 48: (A) Secondary electron image and $(B-F)$ elemental maps of a splatter particle collected near the spill zone during Test 2 . 
carbon tape of a lower coupon near the salt spill zone during Test 2 with an initial salt temperature of $500^{\circ} \mathrm{C}$. The lack of signal from the lower half of the elemental maps of the particle is due to the particle not being flat, which blocks the line of sight to the detector. Some regions of the particle appear to have slightly higher concentrations of sodium and cesium. Otherwise, sodium, potassium, fluorine, cesium, and iodine appear to be homogeneously distributed.

Coupons coated in carbon tape adhesive that were placed directly below the filter inlet (Coupon 7 in Figure 37) were imaged using SEM to search for small particles not detected by the visible camera $(<50 \mu \mathrm{m}$ diameter) that were likely suspended in the atmosphere prior to deposition. When small particles were identified, EDS line scans and spectra of individual particles were collected to determine particle composition. The most prevalent elements found in particles that were deposited on the coupon but were not constituents of the molten salt were oxygen, iron, and silicon. Each sample was prepared on carbon tape attached to a nickel coupon, so the detection of carbon and nickel in EDS spectra is expected.

Grains of FLiNaK powder were sprinkled onto carbon tape that coated a nickel coupon and analyzed as a control. Figure 49 provides a secondary electron image, the results from an EDS line scan that passed through several salt particles, and an EDS spectrum of a spot on a single

(A)

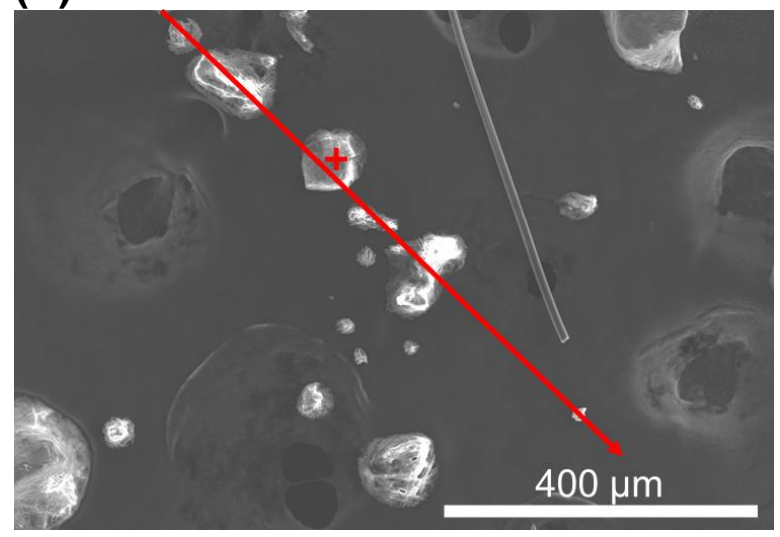

(C)

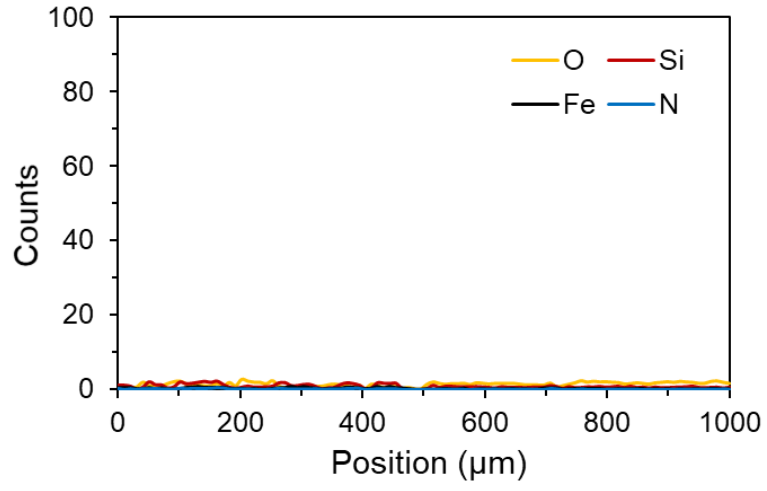

(B)

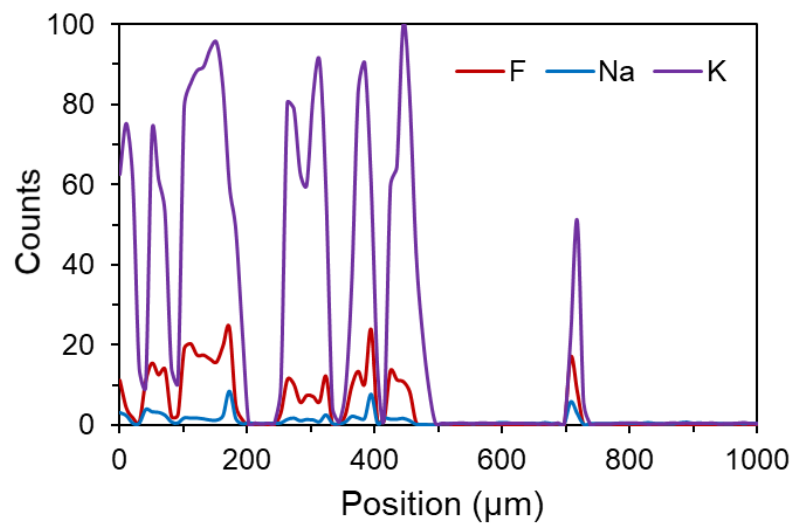

(D)

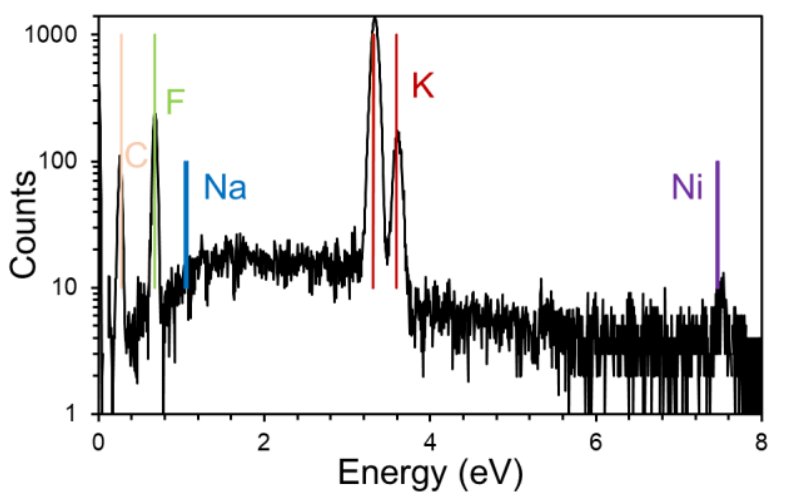

Figure 49: (A) Secondary electron image, (B) EDS line scan for salt component elements, (C) EDS line scan for common contaminant elements, and (D) EDS spectrum of the spot marked by the red cross for the control which consisted of FLiNaK powder that was sprinkled onto carbon tape coating a nickel coupon. 
particle. The line scan identifies potassium, fluorine, and occasionally sodium at locations that correspond with particles in the SEM image (Figure 49B). Common contaminants oxygen, iron, silicon, and nitrogen are not detected at locations that correspond with particles in the SEM image (Figure 49C). The EDS spectrum of a spot on a particle (marked by red cross in Figure 49A) reveals the presence of potassium, fluorine, carbon, and nickel, indicating the particle is FLiNaK. The signals from carbon and nickel are attributed to the composition of the background.

Figure 50 provides a secondary electron SEM image and results from an EDS line scan that passes through several salt particles that were identified on Coupon 7 from Test 3 that was run with an initial salt temperature of approximately $650^{\circ} \mathrm{C}$. The five particles in the path of the line scan shown in Figure 50A are salt particles as indicated by the presence of fluorine, potassium, and a small amount of sodium (Figure 50B). These five particles have diameters that range from $10 \mu \mathrm{m}$ to $20 \mu \mathrm{m}$ and are too small to be detected using a visible camera.

\section{(A)}

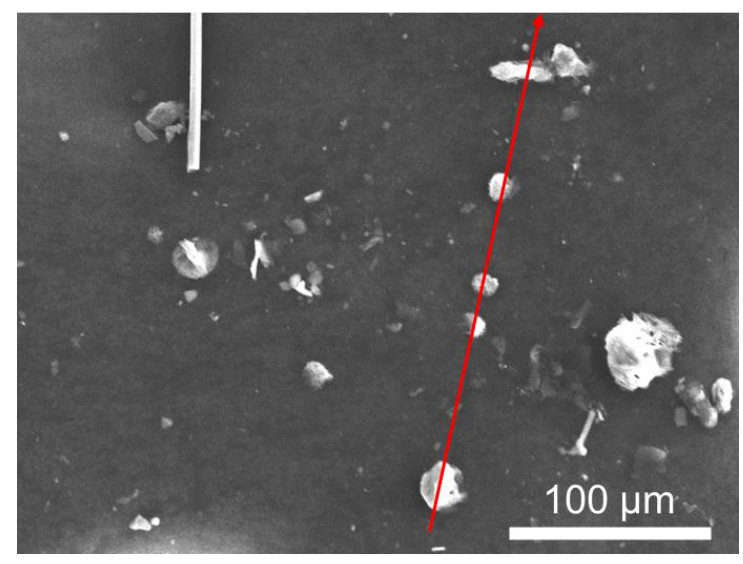

(B)

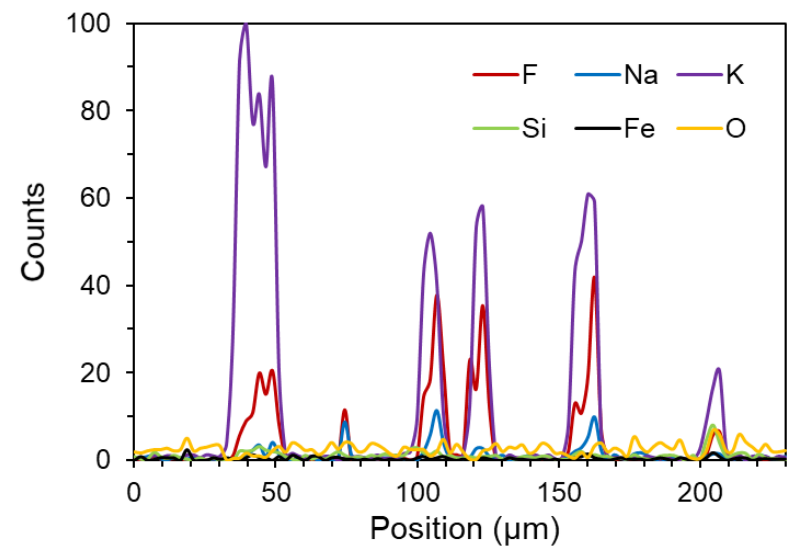

Figure 50: (A) Secondary electron image and (B) EDS line scan that passes through several salt particles that were identified on coupon 7 for Test 3 with an initial salt temperature of approximately $650^{\circ} \mathrm{C}$. The red line in subplot $A$ identifies the path of the line scan.

Figure 51 provides a secondary electron image of several particles that were collected on Coupon 7 during Test 5 with an initial salt temperature of approximately $800^{\circ} \mathrm{C}$. The EDS spectra collected at spots on different particles revealed that some of the particles are salt particles and some are contaminants. Notably, two adjacent particles marked as spot 1 and spot 2 in Figure 51A with diameters of approximately $4 \mu \mathrm{m}$ and $2 \mu \mathrm{m}$, respectively, contained significant amounts of cesium and iodine (Figure 51B and Figure 51C). The EDS spectrum of the particle marked by spot 1 indicates that the particle is primarily composed of cesium and iodine because carbon, oxygen, and nickel are known components of the background (Figure 51B). Some oxygen detected in the particles could have been absorbed during the exposure of the coupon to air during sample preparation for SEM-EDS analysis. The EDS spectrum of the particle marked by spot 2 indicates the presence of cesium and iodine as well as fluorine, magnesium, silicon, chlorine, and potassium (Figure 51C).

The identification of cesium- and iodine-rich particles on Coupon 7 for the salt splashing experiment at $800{ }^{\circ} \mathrm{C}$ agrees with the finding that the particulates collected on the filter located above Coupon 7 have higher cesium and iodine contents relative to the tests conducted on salts at lower temperatures. 
(A)

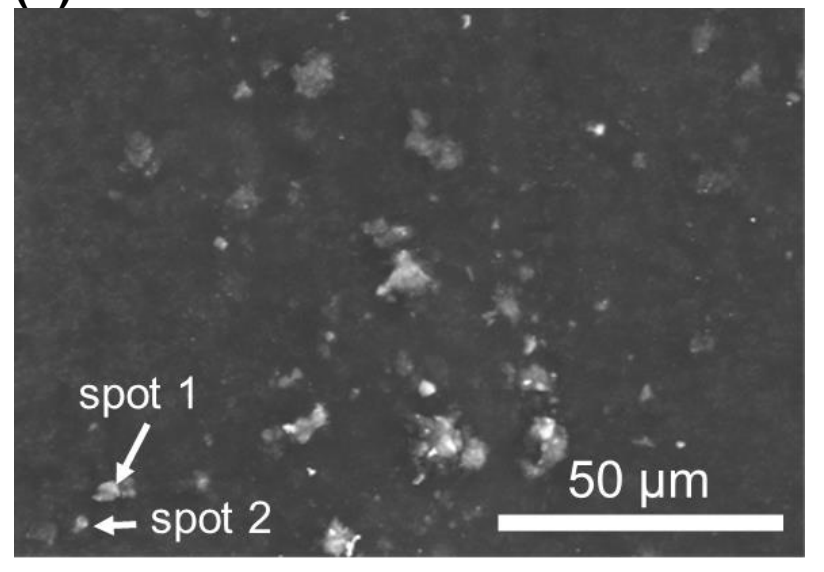

(C)
(B)

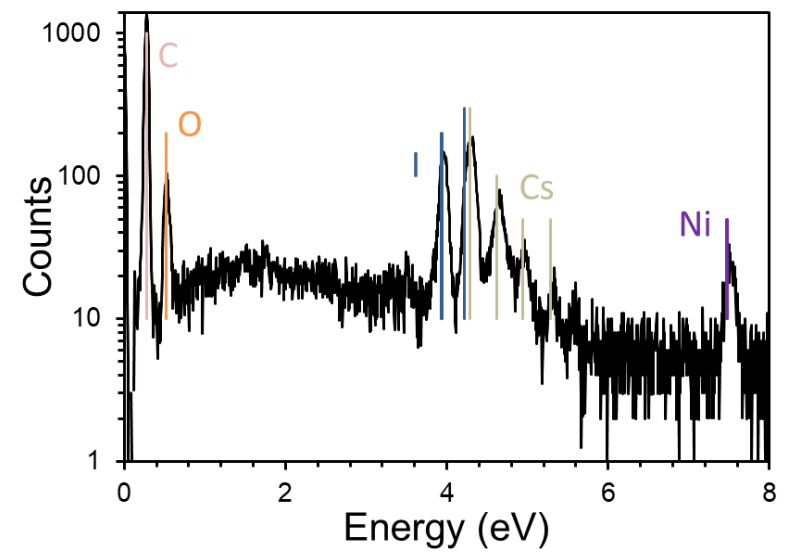

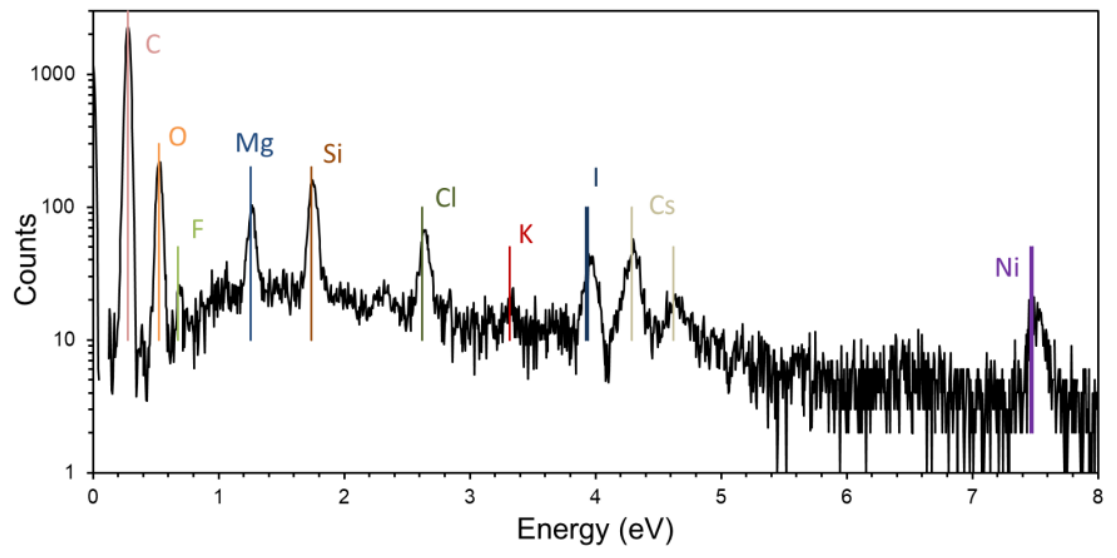

Figure 51: (A) Secondary electron image of particles on Coupon 7 for Test 5 with an initial salt temperature of approximately $800^{\circ} \mathrm{C}$. EDS spectra of (B) spot 1 and (C) spot 2.

\section{Conclusions and recommendations}

Four experimental methods were designed to develop the measurement techniques and provide the data needed to model processes that are expected to have the greatest impact on radionuclide release and the overall fate of the reactor after a salt spill accident. The collection of data needed to model key processes was demonstrated by using eutectic FLiNaK in separate modular experiments that focused on molten salt spreading and heat transfer, molten salt flowing and freezing in tubing, stainless steel corrosion kinetics in molten salt, and molten salt splashing and aerosol generation. Applications of the four methods were successful in generating data that can be used in individual process models, as summarized in Section 7.1. The methods developed to quantify individual processes related to molten salt spills are appropriate for use in integrated and larger scale tests necessary to validate the results from accident progression models for reactor licensing. The results from the tests addressing individual salt spill processes provided insights into the behavior of the salt and the radionuclides within during and after a spill and are summarized for each of the four experimental methods in Section 7.2. Suggestions for improvements and considerations for future tests are discussion in Section 7.3. 


\subsection{Effectiveness of methods for measuring individual processes}

Using an IR camera to measure the surface temperature of both molten salt and structural materials was very successful. The camera used in these studies collected video at a rate of 30 frames per second, which resulted in a sufficiently quick response time to track the migration of flowing salt. The spatial and temporal resolution of the IR video provided detailed information on the salt surface temperature during spreading tests and the outer tube surface temperature during the tests on molten salt flowing and freezing in tubing. The large difference in the emissivities of molten salt and polished stainless steel provided sufficient contrast to differentiate the salt from the stainless steel so that the covered area and leading edge of spreading salt could be determined using the MATLAB® programming language.

Butt-welded thermocouple lead wires with the junction attached to the surface with thermally conductive cement provided accurate surface temperatures of structural materials and were shown to have a response time and sensitivity equivalent to that of the IR camera.

Electrochemical corrosion tests on stainless steel in molten salt provided the steady corrosion rates under controlled redox, temperature, and salt chemistry needed to parameterize accident progression models. These methods can be used to quantify how corrosion behavior is affected by the ranges of redox potentials, chemistries, and temperatures that a structural material may experience when contacted by molten salt after a spill.

The developed methods provided valuable information on the amounts, size distributions, and compositions of molten salt splatter and aerosol particles that were produced due to splashing and vapor condensation from a molten salt pool. The use of carbon tape adhesive to collect splatter enabled the quantification of particle abundance and size distribution using imaging processing techniques and SEM-EDS.

Aerosol particles with diameters greater than $0.45 \mu \mathrm{m}$ were collected on PTFE filters and methods were successfully developed to recover and detect major salt components (lithium, sodium, and potassium) and surrogate fission product dopants (cesium and iodine) of particles captured on these filters. This included developing an analytical method to measure total iodine concentration using ICP-MS with a > 95\% recovery efficiency. A relatively simple but powerful method to provide the composition of individual aerosol particles was developed by flowing an aerosol-containing gas stream over carbon tape adhesive. The aerosols from the gas stream that adhere to the adhesive can be analyzed using SEM-EDS to identify the particles and determine their compositions.

\subsection{Summary of key findings}

A summary of the key findings that provide insight into molten salt and radionuclide behavior that should be considered in model development is provided for the four experimental methods that were employed.

\subsubsection{Experimental method 1: Molten salt spreading and heat transfer}

The key findings from the spreading and heat transfer tests are as follows:

- A crust consistently formed at the salt-substrate interface that left a trail along the salt flow path. The thermal properties of the crust (frozen salt) may differ from the molten salt and may need to be accounted for in models of heat transfer and spreading. 
- The emissivity of FLiNaK at the freezing temperature was estimated using the cooling curve recorded by the IR camera. The freezing temperature provided by the IR camera measurement $\left(457^{\circ} \mathrm{C}\right)$ was the same as the freezing temperature measured by using DSC $\left(456{ }^{\circ} \mathrm{C}\right)$ within experimental uncertainty, which indicates that the emissivity of FLiNaK is approximately unity, at least near its freezing point.

- Supercooling of FLiNaK was observed to occur in pools of spilled salt, consistent with findings from Carotti et al., 2015. Non-equilibrium freezing may influence the behavior of spilled molten salt during an accident.

- The salt spreading behavior appeared to be limited by the balance between the surface tension of the molten salt and gravity for all test conditions and not by freezing.

- The spreading area of the salt on the stainless steel substrate was affected by the initial salt temperature, the pour mass, and pour rate. A higher initial salt temperature correlated with a smaller covered area. A larger pour mass correlated with a larger covered area. The flow velocity of the salt spreading on the stainless steel substrate was positively correlated with the substrate tilt angle and the pour rate.

- The composition of the frozen salt after spreading was the same within analytical uncertainty regardless of the location where it froze on the substrate. However, these experiments were performed with pure FLiNaK within an argon atmosphere and changing the atmosphere or adding impurities to the salt could affect the frozen salt composition after spreading.

\subsubsection{Experimental method 2: Molten salt flowing and freezing behavior through tubing}

The key findings from the tests on flowing and freezing in tubing are summarized as follows:

- The fraction of the total mass poured that froze within the stainless steel tubing was dependent on the ratio of the total mass poured to the inner diameter of the tubing for a constant tube length, tube wall thickness, and initial salt temperature.

- The inner walls of the stainless steel tubing became coated with frozen FLiNaK under all test conditions, and the thickness of the frozen layer varied along the length of the tube. Frozen salt plugs were observed to form at the tube outlet in tests conducted with salt at initial temperatures of approximately $660^{\circ} \mathrm{C}$ and $775^{\circ} \mathrm{C}$ when the inner tube diameter was 0.1875 in.

- The maximum recorded temperature of the outer wall of the stainless steel tube was correlated with the initial salt temperature for tests conducted with the same inner tube diameter.

- The mass fraction of salt that froze on the stainless steel funnel cone before it reached the tubing inlet was dependent on the salt temperature, where the highest mass fraction of frozen salt was recovered at the lowest initial salt temperature. 
- Most of the molten salt flowed through the tubing within two seconds after pouring and was collected in the stainless steel beaker for all test conditions.

- The cooling curves of the underside of the stainless steel beaker that collected the salt that flowed through the tubing were nearly identical for the three tests with initial salt temperatures of approximately $660^{\circ} \mathrm{C}$ and $775^{\circ} \mathrm{C}$. This data can be used to understand the cooling behavior of molten FLiNaK when the bottom of the container is insulated.

\subsubsection{Experimental method 3: Stainless steel corrosion kinetics in molten salt}

The key findings from the tests on stainless steel corrosion in molten salt are summarized as follows:

- The corrosion potential ( $E_{\text {CORR }}$ ) of 316 stainless steel in FLiNaK was measured to be $1.44 \mathrm{~V}$ (vs. $\left.\mathrm{Li}^{\circ} \mathrm{Li}^{+}\right), 1.32 \mathrm{~V}\left(\right.$ vs. $\left.\mathrm{Li}^{\prime} / \mathrm{Li}^{+}\right)$, and $1.30 \mathrm{~V}\left(\mathrm{vs}\right.$. $\left.\mathrm{Li}^{\circ} \mathrm{Li}^{+}\right)$at temperatures of $500^{\circ} \mathrm{C}, 650{ }^{\circ} \mathrm{C}$, and $800^{\circ} \mathrm{C}$, respectively.

- Steady corrosion current densities were measured within 24 hours of test initiation during potentiostatic holds at $0.1 \mathrm{~V}$ above $\mathrm{E}_{\mathrm{CORR}}$ and the same value of $1.8 \times 10^{-4} \mathrm{~A} \mathrm{~cm}^{-2}$ was measured at salt temperatures of $500^{\circ} \mathrm{C}$ and $800^{\circ} \mathrm{C}$.

- The measured steady current density of $1.8 \times 10^{-4} \mathrm{~A} \mathrm{~cm}^{-2}$ is equivalent to a uniform mass corrosion rate of $4.1 \times 10^{-3} \mathrm{~g} \mathrm{~cm}^{-2} \mathrm{~d}^{-1}$ and a penetration rate of $1.9 \mathrm{~mm} \mathrm{yr}$. This corrosion rate corresponds to one salt composition, one fixed surface potential, and the two test temperatures of $500{ }^{\circ} \mathrm{C}$ and $800^{\circ} \mathrm{C}$. Additional electrochemical corrosion tests must be conducted over a range of possible salt compositions and surface potentials that might occur during a salt spill accident to provide the required information on stainless steel corrosion for accident progression models.

\subsubsection{Experimental method 4: Molten salt splashing and aerosol formation}

The key findings from the tests on molten salt splashing and aerosol formation are summarized as follows:

- The mass fraction of molten salt splatter that was produced due to splashing decreased with increasing initial salt temperature. Splatter particles traveled further from the spill zone in tests with salt at lower initial temperatures than in tests with salt at higher initial temperatures. In addition, smaller splatter particles were more abundant near the spill zone in tests run at higher initial salt temperatures, while smaller splatter particles were more abundant further from the spill zone in tests run at lower initial salt temperatures.

- The temperature of the spill containment box atmosphere remained relatively constant during the splashing tests. The maximum atmospheric temperature recorded was $34{ }^{\circ} \mathrm{C}$ (near the filter inlet) for a test that poured $15 \mathrm{~g}$ of molten FLiNaK at $800^{\circ} \mathrm{C}$.

- The composition of frozen FLiNaK doped with cesium and iodine that was collected after splashing was not significantly different among tests conducted at different initial salt temperatures or in samples collected from different locations (i.e., splatter particles vs. pooled salt). 
- Mist was observed to form over the molten salt pool in the spill containment box atmosphere during tests that spilled $15 \mathrm{~g}$ of FLiNaK doped with cesium and iodine at initial temperatures of $650^{\circ} \mathrm{C}$ and $800{ }^{\circ} \mathrm{C}$ but not during tests with salt at an initial temperature of $500{ }^{\circ} \mathrm{C}$. Less mist was observed above the molten salt pool after $15 \mathrm{~g}$ of FLiNaK doped with cesium and iodine at an initial temperature of $650{ }^{\circ} \mathrm{C}$ was spilled. The mist was probably condensed vapor. Mist was not observed in tests with pure FLiNaK at any temperature.

- Aerosols containing cesium were detected on the $0.45 \mu \mathrm{m}$ pore size filters that were used to sample the spill containment box atmosphere when $15 \mathrm{~g}$ of FLiNaK doped with cesium and iodine was spilled at initial temperatures of $500^{\circ} \mathrm{C}, 650^{\circ} \mathrm{C}$, and $800^{\circ} \mathrm{C}$. The amount of cesium detected on the filters increased with the initial salt temperature.

- Aerosols containing iodine were detected on the $0.45 \mu \mathrm{m}$ pore size filters only when cesium- and iodine-doped FLiNaK at $800^{\circ} \mathrm{C}$ was poured into the spill containment box. The ratio of cesium to iodine detected on the filter for this test condition was approximately 10 , which is the same ratio of cesium to iodine in the bulk salt before it was poured.

- Cesium and lithium were detected on a wipe sample that was taken of the ceiling of the spill containment box after the splashing tests concluded. The presence of cesium and lithium on the ceiling is attributed to vapor condensation or particle deposition.

- Salt particles with diameters between 1 and $20 \mu \mathrm{m}$ were detected after splashing on coupons used to sample the gas stream that was generated in the spill containment box atmosphere by using SEM-EDS. Notably, particles with diameters of $2 \mu \mathrm{m}$ and $4 \mu \mathrm{m}$ containing significant amounts of cesium and iodine were detected on coupons that sampled the spill containment box atmosphere during a test with cesium- and iodine-doped FLiNaK at $800^{\circ} \mathrm{C}$.

\subsection{Suggested improvements and considerations for future tests}

The laboratory tests that were conducted to demonstrate the experimental methods developed to generate data for modeling provided new insights into the behavior of spilled molten salt with and without added surrogate fission products. The lessons that were learned, suggestions to improve the measurements of certain processes, and considerations for future tests at small and large scales are discussed in this section.

- Salt was poured manually in these initial experiments to first demonstrate the efficacy of the approaches and data collection methods. An automated pouring system would improve the reproducibility of the pour rate and the pour direction and provide an unbiased measure of pour rate. An automated pour system would also need to be developed for engineering scale tests that would be compatible with large salt volumes and enable experiments to be run remotely.

- The finding that the temperature of the spill containment box atmosphere does not increase significantly upon spilling salt means the use of temperature-sensitive aerosol detection instrumentation that would provide real time particle size distribution is practical (see 
Appendix C Section C.1 for descriptions of applicable techniques). Use of a technique such as time-of-flight (TOF) mass spectrometry would provide information on the true airborne behavior of the aerosols of interest that modelers require. The fact that particles bearing salt components were collected on $0.45 \mu \mathrm{m}$ pore size filters and were observed to have a size range of 1 to $20 \mu \mathrm{m}$ on the adhesive tape used to sample the spill containment box atmosphere indicates that instrumentation with size detection limits of $0.5 \mu \mathrm{m}$ will be suitable to study molten salt aerosols that are generated during splashing and vapor condensation processes.

- The structural materials contacted by molten salt in the described experiments showed no indication of warping when contacted by salt. Large scale tests that involve the salt remaining molten for a longer duration will likely be required to study warping of structural materials.

- The temperature measurements of the FLiNaK surface using the IR camera assumed an emissivity of unity, which is consistent with experimental evidence from the cooling curves presented in this report (Section 3.2.2). However, determinations of the FLiNaK surface temperature would be improved by knowing the emissivity of FLiNaK as a function of temperature. The data collected using an IR camera can be corrected for changes in emissivity during data processing.

- The data logging scale employed in this work has the capability to log mass at intervals of one second. The results on molten salt flowing and freezing through tubing showed that molten salt flowed quickly for all conditions that were tested. A scale with finer temporal resolution would provide more detailed flow rates.

- The emissivity measurements of 316 stainless steel and high temperature tape were only run to $360^{\circ} \mathrm{C}$ due to the temperature limitations of the current system used to measure the emissivity of non-transparent materials. Emissivity measurements at higher temperatures would be required in future tests that use an IR camera to measure surface temperature if surface temperatures are expected to exceed $360^{\circ} \mathrm{C}$.

The experimental and analytical methods developed herein can be used to measure the effects of additional variables to account for the wide range of conditions that are possible during a salt spill accident. Considerations and suggestions for applying the methods to different test conditions are discussed below.

- The initial tests were conducted with a small volume of salt doped with relatively high concentrations of cesium and iodine to facilitate detection. The analytical methods were shown to be sufficiently sensitive that future tests should be conducted using salts with lower concentrations of surrogate fission products that are more representative of actual reactor salts. Using larger salt volumes and scaling up the experimental apparatus would increase the total amounts of surrogate fission products and facilitate the detection of lower concentrations.

- Salts that contains actinides or fission products may behave differently than the base salts. Future tests should use actinide-bearing and fission product-bearing salts to gauge the physical and chemical behavior of molten salt in simulated spill scenarios.

- Conducting tests under oxidizing conditions (e.g., in the presence of air) may accelerate the corrosion of the substrate that is in contact with the salt and introduce corrosion 
products (e.g., chromium, manganese, and iron) into the salt. The presence of an air atmosphere also might affect the wetting behavior of salt on stainless steel. Finally, the absorption of $\mathrm{O}_{2}$ and $\mathrm{H}_{2} \mathrm{O}$ from air can greatly affect salt chemistry. Fluoride and chloride salts are difficult to work with in air environments due to their hygroscopicity and the potential to produce dangerous gases (i.e., HF) from reactions with the moisture in air. Special consideration will be needed to construct apparatuses to perform tests in air atmospheres. The spill containment box built for these tests can be adapted for use in laboratory tests to evaluate those effects.

- The tests on spreading, heat transfer, and freezing were performed on stainless steel sheets that were not insulated at the underside. Depending on the reactor design, structures that are contacted by molten salt may be insulated and additional tests on heat transfer and freezing using insulated substrates should be performed. 


\section{References}

Allelein, H.-J., Auvinen, A., Ball, J., et al. (2009). "State-of-the-Art Report on Nuclear Aerosols." Nucelar Energy Agency Committee on the Safety of Nuclear Installations report NEA/CSNI/R(2009)5.

ASTM-E1933. (2018). "Standard Practice for Measuring and Compensating for Emissivity Using Infrared Imaging Radiometers." ASTM Book of Standards Vol. 03-03. ASTM International West Conshohocken, PA.

ASTM-G102. (2015). "Standard Practice for Calculation of Corrosion Rates and Related Information from Electrochemical Measurements." ASTM Book of Standards Vol. 03-02. ASTM West Conshohocken, PA.

Beneš, O., Capelli, E., Vozárová, N., et al. (2021). "Cesium and lodine Release from FluorideBased Molten Salt Reactor Fuel." Physical Chemistry Chemical Physics 23 (15): 9512-23.

Boehmer, W. D. and Hilliard, R. K. (1975). Sodium Fire Protection by Space Isolation, Open Catch Pan, and Nitrogen Flooding - FFTF Proof Test F5. Hanford Engineering Development Laboratory report HEDL-TME 75-98.

Briggs, R. B. (1962). Molten-Salt Reactor Program Semiannual Progress Report for Period Ending February 28, 1962. Oak Ridge National Laboratory report ORNL-3282.

Capelli, E., Beneš, O., and Konings, R. J. M. (2018). "Thermodynamics of Soluble Fission Products Cesium and lodine in the Molten Salt Reactor." Journal of Nuclear Materials 501: 238-52.

Carlomagno, G. M. and Cardone, G. (2010). "Infrared Thermography for Convective Heat Transfer Measurements." Experiments in Fluids 49 (6): 1187-1218.

Carotti, F., Abou Dbai, M., Ahmed, K., and Scarlat, R. O. (2015). "Experimental and Modeling Studies of Over-Cooling Transients in Fluoride-Salt Cooled High Temperature Reactors." In Proceedings of the International Topical Meeting on Nuclear Rector Thermalhydraulics (NURETH-16), 6169-82.

Compere, E., Kirslis, S., Bohlmann, E., Blankenship, F., and Grime, W. (1975). Fission Product Behavior in the Molten Salt Reactor Experiment. Oak Ridge National Laboratory report ORNL-4865.

Eckerman, K. F., Wolbarst, A. B., and Richardson, A. C. B. (1988). Limiting Values of Radionuclide Intake and Air Concentration and Dose Conversion Factors for Inhalation, Submersion, and Ingestion: Federal Guidance Report No. 11. Environmental Protection Agency, Washington, DC (USA). Office of Radiation.

Gattu, V. K. and Ebert, W. (2020). Electrochemical Corrosion Under Controlled Redox Conditions. Patent 16/353695, issued 2020.

Grosu, Y., González-Fernández, L., Nithiyanantham, U., and Faik, A. (2019). "Wettability Control for Correct Thermophysical Properties Determination of Molten Salts and Their Nanofluids." Energies. 12 (19): 3765. 
Holcomb, D. E., Qualls, A. L., Thomas, S., Jerden, J., Bucknor, M., Andrews, N. C., and Luxat, D. L. (2020). Early Phase Molten Salt Reactor Safety Evaluation Considerations DRAFT. Oak Ridge National Laboratory report ORNL/TM-2020/1719.

Humphries, L., Beeny, B., Louie, D., Esmaili, H., and Salay, M. (2018). Non-LWR Model Development for the MELCOR Code. Sandia National Laboratories report SAND20180297C.

Humphries, L. L., Beeny, B. A., Gelbard, F., Louie, D. L., and Phillips, J. (2017). MELCOR Computer Code Manuals. Vol. 1: Primer and Users' Guide. Version 2.2.9541 2017. Sandia National Laboratories report SAND2017-0455 O.

Hunnewell, T. S., Walton, K. L., Sharma, S., Ghosh, T. K., Tompson, R. V, Viswanath, D. S., and Loyalka, S. K. (2017). "Total Hemispherical Emissivity of SS 316L with Simulated Very High Temperature Reactor Surface Conditions.” Nuclear Technology 198 (3): 293-305.

Kalilainen, J., Nichenko, S., and Krepel, J. (2020). "Evaporation of Materials from the Molten Salt Reactor Fuel under Elevated Temperatures." Journal of Nuclear Materials 533: 152134.

Ke, W.-R., Kuo, Y.-M., Lin, C.-W., Huang, S.-H., and Chen, C.-C. (2017). "Characterization of Aerosol Emissions from Single Bubble Bursting." Journal of Aerosol Science 109: 1-12.

Keiser, J. R., DeVan, J. H., and Manning, D. L. (1977). The Corrosion Resistance of Type 316 Stainless Steel to $\mathrm{Li}_{2} \mathrm{BeF}_{4}$. Oak Ridge National Laboratory report ORNL/TM-5782.

Kirslis, S. S. and Blankenship, F. F. (1968). Fission Product Behavior in the MSRE. Molten Salt Reactor Program Semi-annual Progress Report - For period ending February 29, 1968, Oak Ridge National Laboratory report ORNL-4254.

Kirslis, S. S. and Blankenship, F. F. (1969). Fission Product Volatilization Tests." Molten Salt Reactor Program Semi-annual Progress Report - For period ending February 28, 1969, Oak Ridge National Laboratory report ORNL-4396.

Kulkarni, P., Baron, P. A., and Willeke, K. (2011). Aerosol Measurement: Principles, Techniques, and Applications. John Wiley \& Sons.

Leute, J., Beeny, B., Gelbard, F., and Clark, A. (2021). Identification and Resolution of Gaps in Mechanistic Source Term and Consequence Analysis Modeling for Molten Salt Reactors. Sandia National Laboratories report. (in progress).

Lichtenstein, T., Rose, M. A., Krueger, J., et al. (2020). "Thermochemical Property Measurements of FLiNaK and FLiBe in FY 2020.” Argonne National Laboratory report ANL/CFCT-20/37.

McMurray, J., Johnson, K., Agca, C., et al. (2021). "Roadmap for Thermal Property Measurements of Molten Salt Reactor Systems." Oak Ridge National Laboratory report ORNL/SPR$2020 / 1865$.

NRC. (2016). Accident Source Terms and Siting for Small Modular Reactors and Non-Light Water Reactors. Nuclear Regulatory Commission report SECY-16-0012. 
NRC. (2020). Guidance for a Technology-Inclusive, Risk-Informed, and Performance-Based Methodology to Inform the Licensing Basis and Content of Applications for Licenses, Certifications, and Approvals for Non-Light-Water-Reactors. Nuclear Regulatory Commission Regulatory Guide 1.233 Revision 0.

Nuclear Energy Institute. (2018). Risk-Informed Performance-Based Guidance for Non-Light Water Reactor Licensing Basis Development. Draft Report Revision N. NEI-18-04.

ORNL. (1955). ART Reactor Accident Hazards Tests. Oak Ridge National Laboratory report ORNL CF-55-2-100.

Parker, G. W. and Buchholz, H. (1968). Size Classification of Submicron Particles by a LowPressure Cascade Impactor. Oak Ridge National Laboratory report ORNL-4226.

Qiu, J., Wu, A., Li, Y., Xu, Y., Scarlat, R., and Macdonald, D. D. (2020). "Galvanic Corrosion of Type 316L Stainless Steel and Graphite in Molten Fluoride Salt." Corrosion Science 170: 108677.

Rose, M. A., Wu, E., and Williamson, M. A. (2020). Thermophysical Property Measurements: Improved Density, Viscosity, and Thermal Diffusivity Methods. Argonne National Laboratory report. ANL/CFCT-20/38.

Shahbazi, S. and Grabaskas, D. (2021). A Pathway for the Development of Advanced Reactor Mechanistic Source Term Modeling and Simulation Capabilities. Argonne National Laboratory report. ANL/NSE-21/21.

Tetreault-Friend, M. (2018). "Thermal-Fluid Characterization and Performance Enhancement of Direct Absorption Molten Salt Solar Receivers." Massachusetts Institute of Technology.

Thomas, S. and Jackson, J. (2021). Data Package of Results from Salt Spill Testing. Argonne National Laboratory report. ANL/CFCT-21/28.

Thomas, S., Jackson, J., and Farmer, M. (2021). Modeling Molten Salt Spreading and Heat Transfer using MELTSPREAD - An Uncertainty Analysis. Argonne National Laboratory report. ANL/CFCT-21/27.

Zheng, G. and Sridharan, K. (2018). "Corrosion of Structural Alloys in High-Temperature Molten Fluoride Salts for Applications in Molten Salt Reactors." JOM 70 (8): 1535-41. 


\section{Appendix A: Common equipment}

This appendix provides descriptions of the common equipment that was used in two or more of the experiments in this report.

\section{A.1. Infrared camera}

Two FLIR T540 infrared (IR) cameras with a $42^{\circ}$ lens were used to measure the temperatures of the salt and steel surfaces for the spreading and heat transfer tests and the flowing and freezing tests. The IR camera has three calibration ranges: $0^{\circ} \mathrm{C}$ to $120^{\circ} \mathrm{C}, 0^{\circ} \mathrm{C}$ to $650{ }^{\circ} \mathrm{C}$, and $300^{\circ} \mathrm{C}$ to $1500^{\circ} \mathrm{C}$. The IR camera detects infrared wavelengths within the range of 7.5 to $14 \mu \mathrm{m}$ and has a resolution of $348 \times 464$ pixels. The IR cameras were operated in video mode during the tests described herein, which provides a radiometric data file (temperature of each pixel in the field of view) for each frame at a default collection rate of 30 frames per second.

\section{A.2. Data logger for thermocouple measurements}

Several thermocouples were used to measure the temperatures of surfaces and the vapor space in the experiments described in this report. A groov Edge Programmable Industrial Controller (EPIC) from Opto 22 was used to record the temperatures from every thermocouple used in the different tests. The thermocouples were attached to the groov EPIC using GRV-ITMI-8 analog input modules. Each module allows 8 isolated thermocouple connections so that multiple grounded thermocouples can be employed without interference. The groov EPIC was programmed using the PAC Control software to record the temperature of each thermocouple connected at one second intervals.

\section{A.3. Visible camera}

A Canon PowerShot SX740 HS Wi-Fi 4K digital camera was used to record the visible video for the spreading and heat transfer tests and the flowing and freezing tests. A GoPro HERO9 black $5 \mathrm{~K}$ video streaming camera was used to record video at 240 frames per second for the splashing and aerosol generation tests.

\section{A.4 Furnace}

The furnace used to heat the salt in these experiments was a KERR Electro-Melt furnace with a $100 \mathrm{oz}$ capacity. An external J-Kem 270 controller was used to control the furnace at the desired target temperature. 


\section{Appendix B: Experimental methods for measuring surface temperature}

This section describes the experimental methods and equipment that were used to measure surface temperatures with an IR camera and with thermocouples.

\section{B.1 Temperature measurement of surfaces by IR camera}

\section{B.1.1 Principles of radiation and infrared camera usage}

The usage of an IR camera to determine the temperature of an object requires an understanding of the principles of radiative heat transfer and is reviewed in Carlomagno and Cardone, 2010. The transfer of heat by radiation occurs in the form of electromagnetic waves. Bodies may absorb, reflect, and transmit thermal radiation, which must be conserved according to the following equation:

$$
\alpha_{r}+\rho_{r}+\tau_{r}=1
$$

where $\alpha_{r}, \rho_{r}$, and $\tau_{r}$ are the absorptivity, reflectivity, and transmissivity coefficients of the body, respectively. These coefficients can depend on the radiation wavelength and propagation direction.

All bodies emit radiation if their absolute temperature is greater than zero. A blackbody is an object that emits the greatest amount of energy at a given temperature. Real objects are generally not perfect blackbodies and emit only a fraction of the radiation emitted by a blackbody. The radiation that a real object emits $(I(\lambda))$ is related to the radiation that a blackbody emits $\left(I^{b}(\lambda)\right)$ at the same temperature by the spectral emissivity coefficient $(\varepsilon(\lambda))$ according to Equation B-2.

$$
\varepsilon(\lambda)=\frac{I(\lambda)}{I^{b}(\lambda)}
$$

According to Kirchhoff's law, the spectral emissivity coefficient of an object at wavelength $\lambda(\varepsilon(\lambda))$ is equal to the spectral absorptivity coefficient or $\alpha_{r}(\lambda)$. For non-transparent bodies $\left(\tau_{r}=0\right)$, from which radiation originates from the surface only, Equation B-1 simplifies to:

$$
\varepsilon(\lambda)+\rho_{r}(\lambda)=1
$$

The energy detected by an IR camera depends on the conditions of the environment as well as the emissivity of the surface being measured $(\varepsilon)$. The total radiation $(I)$ detected by the camera for a non-transparent object can be written as follows:

$$
I=\tau_{a t m} \varepsilon I_{o b j}^{b}+\tau_{a t m}(1-\varepsilon) I_{a m b}^{b}+\left(1-\tau_{a t m}\right) I_{a t m}^{b}
$$

where $I_{o b j}^{b}$ is the radiation intensity that corresponds to a blackbody at the same temperature as the object $\left(T_{o b j}\right), I_{a m b}^{b}$ is the radiation intensity corresponding to a blackbody at the (effective) temperature of the ambient environment, $I_{a t m}^{b}$ is the radiation intensity corresponding to a blackbody at the temperature of the atmosphere, and $\tau_{a t m}$ is the transmissivity of the atmosphere. 
The transmissivity of the atmosphere is generally assumed to be unity, which greatly simplifies Equation B-4. This simplified equation can be written in terms of the temperature measured by the IR camera $\left(T_{a p p}\right)$ as follows:

$$
T_{a p p}=\varepsilon T_{o b j}+(1-\varepsilon) T_{a m b}
$$

Equation B-5 was used to correct for the surface temperatures of non-transparent objects. Both $T_{a p p}$ and $\varepsilon$ may depend on temperature, and the temperature-dependence of these terms was considered. The dependence on wavelength was not determined, and all measurements were confined to the range of spectral wavelengths detected by the IR camera $(7.5-14 \mu \mathrm{m})$.

The radiation detected by an IR camera when the object under measurement is transparent, as is the case for molten salt, is more complicated. The use of an IR camera to determine the surface temperature of molten salt is discussed further in Section 3.2.2.

B.1.2 Emissivity of stainless steel, high temperature tape, and thermally conductive cement

The emissivity of 316 stainless steel, high temperature tape, and thermally conductive cement were measured using an IR camera as a function of temperature using the methods reported in ASTM-E1933-14 (2018). The measured emissivity of the thermally conductive cement was used to test the temperature response of the thermocouples attached to stainless steel surfaces (as described in Section B.2), and the emissivity of 316 stainless steel was required to correct for the temperature measurements made using the IR camera during the molten salt spreading experiments (Section 3). The high temperature tape was used as a high-emissivity coating for surface temperature measurements with the IR camera (Section 4), which required the determination of the emissivity of the high temperature tape for use in temperature corrections.

\section{B.1.2.1 Emissivity of cement by contact thermometer method}

The emissivity of thermally conductive cement was measured using the contact thermometer method described in ASTM-E1933 (ASTM 2018). The required equipment included an IR camera, a multivolt meter, a tripod, K-type thermocouple lead wires (OMEGA ${ }^{\mathrm{TM}}$, item no. CHAL-010-BW), a hot plate, a 0.0625 in. thick copper plate, and a 0.0625 in. thick 316 stainless steel sheet (Figure B-1). The exposed thermocouple junctions were attached to the stainless steel sheet using thermally conductive cement (OMEGA ${ }^{\mathrm{TM}}$, item no. OB-700) and ceramic insulation for the lead wires (Figure B-1). Thermally conductive cement was used to ensure good thermal contact between the thermocouple junction and the stainless steel sheet. The stainless steel sheet with thermocouples attached was mounted on a copper plate placed on the heating element of a hot plate to promote uniform temperature distribution. The hot plate was heated to a desired temperature and allowed to stabilize for approximately 30 minutes. The IR camera was slightly

offset from the hot plate to minimize the extent of radiative heating of the camera. The camera settings for emissivity were set to 1 and the lens was focused prior to the start of the test. 
Butt-welded thermocouple bead attached to sheet by thermally conductive cement

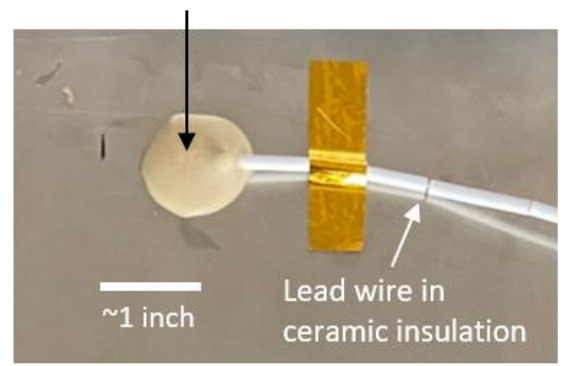

thermocouples contacting stainless-steel sheet

Stainless-steel sheet

Copper plate

Hot plate

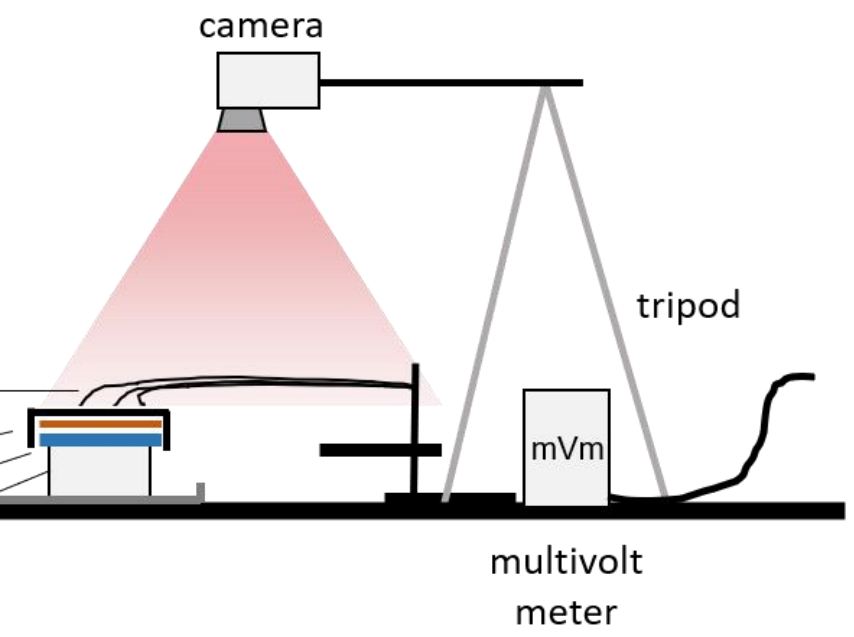

Figure B-1: Benchtop setup for measuring the emissivity of a surface using thermocouples and an IR camera.

When the temperature of the stainless steel sheet stabilized (as determined by the temperature measurements recorded by the thermocouples), an IR video of the entire stainless steel sheet was recorded for approximately 30 seconds. Readings from the thermocouples attached to the stainless steel sheet were simultaneously recorded. A region of interest in the cement with an area of 20 to 50 pixels was selected in the IR camera field of view. The responses of those pixels were averaged spatially and used as the apparent temperature of the cement. An example of the apparent temperature of the cement measured by the IR camera (red) and the actual temperature of the cement measured by the thermocouple (blue) is provided for two separate measurements in Figure B-2.

(A)

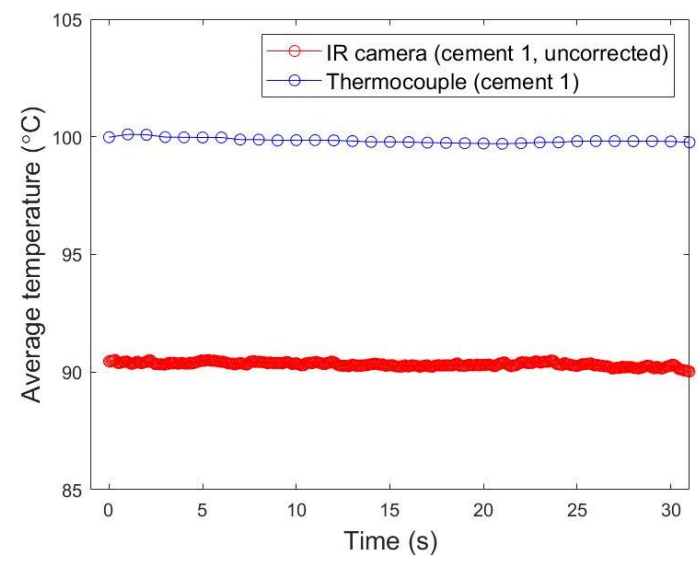

(B)

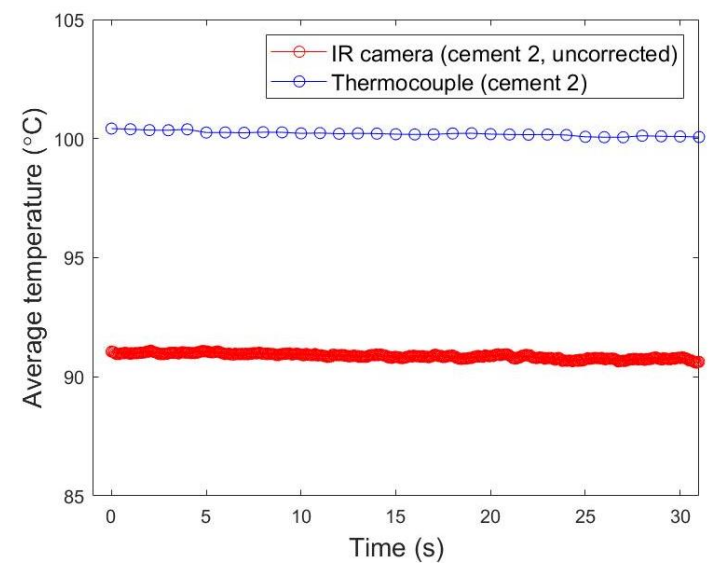

Figure B-2: The apparent temperature (red) and the actual temperature (blue) of thermally conductive cement measured using an IR camera and thermocouple, respectively, for two separate measurements ( $A$ and $B)$. 
The emissivity $(\varepsilon)$ of the cement surface was calculated using the following equation:

$$
\varepsilon=\frac{\mathrm{T}_{\text {apparent }}-\mathrm{T}_{\text {reflected }}}{\mathrm{T}_{\text {actual }}-\mathrm{T}_{\text {reflected }}}
$$

where $T_{\text {apparent }}$ is the apparent temperature of the object measured by the IR camera, $T_{\text {actual }}$ is the actual temperature of the object measured by the thermocouple, and $T_{\text {reflected }}$ is the effective ambient temperature that is reflected by the object. The value for $\mathrm{T}_{\text {reflected }}$ was determined by measuring the average apparent temperature of the laboratory ceiling with the IR camera, which was determined to be $25^{\circ} \mathrm{C}$. The average $T_{\text {apparent }}$ and $T_{\text {actual }}$ over the 30 -second measurement duration was used in Equation B-6. Figure B-3A shows the emissivity of the cement as a function of its actual temperature measured by the thermocouple, and Figure B-3B shows the emissivity of the cement as a function of its apparent temperature that was measured by the IR camera when $T_{\text {reflected }}$ was $25^{\circ} \mathrm{C}$. The data points in Figure B-3 are averages from two measurements, and the curves are best fit with quadratic equations. The emissivity of the cement is approximately 0.88 when its actual temperature is between $50-200{ }^{\circ} \mathrm{C}$ and decreases slightly at temperatures above $200^{\circ} \mathrm{C}$.

\section{(A)}

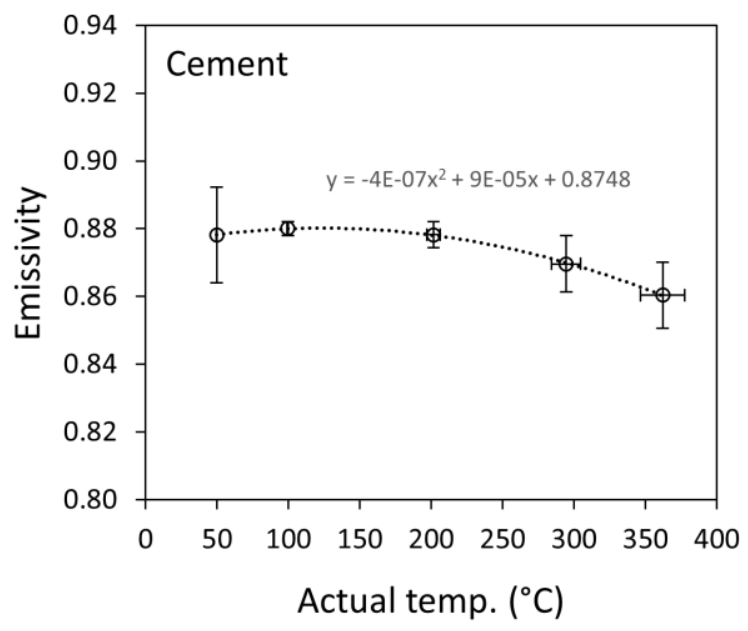

(B)

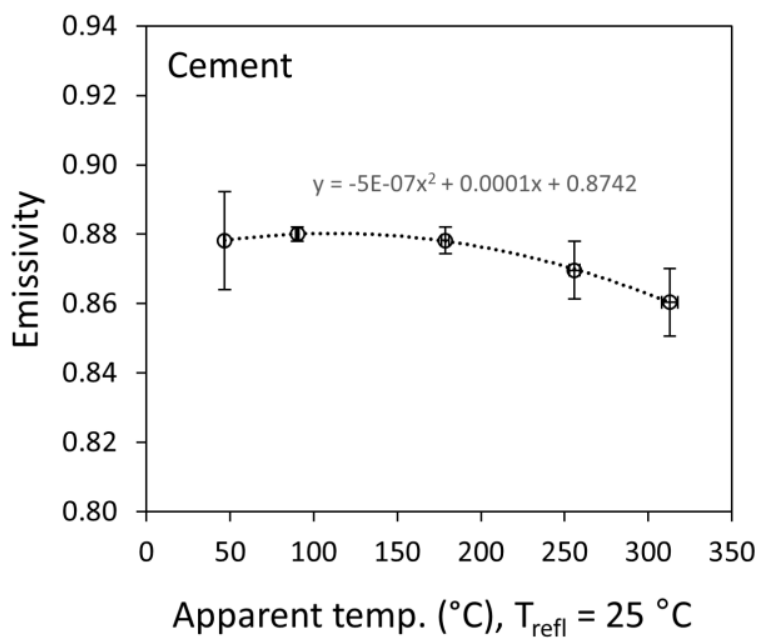

Figure B-3: The emissivity of thermally conductive cement as a function of its (A) actual temperature measured by the thermocouple and (B) apparent temperature measured by the IR camera when $\mathrm{T}_{\text {refl }}=25^{\circ} \mathrm{C}$.

\section{B.1.2.2 Emissivity of stainless steel and high temperature tape by non-contact thermometer method}

The non-contact thermometer method (ASTM, 2018) was used to measure the emissivity of 316 stainless steel (McMaster-Carr, item no. 88885K24) and high temperature tape (McMaster-Carr, item no. 1618N1). For this method, the emissivity of an object (Object 1) that is adjacent to an object with known emissivity (Object 2 ) is determined using the apparent temperature readings from an IR camera with the assumption that the adjacent objects are at the same temperature. The actual temperature ( $\left.T_{\text {actual }}\right)$ of Object 2 can then be calculated by using Equation B-7: 


$$
T_{\text {actual }}=\frac{T_{\text {apparent }}-(1-\varepsilon) \cdot T_{\text {reflected }}}{\varepsilon}
$$

where $T_{\text {apparent }}$ is the apparent temperature of Object 2 measured by the IR camera, $T_{\text {reflected }}$ is the effective ambient temperature of the room, and $\varepsilon$ is the emissivity of Object 2 at $T_{\text {apparent }}$ and $\mathrm{T}_{\text {reflected. }}$ The thermally conductive cement was used as Object 2 (the object with known emissivity) for these calculations and the quadratic equation in Figure B-3B was used to determine $\boldsymbol{\varepsilon}$. The same setup and general protocol described in Section B.1.2.1 was used to determine the emissivity of Object 1 (i.e., either the high temperature tape or 316 stainless steel). High temperature tape was placed adjacent to the cement on the stainless steel sheet that was mounted on the hot plate. A 20-to-50-pixel region of interest on the high temperature tape or stainless steel sheet adjacent to the cement was selected for emissivity analysis for the respective materials. Equation B-6 was used to calculate the emissivity of the materials. The emissivity of 316 stainless steel as a function of temperature is shown in Figure B4-A and was best fit using a power law. The emissivity of 316 stainless steel measured using an IR camera agrees well with recent literature (to approximately $700^{\circ} \mathrm{C}$ ) that reported the total hemispherical emissivity of $316 \mathrm{~L}$ stainless steel measured by vacuum calorimetry (Hunnewell et al., 2017). The emissivity of high temperature tape as a function of temperature was best fit with a linear equation (Figure B-4B).

(A)

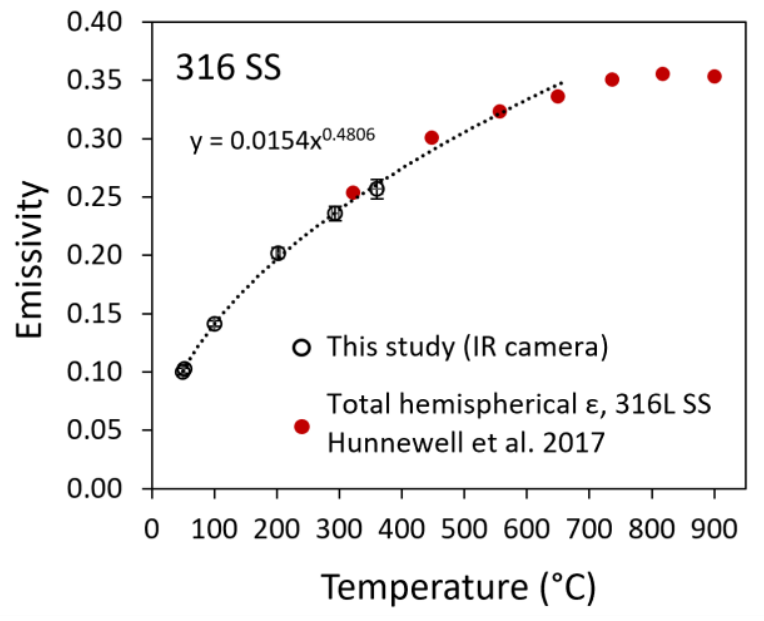

(B)

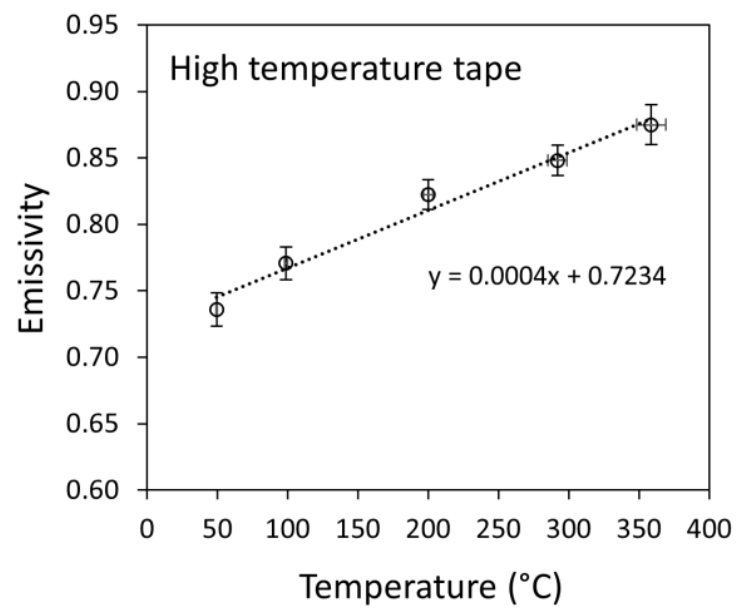

Figure B-4: The emissivity of (A) 316 stainless steel and (B) high temperature tape as a function of temperature. (A) The total hemispherical emissivity of 316L stainless steel measured by a vacuum calorimeter is shown for comparison (Hunnewell et al., 2017).

\section{B.1.3 Temperature correction for stainless steel and high temperature tape}

The temperature data contained in the radiometric data file obtained from an IR video files consists of one temperature value per pixel in the frame, with 30 frames collected per second. The MATLAB® programming platform was used to perform temperature corrections on radiometric data files collected with the IR camera to facilitate processing millions of temperature measurements. The radiometric data file of the IR video was uploaded to the FLIR ResearchIR Max software (Version 4.40.11.35), and then the frames of interest in the video were exported to 
a MATLAB®-readable format. The temperature corrections for 316 stainless steel and high temperature tape were done using the measured emissivity reported in Section B.1.2.2. The actual temperature of the material of interest $\left(T_{\text {actual }}\right)$ was determined by using Equation B-7.

Due to the low emissivity of stainless steel, the $\mathrm{T}_{\text {reflected }}$ can greatly influence the corrected temperature ( $\left.T_{\text {actual }}\right)$ that is calculated by using Equation B-7. $T_{\text {reflected is commonly not uniform }}$ over a surface. Therefore, it is important to have a value for $T_{\text {reflected }}$ at each pixel in the IR image instead of using the ambient temperature of the room. Directly before a test commenced that required the surface temperature of stainless steel using an IR camera, an IR image of the stainless steel material of interest was captured for use in calculating the $T_{\text {reflected }}$ at each pixel. Specifically, $T_{\text {reflected }}$ at each pixel was calculated by using Equation B-8, where $T_{\text {apparent }}$ is the temperature at each pixel from the raw IR image captured directly before the test began, $T_{\text {actual }}$ is the actual temperature of the stainless steel surface, and $\varepsilon$ is the emissivity of the stainless steel at $\mathrm{T}_{\text {actual. }}$.

$$
T_{\text {reflected }}=\frac{T_{\text {apparent }}-\varepsilon \cdot T_{\text {actual }}}{(1-\varepsilon)}
$$

Thermocouples attached to the stainless steel surface with thermally conductive cement provided values of $T_{\text {actual. }}$. The entire stainless steel surface was assumed to be at the same temperature and any differences in $T_{\text {apparent }}$ in the pixels were attributed to differences in $T_{\text {reflected. The overhead }}$ lights in the laboratory were usually turned off for tests that involved temperature measurements using the IR camera to minimize the differences in the observed $T_{\text {reflected }}$ among pixels within the camera field of view.

For stainless steel, solving for $T_{\text {actual }}$ by using Equation B-7 requires plugging in the equation of $\varepsilon$ as a function of $T_{\text {actual }}$ (reported in Figure B4-A) because the emissivity of stainless steel changes with temperature. We attempted to determine an equation for $\varepsilon$ as a function of $T_{\text {apparent }}$ and $T_{\text {reflected }}$ by combining Equation B-7 and the power law equation in Figure B4-A so that $\mathrm{T}_{\text {actual }}$ did not have to be known to solve for $\mathrm{T}_{\text {actual. }}$. However, a mathematical solution was not achieved. Instead, equations for $\varepsilon$ as a function of $T_{\text {apparent }}$ and $T_{\text {reflected }}$ were determined for fixed values of $T_{\text {reflected. }}$ Specifically, an equation for $\varepsilon$ vs. $T_{\text {apparent }}$ was obtained for each integer value of $\mathrm{T}_{\text {reflected }}$ within the range $22{ }^{\circ} \mathrm{C}$ to $60^{\circ} \mathrm{C}$. To correct for the temperature of a pixel, if the $T_{\text {reflected }}$ at that pixel fell within $\pm 0.5^{\circ} \mathrm{C}$ of an integer value, the equation for $\mathrm{T}_{\text {refected }}$ at that integer value was used to obtain

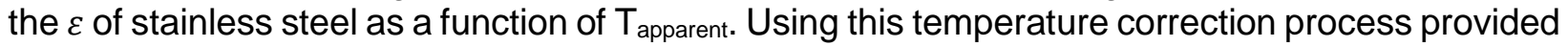
temperature estimates for each pixel of the stainless steel surface in the IR video. It is important to note that error propagates through the temperature corrections due to the uncertainty in the equations for $\varepsilon$ vs. temperature and the $T_{\text {reflected }}$ used for each pixel. The error in the temperature corrections has not yet been estimated. It is also important to note that $T_{\text {reflected }}$ for each pixel was assumed to not change throughout the duration of the experiment.

Temperature corrections for the high temperature tape were made following a similar protocol as the temperature correction of stainless steel. The one difference was that an equation for the emissivity of high temperature tape $\left(\varepsilon_{\text {tape }}\right)$ as a function of $\mathrm{T}_{\text {apparent }}$ and $\mathrm{T}_{\text {reflected }}$ was obtained using Equation B-7 and the linear relationship between $\varepsilon$ and $\mathrm{T}_{\text {actual }}$ provided in Figure B4-B:

$$
\varepsilon_{\text {tape }}=\left(1.472 \cdot 10^{-4}\right) T_{\text {apparent }}+\left(2.529 \cdot 10^{-4}\right) T_{\text {reflected }}+0.7234
$$

This equation for $\varepsilon$ as a function of $T_{\text {apparent }}$ and $T_{\text {reflected }}$ was inserted into Equation B-7 so that $\mathrm{T}_{\text {actual }}$ could be calcuated from known values of $\mathrm{T}_{\text {apparent }}$ and $\mathrm{T}_{\text {reflected. }}$ 


\section{B.2 Temperature measurement of surfaces using thermocouples}

Surface temperatures were measured using butt-welded, K-type thermocouple lead wires $\left(\mathrm{OMEGA}^{\mathrm{TM}}\right.$, item no. CHAL-010-BW) with the exposed junction attached to surfaces with thermally conductive cement $\left(\mathrm{OMEGA}{ }^{\mathrm{TM}}\right.$, item no. OB-700). The lead wires were covered by ceramic insulation, as shown in Figure B-1. The accuracy and response of the temperature measurement was assessed by comparing the temperatures measured at the same spot and time by the IR camera and by the thermocouple. We chose to use the thermally conductive cement that encased the exposed thermocouple junction as the test surface because it has a high emissivity that is known as a function of temperature and is less sensitive to the temperature of the ambient environment $\left(T_{\text {reflected }}\right)$. Using the same setup that is shown in Figure B-1, the temperature of the thermally conductive cement (and the stainless steel sheet to which it was attached) was controlled by a hot plate. When the temperature of the thermally conductive cement stabilized on the hot plate at around $80{ }^{\circ} \mathrm{C}$, the knob was turned slightly to increase the temperature of the hot plate, and the temperature response of the thermocouple and IR camera was recorded for approximately 80 seconds (Figure B-5A). The temperature recorded by the IR camera was corrected for the emissivity of the cement by using Equation B-7, where $T_{\text {reflected }}$ was $25^{\circ} \mathrm{C}$ and $\varepsilon$ was obtained from the quadratic relationship between $\varepsilon$ and $T_{\text {apparent }}$ provided in Figure $\mathrm{B}-3 \mathrm{~B}$. The temperature of the hot plate was increased further and the temperature of the thermally conductive cement was measured by using the thermocouple and IR camera over two additional temperature ranges (Figure B-5B and Figure B-5C).

(A)

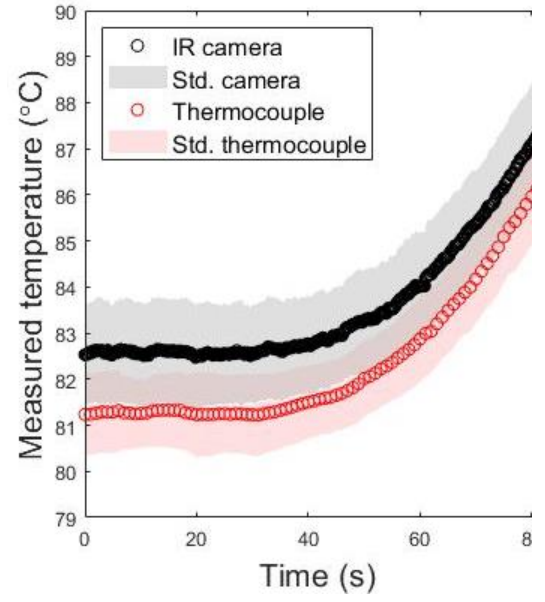

(B)

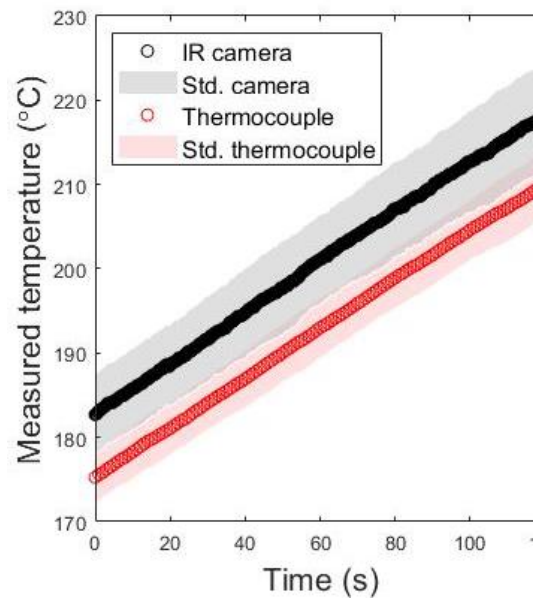

(C)

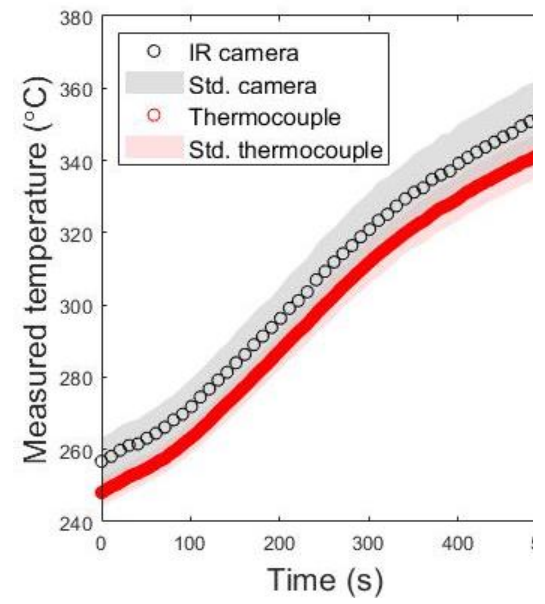

Figure B-5: The temperature of thermally conductive cement measured using a thermocouple (red) and an IR camera (black) as the cement is continuously heated on a hot plate for temperature ranges (A) $80^{\circ} \mathrm{C}$ to $90^{\circ} \mathrm{C}$, (B) $170{ }^{\circ} \mathrm{C}$ to $220^{\circ} \mathrm{C}$, and (C) $240{ }^{\circ} \mathrm{C}$ to $360^{\circ} \mathrm{C}$.

The curves Figure B-5 are the average of measurements taken for two separate and adjacent pieces of thermally conductive cement on the same hot plate. The red curves are averages from thermocouple measurements from the two pieces of cement. The temperatures reported by the black curves were obtained by taking the spatial average of a 20-to-50-pixel region of interest on the respective pieces of cement and then averaging the values from the two pieces of cement at each time point. 
The shaded regions in Figure B-5 show the standard deviation for the two thermocouple and IR camera measurements. The slope of the curves in each subplot of Figure B-5 show parallel temperature rise, which indicates that the temperature responses of the thermocouple and IR camera are the same. The temperature response of the IR camera is assumed to be instantaneous. The temperature difference was approximately $1.2^{\circ} \mathrm{C}$ between the thermocouple and IR camera measurements at the lower temperatures of Figure B-5A. The temperature difference increases to 7 to $8{ }^{\circ} \mathrm{C}$ at the intermediate temperatures of Figure $\mathrm{B}-5 \mathrm{~B}$ and 8 to $10^{\circ} \mathrm{C}$ at the higher temperatures of Figure B-5C. The differences in the temperatures measured by using each method could be because the thermocouple acted as a heat sink that did not equilibrate with the temperature of the cement quickly enough. This could explain why the IR camera consistently recorded a higher temperature. It is also possible that the uncertainty in the equation for the emissivity of the thermally conductive cement, which was used to correct for the temperature measured by the IR camera, is responsible for the difference in temperature measured by the two methods for the same system. Nonetheless, the difference in temperature measured by IR camera and thermocouple was lowest at lower temperatures and was still $10^{\circ} \mathrm{C}$ or less when the temperature of the system was less than $360{ }^{\circ} \mathrm{C}$. 


\section{Appendix C: Molten salt aerosol measurement techniques and historical data}

\section{C.1 Summary of techniques to quantify aerosol abundance and size}

Knowing the abundance, size distribution, and composition of molten salt aerosols is essential for modeling aerosol transport and predicting the source term of radionuclide-bearing aerosol particles. Techniques to quantify aerosol abundance, size, and composition are described in this section to facilitate the selection of aerosol quantification equipment for future tests.

\section{C.1.1 Light scattering}

Particle size can be quantified by measuring light that is scattered by particles. However, the technique calculates the particle size based on a default calibration curve obtained for specific dust, which may not have the same refractive index as the particulate material of interest. Thus, the measured size may not represent actual size. The method provides real time particle size distribution with a detection size range of approximately $0.1 \mu \mathrm{m}$ to $10 \mu \mathrm{m}$. Instruments that are purchased with a filter attachment may collect samples for chemical analysis. However, light scattering instrumentation is not compatible with high temperature $\left(>40^{\circ} \mathrm{C}\right)$ or corrosive gas streams.

\section{C.1.2 Time of flight mass spectrometry}

Particle size distribution can be quantified by time of flight (TOF) mass spectrometry, which determines the aerodynamic size of the particle by measuring its rate of acceleration through a nozzle. The aerodynamic diameter is a measure of the particle's true airborne behavior (as opposed to its actual diameter) and is the property that is required for modeling aerosol transport. This technique is unaffected by index of refraction and is superior to light scattering methods. TOF mass spectrometry provides real time particle size distribution with a detection size range of approximately $0.5 \mu \mathrm{m}$ to $20 \mu \mathrm{m}$. Similar to light scattering instrumentation, TOF mass spectrometers for aerosol quantification can be purchased with a filter attachment to collect samples for chemical analysis. This technique is not compatible with high temperature $\left(>40^{\circ} \mathrm{C}\right)$ or corrosive gas streams.

\section{C.1.3 Cascade impactors}

In contrast to light scattering or TOF mass spectrometry techniques, cascade impactors are compatible with high temperature (up to $600^{\circ} \mathrm{C}$ ) and corrosive gas streams, depending on the body material and impaction substrates. Cascade impactors are made up of a series of impaction plates through which a gas stream flows. The gas stream carrying aerosol particles is accelerated through the impaction plates, which have perforations of successively smaller size to increase the flow velocity through each successive impaction plate. The particles with large enough inertia will leave the jet stream and settle on the impaction plate while the rest remain in the jet stream. In this way, successive impaction plates collect particles with successively smaller aerodynamic diameter. Collection substrates with low mass (i.e., metal foils) can be employed so that the total mass of collected aerosols of a particular size range can be determined by weight.

Cascade impactors do not provide the same temporal or size distribution resolution as light scattering or TOF mass spectrometry instrumentation and instead provide the total abundance of aerosols (by weight) within a certain aerodynamic size range over the collection period. Cascade 
impactors have a detection size range of approximately $0.2 \mu \mathrm{m}$ to $30 \mu \mathrm{m}$ and can handle relatively large aerosol loadings. The chemical composition of particles collected on the substrates can be assessed using analytical methods (e.g., ICP-MS or X-ray fluorescence spectroscopy). It should be noted that quantifying aerosol size and abundance using cascade impactors is prone to artifacts including inefficient adhesion of particles to collection substrates and non-selective plate out of gaseous species, which are described in Section C.2.3.

\section{C.2 Historical data on molten salt aerosols}

The literature on molten salt aerosols is very sparse, although a few studies have attempted to measure the size and composition of molten salt aerosols.

\section{C.2.1 Vapor condensation and collection on filters}

MSRE scientists attempted to measure the particle size and composition of aerosols that formed due to the condensation of vapors coming off static MSRE fuel salt (Kirslis and Blankenship, 1969). Helium was passed over the molten fuel salt surface, then through a 0.25 in diameter nickel tube (12 in long) to a Millipore filter that was coated with a thin evaporated carbon film. The intention was to collect aerosol particles on the Millipore filter. Five runs were performed with flow rates varying from 15 to $100 \mathrm{~cm}^{3} \mathrm{~min}^{-1}$ and flow durations between 1 and 4 hours. No particular matter was detected on the filter by electron microscope imaging because the fuel salt vapor and aerosols had condensed or deposited along the length of the 12 in long nickel tube before they could reach the filter.

\section{C.2.2 Vapor condensation and deposition on copper screens}

A separate experiment to collect and study aerosol particles from a sample of the MSRE fuel salt was also conducted (Kirslis and Blankenship, 1968). In this experiment, six 0.125 in diameter copper screens were attached to a stainless steel rod that was positioned above the fuel salt surface. The screens that were attached to the rod were $0.5 \mathrm{in}, 1 \mathrm{in}, 1.5 \mathrm{in}, 2.5 \mathrm{in}, 3.5 \mathrm{in}$, and 4.5 in from the fuel salt surface. Helium flowed over the fuel salt surface at $15 \mathrm{~cm}^{3} \mathrm{~min}^{-1}$ for 40 minutes and through a 0.5 in diameter tube that was surrounding the rod holding the screens. The gas traversed the screens at a linear velocity of approximately $0.5 \mathrm{~cm} \mathrm{~s}^{-1}$ so that particulate matter could deposit on the screens. The lower 5 samples showed ${ }^{131}$ I activities that were so high that other elements could not be detected. The $6^{\text {th }}$ (top) screen had less ${ }^{131} \mathrm{I}$, and ${ }^{99} \mathrm{Mo},{ }^{103} \mathrm{Ru}$, ${ }^{95} \mathrm{Nb}$, and ${ }^{140} \mathrm{La}$ were also detected. At the time of writing the report, the 3 top screens had been removed from the rod and analyzed to determine their size using electron microscopy. Many particles could be seen on each screen, but the samples had appeared to have absorbed moisture from the atmosphere between collection and imaging. The particles were arranged in near perfect circles, which was likely an artifact that was caused by salt particle rearrangement due to the moisture evaporating under vacuum.

C.2.3 Collection of aerosols from molten $\mathrm{NaCl}, \mathrm{CsNO}_{3}$, and $\mathrm{Pbl}_{2}$ using cascade impactors

Cascade impactors have been successfully employed to collect aerosols generated from molten $\mathrm{NaCl}, \mathrm{CsNO}_{3}$, and $\mathrm{Pbl}_{2}$, and the results of these experiments are documented in Parker and Buchholz, 1968. Air was drawn by suction over the molten salt surface in the furnace, forming particles by the condensation of vapors in the cool air stream. After steady state was reached, the particle-containing air stream was transferred to a containment tank for 1 to 3 hours where the particles agglomerated and increased in size. After, the aged particles were directed towards 
the cascade impactor sampler. Runs were conducted at normal pressure and low pressure, depending on whether a commercially available or modified cascade impactor, respectively, were used. Low pressure was required to collect smaller particles than what was achievable with commercially available cascade impactors.

Radioactive tracers $\left({ }^{134} \mathrm{Cs},{ }^{131} \mathrm{I}\right.$, and $\left.{ }^{24} \mathrm{Na}\right)$ were employed to determine the elemental composition of particles collected on each impaction plate for mixed salts. The results showed that the low pressure $(40 \mathrm{~mm} \mathrm{Hg})$ cascade impactor was more efficient than the normal pressure $(750 \mathrm{~mm}$ $\mathrm{Hg}$ ) cascade impactor at collecting the particulates that were generated. This was evidenced by detecting most of the activity among the impaction plates and little activity at the back filter for the low pressure cascade impactor. In contrast, a greater amount of activity was detected at the back filter for the normal pressure cascade impactor. The authors noted two issues that arose when using cascade impactors to collect salt aerosols.

The first issue was the selective plate out of gaseous iodine. Gaseous molecular iodine can plate out non-selectively in the cascade impactor sampler, which may interfere with the interpretation of results if the iodine concentration is high enough. To address this issue, three silver-coated screens were placed in front of the series of impaction plates to collect gaseous iodine. Gaseous molecular iodine was mixed with $\mathrm{NaCl}$ aerosol particles in the gas stream to determine the effectiveness of gaseous iodine capture by the silver screens. It was demonstrated that the screens collected $\sim 98 \%$ of the total iodine, while retaining only $\sim 1.5 \%$ of the $\mathrm{NaCl}$ particles. Silver screens are therefore an effective way to limit the amount of gaseous iodine in cascade impactors.

The second issue was the deposition of particles on the walls of the sampler and not just on the impaction plates. In general, as the total amount of material in the sampler increases, the relative loss of material to the sampler wall increases. Loss also appears to be correlated with stage number due to two processes. The first seems to be loss by diffusion because it increases at lower flow rates, and the second is particle bounce from the stages. Particle bouncing can occur as a result of both elastic and inelastic collisions for particles that have high enough inertia to settle on the impaction plate. A particle will bounce due to an elastic collision if its kinetic energy is higher than the energy absorbed by the surface, and fragments of a particle may bounce due to an inelastic collision that causes the particle to break apart. The impaction plates were coated with a silicone oil, forming a layer several microns thick, to decrease the probability of bouncing and increase particle adhesion. Particle bouncing can also be reduced by limiting the particle load, which appears to be positively correlated with the relative particle fraction deposited on the sampler walls. 


\section{Argonne}

Chemical and Fuel Cycle Technologies Division

Argonne National Laboratory

9700 South Cass Avenue, Bldg. 205

Argonne, IL 60439

www.anl.gov 